UNIVERSIDADE DE SÃO PAULO

FACULDADE DE FILOSOFIA, CIÊNCIAS E LETRAS DE RIBEIRÃO PRETO DEPARTAMENTO DE PSICOLOGIA PROGRAMA DE PÓS-GRADUAÇÃO EM PSICOLOGIA

Evidências de validade e precisão do Teste das Fábulas em escolares

MARCELLE LOUISE COELHO DE FREITAS

Ribeirão Preto 



\section{MARCELLE LOUISE COELHO DE FREITAS}

\section{Evidências de validade e precisãodo Teste das Fábulas em escolares}

Dissertação apresentada ao Programa de PósGraduação em Psicologia da Faculdade de Filosofia, Ciências e Letras de Ribeirão Preto da Universidade de São Paulo, como parte dos requisitos para obtenção do grau de Mestre em Ciências, Área de Concentração: Psicologia.

Orientadora: Prof. Dra. Sonia Regina Pasian 
Autorizo a reprodução e divulgação total ou parcial deste trabalho, por qualquer meio convencional ou eletrônico, para fins de estudo e pesquisa, desde que citada a fonte.

Freitas, Marcelle Louise Coelho de

Evidências de validade e precisão do Teste das Fábulas em escolares. Ribeirão Preto, 2014.

158p. : il. ; $30 \mathrm{~cm}$

Dissertação de Mestrado, apresentada à Faculdade de Filosofia Ciências e Letras de Ribeirão Preto/USP. Área de concentração: Psicologia.

Orientador: Pasian, Sonia Regina.

1. Crianças. 2. Avaliação Psicológica. 3. Teste das Fábulas.

4. Método Projetivo. 5. Saúde Mental Infantil. 


\section{FOLHA DE APROVAÇÃO}

\section{Nome: Freitas, Marcelle Louise Coelho de}

Título: Evidências de validade e precisão do Teste das Fábulas em escolares.

Dissertação de Mestrado apresentado ao Programa de PósGraduação em Psicologia do Departamento de Psicologia da Faculdade de Filosofia, Ciências e Letras de Ribeirão Preto, Universidade de São Paulo, Ribeirão Preto. Para obtenção de título de Mestre em Ciências, Área: Psicologia.

Aprovado em:

Banca Examinadora

Prof. Dr.

Instituição: Assinatura:

Prof. Dr.

Instituição: Assinatura:

Prof. Dr.

Instituição: Assinatura: 



\section{AGRADECIMENTOS}

Agradeço à Profa. Dra. Sonia Pasian pela convivência, pelos ensinamentos e pelo empenho na realização deste trabalho; à Profa. Dra. Sonia Regina Loureiro pela escuta, pelo apoio, pela ajuda na concepção deste sonho. Às duas Sonias agradeço pela inspiração e pelo modelo profissional e ético que nos oferecem. Agradeço à Profa. Dra. Maria Lúcia Tiellet pelo belo trabalho com as Fábulas, que proporcionou solo fértil o bastante para deixar nascer muitas sementes. Obrigada também pela generosidade e pelo contato sempre vivaz.

Agradeço em especial à Lívia Loosli e Joana Brasileiro Barroso pela contribuição e cuidados ao nosso trabalho.

Agradeço também aos amigos e colegas de profissão, que tornaram esse trabalho viável e por todo incentivo:Rosana Selegatto, Marcus Vinícius Santos, Fernanda Marletta e Erika Okino e Adriana Saur.

Agradeço à minha mãe Elza das Graças Coelho pelo amor e apoio e ao meu marido, José Luis de Freitas, não apenas pelas consultorias em informática, mas principalmente por se fazer presente e participativo em cada projeto de vida.

"Gracias à la vida", por permitir conquistar este sonho. 
"Como no caso dos pacientes da medicina hindu, aos quais se solicitava que meditassem sobre um conto de fadas para encontrar um caminho fora da escuridão que obscurecia suas mentes, as crianças também deveriam ter a oportunidade de transformar o conto de fadas em algo de seu, pela inclusão das próprias associações" (Bruno Bettelheim, 1903, p. 75). 


\section{RESUMO}

Freitas, Marcelle Louise Coelho de (2014). Evidências de validade e precisão do Teste das Fábulas em escolares. Dissertação de Mestrado no Programa de Pós-Graduação em Psicologia do Departamento de Psicologia da Faculdade de Filosofia, Ciências e Letras de Ribeirão Preto, Universidade de São Paulo, Ribeirão Preto. (Orientadora: Profa. Dra. Sonia Regina Pasian).

Dentre os diversos recursos para avaliação psicológica, os métodos projetivos destacam-se pela riqueza de suas informações a respeito dos componentes e do funcionamento psíquico, nomeadamente na área da investigação de características de personalidade. Para examinar a faixa etária infantil, o Teste de Fábulas (TF) é um dos métodos projetivos disponíveis, baseado na teoria psicanalítica e tem se mostrado relevante e útil, embora com necessidade de revisão de suas evidências psicométricas no contexto brasileiro. $O$ teste consiste em 10 historietas inacabadas que são contadas para a criança, sendo que o personagem principal está exposto a situações conflitivas inerentes a estágios do desenvolvimento psicossexual. A criança é solicitada a completar essas fábulas, a partir de sua imaginação e necessidades próprias, o que permite indicadores projetivos de sua dinâmica da personalidade e da qualidade dos mecanismos de defesa utilizados. Atualmente, no Brasil, esse método projetivo encontra-se em processo de revisão de suas evidências psicométricas. Nesse contexto, o presente trabalho objetivou buscar evidências de validade e indicadores de precisão e consistência do Teste das Fábulas, em seu uso em crianças escolares de seis a 12 anos de idade, comparando as produções obtidas com três grupos: a) crianças usuárias de um serviço de psiquiatria $(\mathrm{G} 1, \mathrm{n}=20)$; b) crianças com indicadores sugestivos de problemas de saúde mental (G2, n=20); c) crianças sem indicadores de problemas de saúde mental, isto é, com sinais de desenvolvimento psíquico e escolar típicos (G3, n=20). Pretendeu-se, deste modo, examinar variáveis do Teste das Fábulas que identifiquem o diagnóstico clínico diferencial em crianças escolares de seis a 12 anos, analisando-se ainda eventuais efeitos do sexo e da idade sobre os resultados nos três grupos de crianças. Embora não tenha se configurado como objetivo inicial, também foi realizada revisão no sistema avaliativo proposto no manual brasileiro desse instrumento. Os participantes do estudo foram selecionados de serviços clínicos e de escolas públicas do interior do Estado de São Paulo, procurando-se pareá-los em função do sexo e da idade, excluindo-se aqueles com limite intelectual. Para tanto, foram utilizados os seguintes instrumentos: formulário de identificação dos participantes; 
Questionário de Capacidades e Dificuldades (SDQ); Teste das Matrizes Progressivas Coloridas de Raven e o Teste das Fábulas, devidamente aplicados após consentimento dos pais e codificados conforme seus respectivos manuais técnicos. A codificação da produção no Teste das Fábulas foi realizada por três avaliadores independentes, examinando-se sua precisão, que apresentou indicadores bastante positivos. Foi possível caracterizar a produção de cada grupo, bem como identificar diferenças estatísticas significativas entre os mesmos, sinalizando bons indicadores de validade do Teste das Fábulas, consistentes também com diagnóstico obtido pelo SDQ. As variáveis de sexo e idade não se mostraram diferenciadoras na produção infantil. Desse modo, os atuais achados contribuem para o avanço do conhecimento científico sobre este método projetivo, demonstrando suas evidências de validade de modo empírico, bem como salientam a importância de sua utilização na prática profissional de psicólogos no contexto brasileiro e, em especial, no contexto clínico.

Palavras-chave: Crianças, Avaliação Psicológica, Teste das Fábulas, Método Projetivo, Saúde Mental Infantil. 


\begin{abstract}
Freitas, Marcelle Louise Coelho de (2014). Evidence of validity and reliability of the Test of Fables in students. Dissertação de Mestrado no Programa de Pós-Graduação em Psicologia do Departamento de Psicologia da Faculdade de Filosofia, Ciências e Letras de Ribeirão Preto, Universidade de São Paulo, Ribeirão Preto.(Orientadora: Profa. Dra. Sonia Regina Pasian).
\end{abstract}

Among many resources for psychological evaluation, projective methods distinguished by its wealth of information about the components and psychic functioning, particularly in the research area of personality characteristics. To examine the infant age group, the Test of Fables (TF) is one of the available projective methods, based on psychoanalytic theory and has been relevant and useful, although requires review of psychometric evidence in the Brazilian context. The test consists of 10 unfinished short stories that are told to the child, and the main character is exposed to conflicting situations inherent in the stages of psychosexual development. The child is asked to complete these fables from her imagination and needs, allowing projective indicators of their dynamic personality and quality of defense mechanisms used. Currently, in Brazil, this projective method lies in its psychometric evidence review process. In this context, the present study aimed to gather validity evidence and indicators of accuracy and consistency of the pattern of Fables in its use in school children aged six to 12 years, comparing the yield obtained with three groups: a) children who have a psychiatry service $(\mathrm{G} 1, \mathrm{n}=20)$; b) children with suggestive indicators of mental health problems $(\mathrm{G} 2, \mathrm{n}$ $=20$ ); c) indicators of children without mental health problems, or with signs of psychic development and typical school $(\mathrm{G} 3, \mathrm{n}=20)$. The intention was thus to examine the variables of Fables Test to identify the differential clinical diagnosis in school children aged six to 12 years, still analyzing possible effects of sex and age on outcomes in three groups of children. Although not set as an initial goal, a review was also performed in the evaluation system proposed in the Brazilian guider publication of the instrument. Study participants were selected from clinical services and public schools in the state of São Paulo, trying to pair them by gender and age, excluding those with intellectual limit. To this end, the following instruments were used: form identification of participants; Strengths and Difficulties Questionnaire (SDQ); Raven Coloured Progressive Matrices Test and Fables Test, properly applied after parental consent and coded according to their respective technical manuals. The encoding of the production test of Fables was performed by three independent evaluators, 
examining their accuracy, which showed very positive indicators. It was possible to characterize the production of each group as well as to identify statistically significant differences between them, signaling good indicators of validity of the Test of Fables, consistent with a diagnosis obtained by the SDQ. The variables of sex and age were not differentiated in child production. Thus, the current findings contribute to the advancement of scientific knowledge on this projective method, demonstrating their validity evidence empirically as well as emphasize the importance of its use in the professional practice of psychologists in the Brazilian context and, in particular, in the clinician context.

Keywords: Children, Psychological Assessment, Testing Fables, Projective Method, Children's Mental Health. 


\section{LISTA DE TABELAS}

Tabela 1: Descrição dos estudos realizados com o Teste das Fábulas no período de 1989 a 2012

Tabela 2: Caracterização demográfica e clínica dos participantes do Grupo $1(\mathrm{n}=20) \ldots . . .46$

Tabela 3: Caracterização dos participantes $(n=60)$ e seus subgrupos em função do sexo, idade, escolaridade e nível cognitivo.

Tabela 4:Resultados (em frequência simples e porcentagem) e comparação estatística das categorias avaliativas da Fábula 1 (Fábula do Passarinho) em função dos grupos e na amostra total $(n=60)$.

Tabela 5: Resultados (em frequência simples e porcentagem) e comparação estatística das categorias avaliativas da Fábula 2 (Fábula do Casamento) em função dos grupos e na amostra total $(n=60)$

Tabela 6: Resultados (em frequência simples e porcentagem) e comparação estatística das categorias avaliativas da Fábula 3 (Fábula do Cordeirinho) em função dos grupos e na amostra total $(\mathrm{n}=60)$

Tabela 7: Resultados (em frequência simples e porcentagem) e comparação estatística das categorias avaliativas da Fábula 4 (Fábula do Enterro) em função dos grupos e na amostra total $(n=60)$ .77

Tabela 8: Resultados (em frequência simples e porcentagem) e comparação estatística das categorias avaliativas da Fábula 5 (Fábula do Medo) em função dos grupos e na amostra total $(n=60)$ .79

Tabela 9:Resultados (em frequência simples e porcentagem) e comparação estatística das categorias avaliativas da Fábula 6 (Fábula do Elefante) em função dos grupos e na amostra total $(n=60)$

Tabela 10: Resultados (em frequência simples e porcentagem) e comparação estatística das categorias avaliativas da Fábula 7 (Fábula do Objeto Fabricado) em função dos grupos e na amostra total $(n=60)$.

Tabela 11: Resultados (em frequência simples e porcentagem) e comparação estatística das categorias avaliativas da Fábula 8 (Fábula do Passeio) em função dos grupos e na amostra total $(n=60)$.

Tabela 12: Resultados (em frequência simples e porcentagem) e comparação estatística das categorias avaliativas da Fábula 9 (Fábula da Notícia) em função dos grupos e na amostra total $(\mathrm{n}=60)$ 
Tabela 13: Resultados (em frequência simples e porcentagem) e comparação estatística das categorias avaliativas da Fábula 10 (Fábula do Sonho Mau) em função dos grupos e na amostra total $(\mathrm{n}=60)$

Tabela 14: Resultados da classificação diagnóstica de juízes independentes e às cegas em relação à produção das crianças de G2 e G3 $(n=40)$ no Teste das Fábulas comparativamente ao resultado no SDQ

Tabela 15: Distribuição dos escolares avaliados $(n=170)$ em função da classificação no SDQ e do sexo. 


\section{SUMÁRIO}

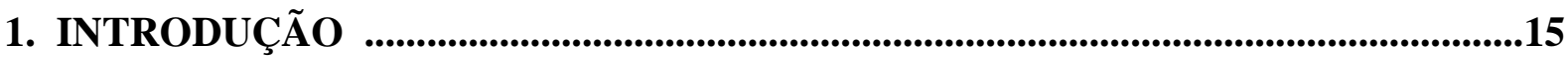

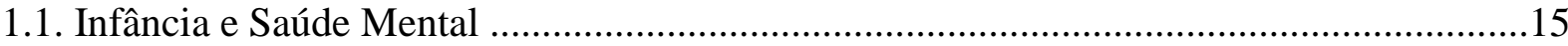

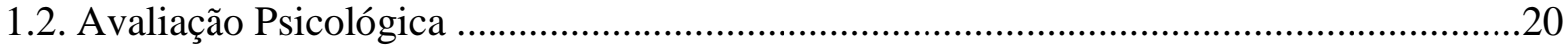

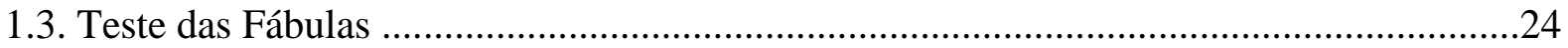

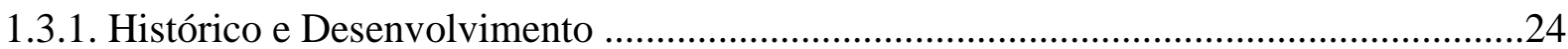

1.3.2. Evidências Psicométricas e de Aplicabilidade ..............................................................28

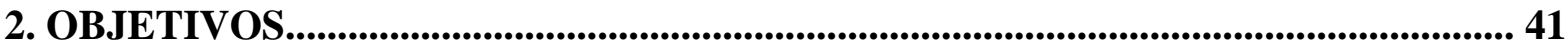

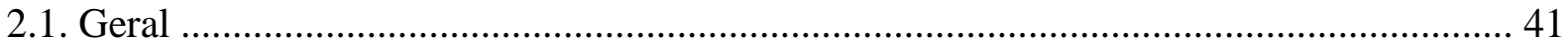

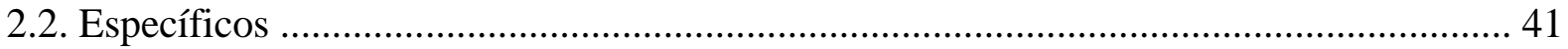

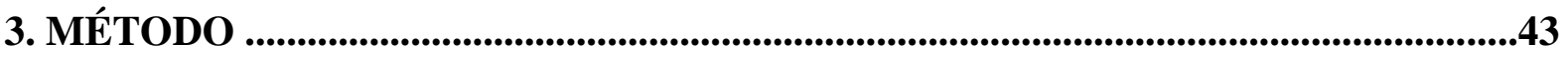

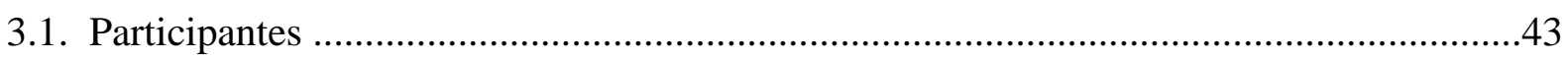

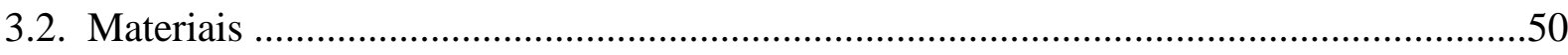

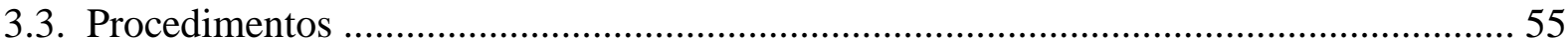

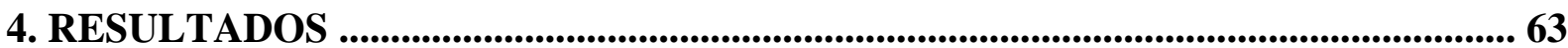

4.1. Relativos à revisão do sistema avaliativo

63

4.2. Relativos à análise da produção no conjunto das dez fábulas 65

4.3.Relativos a evidências de validade e de precisão do Teste das Fábulas 96

4.4.Relativos ao SDQ na amostra de escolares

98

5. DISCUSSÃO 101

6.CONSIDERAÇÕES FINAIS. 107 
ANEXO 1 - Aprovação do projeto pelo Comitê de Ética em Pesquisa com Seres Humanos da FFCLRP/USP. 117

ANEXO 2 -Autorização da Profa. Dra. Sonia Regina Loureiro para uso do Banco de Dados do Serviço de Psicodiagnóstico do Hospital das Clínicas da FMRP-USP. 118 APÊNDICE A - Carta de Apresentação da Pesquisa. 119 APÊNDICE B - Termo de Consentimento Livre Esclarecido. 120 APÊNDICE C -Tabelas descritivas dos resultados no Teste das Fábulas a partir do sistema de classificação original (Cunha \& Nunes, 1993), seguidos pela descrição dos itens que foram agrupados na presente revisão das categorias e itens avaliativos.

APÊNDICE D - Tabelas descritivas dos resultados em termos de frequência e porcentagem no Teste das Fábulas com sistema de classificação revisto. 

16| In trodu çã o

\section{INTRODUCÃO}

\subsection{INFÂNCIA E SAÚDE MENTAL}

Dados epidemiológicos têm evidenciado aumento do impacto da psicopatologia infantil em termos mundiais, em diversos setores,entretanto há escassez de políticas públicas para a demanda em saúde mental nessa faixa etária. Segundo Loosli e Loureiro (2012), há crescente número de crianças e adolescentes expostos a riscos psicossociais, os quais vêm sendo encaminhados para atendimento psicológico e psiquiátrico.

Em diferentes países, é evidente a defasagem entre a necessidade de atenção em saúde mental para crianças e adolescentes e a oferta de uma rede de serviços capaz de responder suficientemente à demanda existente. Esta defasagem está presente em nações de todas as regiões do mundo, independente de seus níveis econômicos e de distribuição de renda, mas é especialmente significativa no grupo de países em desenvolvimento (Couto, Duarte \& Delgado, 2008).

A saúde mental infantil no Brasil, enquanto campo de intervenção, cuidados e estudos sobre a criança, não possuía estrutura ou sistemática própria até o século XIX, momento em que surgiram as primeiras teses em Psicologia e em Psiquiatria. Foi também nessa época criado o primeiro hospital psiquiátrico brasileiro (Hospício D. Pedro II, em 1852), seguido de vários outros ao longo do território nacional (Ribeiro, 2006).

A constatação desse déficit assistencial contrasta com a magnitude dos problemas de saúde mental em crianças e adolescentes e das consequências a eles associadas. A ausência de políticas oficiais de saúde mental infantil, na extensa maioria dos países, vem sendo destacada como fator agravante na prevenção e no tratamento para esse público específico (Couto, Duarte \& Delgado, 2008;Loosli\& Loureiro, 2012).

De modo geral, as políticas de saúde mental existentes estão relacionadas aos problemas da população adulta. Em crianças e adolescentes, os tipos de transtorno, principais fatores de risco e de proteção, estratégias de intervenção e organização do sistema de serviços têm especificidades que não podem ser contempladas pela simples 
extensão das estratégias de cuidado dos adultos à população infantil e juvenil (Couto, Duarte \& Delgado, 2008).

Torna-se necessário, assim, tentar circunscrever o que seria problema emocional e seus desdobramentos.Ao retomar ponderações da psiquiatra Koppitz (1976), Santos e Damiani (2004) argumentam que os problemas emocionais são definidos como um conjunto de ansiedades, preocupações e atitudes que alteram o funcionamento pessoal, familiar, social ou educacional, sem estar relacionado à idade ou maturação. Em termos de comportamento, esses problemas se manifestam por meio de ampla variedade de comportamentos, incluindo: isolamento, impulsividade, agressividade, instabilidade, raiva, insegurança, baixa autoestima, baixo rendimento escolar, sentimentos de impotência, depressão, dependência, egocentrismo, dificuldade de conexão com o mundo circundante, dificuldades em se comunicar, mau desempenho escolar, sentimentos de culpa, roubo, medo e ansiedade. Os referidos autores destacam ainda como indicadores de problemas emocionais na infância e juventude: dificuldade de aprendizagem não ocasionada por limitação cognitiva ou alterações a nível orgânico; dificuldade em construir ou manter relações interpessoais satisfatórias com os colegas e professores; comportamentos ou sentimentos inadequados em circunstâncias anteriormente consideradas normais.

Esses problemas relacionados à saúde mental infantil e de adolescentes têm sido divididos em algumas categorias na literatura científica da área, englobando diferentes níveis de dificuldades. Podem abarcar transtornos globais do desenvolvimento (como o Autismo, que apresenta alterações a nível cognitivo e/ou alterações orgânicas), como problemas de comportamento, uso abusivo de substâncias, problemas relacionados à atenção, entre outros transtornos (Bee, 2003; Santos \& Damiani, 2004; Couto, Duarte \& Delgado, 2008;Loosli\& Loureiro, 2012). Sobre os problemas de comportamento é comum o uso de uma subdivisão classificatória das dificuldades, de modo a favorecer a circunscrição dos quadros. Assim, podem ser diferenciados problemas de comportamento que se externalizam, que correspondem a dificuldades comportamentais dirigidas para o ambiente externo (como transtornos de conduta, hiperatividade, desobediência, mentir, roubar, baixo autocontrole, risco de auto e/ou heteroagressividade, insubordinação, destrutividade, rebeldia e birra) e problemas que compreendem manifestações comportamentais mais internas, sinalizando dificuldades de ordem psíquica (como ansiedade, depressão, timidez, tristeza, isolamento, inibição, baixa concentração, queixas somáticas, culpa, pessimismo e inquietação) (Bee, 2003). 
18 | In trodução

Sob a perspectiva da Psicopatologia do Desenvolvimento (Koppitz, 1976; Bee, 2003; Bowlby, 2006), os aspectos comportamentais se configuram como relevantes indicadores do desenvolvimento e dos recursos de saúde mental infantil, visto que permitem observar a presença de sinais e sintomas dos quadros clínicos psiquiátricos que comumente são utilizados na área. São necessárias, portanto, estratégias de investigação específica das características comportamentais dos indivíduos ao longo de seu crescimento, juntamente com as variáveis de seu contexto sociocultural, de modo a identificar, com o devido cuidado, fatores de risco e também fatores de proteção ao desenvolvimento.

Além da sintomatologia, há considerável variação no período de incidência (alguns transtornos eclodem na infância e outros apenas na adolescência) e nos tipos de prejuízos relacionados. Há que se ressaltar que, diferentemente dos adultos, no público infanto-juvenil os aspectos estruturais da personalidade ainda estão em formação, adicionando complexidade à avaliação diagnóstica e situacional. Nesse grupo etário, a formulação de adequado diagnóstico exige específicos procedimentos de avaliação que incluem, além das próprias crianças e adolescentes, o recurso a diversas fontes de informação, como entrevistas com familiares, responsáveis e professores (Couto, Duarte \& Delgado, 2008). É nesse sentido que se faz importante, em um processo se avaliação psicodiagnóstica, o uso de instrumentos de diferente natureza, como os de rastreamento e os de diagnósticoclínico e funcional, psicodinâmico.

Para identificação de sinais sugestivos de problemas em saúde mental, a prática clínica e de pesquisa mostra a utilidade e a relevância de recorrer a instrumentos padronizados de avaliação, de modo a permitir adequada caracterização dos indivíduos e de seu contexto de vida. Há diversidade de materiais avaliativos, com variados objetivos e alcances (Urbina, 2007), incluindo questionários, formulários, roteiros semiestruturados ou estruturados de entrevista e de observação, inventários, escalas, além dos testes psicológicos, sendo esses últimos de uso exclusivo do psicólogo no Brasil (CFP, 2011).

No geral, os dados epidemiológicos relativos à saúde mental advêm de informações coletadas por meio de estratégias sistematizadas e que abordam informações sobre o comportamento manifesto dos indivíduos. Envolvem a aplicação de instrumentos de rastreamento de grupos de pessoas, a partir de suas informações ou de respondentes por elas responsáveis (Bee, 2003). No entanto, há outra natureza de investigação de ordem psicológica: a das vivências internas dos indivíduos, nem sempre 
manifestas em comportamentos observáveis, porém nem por isso de menor relevância informativa. Porém, o acesso a esse tipo de dado exige outro tipo de instrumentos avaliativos, os chamados testes psicológicos, em especial os chamados métodos projetivos. A contraposição de achados advindos desses dois tipos de instrumentais pode examinar evidências empíricas de seu poder informativo a respeito de indicadores de Saúde Mental, tanto do ponto de vista manifesto quanto vivido, no geral enriquecendo a compreensão sobre o funcionamento psíquico dos indivíduos, em especial em crianças e adolescentes.

$\mathrm{Na}$ área da saúde mental infantil, os instrumentos disponíveis para identificar sinais e sintomas (problemas externalizantes) em geral são organizados em formato de escalas ou questionários, constituindo-se como estratégias de rastreamento ou de screeninginicial. Destacam-se como instrumentos sistematizados de avaliação amplamente utilizados como rastreadores da saúde mental infanto-juvenil:

a) ChildBehaviorChecklist - CBCL (Achenbach, 2001): adaptado ao Brasil por Santos e Silvares (2006), abrange a idade de seis a 18 anos. Está composto de 138 itens, sendo a versão mais utilizada aquela destinada a pais/mães ou cuidadores para que forneçam respostas referentes aos aspectos sociais e comportamentais de seus filhos. Do total de itens, 20 são destinados a avaliação da competência social da criança e 118 relativos à avaliação de possíveisproblemas de comportamento. Os itens do instrumento listam uma série de comportamentos desejáveis e outros disruptivos, sendo que, para cada um deles, o respondente deve marcar a frequência com que ocorrem. Este instrumento proporciona ainda o cruzamento de informações respondidas por outros informantes no que se refere ao comportamento da criança, permitindo verificar o quão concordantes são as respostas fornecidas (Santos \& Silvares, 2006; Borsa\& Nunes, 2008).

b) Questionário de Capacidades e Dificuldades (SDQ): proposto por Goodman em 1997, o SDQ é um questionário que rastreia problemas de saúde mental infantil, abrangendo a faixa etária de quatro a 16 anos. O SDQ tem sido amplamente utilizado no Brasil, devido sua praticidade, acessibilidade e facilidade de aplicação, uma vez que pode ser autoaplicável em crianças acima dos 11 anos, ou respondido diretamente por pais ou professores (Saur, Correia, Pasian\& Loureiro, 2009; Saur\& Loureiro, 2012).

Está constituído por 25 itens divididos em cinco subescalas: problemas no comportamento pró-social, hiperatividade, problemas emocionais, de conduta e de relacionamento. A soma de itens identificados em cada subescala e a soma total de pontos permite a classificação da criança em três categorias: desenvolvimento normal 
(DN), limítrofe (DL) ou anormal (DA). Há que se destacar que, na subescala comportamento pró-social, quanto maior a pontuação, menor é a quantidade de queixas. Nas outras subescalas (hiperatividade, problemas emocionais, de conduta e de relacionamento), quanto maior a pontuação, maior o número de queixas.Desde seu desenvolvimento, o SDQ tornou-se o instrumento de pesquisa mais amplamente utilizado para a detecção de problemas relacionados à saúde mental infanto-juvenil (Vostanis, 2006; Saur\& Loureiro, 2012), encontrando-se gratuitamente disponível em mais de 40 idiomas, incluindo o português (http://www.sdqinfo.com).

No tocante às tentativas de caracterização de dificuldades de ordem psíquica (problemas internalizantes do comportamento), no geral pouco identificáveis pela observação direta do comportamento manifesto pela criança, são mais utilizados instrumentos diagnósticos que permitem acesso a seu funcionamento mental, como ostestes psicológicos (Urbina, 2007). Dentre ampla classe desses testes, os métodos projetivos de avaliação psicológica utilizam estímulos pouco estruturados para favorecer a expressão espontânea e livre do sujeito, diminuindo o controle lógico ou julgamento pessoal (desejabilidade social). Desse modo, os testes projetivos auxiliam o acesso de aspectos relativos à personalidade, ao funcionamento mental e ao mundo interno que não são expressos nos instrumentos de avaliação anteriormente descritos como de rastreamento, baseados em informações descritivas e de autorrelato (Anzieu, 1986; Anastasi\&Urbina, 2000).

Ainda é possível destacar, segundo Rodrigues e Loureiro (2012), que os problemas externalizantes tendem a apresentar maior concordância entre os informantes pais e as crianças, por serem mais facilmente observados. Já no tocante a problemas internalizantes, são frequentemente menos reconhecidos pelos pais em comparação às próprias crianças, por tratarem de componentes menos visíveis dos indivíduos.

Entre diversas investigações científicas voltadas a verificar demandas em saúde mental infanto-juvenil, o estudo realizado em Ribeirão Preto (SP) por Loosli e Loureiro (2012) caracterizou crianças e adolescentes que buscaram atendimento psicológico institucional. As pesquisadoras sistematizaram dados dos últimos cinco anos do Serviço de Psicologia do Hospital das Clínicas da Faculdade de Medicina da Universidade de São Paulo (HCFMRP-USP/Setor de Psiquiatria da Infância), o qual atende crianças que são encaminhadas para avaliações psicodiagnósticas, quando há dúvida diagnóstica em função de sua evolução clínica. Os resultados apontaram predomínio de crianças entre nove e 10 anos, sendo a maioria do sexo masculino, com pelo menos cinco queixas, em 
uso de diversos psicofármacos. Para o grupo feminino desse referido estudo, as queixas predominantes foram isolamento, somatização e transtornos alimentares, enquanto para o grupo masculino predominaram irritabilidade, oposição e dificuldades de aprendizagem.

Além de conhecer as características da demanda de serviços psiquiátricos infantis em Ribeirão Preto e região, estudos como o de Loosli e Loureiro (2012) denotam a importância do desenvolvimento de políticas nacionais de saúde mental para a infância e a adolescência. Isso auxiliaria substancialmente a ampliação do sistema de serviços, favoreceria a construção de dados e de informações culturalmente relevantes acerca das questões que lhe são próprias, e contribuiria para o avanço das pesquisas nessa área (Couto, Duarte \& Delgado, 2008). Um dos recursos para embasar pesquisas e práticas de cuidados em saúde mental são os instrumentos sistematizados de avaliação psicológica, focalizando construtos psíquicos, sendo, portanto, foco do próximo tópico aqui tratado.

\subsection{AVALIAÇÃO PSICOLÓGICA}

Testes psicológicos são procedimentos para se obter amostra do comportamento de determinado indivíduo ou grupo de pessoas, em um domínio específico (Anastasi\&Urbina, 2000; Borges 2011). Constituem-se, então, em componentes-chave nos processos de avaliação psicológica, podendo ser definidos como procedimentos sistemáticos de medida, que objetivam acessar características psicológicas dos indivíduos, em amostras de comportamento que sejam relevantes para o seu funcionamento cognitivo e/ou afetivo (Urbina, 2007). Dessa maneira, testes são ferramentas, veículos de acesso a algum construto, estratégias para se alcançar uma finalidade em um determinado contexto circunscrito, resultando em possíveis diagnósticos que favoreçam planos para adequada intervenção. Para Berrios (2008), as classificações têm valor apenas na medida em que podem produzir novas informações sobre os objetos classificados, o que faz sentido também na avaliação dos construtos psicológicos. Desse modo, em processos psicodiagnósticos não se tem a intenção de mera classificação taxativa, sem que esta esteja inserida em um contexto, razão para os devidos cuidados técnicos e éticos necessários para o uso de procedimentos de avaliação 
psicológica, como tem demonstrado claramente a literatura científica da área (Hutz, 2009; CFP, 2011).

Os testes psicológicos podem ser utilizados em contextos diversos e geralmente têm como principal objetivo a avaliação de indivíduos em algum ponto crítico ou circunstância significativa de vida, produzindo informações que auxiliam os profissionais a fazer inferências a respeito de pessoas e de seus comportamentos, que norteiam as indicações de intervenção propostas para cada situação (Loureiro, 2004). Os instrumentos refinam a capacidade do profissional para captar e compreender os indivíduos, os grupos e os fenômenos psicológicos (Urbina, 2007; Werlang, VillemorAmaral \& Nascimento, 2010). Além disto, o uso de testes psicológicos atende à necessidade de se levantar informações importantes sobre o indivíduo avaliado em menor tempo, comparativamente às sessões clínicas ou atendimento psicopedagógico, entre outros tipos de intervenção.

Como um dos agrupamentos possíveis dentre a diversidade de instrumentos de avaliação psicológica, os métodos projetivos, segundo Urbina (2007), surgiram na década de 1920, com uma visão dinâmica das individualidades e como ferramentas para a avaliação qualitativa da personalidade e de aspectos psicopatológicos, trazendo um enfoque em respostas espontâneas e livres, não predeterminadas. Tiveram suas raízes nos métodos de associação livre, introduzidos por Galton e usados clinicamente por Kraepelin, Jung e Freud (Urbina, 2007; Werlang, Villemor-Amaral \& Nascimento, 2010). Além dos aspectos da personalidade,esses instrumentos ainda podem ser utilizados na avaliação de outros aspectos, como as relações interpessoais e a dinâmica familiar. A premissa básica que sustenta esse tipo de método de avaliação psicológica é a de que toda produção de um indivíduo está, de alguma forma e em alguma medida, vinculada a suas capacidades e vivências, que são projetadas ao exterior. Daí advém a denominação: métodos projetivos. Na leitura de um fenômeno projetivo, deve-se também considerar a percepção externa que o indivíduo elabora a respeito de determinado estímulo, que sempre será influenciada por seu mundo interno (Fensterseifer\& Werlang, 2008).

Os métodos projetivos constituem-se como recursos técnicos, disponíveis ao psicólogo, para a avaliação global da personalidade e de seus componentes, examinados predominantemente sob uma perspectiva de base psicodinâmica. Sua principal característica é a apresentação de um estímulo ambíguo ou pouco estruturado, permitindo que o indivíduo elabore, a partir de suas vivências e características internas, 
sua própria resposta para aquela atividade, imprimindo-lhe suas marcas pessoais. Tais técnicas reduzem o controle consciente do indivíduo sobre a conduta a ser analisada e originam respostas que refletem sua própria individualidade, assim, a interpretação que o indivíduo faz do estímulo tende a refletir componentes de sua personalidade. A resposta ao estímulo é organizada em função de suas percepções, atitudes, ideias, emoções e componentes de sua personalidade (Alves, 2004).

Nesse sentido, Anzieu (1986) afirma que a estruturação inconsciente do material, a liberdade das respostas e do tempo, o fluxo relativo das instruções, tornam a situação projetiva em certa medida vazia; vazio este que o sujeito deve preencher, recorrendo menos às aptidões e inteligência e mais aos recursos profundos de sua personalidade. Desse modo, os métodos projetivos de avaliação psicológicafavorecem a abordagem aos processos internos da personalidade e de seus componentes.

A partir de 2000, no Brasil, houve um grande movimento no sentido de enfatizar os necessários cuidados metodológicos com os instrumentos de avaliação psicológica, incluindo aqueles de natureza projetiva. A criação do Sistema de Avaliação dos Testes Psicológicos (SATEPSI) e da Resolução nº 02/2003 do Conselho Federal de Psicologia (CFP, 2003), ressaltou a necessidade da avaliação contínua dos testes psicológicos, de modo a colecionarem evidências empíricas de boas qualidades psicométricas para sua sustentação na prática profissional.

Um dos aspectos a serem destacados é relativo à validade do instrumento de avaliação psicológica. Como argumentam Primi, Muniz e Nunes (2009), por validade de um teste psicológico, entende-se o quão bem o mesmo mede aquilo a que se propõe examinar. O processo de validação é cumulativo, agregando um conjunto de evidências científicas que asseguram as interpretações dos escores do teste e a relevância e utilidade de seu uso, em contextos específicos, enfatizando-se a ideia de que não se valida o teste em si, mas as interpretações propostas por ele e as aplicações práticas a que se propõe (Primi, Muniz \& Nunes, 2009; Santos, 2011).

A validação dos procedimentos de avaliação psicológica é um processo complexo e não unitário. Métodos diferentes são requisitados, a depender do tipo de instrumento avaliativo, seus fins e contextos de aplicação. A credibilidade de um procedimento depende de seus fundamentos e da qualidade de sua articulação com as evidências. A subjetividade e singularidade das respostas, nos métodos projetivos de avaliação psicológica requerem tratamento e assentamento na teoria (Tavares, 2012). 
Segundo Villemor-Amaral (2012), no que se refere aos testes projetivos, a base teórica, os pressupostos subjacentes à criação do método, e a prática clínica, são sua principal fonte de credibilidade. O fato de não existirem dois conjuntos de respostas idênticas nesse instrumental de avaliação psicológica é o que mais dificulta a sua verificação estatística, entretanto, é justamente esse fato que melhor evidencia sua capacidade para expressar a individualidade e particularidade dos indivíduos.

Historicamente, identifica-se aparente dicotomia entre tradições psicométricas e projetivas nos processos de avaliação do funcionamento psíquico, visto que lidam com compreensões distintas para estratégias técnicas de validação de instrumentos. O enquadramento dos estudos de validade das técnicas projetivas em um referencial estritamente psicométrico tem constituído um desafio para quem pretende validá-las, dado o frequente conflito entre critérios de pesquisa estritamente quantitativa e os pressupostos subjacentes à prática clínica, na qual se inserem esses instrumentos de natureza projetiva, essencialmente qualitativos. Todavia, sistemas atuais de avaliação psicológica apresentam visões integradoras e complementares entre técnicas projetivas e instrumentos psicométricos, associando seus métodos de validação, de modo a favorecer estratégias para a investigação e pesquisa de evidências de validade dos instrumentos, apesar de suas especificidades metodológicas (Tavares, 2012; Silva, 2012).

No contexto brasileiro há forte tradição no estudo dos testes projetivos, segundo Primi (2010), apesar de subexistir uma ideia errônea de que não seria possível aplicar métodos psicométricos clássicos na validação desses instrumentos de avaliação psicológica. Com a criação do SATEPSI, a discussão foi aprofundada e se construiu o consenso de que os princípios de validação psicométricos são adequados para todas as técnicas de exame psicológico, incluindo as projetivas. Cumpre destacar, no entanto, que se faz necessário empregar métodos psicométricos mais avançados, diferentes dos usualmente utilizados, conservando as peculiaridades dos métodos projetivos e integrando diferentes perspectivas analíticas, trazendo olhar mais atual e favorecedor de avanço científico da área de avaliação psicológica.

De acordo com as normativas do CFP que constam na Resolução N. ${ }^{\circ}$ 002/2003, que define e regulamenta o uso, a elaboração e a comercialização de testes psicológicos e revoga a Resolução CFP $n^{\circ}$ 025/2001, os instrumentos de avaliação psicológica devem possuir evidências de validade e de precisão demonstradas em estudos brasileiros realizados nos últimos 20 anos, enquanto os referenciais normativos têm 
validade máxima de 15 anos. A partir da criação do SATEPSI, o CFP passou a exigir estudos brasileiros que demonstrassem adequados indicadores de validade, de precisão e a existência de referenciais normativos atualizados para os testes psicológicos. De acordo com Primi (2010) e CFP (2011), aos instrumentos que não atingissem qualidades psicométricas básicas, seriam atribuídos pareceres desfavoráveis a seu uso profissional no Brasil, visto que existem prazos específicos para essas evidências empíricas.

Diante da diversidade de procedimentos de avaliação psicológica e dos métodos projetivos, nesse trabalho será focalizado o instrumento "Teste das Fábulas", descrito em suas principais características no próximo tópico dessa introdução. Dado que o estudo normativo desse método projetivo foi publicado por Cunha e Nunes (1993), sua última avaliação no SATEPSI considerou que as evidências normativas precisavam ser revistas e reavaliadas, de modo a oferecer adequados referenciais para hipóteses interpretativas da produção ali obtida. Esse quadro levou a um parecer desfavorável do Teste das Fábulas para uso profissional no Brasil, emitido pelo CFP no final de 2010, em função do prazo do último estudo normativo desse instrumento ter sido vencido (CFP, 2011). Além disso, fazem-se necessárias novas investigações relativas às evidências de validade do Teste das Fábulas no contexto do Brasil, de modo a oferecer as bases empíricas adequadas para suporte técnico-científico de suas aplicações em vários contextos clínicos da avaliação psicológica. É nesse sentido que esta pesquisa tem o objetivo de contribuir com estudos que fomentem e favoreçam o uso do Teste das Fábulas no cenário científico nacional, com estudos atuais e que possam demonstrar indicadores relativos à sua validade e aplicabilidade.

\subsection{TESTE DAS FÁBULAS}

\subsubsection{Histórico e desenvolvimento}

O Teste das Fábulas é método projetivo de avaliação psicológica, voltado principalmente para o público infantil. Foi divulgado pela primeira vez em 1940, com a denominação de "Método das Fábulas", criado por LouisaDüss (Düss, 1940). Em sua época foi concebido como um instrumento projetivo de vanguarda, sendo que sua 
publicação como livro ocorreu primeiramente na França, em 1950, e logo após na Alemanha. Esse método ficou conhecido como "Fábulas de Düss", seguindo um referencial teórico essencialmente freudiano e buscava a investigação de componentes inconscientes (Cunha \& Nunes, 1993).

LouisaDüss criou dez fábulas em que um herói (uma criança ou um animal) se encontra em uma situação determinada, que representa, simbolicamente, uma situação de um estágio psicossexual da teoria psicanalítica (oral, anal, fálico, genital). A criança tem a possibilidade de determinar, então, que caminhos o herói irá tomar. A hipótese é de que se o sujeito se sente afetado por alguma das histórias e apresenta uma resposta simbólica, ou ao contrário, manifesta alguma resistência para responder, a situação do herói da fábula determina uma cadeia de associações que revela o conflito que está fixado. Segundo Bettelheim (2002), os processos infantis inconscientes só se tornam claros para as crianças por meio de imagens que falam diretamente ao seu inconsciente. As imagens evocadas pelos contos de fadas assim o fazem. Nesse sentido, as historietas que servem como estímulo (para associações) no Teste das Fábulas, promovem associações a conflitos psicossexuais em uma linguagem acessível à criança. Düss (1940), em sua proposição original do método, procurou eliminar, ao máximo possível, aspectos que pudessem influenciar respostas conscientes, questões ligadas à cultura ou educação particular de cada criança.

De acordo com as considerações de Serafini (2004), esse método projetivo não busca diagnóstico de patologias, mas sim evidências para identificação e diagnóstico de conflitos inconscientes que possuem papel determinante na neurose da criança. As fábulas caracterizam-se por favorecer a rápida detecção destes conteúdos conflitivos e podem servir de ponto de partida para processos de intervenção psicoterápica. Desse modo, essa técnica projetiva pode contribuir para compor uma bateria de instrumentos em processos de avaliação psicodiagnóstica infantil.

Na década de 40, Louise Despert traduziu as Fábulas de Düss para a língua inglesa. Seu trabalho alcançou grande repercussão, principalmente na literatura psicanalítica, que acabou sendo conhecido como "Fábulas de Despert" (Cunha \& Nunes, 1993). Entre as décadas de 1940 e 1960, foram realizadas algumas pesquisas procurando revisar e modificar a forma original e a tradução realizada por Despert.

Reuben Fine (1949), por sua vez, produziu uma revisão das Fábulas de Despert para crianças entre quatro e 14 anos, chegando a uma série de vinte fábulas, combinando-as para testar as variáveis psicodinâmicas: dependência, hostilidade, 
identificação, rivalidade fraterna, reações à rejeição parental, temores de castração, complexo de Édipo, medos e desejos. Para avaliar as respostas, elaborou e aplicou um sistema de escores facilitador da sistematização das variáveis psíquicasali projetadas.

Contribuindo para o avanço do conhecimento sobre o teste, Peixotto (1956, 1957, 1960) utilizou a versão de Fine em vários estudos. O primeiro deles foi sobre a fidedignidade das Fábulas de Despert, que foram administradas a um grupo de 177 escolares, com idades entre oito e 14 anos. Peixotto (1956) encontrou que crianças mais novas eram mais consistentes em suas respostas do que crianças mais velhas. Os resultados foram discutidos de acordo com a formulação psicodinâmica de cada fábula. A autora concluiu, por seus achados, que as fábulas se mostravam mais fidedignas em certas idades do que em outras. Dessa forma, haveria um padrão diferente de fidedignidade conforme a maturidade das crianças. Contudo, há que se ressaltar que os seus resultados referentes à faixa de seis a oito anos basearam-se em dados provenientes de administração individual do teste, enquanto os relativos aos grupos de oito a 14 anos foram levantados em administração coletiva (Cunha \& Nunes, 1993), constituindo uma variável importante a ser considerada nesses resultados.

O segundo estudo de Peixotto (1957) investigou quais seriam as respostas populares (mais frequentes) ao Teste de Fábulas de Despert. Com uma amostra de crianças entre seis e 14 anos, chegou a uma série de respostas que foram consideradas como populares, por demonstrarem consistência suficiente em indivíduos considerados normais, ou seja, não pacientes. No seu entender, o número de fábulas apropriadas para crianças mais novas era suficiente para qualquer situação clínica, porém para sujeitos com mais de oito anos de idade seria necessário que novas fábulas fossem adicionadas. Assim, Peixotto concluiu que essa técnica seria mais apropriada para crianças menores de oito anos.

A terceira pesquisa de Peixotto (1960) com as Fábulas de Despert buscou investigar o uso desse instrumento com 83 crianças em tratamento clínico para transtornos emocionais, que foram subdivididas em três grupos, por idade: 47 delas com idades entre seis e oito anos, 33 crianças entre nove e 12 anos e três crianças com 13 anos ou mais. As respostas foram comparadas com as da amostra de seu estudo anterior, de 1957, sobre respostas populares com crianças não pacientes de 6 a 14 anos (Peixotto, 1957). Na maioria dos casos foram encontradas as mesmas respostas populares nos grupos clínicos e de não pacientes, não subsidiando discriminação suficiente por esta variável da técnica. Diferenças significativas se deram em respostas não usuais e 
28 | In tro d u çã o

isoladas, em onze das vinte fábulas. Por meio desses estudos, a pesquisadora concluiu que esse método projetivo reflete a psicodinâmica da criança de forma consciente e inconsciente, mas pareceu limitado para diagnósticos diferenciais nessa etapa do desenvolvimento humano (crianças).

Kramer (1968) realizou estudos sobre a tradução do método das Fábulas do francês para o inglês. Ao revisar essa tradução acabou por elaborar uma nova versão na língua inglesa. $\mathrm{O}$ autor também fez uma revisão da literatura e da utilidade clínica do teste. Revisando a tradução realizada por Despert, Kramer encontrou diferenças do original em francês e detectou cuidados insuficientes na preservação dos conceitos psicanalíticos abordados no original (tópicos referentes às fases psicossexuais). Segundo Kramer, essas mudanças e omissões provavelmente modificariam ou limitariam o repertório de respostas que a criança poderia dar, apesar de nenhuma pesquisa ter confirmado isso. Desse modo, o autor apresentou uma nova tradução para o inglês, buscando ser o mais fiel possível ao original, assim como consistente com os conceitos psicanalíticos e com uma linguagem simples que pudesse ser entendida por crianças pequenas.

A tradução das Fábulas de Düss para a língua portuguesa, no Brasil, foi realizada em São Paulo, sob a supervisão técnica de Professora Doutora Leila Tardivo, segundo as informações de Cunha e Nunes (1993). Passados alguns anos de sua tradução, essa mesma autora normatizou o instrumento para o uso no Brasil (Tardivo, 1992). Para a pesquisa de normatização foi mantida a série original de 10 fábulas proposta por Düss. Em sua tese de doutorado, Tardivo (1992) desenvolveu um referencial para a análise das respostas, caracterizado por um conjunto de categorias usado como roteiro de interpretação para o material, o que não existia até então. Por meio desse estudo, a utilidade do instrumento (denominado como Teste das Fábulas de Düss) para o diagnóstico psicológico ficou destacada e foi favorecida em termos operacionais.

Concomitantemente, as Fábulas de Düss estavam em estudo por outro centro de investigações científicas brasileiro, coordenado pela Professora Doutora Jurema Alcides Cunha. De acordo com Cunha e Nunes (1993), desejava-se avaliar características de personalidade de crianças pré-escolares e, para tanto, o grupo de pesquisa aproveitou a ideia de um projeto inacabado que se iniciou na Argentina com o objetivo de criar uma versão pictórica para as fábulas. Consideraram que seria vantajoso desenvolvê-la para a população brasileira. 
Cunha, Oliveira e Heineck (1989a) utilizaram o material básico traduzido por Tardivo (1992) e elaboraram uma nova versão do Teste das Fábulas, juntando a versão verbal a uma versão pictórica. Este material foi publicado, pela primeira vez no Brasil, em Cunha e Nunes (1993). Foram introduzidas algumas mudanças na formulação de determinadas fábulas, mas de modo geral a forma verbal seguiu a tradução brasileira das Fábulas de Düss (Tardivo, 1992). As ilustrações da forma pictórica foram elaboradas por uma desenhista, sob a orientação das pesquisadoras. Ao longo do desenvolvimento das ilustrações, estas sofreram diversas mudanças a fim de eliminar aspectos que foram considerados sugestivos, chegando ao manual de Cunha e Nunes (1993) para então o denominado Teste das Fábulas. Vale ressaltar que o material produzido por Tardivo (1992) constitui-se na tradução literal das Fábulas de Düss, enquanto o Teste das Fábulas constitui-se na nova versão produzida para o Brasil por Cunha e Nunes (1993),sendo o título do instrumento um referencial importante para se detectar qual versão está a ser utilizada. A história do desenvolvimento desse método projetivo de avaliação psicológica foi também abordada na introdução do trabalho de Serafini (2004), podendo ser de auxílio para compreender o processo de sua adaptação para uso na realidade do Brasil. Informações relativas às características psicométricas do Teste das Fábulas são tratadas a seguir, de modo a apresentar fundamentos para sua adequada utilização em contextos variados.

\subsubsection{Evidências psicométricas e de aplicabilidade}

Na tentativa de identificar e descrever, de modo sintético, os estudos realizados com o Teste das Fábulas (Cunha \& Nunes, 1993) e o Teste das Fábulas de Düss (Tardivo, 1992), fez-se uma busca bibliográfica ativa em bases de dados, sem delimitação do período, com base apenas na palavra-chave: "Teste das Fábulas" (já que foram realizadas também tentativas com os termos "Métodos projetivos" e "Técnicas Projetivas", sem ocorrência de estudos para o Teste das Fábulas com estas palavraschave). Foram identificados 22 estudos, abrangendo o período de 1989 a 2012, notandose que poucos estudos psicométricos foram produzidos, sendo a maior parte relativa à aplicabilidade do instrumento, como se pode ver na Tabela 1. 
Tabela 1 -Descrição dos estudos realizados com o Teste das Fábulas (TF) no período de 1989 a 2012.

\begin{tabular}{|c|c|c|c|c|}
\hline Ano & Título & Autores & Objetivos & Principais resultados \\
\hline $\begin{array}{l}1989 \\
\text { (a) }\end{array}$ & $\begin{array}{l}\text { Teste das Fábulas: forma } \\
\text { verbal e pictórica }\end{array}$ & Cunha et al. & $\begin{array}{c}\text { Estudo da fidedignidade entre } \\
\text { a administração verbal e } \\
\text { pictórica }\end{array}$ & $\begin{array}{c}\text { Confirmou-se a fidedignidade de } \\
\text { ambas as formas }\end{array}$ \\
\hline $\begin{array}{l}1989 \\
\text { (b) }\end{array}$ & $\begin{array}{l}\text { Respostas populares ao } \\
\text { Teste das Fábulas }\end{array}$ & Cunha et al. & $\begin{array}{l}\text { Identificação das respostas } \\
\text { popularesde meninos e } \\
\text { meninas em idade escolar }\end{array}$ & $\begin{array}{l}\text { Foi construído quadro de } \\
\text { respostas populares }\end{array}$ \\
\hline $\begin{array}{l}1989 \\
\text { (c) }\end{array}$ & $\begin{array}{l}\text { Modelo das Fábulas - } \\
\text { uma versão pictórica }\end{array}$ & Cunha et al. & $\begin{array}{l}\text { Apresentar a versão pictórica } \\
\text { do modelo das Fábulas }\end{array}$ & $\begin{array}{c}\text { Divulgação dos cuidados } \\
\text { metodológicos utilizados na } \\
\text { construção da versão pictórica do } \\
\text { TF, favorecendo sua realização } \\
\text { por crianças, principalmente as } \\
\text { pré- escolares. }\end{array}$ \\
\hline 1990 & $\begin{array}{c}\text { Estudo do tempo de } \\
\text { reação ao CAT e ao TF } \\
\text { em crianças pré- escolares }\end{array}$ & $\begin{array}{c}\text { Cunha, Werlang } \\
\text { e Nunes }\end{array}$ & $\begin{array}{c}\text { Comparar tempo de reação no } \\
\text { TF e no CAT em pré- } \\
\text { escolares }\end{array}$ & $\begin{array}{l}\text { Crianças respondem ao TF com } \\
\text { maior prontidão } \\
\text { comparativamente ao CAT }\end{array}$ \\
\hline 1990 & $\begin{array}{l}\text { O valor clínico do escore } \\
\text { de concordância social no } \\
\text { Teste das Fábulas }\end{array}$ & $\begin{array}{l}\text { Nunes, Cunha } \\
\text { e Oliveira }\end{array}$ & $\begin{array}{l}\text { Verificar se a ocorrência de } \\
\text { concordância social seria de } \\
\text { valor clínico discriminativo }\end{array}$ & $\begin{array}{l}\text { Mostrou-se discriminativo na } \\
\text { medida em que menor a } \\
\text { concordância social, houve mais } \\
\text { indicadores de psicopatologia }\end{array}$ \\
\hline 1992 & $\begin{array}{c}\text { Teste da Apercepção } \\
\text { Infantil com figuras de } \\
\text { animais (CAT-A) e Teste } \\
\text { das Fábulas de Duss: } \\
\text { estudos normativos e } \\
\text { aplicações no contexto } \\
\text { das técnicas projetivas }\end{array}$ & Tardivo & Tese de Doutorado & $\begin{array}{c}\text { Tradução do Teste das Fábulas } \\
\text { de Düss para o Brasil e } \\
\text { desenvolvimento de sistema } \\
\text { interpretativo do instrumento }\end{array}$ \\
\hline 1998 & $\begin{array}{l}\text { O Teste da Apercepção } \\
\text { Temática e o Teste das } \\
\text { Fábulas de Düss: } \\
\text { Aplicações no campo das } \\
\text { técnicas projetivas }\end{array}$ & Tardivo & $\begin{array}{l}\text { Apresentar o Teste das } \\
\text { Fábulas de Düss e a } \\
\text { contribuição dos dois } \\
\text { instrumentos na âmbito das } \\
\text { técnicas projetivas para } \\
\text { público infantil } \\
\end{array}$ & $\begin{array}{c}\text { Apresentação de como cada } \\
\text { instrumento (Teste das Fábulas } \\
\text { de Düss e TAT) contribui para a } \\
\text { identificação dos aspectos } \\
\text { psicodinâmicos aparentes e } \\
\text { latentes } \\
\end{array}$ \\
\hline 1993 & $\begin{array}{l}\text { Manual do Teste das } \\
\text { Fábulas }\end{array}$ & Cunha e Nunes & Apresentar o instrumento & $\begin{array}{l}\text { Apresentação do instrumento, } \\
\text { dos cuidados metodológicos de } \\
\text { sua aplicação, apresentação de } \\
\text { sistema de avaliação, bem como } \\
\text { seus referenciais normativos } \\
\end{array}$ \\
\hline 1996 & $\begin{array}{c}\text { Considerações sobre os } \\
\text { resultados da } \\
\text { administração coletiva do } \\
\text { Teste das Fábulas em } \\
\text { adolescentes } \\
\end{array}$ & $\begin{array}{l}\text { Cunha, Argimon, } \\
\text { Santos e Escobar }\end{array}$ & $\begin{array}{c}\text { Evidenciar possível efeito da } \\
\text { aplicação coletiva em } \\
\text { adolescentes }\end{array}$ & $\begin{array}{l}\text { A administração coletiva } \\
\text { dificulta, em certa medida, a } \\
\text { manifestação do conteúdo } \\
\text { projetivo no teste. }\end{array}$ \\
\hline 1997 & $\begin{array}{l}\text { Medo em crianças pré- } \\
\text { escolares em situação pré- } \\
\text { cirúrgica }\end{array}$ & Feijó & $\begin{array}{l}\text { Identificar tipos de medo de } \\
\text { crianças diante de uma } \\
\text { situação cirúrgica }\end{array}$ & $\begin{array}{l}\text { Caracterização dos tipos de } \\
\text { medos infantis e de tendência à } \\
\text { regressão nesse contexto; } \\
\text { evidências de conflito situacional }\end{array}$ \\
\hline 1998 & $\begin{array}{c}\text { Fábulas de L. Düss: } \\
\text { Unestudio de psicología } \\
\text { educativa }\end{array}$ & Luque & $\begin{array}{c}\text { Analisarrelação entre emoção } \\
\text { e desempenho escolar por } \\
\text { meio do TF de Düss e Teste } \\
\text { da Família de Corman }\end{array}$ & $\begin{array}{l}\text { Evidências de que componentes } \\
\text { afetivos das crianças ligados à } \\
\text { dinâmica familiar afetam o } \\
\text { desempenho escolar, bem como a } \\
\text { presença de conflitos situacionais }\end{array}$ \\
\hline 1998 & $\begin{array}{c}\text { Fábulas de Düss e o nível } \\
\text { de maturidade afetiva: } \\
\text { Avaliação de crianças } \\
\text { com dificuldades }\end{array}$ & $\begin{array}{l}\text { Pietro, } \\
\text { Avancini e } \\
\text { Loureiro }\end{array}$ & $\begin{array}{l}\text { Avaliar o nível de maturidade } \\
\text { emocional das crianças com } \\
\text { dificuldade de aprendizagem } \\
\text { com as Fábulas } 1,3,7 \text { e } 9 \\
\end{array}$ & $\begin{array}{c}\text { Crianças com dificuldades } \\
\text { escolares tendem a resolver } \\
\text { situações de forma realista e } \\
\text { adaptada, mas apresentam baixa }\end{array}$ \\
\hline
\end{tabular}


escolares.

tolerância à frustração e imaturidade afetiva

\begin{tabular}{|c|c|c|c|c|}
\hline 1998 & $\begin{array}{c}\text { Características borderlines } \\
\text { na infância, manifestações } \\
\text { através do Rorschach e } \\
\text { das Fábulas de Düss }\end{array}$ & Pietro e Loureiro & $\begin{array}{l}\text { Estudo de caso de criança } \\
\text { com diagnóstico Borderline } \\
\text { por meio do Rorschach e } \\
\text { Teste das Fábulas }\end{array}$ & $\begin{array}{c}\text { Identificação de sinais de } \\
\text { imaturidade, tendência } \\
\text { regressiva, fantasias de rejeição, } \\
\text { tendência autodestrutiva, } \\
\text { ansiedade persecutória no caso } \\
\text { avaliado. }\end{array}$ \\
\hline 2004 & $\begin{array}{c}\text { Teste das Fábulas: um } \\
\text { estudo com crianças } \\
\text { abrigadas }\end{array}$ & Serafini & $\begin{array}{l}\text { Caracterizar o funcionamento } \\
\text { psicodinâmico de crianças } \\
\text { institucionalizadas }\end{array}$ & $\begin{array}{l}\text { Crianças institucionalizadas } \\
\text { apresentaram indicadores de } \\
\text { ruptura do vinculo parental, } \\
\text { distinguindo-se das respostas da } \\
\text { amostra de padronização }\end{array}$ \\
\hline 2004 & $\begin{array}{c}\text { Respuestas características } \\
\text { enel Test de las Fábulas } \\
\text { de Düss y su poder para } \\
\text { discriminar entre } \\
\text { niñoscon y sin problemas } \\
\text { emocionales } \\
\end{array}$ & Santos e Damiani & $\begin{array}{l}\text { Apresentar projeto de } \\
\text { pesquisa com Teste das } \\
\text { Fábulas de Düss }\end{array}$ & $\begin{array}{l}\text { Apresentam projeto de pesquisa } \\
\text { com Teste das Fábulas de Düss, } \\
\text { procurando discriminar respostas } \\
\text { de crianças com e sem problemas } \\
\text { emocionais }\end{array}$ \\
\hline 2005 & $\begin{array}{l}\text { Avaliação psicológica de } \\
\text { crianças vítimas de } \\
\text { violência por meio do } \\
\text { Teste das Fábulas de Düss }\end{array}$ & Tardivo & $\begin{array}{c}\text { Evidenciar a sensibilidade do } \\
\text { Teste das Fábulas de Düss a } \\
\text { demandas de crianças vítimas } \\
\text { de violência social }\end{array}$ & $\begin{array}{c}\text { Crianças vitimizadas } \\
\text { apresentaram sinais de: maior } \\
\text { ambivalência às figuras parentais } \\
\text { e maior independência da figura } \\
\text { materna ou paterna nas histórias } \\
\text { (de acordo com a figura } \\
\text { agressora na realidade) } \\
\end{array}$ \\
\hline 2008 & $\begin{array}{l}\text { Mãe, quero ficar contigo: } \\
\text { Comportamentos de } \\
\text { dependência do } \\
\text { primogênito no contexto } \\
\text { da gestação de um irmão. }\end{array}$ & Oliveira e Lopes & $\begin{array}{l}\text { Evidenciar possível impacto } \\
\text { da chegada do segundo filho } \\
\text { no primogênito }\end{array}$ & $\begin{array}{c}\text { Identificaram sinais de } \\
\text { ambivalência afetiva, conflito } \\
\text { dependência X independência, } \\
\text { aspectos ligados à regressão, bem } \\
\text { como de conflitos situacionais } \\
\text { nos primogênitos. }\end{array}$ \\
\hline 2010 & $\begin{array}{c}\text { O momento de brincar no } \\
\text { ato de contar histórias: } \\
\text { uma modalidade } \\
\text { diagnóstica. }\end{array}$ & Conti e Souza & $\begin{array}{l}\text { Avaliar a capacidade } \\
\text { simbólica de crianças }\end{array}$ & $\begin{array}{l}\text { Identificaram sinais de } \\
\text { capacidade de simbolização em } \\
\text { crianças, sem marcas de } \\
\text { concretude. }\end{array}$ \\
\hline 2011 & $\begin{array}{c}\text { O desenvolvimento } \\
\text { emocional de crianças } \\
\text { submetidas a transplante } \\
\text { hepático. }\end{array}$ & Anton e Piccinini & $\begin{array}{l}\text { Estudar o impacto da doença } \\
\text { crônica e do transplante } \\
\text { hepático no desenvolvimento } \\
\text { infantil }\end{array}$ & $\begin{array}{c}\text { Evidenciaram conflitos } \\
\text { dependência X independência, } \\
\text { fantasias de morte e privação, } \\
\text { tendência a regressão em } \\
\text { crianças transplantadas }\end{array}$ \\
\hline 2011 & $\begin{array}{l}\text { Psicoterapia baseada na } \\
\text { mentalização de crianças } \\
\text { que sofreram maus-tratos. }\end{array}$ & $\begin{array}{l}\text { Ramires e } \\
\text { Godinho }\end{array}$ & $\begin{array}{l}\text { Examinar a capacidade de } \\
\text { mentalização/simbolização de } \\
\text { crianças vitimizadas, de } 10 \text { a } \\
12 \text { anos, e seu tipo de apego }\end{array}$ & $\begin{array}{l}\text { Identificaram sinais de limitada } \\
\text { mentalização nas crianças que } \\
\text { sofreram maus-tratos, com } \\
\text { ampliação após psicoterapia. } \\
\text { Sinais de apego inseguro, } \\
\text { ambivalência e passividade } \\
\end{array}$ \\
\hline 2012 & $\begin{array}{l}\text { O Teste das Fábulas em } \\
\text { crianças vítimas de } \\
\text { violência doméstica. }\end{array}$ & Lima e Ribeiro & $\begin{array}{c}\text { Estudar a psicodinâmica de } \\
\text { crianças vítimas de violência } \\
\text { doméstica residentes em } \\
\text { abrigo }\end{array}$ & $\begin{array}{l}\text { Encontraram sinais de fantasias } \\
\text { de privação e agressão deslocada } \\
\text { para o ambiente, bem como de } \\
\text { conteúdos de hetero e auto- } \\
\text { agressão nas crianças vitimizadas }\end{array}$ \\
\hline 2012 & $\begin{array}{l}\text { O Teste das Fábulas na } \\
\text { avaliação do } \\
\text { funcionamento de } \\
\text { crianças envolvidas no } \\
\text { fenômeno da alienação } \\
\text { parental }\end{array}$ & Ramires e Damiani & $\begin{array}{c}\text { Avaliar características } \\
\text { psicodinâmicas de crianças } \\
\text { vítimas de alienação parental }\end{array}$ & $\begin{array}{c}\text { Identificaram marcas de } \\
\text { fragilidade egóica, ansiedade de } \\
\text { separação em relação às mães } \\
\text { alienadoras, características de } \\
\text { dependência e passividade, } \\
\text { funcionamento regressivo nas } \\
\text { crianças avaliadas. }\end{array}$ \\
\hline
\end{tabular}


Há que se comentar que, averiguadas as adequadas qualidades psicométricas desse método projetivo de avaliação psicológica no Brasil, efetivaram-se estudos relativos a sua aplicabilidade em diferentes contextos, como se confirma pelos dados sistematizados nessa revisão bibliográfica, identificando-se 17 trabalhos utilizando o Teste das Fábulas (Cunha \& Nunes, 1993) e cinco o Teste das Fábulas de Düss (Tardivo, 1998). Um primeiro comentário geral é o de que os estudos de natureza psicométrica a respeito do Teste das Fábulas foram devolvidos até a publicação do seu manual técnico, ou seja, são todos anteriores a 1993, exigindo atualização. Pode-se observar também que o Teste das Fábulas, sozinho ou em conjunto com outras técnicas, tem se mostrado de grande utilidade em vários contextos. A maioria dos estudos de aplicabilidade desse método projetivo de avaliação psicológica procurou descrever o funcionamento psicodinâmico e identificar o possível impacto emocional de conflitos situacionais vivenciados por crianças. A seguir, buscar-se-á explorar esses trabalhos de modo descritivo e analítico, embora sintético.

Antes de publicar o manual do Teste das Fábulas, Cunha e Nunes (1993) realizaram alguns estudos para examinar as características psicométricas desse método de avaliação psicológica, em sua versão pictórica e verbal, como por elas proposto para uso no Brasil.Uma das pesquisas (Cunha et al, 1989a)objetivou analisar a fidedignidade da nova versão do instrumento quanto à produtividade e aspectos clínicos, a partir de uma amostra de 18 crianças pré-escolares de três anos e 11 meses a seis anos e nove meses. A amostra foi dividida em dois subgrupos: no primeiro subgrupo foi realizada apenas a administração da forma verbal e, no segundo subgrupo, a forma verbal e pictórica desenvolvida pelas pesquisadoras. Foi realizada, às cegas, uma contagem das verbalizações obtidas e as autoras desenvolveram um sistema de categorização de respostas contendo itens e alternativas para cada fábula. O total de verbalizações foi submetido a uma análise de variância, identificando-se que tanto a forma apenas verbal quanto a versão verbal e pictórica do Teste das Fábulas podem ser utilizadas indiferentemente, sem que haja alteração na produtividade. No que se refere à fidedignidade, foi realizado um levantamento do número de respostas categorizadas de forma idêntica nos dois grupos e, então, realizado o teste de significância da diferença entre as proporções.A conclusão a que chegaram foi de que o instrumento se mostrou fidedigno sob o ponto de vista formal e clínico (Cunha \& Nunes, 1993).

$\mathrm{Na}$ sequência dos estudos sobre esse método projetivo, Cunha et al (1989b) investigaram quais seriam as respostas populares ao Teste de Fábulas e avaliaram se 
havia diferença entre aplicação de sua forma verbal ou da forma pictórica, recorrendo a uma amostra de 18 crianças pré-escolares de três anos e 11 meses a seis anos e nove meses. Não foram encontradas diferenças significativas na produtividade de respostas entre a forma verbal e pictórica do teste, contudo observou-se diferenciado nível de interesse das crianças na atividade, assim como foi diferenciada a qualidade das respostas dadas no inquérito. A partir desse estudo, foi possível ainda construir um quadro de referência de respostas populares para cada sexo nesse método de avaliação psicológica.

Em seguida, Cunha e Nunes (1989c) apresentaram a versão pictórica desenvolvida por seu grupo de pesquisa (1989a), no Congresso Interamericano de Psicologia em Buenos Aires, ressaltando o extenso e minucioso cuidado no desenvolvimento dos desenhos por uma desenhista profissional e o cuidado com a manutenção da neutralidade nos desenhos, para que não interferissem nas respostas das crianças. Descreveram, ainda, as vantagens do uso da forma pictórica quanto a maior aproximação entre criança e examinador.

O Teste das Fábulas foi também foco de investigação desenvolvida por Cunha, Werlang e Nunes (1990) no Brasil, com objetivo de avaliar diferenças no tempo de reação de crianças pré-escolares frente a esse método projetivo e à forma animal do ChildrenAperception Test (CAT-A). A amostra foi constituída por 20 crianças em idade pré-escolar que demonstraram menor tempo de reação ao Teste das Fábulas do que ao CAT-A, sugerindo, assim, maior prontidão ao primeiro. As autoras concluíram que o fato do Teste das Fábulas apresentar dois tipos de estímulos em conjunto (forma verbal e pictórica) facilita o trabalho associativo e interpretativo (necessário para responder ao material) nessa faixa etária (crianças pré-escolares).

Outro estudo relevante sobre esse método projetivo realizado no Brasil focalizou a análise do valor clínico do escore relativo à "concordância social", obtido a partir do Teste das Fábulas (Nunes, Cunha \& Oliveira, 1990). A pesquisa foi realizada com uma amostra de 40 crianças em idade pré-escolar, 20 delas frequentando alguma instituição considerada socializante há pelo menos seis meses, e 20 que não frequentavam nenhuma instituição. Os resultados indicaram que os fatores socioculturais não se mostraram diretamente associados aos escores no Teste das Fábulas, pois a concordância social não foi afetada pela experiência institucional. Contudo, identificaram sinais de que a baixa concordância social estava associada a indicadores de psicopatologia, comprovando o valor clínico deste instrumento. 
34 | In trod u çã o

Um breve histórico desses estudos iniciais também foi apresentado e comentado por Serafini (2004), retratando as evidências de validade desse método projetivo no contexto do Brasil, sendo agora sintetizado o seu destaque para os estudos das Fábulas de Düss desenvolvidos por Tardivo, posto que a tradução do teste para a língua portuguesa foi realizada em São Paulo, sob a supervisão técnica de Tardivo. Em seu estudo de Doutorado, Tardivo (1992) realizou cuidadoso trabalho com o Teste das Fábulas de Düss, objetivando elaborar referenciais normativos para esse instrumento, bem como evidenciar suas possibilidades de aplicação no contexto das demais técnicas projetivas de avaliação psicológica. Para a pesquisa de normatização, Tardivo (1992) manteve a série original de 10 fábulas proposta por Düss e desenvolveu um referencial para a análise das respostas (roteiro de interpretação para o teste), organizado em um conjunto de categorias avaliativas. Exemplos dessas categorias seriam: a) na Fábula 1: conflito Independência versus dependência, passividade versus atividade, relação com a figura paterna e materna; b) na Fábula 3: ansiedade presente diante da situação de desmame (esquizoparanóideversus depressiva).

Por meio desse trabalho desenvolvido por Tardivo (1992), foi possível evidenciar a utilidade do Teste das Fábulas de Düss para o diagnóstico psicológico. Essa autora publicou, em 1998, um livro reunindo informações técnicas e clínicas sobre o Teste da Apercepção Temática e o Teste das Fábulas de Düss. Essa pesquisadora apresentou os dois instrumentos projetivos, suas características metodológicas e aplicações clínicas, ressaltando sua importância no psicodiagnóstico infantil (Tardivo, 1998).

Fica claro que os estudos de natureza psicométrica a respeito do Teste das Fábulas encerraram-se nesse período no Brasil, sem a identificação de novos trabalhos nessa direção até o presente momento. Essa situação desencadeou, como já informado, um parecer desfavorável do SATEPSI (CFP, 2011) ao uso do Teste das Fábulas no Brasil, apesar de suas promissoras hipóteses avaliativas, como aqui apontado. Esse contexto fortalece a sistematização das pesquisas com esse instrumento projetivo de avaliação psicológica, bem como novas investigações, como a presentemente realizada.

Cabe ainda destacar que, em termos de aplicabilidade clínica, a partir da publicação do manual do Teste das Fábulas por Cunha e Nunes (1993), várias pesquisas com esse instrumento avaliativo puderam ser desenvolvidas, auxiliando a compreensão de necessidades e do funcionamento psíquico infantil. Será agora brevemente descrito esse conjunto de trabalhos identificados na atual revisão bibliográfica, conforme 
informações apresentadas na Tabela 1, seguindo-se sua cronologia. Cunha, Argimon, Santos e Escobar (1996) aplicaram o Teste das Fábulas (Cunha \& Nunes, 1993) de modo coletivo em uma amostra de 88 adolescentes, de ambos os sexos, com idades entre 12 e 17 anos, objetivando avaliar possível efeito deste tipo de aplicação do instrumento sobre as respostas dadas pelos sujeitos. Foi identificado que a administração coletiva dificulta, em certa medida, a manifestação do conteúdo projetivo, mas ainda assim favorece contato inicial com aspectos da personalidade do indivíduo. Apesar dessas restrições no estilo produtivo, o referido trabalho apontou que, nessa faixa etária (12 a 17 anos), a primeira fábula mobilizou respostas relacionadas aos conflitos da adolescência, tais como: impotência versus onipotência, imaturidade versus maturidade, dependência versus independência. Além disso, descobriram que os adolescentes com características depressivas (confirmadas também por outros instrumentos) apresentaram personagens com bons indicadores no que se refere à adaptabilidade, riqueza de recursos emocionais e defesas maduras em suas histórias. Apesar de seus recursos, sua produção apresentou enredos com heróis muitas vezes torturados, perseguidos ou mortos, com respostas geralmente curtas e, por vezes, os temas eram tratados com tentativas de humor e negação (Cunha, Argimon, Santos \& Escobar, 1996). Corroborou-se, desse modo, que o Teste das Fábulas pode ser adequado e sensível a conteúdos psíquicos em várias idades, embora seja mais utilizado com o público infantil, carecendo de mais pesquisas que possam explorá-lo em outras faixas etárias (Cunha \& Nunes, 1993), como nessa faixa adolescente.

Há também pesquisas que usaram o Teste das Fábulas como um dos instrumentos para avaliar a dinâmica afetiva de crianças em situações clínicas distintas, como quadros sintomáticos de medo em pré-escolares numa situação pré-cirúrgica (Feijó, 1997). Nesse estudo, o Teste das Fábulas foi administrado em pré-escolares para investigar a presença de medos nesses contextos clínicos, examinando-se possíveis efeitos da situação pré-cirúrgica e renda familiar (média ou baixa). Foi possível identificar sinais de tendência à regressão e de conflitos situacionais nessas crianças, caracterizando tipos de medo mais frequentes em momentos anteriores a intervenções cirúrgicas hospitalares.

No que se refere ao contexto escolar, Luque (1998) realizou um estudo, utilizando o Teste das Fábulas e o Teste da Família de Corman, para analisar eventual associação entre emoções e desempenho escolar. A amostra foi composta de 50 estudantes de escolas públicas de Málaga (Espanha). Encontrou-se consistência entre os 
36 | In trod u çã o 
sugeriram frágil estruturação da personalidade, com características de funcionamento psíquico compatível com o diagnóstico inicialmente proposto.

O sistema de categorização pelo qual a produção derivada das fábulas está exposto no manual do Teste das Fábulas (Cunha \& Nunes, 1993) foi objeto de explanação em Serafini (2004), sendo detalhadamente descrito na sessão relativa aos instrumentos dessa tese. De modo geral, são considerados elementos a serem avaliados: tempo médio de reação, número de respostas populares e fenômenos especiais, como autorreferência ao responder o instrumento, perseveração ou contaminação de conteúdos de uma fábula para outra. As respostas ainda são classificadas por itens como: tipo de ação do herói, enredo da história, forma de desfecho, personagens citados, medos ou desejos do herói, fantasias, estados emocionais e mecanismos de defesas. Esses itens variam de acordo com a fábula que está sendo apresentada. Posteriormente à classificação dos conteúdos projetados diante das fábulas, é necessário realizar a interpretação dinâmica dos resultados (Cunha, 2000).

Descrito o sistema avaliativo de Cunha e Nunes (1993) para o Teste das Fábulas, Serafini (2004) conseguiu mostrar evidências empíricas de sua utilidade e validade para se compreender o funcionamento psíquico de crianças institucionalizadas. Essa pesquisadora checou a possível existência de um padrão de respostas ao instrumento em crianças que foram institucionalizadas, comparando-as com as respostas obtidas na amostra de padronização do instrumento (Cunha \& Nunes, 1993). Participaram da pesquisa 62 crianças que residiam em abrigo, de ambos os sexos, sendo 41 meninos e 21 meninas, com idades entre quatro anos e nove meses e 11 anos e oito meses. Os dados obtidos demonstraram que crianças abrigadas, em geral, responderam de forma diversa da amostra padronizada do instrumento. Tais diferenças foram relativas a indicadores clínicos de ruptura do vínculo parental vivenciada pelas crianças abrigadas.

O trabalho publicado por Santos e Damiani (2004) é bastante peculiar, pois descreve um projeto de investigação científica a ser desenvolvido com objetivo de determinar as respostas características noTeste Fábulas de Düss em uma amostra de 240 crianças escolares de oito, nove e 10 anos, advindas da classe média alta da Grande Caracas (Venezuela). Pretendiam, ainda, examinar a capacidade do teste para identificar crianças com problemas emocionais, utilizando-se o sistema avaliativo proposto por Tardivo (1998), contraposto a indicadores emocionais de Koppitz (1976) para o Teste da Figura Humana (critério de validade externa). Examinariam ainda o índice de acordo 
entre avaliadores independentes dos resultados. Apesar da riqueza da proposta, não foi possível identificar qualquer publicação posterior relativa a esse projeto de pesquisa.

Também em um contexto clínico, Tardivo (2005) estudou a produção no Teste das Fábulas de Düss a partir de seu sistema de categorização de respostas (Tardivo, 1998) aplicado em 13 crianças (oito meninos e cinco meninas) entre quatro e 11 anos, vítimas de violência doméstica física e/ou sexual. Seu objetivo residia em examinar a sensibilidade e a possibilidade de uso desse teste no desvelamento de questões psíquicas profundas nesse público específico. Os dados sugeriram que, ao mesmo tempo em que a criança vitimizada apresenta maior ambivalência com relação às figuras parentais, o fator determinante, nesse caso, pareceu ser a forma como a relação mãe/criança é estabelecida, nesse caso, protetora ou abusiva. Esses dados indicaram que a criança vitimizada no lar tende a se afastar da figura abusiva e vitimizadora (quer seja o pai ou a mãe), provavelmente pela vivência de ameaça que essa pessoa representa em sua integridade física e/ou psicológica. Evidenciaram maior independência de cada figura materna ou paterna, no contexto das fábulas, de acordo com a figura (pai ou mãe agressor) correspondente na realidade. Ao final do estudo, Tardivo (1998) confirmou o valor diagnóstico dos indicadores desse método projetivo.

Em estudo sobre a vivência da chegada do segundo filho no núcleo familiar, Oliveira e Lopes (2008) avaliaram cinco primogênitos em idade escolar e suas respectivas mães (com idades entre 31 e 38 anos, casadas) no terceiro trimestre de gestação. Utilizaram o Teste das Fábulas e entrevistas semidirigidas, respectivamente. Uma análise qualitativa a respeito do conteúdo das respostas das mães foi realizada com vistas a identificar comportamentos de dependência do primogênito. A produção das mães e das crianças foi dividida em duas categorias: a) comportamento de dependência do primogênito (associado a aspectos da criança evidenciados na técnica projetiva); b) alterações no comportamento de dependência do primogênito (associado a categorias identificadas no discurso das mães durante as entrevistas). Os dados obtidos apontaram para um aumento dos comportamentos de dependência do primogênito (como o uso de chupeta, mamadeira) e maiores dificuldades na hora do sono, bem como aumento da ambivalência afetiva. O cruzamento das produções das mães e das crianças permitiu verificar a sensibilidade do Teste das Fábulas para a situação circunscrita nesse estudo (questão situacional), bem como aspectos relativos ao funcionamento psíquico infantil.

O Teste das Fábulas também se mostrou capaz de identificar o nível de maturidade e capacidade simbólica de crianças no estudo de Conti e Souza (2010). O 
Teste das Fábulas foi utilizado em conjunto com outros métodos projetivos para estudar a capacidade simbólica versus concretude das expressões infantis. Nesse trabalho, as atividades de contar histórias por meio dos testes projetivos (como o Teste das Fábulas, o TAT), foram compreendidas como expressões da capacidade de brincar dos indivíduos e alguns desses recortes foram utilizados como demonstração da capacidade de fantasiar e, portanto, do brincar, sinalizando funcionamento abstrato e de natureza simbólica, segundo os autores.

No contexto hospitalar, Anton e Piccinini (2011) realizaram um estudo com seis crianças com idade entre quatro e oito anos, transplantados de fígado, e suas respectivas mães, sendo aplicado o Teste das Fábulas às crianças e realizadas entrevistas com suas mães. A pesquisa buscou avaliar o impacto da doença crônica e do transplante hepático infantil no desenvolvimento da criança. Por meio do Teste das Fábulas foi possível identificar a presença de sinais de sentimentos de insegurança, impotência, solidão, fantasias de morte e privação, conflitos de dependência-independência, dificuldades na aquisição da autonomia e comportamento tendendo à regressão, com baixa tolerância à frustração. Com esses resultados os autores apontaram a necessidade de acompanhamento psicológico desse grupo clínico, de modo a favorecer o desenvolvimento dessas crianças, tendo o Teste das Fábulas se mostrado instrumento adequado para identificara intervenção clínica necessária à situação.

No que se refere ao público infanto-juvenil, o Teste das Fábulas tem confirmado indicadores clínicos obtidos com outros recursos de avaliação psicológica, como apresentado por Ramires e Godinho (2011). Esses pesquisadores realizaram estudo de casos múltiplos, com objetivo de avaliar a capacidade de mentalização de duas crianças (meninas de 10 e 12 anos) vítimas de maus-tratos, após intervenção clínica. O Teste das Fábulas foi um dos instrumentos utilizados na fase diagnóstica inicial e permitiu identificar sinais de características psíquicas sugestivas de ambivalência, passividade e insegurança, bem como indícios de conflitos relacionados às figuras parentais, que não pareciam sentidas como referências significativas ou figuras com as quais fosse possível contar. Os resultados do Teste das Fábulas estavam consistentes com o conteúdo obtido na hora de jogo diagnóstica, em que predominavam vivências de perda e privação, fantasias de abandono que geravam comportamentos de rebeldia, oposição e a agressão parecia deslocada para o ambiente, havendo fantasias de culpa e punição. Desse modo, esse estudo ressaltou a contribuição do instrumento para diagnóstico do funcionamento psicodinâmico infanto-juvenil. 
Lima e Ribeiro (2012), por sua vez, aplicaram o Teste das Fábulas em seis crianças com idade entre seis e 10 anos, vítimas de violência doméstica e temporariamente abrigadas, sendo quatro do sexo masculino e duas do sexo feminino. Por meio do instrumento foi possível identificar que, com relação ao estado emocional, a categoria 'alegria' apareceu de modo mais frequente (talvez derivado ou associado à experiência concreta de estar sendo acolhida e protegida por uma instituição, no momento), seguida de 'medo' e 'tristeza'. Evidenciaram-se fantasias de 'agressão deslocada para o ambiente' e 'privação'. As situações mais conflitantes vivenciadas por essas crianças foram: na 'Fábula 6', ao tratar das reações frente às experiências fálicas; na 'Fábula 8', em relação ao conflito edípico (pai agressor); na 'Fábula 9', em relação aos medos e proibições; e na 'Fábula 10', sinalizada pela heteroagressão e autoagressão. Observou-se novamente a sensibilidade do teste, mostrando-se capaz de identificar questões e particularidades situacionais e não somente elementos relativos à estruturação da personalidade.

No contexto da Psicologia Judiciária, Ramires e Damiani (2012) fizeram o uso do Teste das Fábulas na avaliação de características do funcionamento psicodinâmico de crianças envolvidas no fenômeno da alienação parental. Realizaram estudos de caso com dois meninos e duas meninas, com idades entre seis e 10 anos. Os resultados apontaram sinais de conflitos das crianças com as figuras parentais, sendo predominantes temas relacionados à separação-individuação, com características de dependência, passividade, controle da expressão afetiva e imaturidade, pobreza de fantasias, fragilidade egóica. Os indicadores apontaram, portanto, para funcionamento psicodinâmico regressivo, com ansiedade de separação associada a vivências de relação fusional com genitoras alienadoras. Desse modo, foi possível colecionar evidências empíricas de validade e sensibilidade do Teste das Fábulas como instrumento projetivo útil na investigação da dinâmica psíquica infantil.

Apesar da diversidade de aplicações encontradas para o Teste das Fábulas, bem como de bons cuidados metodológicos e estudos normativos, esse instrumento projetivo encontra atualmente limites técnicos para seu uso no Brasil (CFP, 2011). Assim, novos estudos são necessários de modo a contribuir para a produção de conhecimento desse recurso de avaliação psicológica. Nesse sentido, a presente pesquisa procura contribuir com a produção do conhecimento a respeito do Teste das Fábulas, importante em diversas áreas de aplicação da Psicologia. Esse trabalho, portanto, busca o aprimoramento técnico-científico desse método projetivo no contexto da avaliação 
psicológica infantil, focalizando a produção de crianças escolares com vivências diferenciadas em termos de indicadores de Saúde Mental. 


\section{OBJETIVOS}

\subsection{GERAL}

O presente estudo tem como objetivo examinar indicadores empíricos de validade e precisão do Teste das Fábulas, em seu uso em crianças escolares de seis a 12 anos de idade. Pretende-se, dessa forma, contribuir para o avanço do conhecimento científico sobre esse método projetivo e embasar sua utilização na prática profissional de psicólogos no contexto do Brasil.

\subsection{ESPECÍFICOS}

2.2.1. Caracterizar e comparar o padrão de respostas de crianças escolares de seis a 12 anos no Teste das Fábulas, seguindo-se classificação dos resultados conforme proposta avaliativa de Cunha e Nunes (1993), sendo os participantes subdivididos em três grupos:

a) crianças com diagnóstico e tratamento para problemas de saúde mental

b) crianças com indicadores sugestivos de problemas de saúde mental

c) crianças sem indicadores de problemas de saúde metal

2.2.2. Identificar variáveis do Teste das Fábulas que possam se associar a indicadores de problemas de saúde mental em crianças escolares de seis a 12 anos.

2.2.3. Analisar possíveis associações das variáveis sexo e idade com os resultados no Teste das Fábulas nos três grupos de crianças avaliados.

2.2.4. Examinar indicadores de precisão (pelo método de avaliação independente de avaliadores) do Teste das Fábulas. 
2.2.5. Testar e revisar o sistema avaliativo de Cunha e Nunes (1993) para o Teste das Fábulas, de modo a facilitar sua operacionalização e o adequado uso profissional. 


\section{MÉTODO}

\subsection{PARTICIPANTES:}

Com base nos objetivos propostos para o presente estudo, foram avaliadas 60 crianças de seis a 12 anos de idade, subdivididas em três grupos: a) Grupo 1 (G1, n=20): crianças com diagnóstico e tratamento por problemas de Saúde Mental; b) Grupo 2 (G2, n=20): crianças com indicadores sugestivos de problemas de Saúde Mental; c) Grupo 3 (G3, n=20): crianças sem indicadores sugestivos de problemas de Saúde Mental.

Os critérios de inclusão dos participantes no estudo foram:

a) Geral: idade entre seis e 12 anos; série escolar compatível com a esperada para a idade; participação voluntária no estudo e devidamente autorizada por seus pais ou responsáveis.

b) Para Grupo 1 - G1 (Grupo Clínico): crianças que receberam diagnóstico psiquiátrico e tratamento por problemas de Saúde Mental. Realizaram processo psicodiagnóstico e atendimento clínico no Serviço de Psiquiatria Infantil do Hospital das Clínicas da Faculdade de Medicina de Ribeirão Preto da Universidade de São Paulo (HC/FMRPUSP).

c) Para Grupo 2 - G2 (Grupo com indicadores de problemas de Saúde Mental): crianças que obtiverem pontuação classificada como "clínica" na escala total de sintomas do Questionário de Capacidades e Dificuldades (SDQ), sugerindo indicadores de prejuízo funcional no âmbito escolar e emocional a partir da percepção de seus pais ou responsáveis.

d) Para Grupo 3 - G3 (Grupo sem indicadores de problemas de Saúde Mental): crianças que obtiverem pontuação classificada como "não clínica" na escala total de sintomas do Questionário de Capacidades e Dificuldades (SDQ), sugerindo indicadores de desenvolvimento típico para sua idade e contexto sociocultural na percepção dos pais ou responsáveis.

O critério de exclusão geral dos participantes do estudo foi a limitação cognitiva, avaliada pelo Teste das Matrizes Progressivas Coloridas de Raven. Foram 
excluídas as crianças que alcançaram resultado inferior ao percentil 25 nesse teste psicológico, segundo normas de Angelini, Alves, Custódio, Duarte e Duarte (1999).

Para compor o Grupo 1 foi utilizado o banco de dados de avaliação psicológica do Serviço de Psiquiatria Infantil do Hospital das Clínicas de Ribeirão Preto (HCFMRP-USP), hospital terciário, mantido por meio de convênio entre o Sistema Único de Saúde (SUS) e a FMRP-USP e que atende casos de alta complexidade. Este hospital é o Centro de Referência da região e, como está vinculado à USP, também oferece ensino e pesquisa em diversas áreas da Saúde. A maioria da população atendida é de renda econômica baixa até média, encaminhada por serviços primários e secundários da rede pública de Saúde, procedentes de Ribeirão Preto e da região, no entorno de 100 $\mathrm{km}$, aproximadamente.

Mais especificamente, o Serviço de Psiquiatria Infantil é composto por uma equipe fixa de profissionais incluindo psiquiatras, psicólogos e terapeutas ocupacionais, além de residentes da Psiquiatria e aprimorandos de Psicologia e Terapia Ocupacional. Esses últimos fazem parte do programa de residência médica nessa área $\mathrm{e}$ aprimoramento profissional do referido hospital, dada sua a função de ensino e aprendizagem, dedicando-se à formação de profissionais na área da saúde. No Ambulatório de Psiquiatria Infantil do HC, o usuário é atendido por meio de consultas psiquiátricas e atendimentos individuais em Psicologia e em Terapia Ocupacional, além de grupos para orientação de pais. O serviço de Psicologia do Setor de Psiquiatria Infantil tem pressupostos baseados na teoria psicodinâmica e, além de atendimento clínico individual, realiza processos de avaliação psicodiagnóstica que auxiliam o diagnóstico clínico psiquiátrico e o planejamento terapêutico.

Crianças atendidas no $\mathrm{HC}$ e que apresentam queixas sugestivas de problemas de Saúde Mental, de maior complexidade, são encaminhadas para o serviço de Psiquiatria do hospital, sendo avaliadas por residentes do terceiro/último ano de residência em Psiquiatria, com supervisão de um psiquiatra docente da FMRP-USP. Além de anamnese e entrevistas clínicas, quando ainda há dúvidas sobre o diagnóstico clínico, os casos são encaminhados para avaliação psicodiagnóstica, de modo a auxiliar no esclarecimento de dúvidas quanto ao funcionamento psicodinâmico da criança e na identificação de seus recursos e eventuais limitações. Estas solicitações de psicodiagnóstico são realizadas por meio de pedido de interconsulta hospitalar, registrando-se questões específicas que o psiquiatra considera relevantes para adequada compreensão do caso (por exemplo, com relação a nível intelectual), de modo que essas 
informações balizem o delineamento da avaliação psicológica a ser realizada (definição de instrumentos específicos a partir da demanda apresentada).

Faz-se necessário informar os casos do Grupo 1 foram identificados em banco de dados do referido serviço clínico, devidamente autorizado para o presente trabalho (ANEXO 2), sendo selecionados do conjunto total de crianças avaliadas no período de 2005 a 2011, e que atendessem aos critérios de inclusão e de exclusão nessa pesquisa. Desse modo, de um total de 67 casos avaliados no Serviço de Psiquiatria Infantil do HC/FMRP-USP no período, chegou-se exatamente a 20 casos clínicos para esse grupo, embora com leve desequilíbrio em função do sexo dos participantes. Há que se ressaltar, portanto, que os dados de G1 (advindos de banco de registros de serviço clínico especializado) foram produzidos em período anterior ao processo atual de coleta de dados realizado em G2 e em G3.

De modo a descrever as principais características das crianças de G1, apresentase na Tabela 2 sua caracterização demográfica e clínica. Destaca-se que o objetivo desse detalhamento é a visualização dos casos e de seus diagnósticos e tratamentos, de modo a descrever a composição geral do grupo, inclusive contendo algumas crianças com atraso escolar. Embora tenha se tentado excluir esse tipo de casos no estudo, no grupo clínico (G1) esse processo acabou não sendo possível para algumas crianças, justamente por suas características específicas de desenvolvimento, justificando-se sua inclusão na amostra clínica desse trabalho.

$\underline{\text { Tabela } 2}$ - Caracterização demográfica e clínica dos participantes do Grupo 1 (n=20). 


\begin{tabular}{|c|c|c|c|c|c|c|c|}
\hline Idade & Sexo & $\begin{array}{c}\text { Hipótese } \\
\text { Diagnóstica }\end{array}$ & Medicação em uso & $\begin{array}{c}\text { Série } \\
\text { escolar }\end{array}$ & Tratamentos & $\begin{array}{c}\text { Antecedentes } \\
\text { psiquiátricos } \\
\text { familiares } \\
\end{array}$ & TOTAL \\
\hline \multirow[t]{2}{*}{6 anos } & M & - & - & - & - & - & \\
\hline & $\mathrm{F}$ & Esquizofrenia & Risperidona & $1^{\mathrm{a}}$ & Psicoterapia & - & 1 \\
\hline \multirow{3}{*}{$\begin{array}{c}7 \\
\text { anos }\end{array}$} & \multirow[b]{2}{*}{ M } & $\begin{array}{c}\text { Depressão com } \\
\text { sintomas psicóticos }\end{array}$ & Haloperidol & $2^{\mathrm{a}}$ & - & - & \multirow{3}{*}{2} \\
\hline & & $\begin{array}{c}\text { Transtorno } \\
\text { Psicótico/ } \\
\text { Esquizofrenia } \\
\text { (em instalação) }\end{array}$ & - & $2^{\mathrm{a}}$ & Psicoterapia & Existentes & \\
\hline & $\mathrm{F}$ & - & - & - & - & - & \\
\hline \multirow{4}{*}{$\begin{array}{c}8 \\
\text { anos }\end{array}$} & \multirow{3}{*}{ M } & $\begin{array}{c}\text { Transtorno } \\
\text { Afetivo Bipolar }\end{array}$ & Clorpromazina & $4^{\mathrm{a}}$ & Psicoterapia & Existentes & \multirow{4}{*}{3} \\
\hline & & $\begin{array}{c}\text { Transtorno } \\
\text { Afetivo Bipolar }\end{array}$ & $\begin{array}{c}\text { Ácido Valpróico e } \\
\text { Neuleptil }\end{array}$ & $3^{\mathrm{a}}$ & Psicoterapia & Existentes & \\
\hline & & $\begin{array}{c}\text { Transtorno } \\
\text { Esquizoafetivo }\end{array}$ & $\begin{array}{l}\text { Ácido Valpróico, } \\
\text { Imipramina e } \\
\text { Risperidona }\end{array}$ & $1^{\mathrm{a}}$. & $\begin{array}{l}\text { Psicoterapia e } \\
\text { Fonaudiologia }\end{array}$ & - & \\
\hline & $\mathrm{F}$ & - & - & - & - & - & \\
\hline \multirow{7}{*}{$\begin{array}{c}9 \\
\text { anos }\end{array}$} & \multirow{5}{*}{ M } & $\begin{array}{c}\text { Transtorno } \\
\text { Esquizoafetivo }\end{array}$ & - & $3^{a}$ & - & - & \multirow{7}{*}{7} \\
\hline & & $\begin{array}{c}\text { Transtorno } \\
\text { Esquizoafetivo }\end{array}$ & Imipramina & $3^{\mathrm{a}}$. & - & - & \\
\hline & & $\begin{array}{c}\text { Transtorno } \\
\text { Afetivo Bipolar }\end{array}$ & $\begin{array}{c}\text { Oxicarbamazepina } \\
\text { e Risperidona }\end{array}$ & $3^{\mathrm{a}}$ & $\begin{array}{c}\text { Terapia } \\
\text { Ocupacional }\end{array}$ & Existentes & \\
\hline & & $\begin{array}{c}\text { Transtorno } \\
\text { Afetivo Bipolar }\end{array}$ & $\begin{array}{c}\text { Ácido Valpróico e } \\
\text { Haloperidol }\end{array}$ & $4^{\mathrm{a}}$. & - & Existentes & \\
\hline & & $\begin{array}{c}\text { Transtorno } \\
\text { Afetivo Bipolar }\end{array}$ & - & $2^{\mathrm{a}}$ & $\begin{array}{c}\text { Terapia } \\
\text { Ocupacional }\end{array}$ & - & \\
\hline & \multirow[t]{2}{*}{$\mathrm{F}$} & $\begin{array}{c}\text { Transtorno } \\
\text { Alimentar/ } \\
\text { Funcionamento } \\
\text { Borderline }\end{array}$ & Clomipramina & $5^{\mathrm{a}}$ & Psicoterapia & Existentes & \\
\hline & & $\begin{array}{c}\text { Ansiedade de } \\
\text { Separação / } \\
\text { Episódio Depressivo }\end{array}$ & $\begin{array}{l}\text { Imipramina e } \\
\text { Risperidona }\end{array}$ & $3^{a}$ & Psicoterapia & - & \\
\hline \multirow{3}{*}{$\begin{array}{c}10 \\
\text { anos }\end{array}$} & M & $\begin{array}{l}\text { Transtorno } \\
\text { Depressivo }\end{array}$ & - & $1^{\mathrm{a}}$ & $\begin{array}{c}\text { Terapia } \\
\text { Ocupacional }\end{array}$ & - & \multirow{3}{*}{3} \\
\hline & & $\begin{array}{c}\text { Transtorno } \\
\text { Hipercinético }\end{array}$ & $\begin{array}{c}\text { Amitriptilina e } \\
\text { Ritalina }\end{array}$ & $2^{\mathrm{a}}$ & Psicoterapia & Existentes & \\
\hline & $\mathrm{F}$ & $\begin{array}{c}\text { Traços Obsessivos / } \\
\text { Transtorno Afetivo } \\
\text { Bipolar (latente) }\end{array}$ & Clomipramina & $3^{\mathrm{a}}$ & - & Existentes & \\
\hline 11 & $\mathrm{M}$ & - & - & - & - & - & - \\
\hline anos & $\mathrm{F}$ & - & - & - & - & - & \\
\hline \multirow{4}{*}{$\begin{array}{c}12 \\
\text { anos }\end{array}$} & M & $\begin{array}{c}\text { Transtorno } \\
\text { Psicótico/ } \\
\text { Esquizofrenia } \\
\text { (em instalação) }\end{array}$ & Risperidona & $4^{\mathrm{a}}$ & - & Existentes & \multirow{4}{*}{4} \\
\hline & & $\begin{array}{l}\text { Síndrome de } \\
\text { Tourette }\end{array}$ & - & $7^{\mathrm{a}}$ & - & - & \\
\hline & \multirow[t]{2}{*}{$\mathrm{F}$} & $\begin{array}{c}\text { Transtorno } \\
\text { Alimentar / } \\
\text { Transtorno Afetivo } \\
\text { Bipolar (latente) }\end{array}$ & - & $6^{\mathrm{a}}$ & $\begin{array}{l}\text { Psicoterapia e } \\
\text { Orientação de } \\
\text { Pais }\end{array}$ & - & \\
\hline & & $\begin{array}{c}\text { Transtorno } \\
\text { Esquizoafetivo }\end{array}$ & $\begin{array}{l}\text { Imipramina e } \\
\text { Risperidona }\end{array}$ & $6^{\mathrm{a}}$. & - & - & \\
\hline
\end{tabular}


Nota-se que há predomínio de crianças do sexo masculino (13 casos), a partir de nove anos de idade (14 casos), com histórico familiar de antecedentes clínicos de ordem psiquiátrica e com algum atraso escolar. A maioria desses casos clínicos está sob prescrição medicamentosa (13 casos), além da intervenção psicoterápica ou de terapia ocupacional e com fonoaudiólogo, em alguns casos. As hipóteses diagnósticas mais frequentes nessas crianças eram: Transtorno Afetivo Bipolar, Transtorno esquizoafetivo, Episódio Depressivo, Esquizofrenia e Transtorno Alimentar. Caracteriza-se, portanto, como um grupo de crianças considerado clínico, atendendo ao delineamento desejado para o presente trabalho.

Para compor o Grupo 2 e Grupo 3 foram selecionadas crianças de uma escola pública municipal de ensino fundamental da região de Ribeirão Preto (SP), com estrutura física adequada para a pesquisa e cuja diretoria acolheu prontamente a investigação, sendo selecionada, portanto, por viabilidade prática. Essa institucional educacional atende a 400 crianças provenientes de famílias de renda econômica baixa até média, cujos pais possuem escolaridade variando entre o ensino fundamental e o ensino médio completo, predominando, no entanto, reduzido nível educacional. Essas características sociodemográficas eram compatíveis com o padrão geral das crianças do grupo clínico, como já apontado, favorecendo a possibilidade de comparação dos casos desse estudo.

A partir do conjunto dos critérios de seleção adotados para esse trabalho foi possível constituir uma amostra compatível ao delineamento inicialmente proposto, embora constituída por conveniência nas instituições colaboradoras. A Tabela 3 descreve as características etárias, acadêmicas e de nível intelectual dos participantes, em função do sexo e do grupo constituído, cada qual com 20 participantes. 
$\underline{\text { Tabela } 3}$ - Caracterização dos participantes $(n=60)$ e seus subgrupos em função do sexo, idade, escolaridade e nível cognitivo.

\begin{tabular}{|c|c|c|c|c|c|c|c|c|c|}
\hline \multicolumn{2}{|c|}{ VARIÁVEL } & \multicolumn{2}{|c|}{$\begin{array}{c}\text { Grupo } 1 \\
(n=20)\end{array}$} & \multicolumn{2}{|c|}{$\begin{array}{c}\text { Grupo } 2 \\
(\mathrm{n}=20)\end{array}$} & \multicolumn{2}{|c|}{$\begin{array}{c}\text { Grupo } 3 \\
(n=20)\end{array}$} & \multicolumn{2}{|c|}{ TOTAL } \\
\hline \multicolumn{2}{|c|}{ Sexo } & $\mathrm{M}^{*}$ & $\mathrm{~F}^{*}$ & $\mathrm{M}$ & $\mathrm{F}$ & $\mathrm{M}$ & $\mathrm{F}$ & $\mathrm{M}$ & $\mathrm{F}$ \\
\hline \multirow{7}{*}{$\begin{array}{c}\text { Idade } \\
\text { (em anos) }\end{array}$} & 6 & - & 1 & 1 & 1 & 1 & 1 & 2 & 3 \\
\hline & 7 & 2 & - & 1 & 2 & 1 & 1 & 4 & 3 \\
\hline & 8 & 3 & - & 5 & 2 & 2 & 2 & 10 & 4 \\
\hline & 9 & 5 & 2 & 3 & 2 & 6 & 4 & 14 & 8 \\
\hline & 10 & 2 & 1 & 1 & 1 & - & 1 & 3 & 3 \\
\hline & 11 & - & - & - & 1 & - & 1 & - & 2 \\
\hline & 12 & 2 & 2 & - & - & - & - & 2 & 2 \\
\hline \multicolumn{2}{|c|}{ Subtotal } & 14 & 6 & 11 & 9 & 10 & 10 & 35 & 25 \\
\hline \multirow{7}{*}{$\begin{array}{l}\text { Escolari- } \\
\text { dade } * *\end{array}$} & $1^{\circ}$. ano & 2 & 1 & 2 & 2 & 2 & 2 & 6 & 5 \\
\hline & $2^{\circ}$. ano & 4 & - & 2 & 2 & 2 & 2 & 8 & 4 \\
\hline & $3^{\circ}$. ano & 4 & 2 & 3 & 1 & 2 & 2 & 9 & 5 \\
\hline & $4^{\circ}$. ano & 3 & - & 2 & 2 & 2 & 2 & 7 & 4 \\
\hline & $5^{\circ}$. ano & - & 1 & 2 & 2 & 2 & 2 & 4 & 5 \\
\hline & $6^{\circ}$. ano & - & 2 & - & - & - & - & - & 2 \\
\hline & $7^{\circ}$. ano & 1 & - & - & - & - & - & 1 & - \\
\hline \multicolumn{2}{|c|}{ Subtotal } & 14 & 6 & 11 & 9 & 10 & 10 & 35 & 25 \\
\hline \multirow{4}{*}{$\begin{array}{l}\text { Potencial } \\
\text { Cognitivo } \\
\text { *** }\end{array}$} & $\begin{array}{c}25 \leq \mathrm{P}<75 \\
\text { (médio) }\end{array}$ & 5 & 1 & 4 & 4 & 5 & 3 & 14 & 8 \\
\hline & $\begin{array}{c}75 \leq \mathrm{P}<90 \\
\text { (médio }\end{array}$ & 4 & 2 & 4 & 4 & 4 & 4 & 12 & 10 \\
\hline & superior) & & & & & & & & \\
\hline & $\begin{array}{c}\mathrm{P} \geq 90 \\
\text { (superior) }\end{array}$ & 2 & - & 3 & 1 & 1 & 3 & 6 & 4 \\
\hline Sub & & 11 & 3 & 11 & 9 & 10 & 10 & 32 & 22 \\
\hline
\end{tabular}

$* \mathrm{M}=$ sexo masculino, $\mathrm{F}=$ sexo feminino.

**Escolaridade expressa em anos escolares, atualmente vigentes no ensino fundamental.

*** No grupo 1 (clínico) seis crianças não foram avaliadas pelo Raven (três do sexo masculino e três do sexo feminino), resultando em subtotais diferentes nesse quesito. 
Pode-se notar que foi possível equilibrar os participantes dos grupos e da amostra como um todo em função do sexo, embora no Grupo 1 exista predomínio do sexo masculino. Em termos acadêmicos procurou-se incluir na amostra dois participantes de cada sexo distribuídos do primeiro ao quinto ano, porém isso não foi possível no Grupo 1, visto suas peculiaridades psiquiátricas e dificuldades de vida das crianças, não seguindo escolarização regular. No total da amostra, grande maioria das crianças encontra-se nos primeiros anos do ensino fundamental, no geral compatível com sua idade.

Há ainda necessidade de se comentar que, no Grupo 1, embora a idade variasse até os 12 anos, os anos escolares distribuíram-se até o sétimo ano, o que aponta prejuízo no desempenho escolar desse grupo, não necessariamente associado a baixo potencial cognitivo. Desse modo, cabe pensar que o prejuízo no desempenho escolar (atraso em ano escolar) do Grupo 1 possivelmente está associado mais à condição psiquiátrica do que a falta de recursos intelectuais. Vale ressaltar ainda que do grupo clínico, seis crianças (três meninos e três meninas) não foram avaliadas pelo Teste de Raven, pois clinicamente (visto antecedentes pessoais e clínicos) não havia dúvidas relativas a seu bom potencial cognitivo, portando não havia pedido formal de específica avaliação cognitiva (Raven) no processo psicodiagnóstico. Nos demais casos do Grupo 1, o Teste de Raven foi parte do processo psicodiagnóstico clínico, sendo selecionados para participar da pesquisa apenas os casos com potencial cognitivo a partir do nível médio (percentil acima de 25). Esse dado reafirma a hipótese de que suas dificuldades de rendimento acadêmico provavelmente se associam a outra natureza de variáveis.

Visto que o nível intelectual foi utilizado como critério de seleção de participantes ao estudo (excluindo-se aqueles com percentil inferior a 25), seria esperado que a amostra apresentasse resultados cognitivos superiores à classificação mediana. No entanto, há que se destacar que mais da metade dos participantes, independentemente dos grupos, alcançou resultado superior ao percentil 75 no Teste de Raven. Assim, a amostra, como um todo, possui indicadores de superioridade intelectual em considerável proporção de participantes.

Diante do exposto, pode-se afirmar que os grupos constituintes da amostra do presente trabalho atenderam plenamente às condições desejadas para esse estudo, fortalecendo seus achados. 


\subsection{MATERIAIS}

\subsubsection{Carta de apresentação da pesquisa}

A Carta de Apresentação do projeto de pesquisa (APÊNDICE A) foi entregue à diretora da escola previamente selecionada (por conveniência técnica e viabilidade operacional do estudo), a fim de que pudesse avaliar a possibilidade de colaborar como desenvolvimento do projeto, autorizando a inserção da pesquisadora no estabelecimento educacional sob sua responsabilidade. Nela estão contidas informações a respeito dos objetivos do trabalho e de como a coleta de dados seria desenvolvida, além de espaço adequado para o dirigente institucional atestar sua concordância com o projeto, autorizando a execução em seu estabelecimento.

\subsubsection{Termo de consentimento livre e esclarecido}

O Termo de Consentimento Livre e Esclarecido (TCLE - APÊNDICE B) apresentou os objetivos da pesquisa aos pais ou responsáveis dos possíveis participantes, bem como os deveres e os direitos dos participantes, o nome e o telefone de contato da pesquisadora responsável. O documento foi assinado em duas vias por aqueles que concordaram com a participação do(a) filho(a) no trabalho, permanecendo uma cópia com eles e outra com a pesquisadora.

\subsubsection{Questionário de Capacidades e Dificuldades (SDQ)}

O Questionário de Capacidades e Dificuldades (StrengthsandDifficultiesQuestonnaire, SDQ) é um instrumento objetivo de avaliação psicológica, que rastreia problemas de saúde mental infantil em crianças e adolescentes de quatro a 16 anos. Esse instrumento foi construído em 1997 por Goodman e validado no Brasil por Fleitlich, Cartázar e Goodman (2000). É composto por 25 itens, sendo 10 
itens sobre capacidades, 14 itens sobre dificuldades e um item neutro, subdivididos em cinco subescalas (com um até cinco itens), a saber: problemas no comportamento prósocial, hiperatividade, problemas emocionais, de conduta e de relacionamento. Apresenta bons indicadores psicométricos, fortalecendo a qualidade de suas informações (Saur, Pasian\& Loureiro, 2009; Saur\& Loureiro, 2012).

O instrumento está disponível para uso em pesquisa (gratuitamente) em seu endereço eletrônico oficial (http://www.sdqinfo.com) em mais de 40 idiomas, incluindo o português.É apresentado em três versões, indicadas para serem respondidas pelas próprias crianças (acima de 11 anos), por seus pais ou responsáveis e pelos professores. As alternativas para resposta são: falso (zero ponto para esse tipo de resposta), mais ou menos verdadeiro (um ponto) e verdadeiro (dois pontos), podendo ser assinalada apenas uma única opção por item. Para cada uma das cinco subescalas a pontuação pode variar de zero a 10, sendo a soma dos resultados (excetuando-se a subescala de sociabilidade) correspondente ao escore geral de dificuldades da criança, podendo variar de zero a 40 pontos. A nota de corte estabelecida para o escore total de dificuldades foi de 17 para a versão dos pais e 16 para a versão dos professores (Saur\& Loureiro, 2012). Quanto mais alto o escore geral obtido, mais indicadores de dificuldades na área de Saúde Mental estarão presentes.

As características do SDQ facilitam seu uso cotidiano na prática clínica e em pesquisa, dada sua formatação compacta, facilidade de aplicação, focalização em itens avaliativos de capacidades e limites da criança, além de informações sobre dificuldades específicas como de atenção/hiperatividade, relação com colegas e comportamento prósocial. As especificidades das subáreas do instrumento coincidem com as áreas de medição geral da Saúde Mental em crianças e adolescentes (Fleitlich, Cartázar\& Goodman, 2000; Cury \&Golfeto, 2003).

No presente estudo foi utilizada a versão do SDQ dirigida aos pais, de modo a permitir a identificação das crianças com indicadores sugestivos de problema de Saúde Mental (G2) e as que não apresentavam tais indicadores (G3), a fim de compor a amostra dos referidos grupos para o estudo. Este instrumento de rastreamento em Saúde Mental não foi aplicado a G1,visto que já possuíam diagnóstico clínico psiquiátrico, bem como processo psicodiagnóstico (que ocorreu entre 2005 a 2011). Além disso, as informações referentes a G1 foram retiradas de banco de dados do referido serviço psiquiátrico, sem contato direto com os participantes e/ou responsáveis pelos mesmos no decorrer dessa pesquisa. 


\subsubsection{Teste das Matrizes Progressivas Coloridas de Raven}

O Teste das Matrizes Progressivas de Raven é uma técnica de múltipla escolha, com objetivo de avaliação do nível intelectual geral. Existem várias versões do instrumento, sendo que as Matrizes Progressivas Coloridas são voltadas à avaliação de crianças de seis a 11 anos.

A técnica propõe uma matriz de figuras onde há um padrão lógico entre as representações figurativas presentes na página, sendo solicitado à criança que escolha apenas uma das alternativas para completar a matriz. Uma das caselas da matriz é deixada em branco e o examinando é solicitado a preencher a casela com a figura correta, segundo o seu raciocínio.

Essa técnica foi estudada no contexto do Brasil por Angelini, Alves, Custódio, Duarte e Duarte (1999), sendo esse o referencial técnico e normativo adotado no presente trabalho, complementado pelos dados de Bandeira, Alves, Giacomel e Lorenzatto (2004). Os resultados no Teste das Matrizes Coloridas de Raven foram utilizados como critério de seleção de participantes na pesquisa, sendo aceitos apenas os casos cujo resultado foi classificado como igual ou superior ao percentil 25, correspondendo a uma classificação de inteligência igual ou superior ao nível médio.

\subsubsection{Teste das Fábulas}

O Teste das Fábulas é um método projetivo de avaliação psicológica, voltado ao exame da personalidade. Foi criado por LouisaDuss, em 1940, e adaptado para o Brasil por Cunha e Nunes (1993). É constituído por dez fábulas, contadas uma de cada vez, para a criança, acompanhada de cartões ilustrativos do texto (versão pictórica). O conteúdo das mesmas apresenta uma personagem principal, denominado de herói (uma criança ou um animal), que se encontra em uma situação determinada (narrada pelo avaliador) e que teoricamente representa uma fase dos estágios psicossexuais (dentro da abordagem psicodinâmica que embasa essa técnica). A tarefa da criança é continuar narrando a história a partir do ponto em que o examinador parou. Desse modo, a criança tem a possibilidade de determinar que caminhos o herói irá tomar, podendo projetar 
suas peculiaridades de funcionamento psíquico. Passa-se, a seguir, a brevemente descrever os conteúdos específicos de cada uma das dez fábulas que compõem o teste, de modo a embasar as análises interpretativas posteriores dos resultados com as crianças presentemente avaliadas.

A Fábula 1 sugereque o respondente se identifique com um filhote passarinho, que sabe voar um pouco e cujos pais, por causa de um vento forte que derrubou seu ninho, voaram cada um para uma árvore diferente. Psicodinamicamente, explora-se o conflito dependência versus independência, podendo-se identificar a presença de apego específico a um dos pais, e a atitude do sujeito frente a uma perda de uma condição confortável e protegida.

$\mathrm{Na}$ Fábula 2, a criança se vê diante da relação conjugal dos pais (que independe de sua existência) e explora a reação do respondente frente às questões edípicas e da cena primária. Na Fábula 3, a criança é levada a se identificar com um cordeirinho que é privado de leite (seu alimento essencial até aquele momento, embora ele já saiba comer capim) pela chegada de um segundo filhote, mais novo, que precisa do leite de sua mãe. Nessa fábula pode-se investigar a rivalidade fraterna e a reação a sentimentos de rejeição materna, conflitos de dependência versus independência e confiança versus desconfiança. Na Fábula 4 o tema central versa sobre enterro e morte, permitindo à criança que dê vazão a conteúdos impulsivos, como hostilidade, pulsões agressivas, desejos de morte, sentimentos de culpa ou desejo de autopunição. Já a Fábula 5 estimula a identificação do respondente com alguém que refere ter medo de algo, criando oportunidade do sujeito dar vazão a seus sentimentos de ansiedade, persecutoriedade, projeção da agressividade ou autopunição. Nota-se que as Fábulas 4 e 5 caracterizam-se por sua função catártica, diferentemente das anteriores que apresentam diretamente questões conflitivas e de mobilização afetiva em diferentes estágios do desenvolvimento psicoemocional.

Na Fábula 6, o herói da história é um elefante com uma tromba bem comprida, e a criança é estimulada a discorrer sobre modificações ocorridas no elefante. Espera-se explorar, a partir dessa fábula, conteúdos relativos ao complexo de castração e ao conflito potência versus impotência, aspectos relativos a modificações ocasionadas pelo desenvolvimento, questões ligadas à sexualidade e à fase fálica.

Na Fábula 7, um objeto de argila é confeccionado pela criança, que pode dá-lo ou não à mãe, que o solicita. Essa fábula explora conflitos ligados à fase anal, identificando eventuais sinais de obstinação e possessividade. Na Fábula 8 a criança sai 
com um dos pais, mais especificamente aquele do sexo oposto ao seu. Quando retorna para casa, o genitor que ali ficou se mostra bravo na fábula. Nesse momento, o avaliador solicita ao respondente o motivo possível para a braveza daquele genitor da fábula, abordando diretamente questões relacionadas ao complexo de Édipo, embora de forma lúdica.

A Fábula 9 informa que o herói recebeu uma notícia de sua mãe e se solicita à criança que informe, sob seu ponto de vista, qual o teor dessa notícia. Isso permite identificação de sinais relativos aos desejos e/ou medos do respondente. Finalmente, a Fábula 10 consiste na historieta de uma criança que acorda pela manhã após ter um "sonho mau" e a pergunta aborda o que ela sonhou. Essa fábula serve de controle para as fábulas anteriores, pois se a criança ficou muito mobilizada por um dos temas de alguma fábula anterior, pode espontaneamente retomá-lo nesse momento. Desse modo, essa fábula permite confirmar a existência de um conflito, bem como oportunizar o fechamento da mobilização afetiva suscitada pelo conjunto do teste ao passar a mensagem de que o conflito nela contido não passou de um sonho, tornando-se uma vivência catártica.

O Teste das Fábulas avalia o conteúdo narrado pela criança, revelando suas defesas e sua dinâmica psíquica frente aos conflitos inerentes às fábulas. A premissa desse método projetivo é a existência de processos projetivos dos conteúdos internos na história criada pela criança ou respondente. O manual brasileiro desse instrumento é de autoria de Cunha e Nunes (1993), sendo que será aqui utilizado como base para aplicação, avaliação e interpretação das variáveis classificadas nesse instrumento projetivo de avaliação psicológica.

De modo geral a produção no Teste das Fábulas é avaliada em seus aspectos qualitativos, levando-se em consideração o tempo de trabalho, a presença de recusa ou bloqueio em responder à tarefa, a interação do sujeito com o avaliador, suas atitudes e falas durante a execução, assim como sua coerência interna com a fábula e a logicidade da resposta. Cunha e Nunes (1993) desenvolveram um sistema de categorização do Teste das Fábulas com múltiplos itens avaliativos, distribuídos em 50 categorias de análise no conjunto das dez fábulas (muitas dessas categorias avaliativas são idênticas em fábulas diferentes). A classificação inicial das respostas nessas categorias favorece a sistematização e o estudo aprofundado das características dos casos avaliados, sendo recomendada sua utilização. Em termos sintéticos, essas categorias avaliativas para cada fábula se encontram esquematizadas no Quadro 1. 
Quadro 1-Descrição das categorias avaliativas do Teste das Fábulas conforme sistema avaliativo de Cunha e Nunes (1993).

Fábula

Fábula 1- Pássaro

Fábula 2 - Casamento

Fábula 3- Cordeirinho

Fábula 4- Enterro

Fábula 5- Medo

Fábula 6- Elefante

Fábula 7- Objeto fabricado

Fábula 8 - Passeio

Fábula 9 - Notícia

Fábula 10 - Sonho Mau
Categorias avaliativas das respostas

Ação; enredo; personagem; desfecho; fantasias; estado emocional; defesas.

Ação; motivo; fantasias; estado emocional; defesas.

Ação; desfecho; fantasias; estado emocional; defesas.

Personagem; fantasias; estado emocional; defesas.

Objeto; fantasias; defesas.

Natureza; identificação da mudança; local; fantasias; estado emocional; defesas.

Ação; fantasias; estado emocional; defesas.

Motivo; fantasias; estado emocional; defesas.

Medos; desejos; proibições; informações; fantasias; estado emocional; defesas.

Perseveração; novos conteúdos; fantasias; estado emocional; defesas.

\subsection{PROCEDIMENTOS}

\subsubsection{Considerações éticas}

O projeto desta pesquisa foi submetido à avaliação pelo Comitê de Ética em Pesquisa da Faculdade de Filosofia, Ciências e Letras de Ribeirão Preto da Universidade de São Paulo, conforme resoluções vigentes na época do início do estudo (Resolução 196/96 do Conselho Nacional de Saúde conselho.saude.gov/br/docs/Resoluções/Reso196.doc; Resolução 16/00 do Conselho Federal de Psicologia). Posteriormente a sua aprovação (ANEXO 1), deu-se início à coleta de dados.

Os devidos cuidados técnicos e éticos inerentes a qualquer avaliação psicológica foram tomados com participantes e responsáveis, que foram informados quanto aos objetivos da pesquisa e consultados sobre a possibilidade de participação nesse trabalho. 
Desse modo, visou-se garantir o sigilo da identidade dos participantes e a liberdade de participação nessa pesquisa, que se caracteriza por ser voluntária e não remunerada. Os pais ou responsáveis que concordaram com essa proposta investigativa assinaram o Termo de Consentimento Livre e Esclarecido, permitindo a avaliação de seu(sua) filho(a) e a própria participação no estudo. Somente após essa formalização de consentimento ao estudo é que se efetivou a coleta de dados.

Aos interessados e à escola colaboradora (de G2 e G3), ao final da pesquisa, foram agendadas palestras informativas a respeito das características do desenvolvimento psíquico dos estudantes da respectiva faixa etária, como um meio de oferecer possível contribuição aos participantes da pesquisa. Além disso, em dois casos onde foram identificadas necessidades específicas de auxílio aos estudantes (como avaliação psicológica e neurológica, psicoterapia e fonoaudiologia), foram agendadas sessões de orientação aos pais, sendo as crianças encaminhadas a serviços de saúde em seus respectivos órgãos de referência de atendimento psicológico da cidade, por orientação da pesquisadora. Com relação aos casos clínicos (retirados de banco de dados e que compõem G1), os mesmos já se encontravam em seguimento clínico no HC-FMRP/USP, de modo que não houve qualquer contato direto deles com a pesquisadora para a presente investigação.

\subsubsection{Coleta de dados}

Cumpre ressaltar que os dados referentes ao Grupo 1 (grupo clínico) já haviam sido colhidos nos processos psicodiagnósticos realizados na Clínica Psiquiátrica do Hospital das Clínicas da Faculdade de Medicina de Ribeirão Preto da Universidade de São Paulo entre os anos de 2005 e 2011. Portanto, este grupo foi composto por casos que compõem banco de dados do referido setor, estando devidamente autorizado este acesso pela coordenadora do Serviço de Psicodiagnóstico, Profa. Dra. Sonia Regina Loureiro, conforme documenta o ANEXO 2. Inicialmente foi realizado levantamento dos casos atendidos nos últimos seis anos desde o início do estudo (período acima citado) e dos 67 casos identificados foram selecionados 20 pacientes, aqueles que melhor atendessem aos critérios de exclusão e inclusão já citados, tentando selecionar casos de sexo e idade variados para constituir a amostra do Grupo 1. 
Para a composição do Grupo 2 e Grupo 3 foi realizado contato com escola de ensino fundamental da região de Ribeirão Preto (SP), a qual abarcou a faixa etária da presente investigação (seis a 12 anos) e atendeu a viabilidade técnica e operacional da pesquisa. Mais especificamente, o contato foi realizado inicialmente com a direção escolar no intuito de entregar a Carta de Apresentação (APÊNDICE A) da pesquisa, solicitando autorização para a mesma.

Depois do parecer favorável da direção escolar ao desenvolvimento da pesquisa no estabelecimento sob sua responsabilidade, a pesquisadora visitou todas as salas de aula daquela instituição em um momento propício: durante reunião de pais de todos os anos escolares, a fim de estabelecer um primeiro contato com os pais dos alunos inseridos dentro da faixa etária em questão. Essa visita teve por objetivo expor a proposta de pesquisa de forma sintética, assim como entregar, aos voluntários iniciais, o Termo de Consentimento Livre e Esclarecido e o Questionário de Dificuldades e Capacidades (SDQ) em um envelope. Foram preparados 400 envelopes contendo os materiais da pesquisa (TCLE e SDQ), com base no cálculo do total de alunos matriculados nos dois turnos de funcionamento da escola (matutino e vespertino). Na reunião de pais foram entregues pela pesquisadora, nesse contato direto com os pais, um total de 300 envelopes e os 100 restantes foram distribuídos entre os professores de todas as séries para que entregassem aos pais que haviam faltado à reunião. Foram devolvidos à pesquisadora 210 envelopes dentre os 400 distribuídos ao total. Do montante recebido, 22 foram recusas em participar da pesquisa e 18 foram invalidados por terem preenchido incorretamente o SDQ ou não terem assinado o TCLE, restando 170 voluntários.

Vale ressaltar que a amplitude de rastreamento dos possíveis participantes da pesquisa no contexto escolar foi um cuidado metodológicoadotado no sentido de assegurar a adequada composição da amostra, compondo grupo de voluntários em que fosse possível o pareamento em termos de sexo e idade entre G2 e G3. Houve ainda cuidado no sentido de averiguar se o ano letivo cursado pelo participante era o esperado para sua idade (por meio das listas de matrícula cedidas pela escola), com vistas a exclusão de casos em que essa discrepância pudesse sinalizar indícios de dificuldades no rendimento acadêmico.

Uma vez recebidos os documentos devidamente assinados pelos pais/responsáveis das crianças, junto com o SDQ preenchido, foi realizada a análise dos resultados desse último instrumento, conforme suas diretrizes técnicas. Assim, dos 
170casos autorizados para o estudo, 70 (41,1\%) foram classificados como "clínicos", 14 $(8,2 \%)$ como "limítrofes" e $86(50,5 \%)$ como "não clínicos", conforme a classificação do SDQ. Essa classificação inicial teve o objetivo de identificar, dentre os autorizados ao estudo, aqueles que seriam incluídos no Grupo 2 (G2) ou no Grupo 3 (G3), conforme critérios delineados para a presente investigação.

Desse total de respondentes ao SDQ, foram eliminados do estudo os casos classificados como "limítrofes", tomando-se para composição de G2 e G3 aqueles considerados "clínicos" e os "não clínicos", respectivamente. Retirados os casos limítrofes do SDQ, todos os demais poderiam participar do presente trabalho. Assim, a pesquisadora organizou o banco de dados desse conjunto de voluntários de tal modo que as informações relativas à classificação inicial do SDQ (caso clínico ou não clínico) estavam reservadas e guardadas para serem utilizadas após aplicação e correção dos outros instrumentos avaliativos, visto que o número de voluntários foi bastante superior ao planejado para o presente estudo. Esse cuidado metodológico (pesquisadora não ter acesso à classificação dos voluntários de acordo com o SDQ no momento de convidar as crianças ao estudo) teve por finalidade a aplicação "às cegas" dos instrumentos de avaliação psicológica nas crianças, procurando-se evitar interveniência dessa variável no processo de coleta de dados realizado pela pesquisadora. Assim, os participantes efetivos de G2 e G3 do presente estudo foram selecionados pela pesquisadora, a partir do banco de voluntários (total de 170 casos), inicialmente composto nessa escola.

A procura de participantes para compor o Grupo 2 (grupo com indicadores de problemas de Saúde metal) e Grupo 3 (grupo sem indicadores de problemas em Saúde mental) foi realizada até se completar 20 indivíduos em cada grupo, de acordo com os critérios de ter entre seis e 12 anos, apresentar percentil no Raven maior que 25, estar com a idade de acordo com o esperado para o ano escolar em que estava matriculado e preferencialmente distribuídos de modo equilibrado em função do sexo. Essa tentativa visou possibilitar dados suficientes para a realização do objetivo específico de comparação dos resultados no Teste das Fábulas em função do sexo dos participantes.

Enquanto esse banco de dados era elaborado pela pesquisadora, a mesma realizou visitas às classes escolares, agora para a apresentação da pesquisa aos alunos, convidando-os a participarem do estudo. Aqueles que concordaram com a proposta tinham seus nomes e turma registrados pela pesquisadora que, a seguir, conferia se possuam TCLE assinado. Dentre esses, a pesquisadora selecionou, ao acaso, voluntários das diferentes turmas, de modo a incluir a diversidade de estudantes disponível ao 
estudo, caracterizando amostra de conveniência. Essas crianças (que tinham autorização formal de seus pais/responsáveis) foram chamadas pela pesquisadora, paulatina e individualmente, ao longo de um ano letivo para a aplicação das provas psicológicas.

Com o consentimento do responsável pelo estabelecimento de ensino, o processo de coleta de dados foi efetivado diretamente pela pesquisadora no contexto escolar, em aplicações individuais, em sala da própria escola com devida iluminação e mobiliário. No primeiro contato com cada participante, foi realizado um breve rapport e uma reapresentação da pesquisa, reafirmando o convite para a criança realizar as atividades previstas. Em sequência, deu-se início ao processo de aplicação dos instrumentos de avaliação psicológica, seguindo-se o esquema: Teste das Matrizes Progressivas Coloridas de Raven (Angelini et al., 1999) e Teste das Fábulas, forma verbal e pictórica (Cunha \& Nunes, 1993), respectivamente, aplicados conforme diretrizes específicas de seus manuais técnicos. A seguir foram realizados os devidos agradecimentos à participação da criança, bem como sua reorientação aos trabalhos escolares, acompanhando-a até sua sala de aula, para continuidade de suas atividades cotidianas naquele contexto. Em média foi necessário realizar um encontro de duração aproximadamente de uma hora com cada criança, para se completar o processo de coleta de dados.

Os passos relativos ao processo de composição dos grupos podem ser visualizados na Figura 1. Ela caracteriza, esquematicamente, o percurso amostral efetivado nesse estudo. 

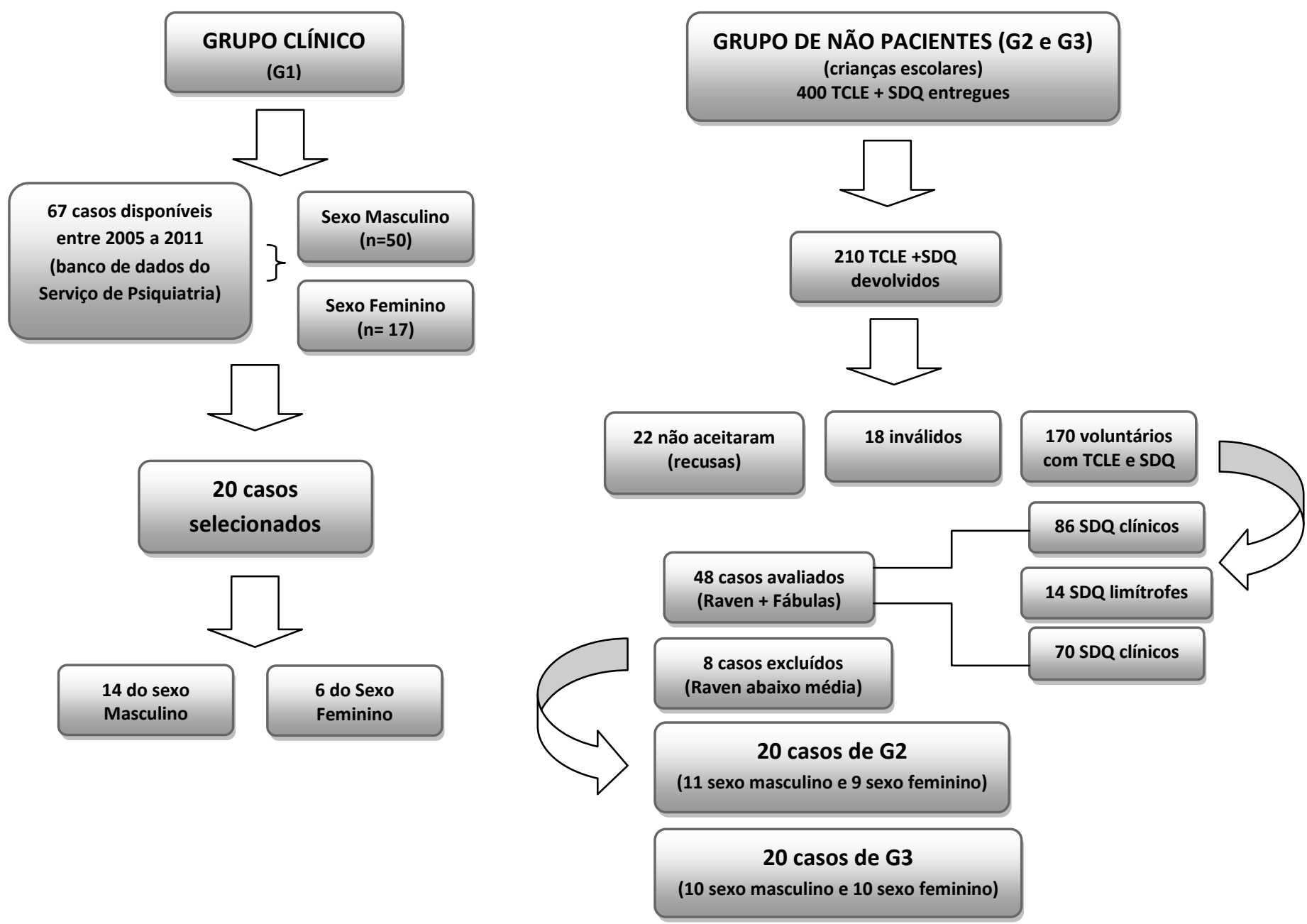

Figura 1 -Percurso amostral do presente estudo, em função do grupo avaliado.

Após a fase de tabulação e devida análise dos resultados, os pais das crianças avaliadas na escola e que foram identificadas com necessidades específicas de ajuda psicológica foram chamados a comparecer na escola para uma entrevista devolutiva dessas informações com a pesquisadora. Nesse momento, fez-se a devida orientação e encaminhamento desses casos (totalizando duas crianças) para serviços da rede pública municipal que pudessem reavaliar e/ou intervir clinicamente, de modo a atender adequadamente suas necessidades específicas. 


\subsubsection{Análise de Resultados}

Inicialmente os instrumentos de avaliação psicológica foram codificados e classificados conforme seus respectivos manuais técnicos. Desse modo, os dados do Questionário de Capacidades e Dificuldades (SDQ) foram examinados com base em Fleitlich et al. (2000), permitindo a identificação dos estudantes com indicadores de problemas de desempenho escolar/emocional (Grupo 2) e daqueles que não apresentam prejuízo funcional (Grupo 3). O desempenho cognitivo dos indivíduos foi examinado a partir do Teste das Matrizes Progressivas Coloridas de Raven, recorrendo-se aos padrões analíticos desenvolvidos por Angelini et al. (1999), complementados por dados de Bandeira et al.(2004).

Por fim, o processo de codificação da produção no Teste das Fábulas seguiu o referencial teórico psicodinâmico, seguindo-se padronização técnico-científica e normas propostas por Cunha e Nunes (1993). A codificação dos protocolos desse método projetivo foi realizada por três avaliadores, em atividades independentes, de modo a possibilitar análise de precisão desse processo. Esses juízes foram psicólogos com experiência prévia nos instrumentos de avaliação psicológica utilizados nesse trabalho e em avaliações psicodiagnósticas e que, ainda assim, receberam orientação específica para realizar as codificações do material coletado.

Dessa forma, cada protocolo passou por três análises independentes, sendo uma delas necessariamente realizada pela própria pesquisadora. Faz-se necessário ressaltar que, no material atribuído a cada avaliador, constou apenas o número de registro do protocolo do Teste das Fábulas e dados sobre idade, sexo e origem escolar do participante, encontrando-se isento de qualquer outra identificação pessoal. Desse modo, as classificações das produções no Teste das Fábulas foram realizadas às cegas pelos avaliadores.

Dadas as três codificações independentes, uma folha final de codificação foi elaborada para cada caso, composta a partir do consenso entre os julgamentos realizados. Considerou-se concordância entre os examinadores quando ao menos dois dos três juízes atribuíram a mesma codificação para cada área avaliada (tipo de defesa, sentimento, entre outros elementos avaliativos) das respostas do protocolo. Em casos em que isto não ocorreu, os protocolos foram examinados por um quarto avaliador (orientadora do trabalho), de modo também independente e às cegas. Juntamente com a 
pesquisadora, esse quarto examinador chegou a uma classificação plausível para aquelas variáveis em foco, considerando as diferentes avaliações prévias. A distribuição de acordos entre os avaliadores foi listada de modo a se encontrar um índice de concordância entre examinadores independentes para o Teste das Fábulas, calculando-se o índice Kappa, o qual corresponderá ao indicador de precisão desse método projetivo no presente trabalho.

Como análise complementar aos objetivos inicialmente planejados para esse trabalho, o sistema avaliativo de Cunha e Nunes (1993) foi revisto, almejando-se sua facilidade operacional, sugerida durante o processo de desenvolvimento do estudo (Nunes \& Loureiro, 2013, comunicação pessoal). Visto que esse processo constituiu em resultado complementar do estudo, será descrito de forma detalhada na próxima seção desse trabalho.

Os resultados obtidos com o Teste das Fábulas foram submetidos a análises estatísticas, inicialmente de natureza descritiva, para caracterizar os achados gerais e específicos de cada grupo de participantes. Para a análise estatística inferencial, recorreu-se ao teste estatístico do $\chi^{2}$ (Qui-quadrado) para amostras independentes, com nível de significância menor ou igual a 5\% ( $p \leq 0,05)$, comparando-se a distribuição de frequência dos casos pelas variadas possibilidades de classificação de suas fábulas. Também foi calculado o $\mathrm{V}$ de Cramer, que representa o valor estatístico do tamanho do efeito para variáveis nominais, como é o caso dos itens avaliativos. Para tanto, recorreuse ao software de análise estatística StatisticalPackage for Social Sciences (SPSS), versão 22, seguindo-se orientações de Marôco (2007).

De modo a se testar possível influência das variáveis sociodemográficas "sexo" e "idade" nos resultados, também foram realizadas análises estatísticas inferenciais em função dessas características. As crianças foram reagrupadas em subgrupos de acordo com o sexo (masculino versus feminino, numa primeira análise) e em duas faixas etárias (seis a oito anos versus nove a 12 anos, numa segunda análise), comparando-se sua produção nas várias categorias analíticas de sua produção diante do Teste das Fábulas. Para tanto, recorreu-se ao teste estatístico não paramétrico de Mann-Whitney para amostras independentes $(p \leq 0,05)$.

O conjunto dos resultados possibilitou a aferição das evidências empíricas de validade desse método projetivo e de sua capacidade diagnóstica, por meio da discriminação de resultados entre os grupos clínicos e não clínico. Desse modo, foi possível o alcance dos objetivos delineados para a presente investigação. 
$64 \mid$ R e s u 1 t a d o s

\section{RESULTADOS}

\subsection{Relativos à revisão do sistema avaliativo}

Como já informado na seção anterior, a codificação da produção no Teste das Fábulas seguiu o referencial teórico psicodinâmico, seguindo-se padronização técnicocientífica e normas propostas por Cunha e Nunes (1993). Nesse sistema de categorização existem 595 itens avaliativos, distribuídos em 50 categorias de análise no conjunto das dez fábulas (muitas dessas categorias avaliativas são idênticas em fábulas diferentes). Apesar da facilidade de aplicação do instrumento, seu processo de análise mostrou-se bastante extenso no que se refere às possibilidades de itens avaliativos, ocasionando dificuldades operacionais e categorias de baixa incidência, pouco informativas e discriminativas no conjunto dos achados dos grupos avaliados. Diante desse contexto e por sugestão do debate suscitado no momento de qualificação desse Mestrado (Loureiro \& Nunes, 2013, comunicação pessoal), desenvolveu-se intenso trabalho no sentido de aglutinar alguns itens avaliativos propostos pelo manual (Cunha \& Nunes, 1993) e tornar o sistema de classificação mais conciso, favorecendo sua operacionalidade e precisão.

Desse modo, considerou-se que esse processo constituía num dado relevante a ser apresentado nesse trabalho, embora originalmente não delineado em seus objetivos. Para essa revisão das categorias avaliativas do sistema de Cunha e Nunes (1993), tomou-se como base as classificações e os comentários dos três psicólogos que atuaram como avaliadores independentes das fábulas das crianças. A partir das categorias de baixa frequência nos grupos avaliados e da verificação de quais itens poderiam ser reunidos em um único (por semelhança em seu conteúdo avaliado), dois profissionais (a pesquisadora e sua orientadora) trabalharam juntos na revisão dos itens avaliativos, procurando sua síntese em quesitos de análise que não alterassem o sentido teoricamente previsto pelo instrumento. Trabalhou-se basicamente de forma a elaborar um novo arranjo dos itens avaliativos existentes, preservando as categorias de análise em termos teóricos e para sua interpretação, conforme manual do instrumento no Brasil (Cunha \& Nunes, 1993). 
Elaborada essa síntese avaliativa das categorias analíticas do Teste das Fábulas, a proposta foi examinada por outro psicólogo colaborador do estudo, de modo a checar sua consistência e validade de face (Urbina, 2007). Chegou-se, desse modo, ao sistema avaliativo utilizado para os atuais resultados, descrito no APÊNDICE C. Permaneceram as 50 categorias avaliativas (muitas delas são as mesmas para as diferentes fábulas), porém o número de itens possíveis para classificação das respostas reduziu para 163 itens, facilitando em muito o processo de análise da produção infantil diante do Teste das Fábulas. Julgou-se mais adequada a apresentação desses resultados como apêndice, pois, embora essenciais para a compreensão dos dados, não constituem objetivo central do presente trabalho.

Nesse apêndice estão apresentadas as categorias avaliativas de cada fábula do teste (classificações originais dos atuais resultados nos itens avaliativos de Cunha \& Nunes, 1993) e seus dados em função dos três grupos de crianças avaliadas. Ao final de cada tabela descritiva constam os itens de classificação das fábulas que foram reunidos de modo a se chegar ao sistema avaliativo agora proposto. Exemplo desse processo pode ser visto na categoria "Estado Emocional", onde os originais itens "medo", "ambivalência" e "ansiedade" foram agrupados em um único item denominado de "ansiedade".

Outra alteração importante realizada foi a codificação de apenas uma possibilidade para cada item avaliativo em cada fábula, priorizando-se a variável de destaque no conteúdo produzido pela criança. Assim, nas categorias avaliativas referentes a "Fantasia", "Estado emocional" e "Defesas" (onde originalmente era possível listar todas as ocorrências existentes nas fábulas), definiu-se que apenas uma possibilidade seria assinalada, aquela que representasse o conteúdo central produzido pela criança. Essa alteração permitiu, além de praticidade analítica, a comparação estatística inferencial entre os grupos avaliados no presente trabalho (teste quiquadrado), etapa central para o exame da possibilidade discriminativa dos itens avaliativos utilizados nas fábulas.

Pode-se notar que as principais modificações implementadas em relação ao sistema original de Cunha e Nunes (1993) representam um processo de síntese de itens avaliativos. Reafirma-se que as grandes categorias de análise foram preservadas, sustentando-se, desse modo, as possibilidades interpretativas originalmente previstas para esse método projetivo de avaliação psicológica. 
No APÊNDICE C é possível verificar detalhadamente quais itens foram aglutinados e a devida categoria a que pertencem, resultando no sistema avaliativo presentemente utilizado nesse trabalho. Assim, os dados a serem apresentados sobre o Teste das Fábulas foram sistematizados já com esse sistema avaliativo reduzido, produto complementar desse estudo.

\subsection{Relativos à análise da produção no conjunto das dez fábulas}

Com base nos princípios avaliativos de Nunes e Cunha (1993), presentemente revistos, cada fábula foi examinada de modo específico, sendo nesse momento apresentados os resultados descritivos encontrados em cada grupo e no conjunto total de participantes. Cabe destacar que, segundo a proposta original, em algumas categorias de análise é possível marcar mais de uma alternativa para uma mesma criança, de modo que o subtotal de assinalamentos de cada item avaliativo pode variar, razão inclusive dos dados serem apresentados em frequência simples e em porcentagem, para facilitar inspeção visual comparativa dos atuais achados entre os grupos avaliados.

A sistematização desses resultados conforme sua frequência e com a devida redução de itens, organizados por fábula, estão apresentados nas Tabelas 1 a 10, no APÊNDICE D deste trabalho. Mais uma vez, embora sejam resultados centrais no estudo, decidiu-se apresentá-los como complemento ao texto apenas em decorrência de sua extensão e detalhamento descritivo, já utilizando o sistema de classificação revisto.

No entanto, para realizar a análise estatística comparativa entre os três grupos no sistema de Nunes e Cunha (1993), aqui revisto e utilizado, fez-se necessário classificar a presença de um único item em cada categoria avaliativa (aquele clinicamente predominante no quesito). Assim, foram contabilizados os tipos de resposta dos integrantes de cada grupo em termos de contagem simples dos indivíduos (permitindo posterior comparação estatística pelo Teste $\chi^{2}$ ), dados que serão os principais desse trabalho e, por essa razão, descritos a seguir. Como previamente informado, também foi calculado o valor do $\mathrm{V}$ de Cramer para avaliar o tamanho do efeito das possíveis diferenças estatisticamente significativas detectadas entre G1, G2 e G3. 
A Tabela 4 apresenta os resultados encontrados com a Fábula 1 (Fábula do Passarinho) do Teste das Fábulas. 
$68 \mid$ R e s u 1 t a d o s

Tabela 4 -Resultados (em frequência simples e porcentagem) e comparação estatística das categorias avaliativas da Fábula 1 (Fábula do Passarinho) em função dos grupos e na amostra total $(n=60)$.

\begin{tabular}{|c|c|c|c|c|c|c|c|c|c|c|c|c|}
\hline \multirow{2}{*}{\multicolumn{2}{|c|}{$\begin{array}{c}\text { GRUPO } \\
\text { VARIÁVEL da Fábula }\end{array}$}} & \multicolumn{2}{|c|}{ Grupo 1} & \multicolumn{2}{|c|}{ Grupo 2} & \multicolumn{2}{|c|}{ Grupo 3} & \multicolumn{2}{|c|}{ TOTAL } & \multirow[t]{2}{*}{$\chi^{2}$} & \multirow[t]{2}{*}{$p$} & \multirow[t]{2}{*}{ V de Cramer** } \\
\hline & & $f$ & $\%$ & $f$ & $\%$ & $f$ & $\%$ & $f$ & $\%$ & & & \\
\hline \multirow{5}{*}{ Ação } & Recusa & 1 & 5,0 & 1 & 5,0 & - & - & 2 & 3,3 & & & \\
\hline & Passiva & 9 & 45,0 & 5 & 25,0 & 6 & 30,0 & 20 & 33,3 & & & \\
\hline & Insegura & 1 & 5,0 & 3 & 15,0 & 10 & 50,0 & 14 & 23,3 & & & \\
\hline & Ativa & 9 & 45,0 & 11 & 55,0 & 4 & 20,0 & 24 & 40,0 & & & \\
\hline & Subtotal & 20 & 100,0 & 20 & 100,0 & 20 & 100,0 & 60 & 100,0 & 13,231 & 0,040 & $0,332 *$ \\
\hline \multirow{4}{*}{ Enredo } & Não adaptado ao conteúdo & 5 & 25,0 & 2 & 10,0 & 2 & 10,0 & 9 & 15,0 & & & \\
\hline & Busca ajuda (dependência) & 5 & 25,0 & 3 & 15,0 & 5 & 45,0 & 13 & 21,6 & & & \\
\hline & $\begin{array}{l}\text { Busca autonomia } \\
\text { (independência) }\end{array}$ & 10 & 50,0 & 15 & 55,0 & 13 & 65,0 & 38 & 63,4 & & & \\
\hline & Subtotal & 20 & 100,0 & 20 & 100,0 & 20 & 100,0 & 60 & 100,0 & 3,376 & 0,497 & 0,168 \\
\hline \multirow{4}{*}{ Personagem } & Figuras parentais & 17 & 85,0 & 15 & 65,0 & 15 & 65,0 & 47 & 78,3 & & & \\
\hline & Figuras não parentais & 1 & 5,0 & 2 & 10,0 & 3 & 15,0 & 6 & 10,0 & & & \\
\hline & Apenas o herói & 2 & 10,0 & 3 & 15,0 & 2 & 10,0 & 7 & 11,6 & & & \\
\hline & Subtotal & 20 & 100,0 & 20 & 100,0 & 20 & 100,0 & 60 & 100,0 & 1,476 & 0,831 & 0,831 \\
\hline \multirow{4}{*}{ Desfecho } & Não adaptado & 5 & 25,0 & 4 & 20,0 & 1 & 5,0 & 10 & 16,6 & & & \\
\hline & Ambivalente & 2 & 10,0 & - & - & 7 & 35,0 & 9 & 15,0 & & & \\
\hline & Adaptado & 13 & 65,0 & 16 & 80,0 & 12 & 60,0 & 41 & 68,3 & & & \\
\hline & Subtotal & 20 & 100,0 & 20 & 100,0 & 20 & 100,0 & 60 & 100,0 & 10,492 & 0,033 & $0,296^{*}$ \\
\hline
\end{tabular}




\begin{tabular}{|c|c|c|c|c|c|c|c|c|c|c|c|c|}
\hline \multirow{5}{*}{ Fantasia } & Agressão & 3 & 15,0 & 1 & 5,0 & 1 & 5,0 & 5 & 8,3 & & & \multirow[b]{5}{*}{0,235} \\
\hline & Onipotência & 7 & 35,0 & 6 & 30,0 & 4 & 20,0 & 17 & 28,3 & & & \\
\hline & Impotência & 10 & 50,0 & 10 & 50,0 & 10 & 50,0 & 30 & 50,0 & \multirow{4}{*}{6,627} & \multirow{4}{*}{0,357} & \\
\hline & Reparação & - & - & 3 & 15,0 & 5 & 25,0 & 8 & 13,3 & & & \\
\hline & Subtotal & 20 & 100,0 & 20 & 100,0 & 20 & 100,0 & 60 & 100,0 & & & \\
\hline \multirow{4}{*}{$\begin{array}{c}\text { Estado } \\
\text { Emocional }\end{array}$} & Ansiedade & 4 & 20,0 & 1 & 5,0 & 2 & 10,0 & 7 & 11,7 & & & \\
\hline & Tristeza & 12 & 60,0 & 8 & 40,0 & 11 & 55,0 & 31 & 51,7 & \multirow{4}{*}{5,396} & \multirow{4}{*}{0,249} & \multirow{4}{*}{0,212} \\
\hline & Alegria & 4 & 20,0 & 11 & 55,0 & 7 & 35,0 & 22 & 36,7 & & & \\
\hline & Subtotal & 20 & 100,0 & 20 & 100,0 & 20 & 100,0 & 60 & 100,0 & & & \\
\hline \multirow{3}{*}{ Defesas } & Com base Negação & 11 & 55,0 & 3 & 15,0 & 5 & 25,0 & 19 & 31,7 & & & \\
\hline & Com base Repressão & 9 & 45,0 & 17 & 85,0 & 15 & 75,0 & 41 & 68,3 & & & \\
\hline & Subtotal & 20 & 100,0 & 20 & 100,0 & 20 & 100,0 & 60 & 100,0 & 9,049 & 0,011 & $0,388 *$ \\
\hline
\end{tabular}

* V de Cramer $<0,05$

** Representa o valor estatístico do tamanho do efeito (para variáveis nominais). 
70|R e s u $1 \mathrm{t}$ a dos

No tocante à Ação efetivada nessa fábula, foi possível identificar diferenças estatisticamente significativas entre os grupos, sinalizando padrão específico de reação diante do conteúdo proposto em cada conjunto de crianças (G1, G2 e G3). Embora no total geral da amostra, a maioria das ações sejam "Ativas" (40\%), em G1 houve 45\% de respostas na categoria "Ativa" e também 45\% em "Passivas", sugerindo polarização em dois extremos de ação diante dessa fábula. Já emG2 houve 55\% de ações "Ativas", enquanto G3 apresentou maior incidência de ações classificadas como "Inseguras". Chama a atenção ainda que quanto menos indicadores de problemas de saúde mental (sentido que vai de G1 para G3) houve tendência de aumento do item "insegurança", o que pode estar associado a maior possibilidade de vivência de angústia (capacidade de contato com o conflito) nas crianças menos comprometidas.

No que se refere ao Enredo, não houve diferenças estatisticamente significativas do perfil de respostas entre os grupos, com predomínio $(63,4 \%$ dos casos) do item "Busca autonomia", ou seja, não necessita ajuda para resolver o problema apresentado (50\% em G1; 55\% em G2 e 65\% em G3), apontando que a busca ativa de autonomia se sobrepôs ao conflito com a dependência e a passividade, proposto nessa fábula. Observando as frequências dos itens do Enredo de G1 para G3 (direção para menor número de indicadores de problemas de saúde mental) houve diminuição da "não adaptação ao conteúdo" e "aumento da autonomia". Esses dados acompanham o esperado, corroborando a especificidade do G1 por representar pacientes psiquiátricos diagnosticados com quadros em que há dificuldade na percepção da realidade externa, podendo produzir respostas ilógicas e não adaptadas.

Também não foram identificadas diferenças estatisticamente significativas entre os grupos na categoria Outros personagens além do herói. Houve concentração de respostas em "Figuras Parentais" (G1 com 85\%; G2 e G3 com 65\%), ou seja, as crianças se centraram nas figuras paterna e materna em sua produção. Apesar disso, notou-se aumento de "figuras não parentais" no enredo das crianças com menor número de indicadores de problemas de saúde mental, sugerindo possibilidade de diversificação dos vínculos.

Para o Desfecho houve diferenças estatisticamente significativas no perfil de respostas entre os grupos, embora com predomínio de "adaptação" em todos os grupos (65\% em G1; 80\% em G2 e 60\% em G3), apontando que a maioria foi capaz de descrever um desfecho adaptativo. A tendência observada entre os grupos foi a de 
quanto menor os indicadores de problemas de saúde mental, menor a "não adaptação ao conteúdo", o que também se observou na categoria Enredo.

$\mathrm{Na}$ categoria avaliativa de Fantasias não houve diferenças estatisticamente significativas no perfil de respostas entre os grupos. Ocorreu predomínio da "impotência" em todos os grupos (todos com 50\%), evidenciando que apesar de poderem se adaptar ao contexto, as crianças sinalizaram insegurança quanto a seus recursos para transpor as dificuldades, pertinentes aos aspectos suscitados na situação conflitiva da Fábula 1. Nesta categoria avaliativa, a relação observada foi a de quanto "mais saudável” o grupo (menor número de indicadores de problemas de saúde mental), maior a presença da "reparação" e menor a "onipotência" enquanto fantasias presentes na produção infantil.

Na categoria Estado Emocional também não houve diferenças estatisticamente significativas no perfil de respostas entre os grupos. O item mais frequente foi "Tristeza" (em G1=60\%; G2=40\%; G3=55\%). No entanto, notou-se uma direção de maior incidência de "Ansiedade" no grupo com mais indicadores de problemas de saúde mental (G1), enquanto nos demais grupos (G2 e G3) ocorreu mais o item “Alegria”.

Com relação às Defesas foi possível identificar diferenças estatisticamente significativas no perfil de respostas entre os grupos, apesar da maior incidência no item "defesas com base na repressão" em todos (G1 com 45\%; G2 com 85\% e G3 com 75\%). Há clara tendência na diminuição no uso de "defesas com base na negação" de G1 para G3, ou seja, na medida em diminuem os indicadores de problemas de saúde mental, corroborando a expectativa teórica a respeito desse item avaliativo.

Em síntese pode-se notar que as categorias avaliativas Ação, Desfecho e Defesas da Fábula 1 diferenciaram, com efeito estatisticamente significativo, as respostas entre os grupos. De modo geral, as crianças com indicadores de mais problemas de saúde mental (G1) sinalizaram maior incidência de defesas com base na negação, mais fantasias de impotência e menos fantasias de reparação em suas produções diante dessa fábula.

Passa-se, a seguir, ao exame dos dados referentes à Fábula 2. Esses resultados compõem a Tabela 5. 
72 |Resultados

Tabela 5 -Resultados (em frequência simples e porcentagem) e comparação estatística das categorias avaliativas da Fábula 2 (Fábula do Casamento) em função dos grupos e na amostra total ( $n=60)$.

\begin{tabular}{|c|c|c|c|c|c|c|c|c|c|c|c|c|}
\hline \multirow{2}{*}{\multicolumn{2}{|c|}{ VARIÁVEL da Fábula }} & \multicolumn{2}{|c|}{ Grupo 1} & \multicolumn{2}{|c|}{ Grupo 2} & \multicolumn{2}{|c|}{ Grupo 3} & \multicolumn{2}{|c|}{ TOTAL } & \multirow[b]{2}{*}{$\chi^{2}$} & \multirow[b]{2}{*}{$p$} & \multirow[b]{2}{*}{$V$ de Cramer } \\
\hline & & $f$ & $\%$ & $f$ & $\%$ & $f$ & $\%$ & $f$ & $\%$ & & & \\
\hline \multirow{4}{*}{ Ação } & Não adaptada & 3 & 15,0 & 6 & 30,0 & 2 & 10,0 & 11 & 18,3 & & & \\
\hline & Passiva & 11 & 55,0 & 9 & 45,0 & 11 & 55,0 & 31 & 51,6 & & & \\
\hline & Ativa & 6 & 30,0 & 5 & 25,0 & 7 & 35,0 & 18 & 30,0 & & & \\
\hline & Subtotal & 20 & 100,0 & 20 & 100,0 & 20 & 100,0 & 60 & 100,0 & 1,246 & 0,870 & 0,102 \\
\hline \multirow{4}{*}{ Motivo } & Não adaptado & 4 & 20,0 & 1 & 5,0 & 4 & 20,0 & 9 & 15,0 & & & \\
\hline & Conflito edípico & 6 & 30,0 & 5 & 25,0 & 7 & 35,0 & 18 & 30,0 & & & \\
\hline & Outros temas & 10 & 50,0 & 14 & 70,0 & 9 & 45,0 & 33 & 55,0 & & & \\
\hline & Subtotal & 20 & 100,0 & 20 & 100,0 & 20 & 100,0 & 60 & 100,0 & 4,589 & 0,332 & 0,196 \\
\hline \multirow{5}{*}{ Fantasia } & Agressão & - & - & 1 & 5,0 & - & - & 1 & 1,7 & & & \\
\hline & Onipotência & 5 & 25,0 & 6 & 30,0 & 7 & 35,0 & 18 & 30,0 & & & \\
\hline & Impotência & 13 & 65,0 & 13 & 65,0 & 10 & 50,0 & 36 & 60,0 & & & \\
\hline & Reparação & 2 & 10,0 & - & - & 3 & 15,0 & 5 & 8,3 & & & \\
\hline & Subtotal & 20 & 100,0 & 20 & 100,0 & 20 & 100,0 & 60 & 100,0 & 6,257 & 0,395 & 0,228 \\
\hline \multirow{5}{*}{$\begin{array}{l}\text { Estado } \\
\text { Emocional }\end{array}$} & Raiva & 2 & 10,0 & - & - & - & - & 2 & 3,3 & & & \\
\hline & Ansiedade & - & - & 4 & 20,0 & 2 & 10,0 & 6 & 10,0 & & & \\
\hline & Tristeza & 14 & 70,0 & 10 & 50,0 & 14 & 70,0 & 38 & 63,3 & & & \\
\hline & Alegria & 4 & 20,0 & 6 & 30,0 & 4 & 20,0 & 14 & 23,3 & & & \\
\hline & Subtotal & 20 & 100,0 & 30 & 100,0 & 27 & 100,0 & 60 & 100,0 & 10,262 & 0,114 & 0,292 \\
\hline \multirow{3}{*}{ Defesas } & Com base negação & 12 & 60,0 & 2 & 10,0 & 3 & 15,0 & 17 & 28,3 & & & \\
\hline & Com base repressão & 8 & 40,0 & 18 & 90,0 & 17 & 85,0 & 43 & 71,7 & & & \\
\hline & Subtotal & 20 & 100,0 & 20 & 100,0 & 20 & 100,0 & 60 & 100,0 & 15,749 & $\leq 0,001$ & $0,512 * *$ \\
\hline
\end{tabular}

$* * \overline{\mathrm{V} \text { de Cramer } \leq 0,001}$ 
No tocante à Ação diante da Fábula 2, os grupos não apresentaram distribuição estatisticamente diferente nos itens avaliativos. Houve predomínio da passividade frente aos conflitos relativos à cena primária (G1 e G3 com 55\%, G2 com 45\%), mas notou-se aumento da postura ativa na medida em que diminuem os indicadores de problemas de saúde mental nas crianças (de G1 para G3).

No que se refere à categoria Motivo também não houve diferenças estatisticamente significativas no perfil de respostas entre os grupos, sendo que foi mais frequente o item "Outros temas" (como rejeição e abandono; G1 com 50\%, G2 com $70 \%$ e G3 com 45\%). A dispersão das respostas dificultou identificar um padrão entre os grupos diante desse quesito avaliativo da Fábula 2, referentes a conteúdos psíquicos inerentes à cena primária (segundo referencial psicodinâmico que embasa o instrumento).

Não foram identificadas diferenças estatisticamente significativas no perfil de respostas entre os grupos no tocante à Fantasia. Observou-se claro predomínio da "impotência" (G1 e G2 com 65\% e G3 com 50\%), sinalizando insegurança das crianças frente a seus recursos e à possibilidade de transpor as dificuldades suscitadas nesta situação conflitiva. Nesta categoria, a tendência identificada foi a de que quanto menor os indicadores de problemas de saúde mental nos grupos, houve aumento da “onipotência" e diminuição da "impotência” diante desse quesito avaliativo da Fábula 2.

No que se refere ao Estado Emocional também não foi possível identificar diferenças estatisticamente significativas no padrão de respostas dos grupos avaliados. Preponderou a "tristeza" (G1 em 70\%; G2 com 50\% e G3 com 70\%), indicando que houve sensibilização das crianças inerente ao conflito proposto nessa fábula. Destacouse, no entanto, a presença da emoção "raiva" em G1, o que não ocorreu nos demais grupos (com menor número de indicadores de problemas de saúde mental).

Houve diferenças estatisticamente significativas (com efeito relevante) entre a frequência com que as crianças usaram as Defesasem suas respostas à Fabula 2. A maior incidência foi das defesas com base na "Repressão" (G1=40\%; G2=90\%; G3=85\%), sugerindo adequada capacidade de contenção dos afetos e uso de defesas maduras em maior número do que as imaturas. Apesar disso, ficou claro que, quanto maior o número de indicadores de problemas de saúde mental, maior a frequência de uso de "defesas com base na negação" da realidade, o que teoricamente seria esperado pelos pressupostos desse método projetivo. 
$74 \mid$ R e s u 1 t a d o s

Diante dessa fábula, notou-se que apenas uma das cinco categorias avaliativas diferenciou as respostas dos grupos de crianças, no entanto, com um efeito estatisticamente significativo. Em síntese, quanto maior os indicadores de problemas de saúde mental, maior o aparecimento de fantasias de impotência, bem como defesas com base na negação da realidade.

Segue-se a análise com foco na Fábula 3. Seus resultados estão apresentados na Tabela 6. 
Tabela 6 -Resultados (em frequência simples e porcentagem) e comparação estatística das categorias avaliativas da Fábula 3 (Fábula do Cordeirinho) em função dos grupos e na amostra total ( $n=60)$.

\begin{tabular}{|c|c|c|c|c|c|c|c|c|c|c|c|c|}
\hline \multirow{2}{*}{\multicolumn{2}{|c|}{$\begin{array}{l}\text { GRUPO } \\
\text { VARIÁVEL da Fábula }\end{array}$}} & \multicolumn{2}{|c|}{ Grupo 1} & \multicolumn{2}{|c|}{ Grupo 2} & \multicolumn{2}{|c|}{ Grupo 3} & \multicolumn{2}{|c|}{ TOTAL } & \multirow[b]{2}{*}{$\chi^{2}$} & \multirow[b]{2}{*}{$p$} & \multirow[b]{2}{*}{$V$ de Cramer } \\
\hline & & $f$ & $\%$ & $f$ & $\%$ & $f$ & $\%$ & $f$ & $\%$ & & & \\
\hline \multirow{5}{*}{ Ação } & Não adaptada & 2 & 10,0 & 1 & 5,0 & 2 & 10,0 & 5 & 8,4 & & & \\
\hline & Resistente & 4 & 20,0 & 2 & 10,0 & 3 & 15,0 & 9 & 15,0 & & & \\
\hline & Ambivalente & 8 & 40,0 & 7 & 35,0 & 10 & 50,0 & 25 & 41,6 & & & \\
\hline & Adaptada & 6 & 30,0 & 10 & 50,0 & 5 & 25,0 & 21 & 35,0 & & & \\
\hline & Subtotal & 20 & 100,0 & 20 & 100,0 & 20 & 100,0 & 60 & 100,0 & 4,549 & 0,603 & 0,195 \\
\hline \multirow{4}{*}{ Desfecho } & Não adaptado & 10 & 50,0 & 10 & 50,0 & 7 & 35,0 & 27 & 45,0 & & & \\
\hline & Ambivalente & 5 & 25,0 & 4 & 20,0 & 8 & 40,0 & 17 & 28,3 & & & \\
\hline & Adaptado & 5 & 25,0 & 6 & 30,0 & 5 & 25,0 & 16 & 26,6 & & & \\
\hline & Subtotal & 20 & 100,0 & 20 & 100,0 & 20 & 100,0 & 60 & 100,0 & 3,946 & 0,413 & 0,181 \\
\hline \multirow{5}{*}{ Fantasias } & Agressão & 2 & 10,0 & 1 & 5,0 & - & - & 3 & 5,0 & & & \\
\hline & Onipotência & 8 & 40,0 & 11 & 55,0 & 6 & 30,0 & 25 & 41,7 & & & \\
\hline & Impotência & 10 & 50,0 & 7 & 35,0 & 12 & 60,0 & 29 & 48,3 & & & \\
\hline & Reparação & - & - & 1 & 5,0 & 2 & 10,0 & 3 & 5,0 & & & \\
\hline & Subtotal & 20 & 100,0 & 20 & 100,0 & 20 & 100,0 & 60 & 100,0 & 7,909 & 0,245 & 0,257 \\
\hline \multirow{5}{*}{$\begin{array}{c}\text { Estado } \\
\text { Emocional }\end{array}$} & Raiva & - & - & 1 & 5,0 & 1 & 10,0 & 2 & 3,3 & & & \\
\hline & Ansiedade & 7 & 35,0 & 3 & 15,0 & 5 & 20,0 & 15 & 25,0 & & & \\
\hline & Tristeza & 6 & 30,0 & 8 & 40,0 & 8 & 40,0 & 22 & 35,7 & & & \\
\hline & Alegria & 7 & 35,0 & 8 & 40,0 & 6 & 30,0 & 21 & 35,0 & & & \\
\hline & Subtotal & 20 & 100,0 & 20 & 100,0 & 20 & 100,0 & 60 & 100,0 & 3,448 & 0,751 & 0,170 \\
\hline \multirow{3}{*}{ Defesas } & Com base negação & 13 & 65,0 & 7 & 35,0 & 16 & 80,0 & 36 & 60,0 & & & \\
\hline & Com base repressão & 7 & 35,0 & 13 & 65,0 & 4 & 20,0 & 24 & 40,0 & & & \\
\hline & Subtotal & 20 & 100,0 & 20 & 100,0 & 20 & 100,0 & 60 & 100,0 & 10,444 & 0,005 & $0,417 *$ \\
\hline
\end{tabular}

$*$ V de Cramer $\leq 0,05$ 
No que se refere à Fábula 3, na categoria referente à Ação não houve diferenças estatisticamente significativas entre os grupos, sendopredominante a "ambivalência", com dispersão nos demais itens avaliativos. $\mathrm{Na} A c ̧ a \tilde{o}$, se considerarmos os grupos em que há indicadores de problemas de saúde mental (G1 e G2) em comparação ao que tem desenvolvimento típico (G3), houve aumento da "ambivalência" em G3, sugerindo clara percepção do conflito, bem como de um particular enfrentamento do tema proposto pela fábula nas crianças avaliadas.

Com relação ao Desfecho também não foram identificadas diferenças estatisticamente significativas no perfil de respostas entre os grupos. Houve maior incidência do item "Não adaptado" em G1 e em G2, sinalizando que houve dificuldade de superação e consequente adaptação frente ao conflito proposto pela fábula. Em G3 houve predomínio do desfecho "ambivalente".

Não houve diferenças estatisticamente significativas entre os grupos no tocante à categoria Fantasia. Ocorreu maior frequência do item "Impotência", sugerindo insegurança das crianças quanto a seus recursos para transpor as dificuldades suscitadas nesta situação conflitiva. Nesta categoria avaliativa, observou-se tendência a aumento da "reparação" e diminuição do item "agressão" em G3 (grupo "mais saudável”, com menor número de indicadores de problemas de saúde mental).

Quanto ao Estado Emocional, também não foram identificadas diferenças estatisticamente significativas entre os grupos. O item "tristeza" esteve presente em elevada proporção nos três grupos, juntamente com "alegria", denotando diferentes experiências afetivas das crianças frente ao conflito dessa fábula. No entanto, notou-se maior presença da "ansiedade" em G1, o que ficou pouco marcado em G2 e em G3. Assim, pode-se sinalizar, nas crianças presentemente avaliadas, que quanto maior o número de indicadores de problemas de saúde mental (G1), maior a presença de sinais de ansiedade.

Com relação às Defesashouve diferenças estatisticamente significativas (com efeito relevante) no perfil de respostas entre os grupos na Fábula do Cordeirinho. As crianças de G1, G2 e G3 evidenciaram recorrer a padrões defensivos com base na repressão e também na negação da realidade para completar essa fábula, o que pode ser considerado como índice de sua elevada mobilização emocional frente ao conteúdo proposto. Essa foi a única categoria avaliativa dessa fábula que diferenciou as respostas de G1, G2 e G3. 
Na sequência das análises dos resultados, tem-se a produção das crianças diante da Fábula 4. Os dados estão apresentados na Tabela 7. 
78 | R e s u 1 t a d o s

Tabela 7 -Resultados (em frequência simples e porcentagem) e comparação estatística das categorias avaliativas da Fábula 4 (Fábula do Enterro) em função dos grupos e na amostra total $(n=60)$.

\begin{tabular}{|c|c|c|c|c|c|c|c|c|c|c|c|c|}
\hline \multirow{2}{*}{\multicolumn{2}{|c|}{$\begin{array}{l}\text { GRUPO } \\
\text { VARIÁVEL da Fábula }\end{array}$}} & \multicolumn{2}{|c|}{ Grupo 1} & \multicolumn{2}{|c|}{ Grupo 2} & \multicolumn{2}{|c|}{ Grupo 3} & \multicolumn{2}{|c|}{ TOTAL } & \multirow[b]{2}{*}{$\chi^{2}$} & \multirow[b]{2}{*}{$p$} & \multirow[b]{2}{*}{$V$ de Cramer } \\
\hline & & $f$ & $\%$ & $f$ & $\%$ & $f$ & $\%$ & $f$ & $\%$ & & & \\
\hline \multirow{6}{*}{ Personagem } & Criança / Irmã(o) & 1 & 5,0 & 1 & 5,0 & - & - & 2 & 3,3 & & & \\
\hline & Homem/Pai & 6 & 30,0 & 8 & 40,0 & 11 & 55,0 & 25 & 41,7 & & & \\
\hline & Mulher/Mãe & 3 & 15,0 & 6 & 30,0 & 4 & 20,0 & 13 & 21,7 & & & \\
\hline & Avô ou avó & 6 & 30,0 & 3 & 15,0 & 2 & 10,0 & 11 & 18,3 & & & \\
\hline & Outros & 4 & 20,0 & 2 & 10,0 & 3 & 15,0 & 9 & 15,0 & & & \\
\hline & Subtotal & 20 & 100,0 & 20 & 100,0 & 20 & 100,0 & 60 & 100,0 & 5,991 & 0,648 & 0,223 \\
\hline \multirow{4}{*}{ Fantasias } & Agressão & 8 & 40,0 & 14 & 70,0 & 7 & 35,0 & 29 & 48,3 & & & \\
\hline & Onipotência & 1 & 5,0 & 1 & 5,0 & 3 & 15,0 & 5 & 8,3 & & & \\
\hline & Impotência & 11 & 55,0 & 5 & 25,0 & 10 & 50,0 & 26 & 43,3 & & & \\
\hline & Subtotal & 20 & 100,0 & 20 & 100,0 & 20 & 100,0 & 60 & 100,0 & 8,367 & 0,079 & 0,264 \\
\hline \multirow{5}{*}{$\begin{array}{l}\text { Estado } \\
\text { Emocional }\end{array}$} & Raiva & - & - & 1 & 5,0 & - & - & 1 & 1,7 & & & \\
\hline & Ansiedade & 2 & 10,0 & 4 & 20,0 & 4 & 20,0 & 10 & 16,7 & & & \\
\hline & Tristeza & 18 & 80,0 & 14 & 70,0 & 15 & 75,0 & 47 & 78,3 & & & \\
\hline & Alegria & - & - & 1 & 5,0 & 1 & 5,0 & 2 & 3,3 & & & \\
\hline & Subtotal & 20 & 100,0 & 20 & 100,0 & 20 & 100,0 & 60 & 100,0 & 4,878 & 0,560 & 0,202 \\
\hline \multirow{3}{*}{ Defesas } & Com base na negação & 6 & 30,0 & 6 & 30,0 & 5 & 25,0 & 17 & 28,3 & & & \\
\hline & Com base na repressão & 14 & 70,0 & 14 & 70,0 & 15 & 75,0 & 43 & 71,7 & & & \\
\hline & Subtotal & 20 & 100,0 & 20 & 100,0 & 20 & 100,0 & 60 & 100,0 & 0,660 & 0,968 & 0,033 \\
\hline
\end{tabular}


Diante da Fábula 4, não houve diferenças estatisticamente significativas em nenhuma das categorias avaliativas entre G1, G2 e G3. Pode-se, no entanto, descrever algumas tendências gerais desses resultados. Na categoria Personagemhouve maior frequência do item "Homem ou Pai”, elevando sua presença na direção dos grupos com menor número de indicadores de problemas em saúde mental. Em G1, no entanto, apareceu elevada incidência do item "Avô ou Avó", o que o foi bem pouco frequente em G2 e em G3. Nesta categoria, a tendência observada foi a de quanto menor os indicadores de problemas de saúde mental no grupo, maior a ocorrência da resposta "Homem/Pai", indicadores que podem representar desejos destrutivos dirigidos à figura masculina.

No tocante à Fantasia da Fábula do Enterro, predominaram a "Impotência" e a “Agressão" entre os grupos. Nesta categoria, apesar da baixa incidência, pode-se notar que quanto menor os indicadores de problemas de saúde mental nas crianças, maior a "onipotência". Cabe destacar ainda que, no grupo com indicadores de problemas de saúde mental ainda não tratados (G2), a "agressão" apareceu com frequência bastante importante $(70 \%)$.

Quanto ao Estado emocionalo item mais frequente foi de "tristeza" para todos os grupos, sinalizando contato das crianças com o conflito, com emoção pertinente ao contexto proposto pela fábula. Notou-se ainda que, com o menor número de indicadores de problemas de saúde mental, aumentou a incidência da "ansiedade".

Por fim, na categoria Defesashouve maior incidência da "Repressão" em todos os grupos, sugerindo predomínio da capacidade de contenção e uso de defesas maduras. Há que se lembrar do caráter catártico dessa fábula, segundo proposição original do instrumento, o que aqui se confirma pela possibilidade dos três grupos de crianças conseguirem responder à demanda de forma a respeitar parâmetros objetivos da realidade.

Em andamento ao processo de apresentação e de análise dos resultados, apresenta-se a seguir os achados frente a Fabula 5 (Fábula do Medo). A Tabela 8 descreve os seus dados, bem como a comparação estatística entre os grupos nas categorias avaliadas. 
$80 \mid$ Resultados

Tabela 8 -Resultados (em frequência simples e porcentagem) e comparação estatística das categorias avaliativas da Fábula 5 (Fábula do Medo) em função dos grupos e na amostra total ( $n=60)$.

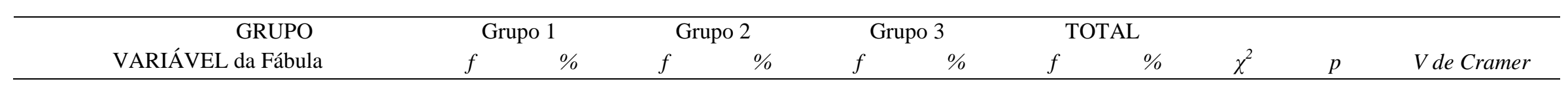


$\mathrm{Na}$ Fábula do medo não foram identificadas diferenças estatisticamente significativas entre os grupos em nenhuma das categorias avaliativas existentes. $\mathrm{Na}$ categoria Objetoos grupos apresentaram respostas dispersas entre os itens avaliativos. Pôde-se observar que predominaram como amedrontadores "Personagens da Ficção" em G1, enquanto em G2 a maior incidência de respostas ocorreu no item "Animal ou Bicho" (50\%). As crianças de G3 relataram medo do "Escuro ou Solidão" em mesma proporção que "Personagens da Ficção".

No que se refere à Fantasia, a maioria das respostas das crianças foi classificada no item "Agressão" para todos os grupos, sinalizando que esta fábula consegue se inserir como possibilidade catártica, como previsto teoricamente. Notou-se em G3, o grupo com desenvolvimento típico, maior incidência das fantasias de "agressão" e "onipotência" e diminuição da "impotência", comparado aos outros grupos, o que de certo modo era esperado, dada sua função catártica. Em complemento, a "impotência" ocorreu mais frequentemente em G1, sugerindo fantasias de fragilidade frente ao tema proposto pela fábula (medo).

Já no tocante às Defesashouve maior incidência de respostas no item "Repressão". Esse dado sinalizou predomínio da capacidade de contenção e uso de defesas adaptativas em todas as crianças, independentemente de seu grupo de origem.

Na sequência das análises tem-se os dados relativos a Fabula 6. Esses resultados estão apresentados na Tabela 9. 
Tabela 9 -Resultados (em frequência simples e porcentagem) e comparação estatística das categorias avaliativas da Fábula 6 (Fábula do Elefante) em função dos grupos e na amostra total $(n=60)$.

\begin{tabular}{|c|c|c|c|c|c|c|c|c|c|c|c|c|}
\hline \multirow{2}{*}{\multicolumn{2}{|c|}{$\begin{array}{c}\text { GRUPO } \\
\text { VARIÁVEL da Fábula }\end{array}$}} & \multicolumn{2}{|c|}{ Grupo 1} & \multicolumn{2}{|c|}{ Grupo 2} & \multicolumn{2}{|c|}{ Grupo 3} & \multicolumn{2}{|c|}{ TOTAL } & \multirow[b]{2}{*}{$\chi^{2}$} & \multirow[b]{2}{*}{$p$} & \multirow[b]{2}{*}{$V$ de Cramer } \\
\hline & & $f$ & $\%$ & $f$ & $\%$ & $f$ & $\%$ & $f$ & $\%$ & & & \\
\hline \multirow{6}{*}{$\begin{array}{c}\text { Natureza } \\
\text { da Mudança }\end{array}$} & Por acidente / Mutilação & 2 & 10,0 & 7 & 35,0 & 5 & 25,0 & 14 & 23,3 & & & \\
\hline & Transformação Física & 4 & 20,0 & 6 & 30,0 & 9 & 45,0 & 19 & 31,7 & & & \\
\hline & Transformação Psicológica & 5 & 25,0 & 5 & 25,0 & 2 & 10,0 & 12 & 20,0 & & & \\
\hline & Substituição & 3 & 15,0 & 1 & 5,0 & 2 & 10,0 & 6 & 10,0 & & & \\
\hline & Outra & 6 & 30,0 & 1 & 5,0 & 2 & 10,0 & 9 & 15,0 & & & \\
\hline & Subtotal & 20 & 100,0 & 20 & 100,0 & 20 & 100,0 & 60 & 100,0 & 10,857 & 0,210 & 0,301 \\
\hline \multirow{5}{*}{$\begin{array}{l}\text { Identificação } \\
\text { da Mudança }\end{array}$} & Sujeira / cor & 3 & 15,0 & 5 & 25,0 & 6 & 30,0 & 14 & 23,3 & & & \\
\hline & Tamanho & 2 & 10,0 & 3 & 15,0 & 2 & 10,0 & 7 & 11,7 & & & \\
\hline & Identidade & 1 & 5,0 & 1 & 5,0 & 4 & 20,0 & 6 & 10,0 & & & \\
\hline & Outras & 14 & 70,0 & 11 & 55,0 & 8 & 40,0 & 33 & 55,0 & & & \\
\hline & Subtotal & 20 & 100,0 & 20 & 100,0 & 20 & 100,0 & 60 & 100,0 & 5,368 & 0,498 & 0,211 \\
\hline \multirow{4}{*}{$\begin{array}{l}\text { Local da } \\
\text { Mudança }\end{array}$} & Tromba & - & - & 2 & 10,0 & 3 & 15,0 & 5 & 8,3 & & & \\
\hline & Elefante & 14 & 70,0 & 17 & 85,0 & 17 & 85,0 & 48 & 80,0 & & & \\
\hline & Fora do elefante & 6 & 30,0 & 1 & 5,0 & - & - & 7 & 11,7 & & & \\
\hline & Subtotal & 20 & 100,0 & 20 & 100,0 & 20 & 100,0 & 60 & 100,0 & 11,971 & 0,018 & $0,316^{*}$ \\
\hline \multirow{5}{*}{ Fantasias } & Agressão & 5 & 25,0 & 3 & 15,0 & 3 & 15,0 & 11 & 18,3 & & & \\
\hline & Onipotência & 2 & 10,0 & 4 & 20,0 & 5 & 25,0 & 11 & 18,3 & & & \\
\hline & Impotência & 12 & 60,0 & 10 & 50,0 & 7 & 35,0 & 29 & 48,3 & & & \\
\hline & Reparação & 1 & 5,0 & 3 & 15,0 & 5 & 25,0 & 9 & 15,0 & & & \\
\hline & Subtotal & 20 & 100,0 & 20 & 100,0 & 20 & 100,0 & 60 & 100,0 & 6,806 & 0,339 & 0,238 \\
\hline
\end{tabular}




\begin{tabular}{|c|c|c|c|c|c|c|c|c|c|c|c|c|}
\hline & Raiva & 1 & 5,0 & - & - & - & - & 1 & 1,7 & & & \\
\hline Estado & Ansiedade & 3 & 15,0 & - & - & 2 & 10,0 & 5 & 8,3 & & & \\
\hline \multirow[t]{4}{*}{ Emocional } & Tristeza & 7 & 35,0 & 13 & 65,0 & 13 & 65,0 & 33 & 55,0 & & & \\
\hline & Alegria & 9 & 45,0 & 7 & 35,0 & 5 & 25,0 & 21 & 35,0 & & & \\
\hline & Subtotal & 20 & 100,0 & 20 & 100,0 & 20 & 100,0 & 60 & 100,0 & 8,231 & 0,222 & 0,262 \\
\hline & Com base na negação & 6 & 30,0 & 7 & 35,0 & 9 & 45,0 & 22 & 36,7 & & & \\
\hline \multirow[t]{2}{*}{ Defesas } & Com base na repressão & 14 & 70,0 & 13 & 65,0 & 11 & 55,0 & 38 & 63,3 & & & \\
\hline & Subtotal & 20 & 100,0 & 20 & 100,0 & 20 & 100,0 & 60 & 100,0 & 0,053 & 0,974 & 0,030 \\
\hline
\end{tabular}

* V de Cramer $\leq 0,05$ 
Na Fábula do Elefante, entre todas as categorias avaliativas existentes, houve resultados estatisticamente diferentes em apenas uma das seis áreas avaliadas, a saber: o "Local da Mudança". Ao examinar, no entanto, a distribuição do conjunto dos resultados dos grupos, pode comentar que, na categoria Natureza da Mudança, em G1 a maioria de respostas ocorreu na categoria "Outra" (que inclui mudanças não condizentes com o conteúdo da história), seguida por “transformação psicológica”. Em G2 e em G3 predominaram as mudanças relacionadas a "acidente/mutilação" ou a "transformação física", aspectos mais concretos. Em G3 observa-se ainda, se comparado aos outros dois grupos, o aumento de respostas de "transformação física" e diminuição da "transformação psicológica".

No que se refere à Identificação da Mudança, o item predominante em todos os grupos foi "Outra" (como doença, por exemplo). Nesta categoria avaliativa pode-se notar que quanto menor o número de indicadores de problemas de saúde mental, maior a frequência de respostas classificadas como "sujeira" e "identidade", diminuindo os outros itens avaliativos, denotando associação positiva com as questões teoricamente suscitadas por essa fábula.

Em relação ao Local da mudança, a maioria das respostas em todos os grupos foi "Elefante", tratando-se de consenso entre as crianças no tocante a essa fábula. Foi possível observar ainda que há um aumento do item "tromba" na direção de G1 para G3, enquanto diminui a frequência do item "fora do elefante". O local da mudança foi apontado como "fora do elefante" em maior proporção nas crianças de G1, aquelas do grupo psiquiátrico.

Quanto à Fantasia,o item mais frequente em todos os grupos foi a "Impotência", sinalizando que para a maioria das criançashouve insegurança em seus recursos e na possibilidade de transpor as dificuldades propostas pela fábula. No entanto, ficou claro que na medida em que diminuem os indicadores de problemas de saúde mental (de G1 para G3), diminuem de frequência os itens "agressão" e "impotência", com aumento da "reparação" e da "onipotência" enquanto fantasias presentes na produção infantil.

Para o Estado Emocional, em G1 houve maior frequência da categoria "alegria", seguida pela "tristeza". Notou-se clara diminuição da incidência da "alegria" e aumento da "tristeza" na direção de G1 para G3, sugerindo que, quanto menor o número de indicadores de problemas de saúde mental, maior a expressão de um estado emocional depressivo, condizente com a temática de mudança apresentada nessa fábula. 
No que se refere às Defesas, houve maior frequência daquelas com base na "Repressão", sinalizando predomínio de estratégias adaptativas à realidade nos três grupos. No entanto, ficou claro que, de G1 para G3, aumentaram as defesas "com base na negação" e diminuíram aquelas "com base na repressão" no enfrentamento do tema proposto pela fábula do elefante, o que deverá ser devidamente considerado no processo interpretativo dos resultados desse método projetivo de avaliação psicológica.

A seguir toma-se para considerações a Fábula 7. Os resultados referentes a essa fábula do objeto fabricado foram sistematizados na Tabela 10. 
$86 \mid$ Resultados

Tabela 10 -Resultados (em frequência simples e porcentagem) e comparação estatística das categorias avaliativas da Fábula 7 (Fábula do Objeto Fabricado) em função dos grupos e na amostra total $(n=60)$.

\begin{tabular}{|c|c|c|c|c|c|c|c|c|c|c|c|c|}
\hline \multirow{2}{*}{\multicolumn{2}{|c|}{$\begin{array}{l}\text { GRUPO } \\
\text { VARIÁVEL da Fábula }\end{array}$}} & \multicolumn{2}{|c|}{ Grupo 1} & \multicolumn{2}{|c|}{ Grupo 2} & \multicolumn{2}{|c|}{ Grupo 3} & \multicolumn{2}{|c|}{ TOTAL } & \multirow[b]{2}{*}{$\chi^{2}$} & \multirow[b]{2}{*}{$p$} & \multirow[b]{2}{*}{$V$ de Cramer } \\
\hline & & $f$ & $\%$ & $f$ & $\%$ & $f$ & $\%$ & $f$ & $\%$ & & & \\
\hline \multirow{4}{*}{ Ação } & Resistente & 3 & 15,0 & 4 & 20,0 & 5 & 25,0 & 12 & 20,0 & & & \\
\hline & Ambivalente & 12 & 60,0 & 11 & 55,0 & 6 & 30,0 & 29 & 48,3 & & & \\
\hline & Ativa e adaptada & 5 & 25,0 & 5 & 25,0 & 9 & 45,0 & 19 & 31,7 & & & \\
\hline & Subtotal & 20 & 100 & 20 & 100 & 20 & 100 & 60 & 100 & 3,309 & 0,507 & 0,166 \\
\hline \multirow{5}{*}{ Fantasias } & Onipotência & 9 & 45,0 & 11 & 55,0 & 15 & 75,0 & 35 & 58,3 & & & \\
\hline & Agressão & 1 & 5,0 & 2 & 10,0 & - & - & 3 & 5,0 & & & \\
\hline & Impotência & 9 & 45,0 & 7 & 35,0 & 3 & 15,0 & 19 & 31,7 & & & \\
\hline & Reparação & 1 & 5,0 & - & - & 2 & 10,0 & 3 & 5,0 & & & \\
\hline & Subtotal & 20 & 100 & 20 & 100 & 20 & 100 & 60 & 100 & 5,991 & 0,200 & 0,223 \\
\hline \multirow{4}{*}{$\begin{array}{l}\text { Estado } \\
\text { Emocional }\end{array}$} & Ansiedade & 7 & 35,0 & 3 & 15,0 & 7 & 35,0 & 17 & 28,3 & & & \\
\hline & Tristeza & 3 & 15,0 & 5 & 25,0 & 4 & 20,0 & 12 & 20,0 & & & \\
\hline & Alegria & 10 & 50,0 & 12 & 60,0 & 9 & 45,0 & 31 & 51,7 & & & \\
\hline & Subtotal & 20 & 100 & 20 & 100 & 20 & 100 & 60 & 100 & 5,014 & 0,286 & 0,204 \\
\hline \multirow{3}{*}{ Defesas } & Com base na negação & 4 & 20,0 & 4 & 20,0 & 6 & 30,0 & 14 & 23,3 & & & \\
\hline & Com base na repressão & 16 & 80,0 & 16 & 80,0 & 14 & 70,0 & 46 & 76,7 & & & \\
\hline & Subtotal & 20 & 100 & 20 & 100 & 20 & 100 & 60 & 100 & 1,903 & 0,386 & 0,178 \\
\hline
\end{tabular}


Na Fábula do Objeto Fabricado não houve resultados estatisticamente diferentes entre os grupos em nenhuma das categorias avaliativas existentes. Cabe, entretanto, explorar algumas direções dos dados em relação aos tópicos examinados. No que se refere à $A c ̧ \tilde{a} o$, o item "ambivalente" foi predominante em G1 e em G2, caindo muito em G3 que, por sua vez, apresentou como mais frequente a ação classificada como "ativa e adaptada". Esses achados sugeriram que quanto menor os indicadores de problemas de saúde mental (de G1 para G3), menor a "ambivalência" e maior a frequência do item "ativa e adaptada", conforme o teoricamente esperado diante dessa fábula, fortalecendo seus achados.

Com relação à Fantasia, notou-se em G1 claro destaque para a "onipotência" e para a "impotência", em mesma proporção. Em G2 cai a presença da "impotência" e aumenta o item "onipotência", o que se reforça em G3. Assim, a relação observada entre os grupos é a de quanto menor os indicadores de problemas de saúde mental (de G1 para G3), houve aumento da "onipotência" e da "reparação", com diminuição da “impotência”, seguindo padrão previsto para essa fábula.

Quanto ao Estado Emocionalhouve maior incidência de "Alegria" para todos os grupos, sinalizando reação afetiva comum frente a essa fábula. As outras expressões afetivas diante dessa fábula acabaram dispersas nas frequências entre G1, G2 e G3.

A "Repressão" foi o item mais frequente nos três grupos no tocante às Defesas suscitadas pela Fábula do Objeto Fabricado, sinalizando predomínio da capacidade de contenção e uso de defesas maduras pelas crianças. Notou-se ainda tendência à pequena elevação no uso de defesas "com base na negação" em G3, o que deverá ser examinado em outros estudos para adequada interpretação.

No andamento do processo de apresentação dos resultados desse estudo tem-se as informações relativas a Fabula 8. Seus dados compõem a Tabela 11. 
Tabela 11 -Resultados (em frequência simples e porcentagem) e comparação estatística das categorias avaliativas da Fábula 8 (Fábula do Passeio) em função dos grupos e na amostra total $(n=60)$.

\begin{tabular}{|c|c|c|c|c|c|c|c|c|c|c|c|c|}
\hline \multirow{2}{*}{\multicolumn{2}{|c|}{$\begin{array}{l}\text { GRUPO } \\
\text { VARIÁVEL da Fábula }\end{array}$}} & \multicolumn{2}{|c|}{ Grupo 1} & \multicolumn{2}{|c|}{ Grupo 2} & \multicolumn{2}{|c|}{ Grupo 3} & \multicolumn{2}{|c|}{ TOTAL } & \multirow[b]{2}{*}{$\chi^{2}$} & \multirow[b]{2}{*}{$p$} & \multirow[b]{2}{*}{ V de Crame } \\
\hline & & $f$ & $\%$ & $f$ & $\%$ & $f$ & $\%$ & $f$ & $\%$ & & & \\
\hline \multirow{4}{*}{ Motivo } & Conflito edípico & 8 & 40,0 & 5 & 25,0 & 9 & 45,0 & 22 & 36,7 & \multirow[b]{4}{*}{7,288} & \multirow[b]{4}{*}{0,124} & \multirow[b]{4}{*}{0,245} \\
\hline & Omissão de deveres & 4 & 20,0 & 12 & 60,0 & 7 & 35,0 & 23 & 38,3 & & & \\
\hline & Outros & 8 & 40,0 & 3 & 15,0 & 4 & 20,0 & 15 & 25,0 & & & \\
\hline & Subtotal & 20 & 100,0 & 20 & 100,0 & 20 & 100,0 & 60 & 100,0 & & & \\
\hline \multirow{5}{*}{ Fantasias } & Agressão & 10 & 50,0 & 7 & 35,0 & 5 & 25,0 & 22 & 36,7 & \multirow[b]{5}{*}{5,497} & \multirow[b]{5}{*}{0,482} & \multirow[b]{5}{*}{0,214} \\
\hline & Onipotência & 3 & 15,0 & 8 & 40,0 & 9 & 45,0 & 20 & 33,3 & & & \\
\hline & Impotência & 3 & 15,0 & 3 & 15,0 & 2 & 10,0 & 8 & 13,3 & & & \\
\hline & Reparação & 4 & 20,0 & 2 & 10,0 & 4 & 20,0 & 10 & 16,7 & & & \\
\hline & Subtotal & 20 & 100,0 & 20 & 100,0 & 20 & 100,0 & 60 & 100,0 & & & \\
\hline \multirow{5}{*}{$\begin{array}{c}\text { Estado } \\
\text { Emocional }\end{array}$} & Raiva & 1 & 12,0 & 1 & 4,2 & 1 & 14,3 & 3 & 5,0 & \multirow[b]{5}{*}{10,189} & \multirow[b]{5}{*}{0,117} & \multirow[b]{5}{*}{0,291} \\
\hline & Ansiedade & 7 & 32,0 & 7 & 37,5 & 16 & 60,7 & 30 & 50,0 & & & \\
\hline & Tristeza & 8 & 36,0 & 10 & 41,7 & 2 & 14,3 & 20 & 33,3 & & & \\
\hline & Alegria & 4 & 20,0 & 2 & 16,6 & 1 & 10,7 & 7 & 11,7 & & & \\
\hline & Subtotal & 20 & 100,0 & 20 & 100,0 & 20 & 100,0 & 60 & 100,0 & & & \\
\hline \multirow{3}{*}{ Defesas } & Com base na negação & 4 & 20,0 & 3 & 15,0 & 2 & 10,0 & 9 & 15,0 & & & \\
\hline & Com base na repressão & 16 & 80,0 & 17 & 85,0 & 18 & 90,0 & 51 & 85,0 & & & \\
\hline & Subtotal & 20 & 100,0 & 20 & 100,0 & 20 & 100,0 & 60 & 100,0 & 0,895 & 0,639 & 0,122 \\
\hline
\end{tabular}


Diante da fábula do passeio também não foram identificadas diferenças estatisticamente significativas entre os grupos em nenhuma das categorias avaliativas existentes. Pode-se, contudo, examinar algumas tendências gerais dos achados, de modo a favorecer sua compreensão. Na categoria Motivosas respostas das crianças ficaram dispersas entre os itens "conflito Edípico", "omissão de deveres" e "Outros" (não ligados ao conteúdo da fábula). Pôde-se observar que G1 destacou-se como o que mais apresentou "outros" motivos se comparado aos outros grupos, o que pode estar associado à possibilidade de particularização do pensamento neste grupo, podendo sinalizar dificuldade de G1 em se ater aos aspectos da realidade. Em G2, aparentemente, houve o deslocamento da questão edípica para “omissão de deveres" e, em G3, houve indicador de maior contato com o conflito edípico, central nessa fábula.

No que se refere à Fantasia houve predomínio no item “Agressão” (sugestiva de angústia persecutória) em G1, enquanto a "Onipotência” foi destaque em G2 e em G3. Houve clara diminuição da fantasia de "agressão" na medida em que diminuíram os sinais de problemas de saúde mental (de G1 para G3), com elevação da "onipotência" e diminuição da "impotência" na produção infantil.

Quanto ao Estado Emocional houve maior frequência foi de "Tristeza" e da "Ansiedade" em G1 e em G2, enquanto em G3 predominou claramente a "Ansiedade", sugerindo mobilização afetiva diferenciada entre os grupos. O padrão de respostas predominante em G3 pode ser considerado como sinalizador de maior capacidade de contato com o conflito suscitado pela fábula nessas crianças. Nesta categoria avaliativa, a relação observada foi a de quanto menor os indicadores de problemas de saúde mental (de G1 para G3), houve aumento da "ansiedade" e claro recuo na frequência de expressões sugestivas de "tristeza" e de "alegria".

Com relação às Defesas não houve diferenças estatisticamente significativas no perfil de respostas entre os grupos, embora com claro predomínio da "Repressão", sugerindo preservação do vínculo com a realidade. Cabe destacar, no entanto, que de G1 para G3 (com a diminuição do número de indicadores de problemas de saúde mental) houve recuo nas defesas "com base na negação" e aumento na frequência das defesas "com base na repressão", sugerindo se tratar de um marcador relevante para compreensão do processo adaptativo infantil frente à temática proposta nessa fábula.

Na sequência são apresentados os resultados da Fábula da Notícia (Fabula 9). A Tabela 12 sistematiza esses dados e sua comparação estatística entre os grupos avaliados. 
$90 \mid$ Resultados

Tabela 12 -Resultados (em frequência simples e porcentagem) e comparação estatística das categorias avaliativas da Fábula 9 (Fábula da Notícia) em função dos grupos e na amostra total $(n=60)$.

\begin{tabular}{|c|c|c|c|c|c|c|c|c|c|c|c|c|}
\hline & \multirow{2}{*}{$\begin{array}{c}\text { GRUPO } \\
\text { VARIÁVEL da Fábula }\end{array}$} & \multicolumn{2}{|c|}{ Grupo 1} & \multicolumn{2}{|c|}{ Grupo 2} & \multicolumn{2}{|c|}{ Grupo 3} & \multicolumn{2}{|c|}{ TOTAL } & \multirow[b]{2}{*}{$\chi^{2}$} & \multirow[b]{2}{*}{$p$} & \multirow[b]{2}{*}{$V$ de Cramer } \\
\hline & & $f$ & $\%$ & $f$ & $\%$ & $f$ & $\%$ & $f$ & $\%$ & & & \\
\hline \multirow{3}{*}{ Medo } & Ausente & 16 & 80,0 & 17 & 85,0 & 14 & 70,0 & 47 & 78,4 & & & \\
\hline & Presente & 4 & 20,0 & 3 & 15,0 & 6 & 30,0 & 13 & 21,6 & & & \\
\hline & Subtotal & 20 & 100,0 & 20 & 100,0 & 20 & 100,0 & 60 & 100,0 & 3,106 & 0,212 & 0,228 \\
\hline \multirow{4}{*}{ Desejos } & Sem resposta & 11 & 55,0 & 7 & 35,0 & 6 & 30,0 & 24 & 40,0 & & & \\
\hline & Ganhar presente ou lazer & 7 & 35,0 & 10 & 50,0 & 9 & 45,0 & 26 & 43,3 & & & \\
\hline & Outros & 2 & 10,0 & 3 & 15,0 & 5 & 25,0 & 10 & 16,7 & & & \\
\hline & Subtotal & 20 & 100,0 & 20 & 100,0 & 20 & 100,0 & 60 & 100,0 & 3,581 & 0,466 & 0,173 \\
\hline \multirow{3}{*}{ Proibições } & Sem resposta & 16 & 80,0 & 15 & 75,0 & 13 & 65,0 & 44 & 73,3 & & & \\
\hline & Escola e interações sociais & 4 & 20,0 & 5 & 25,0 & 7 & 35,0 & 16 & 26,7 & & & \\
\hline & Subtotal & 20 & 100,0 & 20 & 100,0 & 20 & 100,0 & 60 & 100,0 & 0,933 & 0,627 & 0,125 \\
\hline \multirow{3}{*}{ Informações } & Sem resposta & 16 & 80,0 & 12 & 60,0 & 9 & 45,0 & 37 & 61,7 & & & \\
\hline & Vida cotidiana & 4 & 20,0 & 8 & 40,0 & 11 & 55,0 & 23 & 38,3 & & & \\
\hline & Subtotal & 20 & 100,0 & 20 & 100,0 & 20 & 100,0 & 60 & 100,0 & 4,711 & 0,095 & 0,280 \\
\hline \multirow{5}{*}{ Fantasias } & Agressão & 4 & 20,0 & 2 & 10,0 & 5 & 25,0 & 11 & 18,3 & & & \\
\hline & Onipotência & 4 & 20,0 & 11 & 55,0 & 12 & 60,0 & 27 & 45,0 & & & \\
\hline & Impotência & 12 & 60,0 & 7 & 35,0 & 2 & 10,0 & 21 & 35,0 & & & \\
\hline & Reparação & - & - & - & - & 1 & 5,0 & 1 & 1,7 & & & \\
\hline & Subtotal & 20 & 100,0 & 20 & 100,0 & 20 & 100,0 & 60 & 100,0 & 13,240 & 0,039 & $0,332 *$ \\
\hline
\end{tabular}




\begin{tabular}{|c|c|c|c|c|c|c|c|c|c|c|c|c|}
\hline & Raiva & - & - & 1 & 5,0 & 1 & 5,0 & 2 & 3,3 & & & \\
\hline Estado & Ansiedade & 3 & 15,0 & 3 & 15,0 & 6 & 30,0 & 12 & 20,0 & & & \\
\hline \multirow{4}{*}{ Emocional } & Tristeza & 5 & 25,0 & 4 & 20,0 & 3 & 15,0 & 12 & 20,0 & & & \\
\hline & Alegria & 12 & 60,0 & 12 & 60,0 & 10 & 50,0 & 34 & 56,7 & & & \\
\hline & Subtotal & 20 & 100,0 & 20 & 100,0 & 20 & 100,0 & 60 & 100,0 & 5,991 & 0,424 & 0,223 \\
\hline & Com base negação & 6 & 30,0 & 3 & 15,0 & 6 & 30,0 & 15 & 25,0 & & & \\
\hline \multirow[t]{2}{*}{ Defesas } & Com base repressão & 14 & 70,0 & 17 & 85,0 & 14 & 70,0 & 45 & 75,0 & & & \\
\hline & Subtotal & 20 & 100,0 & 20 & 100,0 & 20 & 100,0 & 60 & 100,0 & 3,167 & 0,205 & 0,230 \\
\hline
\end{tabular}

* V de Cramer $\leq 0,05$ 
$\mathrm{Na}$ fábula da notícia, entre as sete categorias avaliativas examinadas, houve resultados estatisticamente diferentes em apenas uma: na categoria Fantasias. Os dados, no entanto, serão explorados em termos de suas tendências gerais. Desse modo, pode-se notar que, diante da primeira categoria avaliativa referente aos Medos, a grande maioria da produção infantil não preencheu o critério de presença de medos. Nos poucos casos onde foi possível identificar esse conteúdo, os medos mostraram-se associados à escola. Isso sinalizou que essa fábula, para esta amostra, estimulou mais outros conteúdos psíquicos do que a própria experiência do medo. Apesar disso, quanto menor os indicadores de problemas de saúde mental (de G1 para G3), maior a presença do medo nos relatos das crianças, conseguindo externalizar suas vivências internas suscitadas pela fábula.

Com relação aos Desejos, em G1 eles pouco estiveram presentes, mas bem marcados em G2 e em G3, relacionados a "ganhar presente ou lazer". Nesta categoria avaliativa da fábula 9, quanto maior os indicadores de problemas de saúde mental, maior a ausência de desejos manifestos na produção das crianças, o que aponta que talvez o grupo psiquiátrico tenha maior dificuldade em vislumbrar bons acontecimentos e/ou isto possa estar relacionado à menor capacidade produtiva no teste, se comparado aos outros grupos de modo geral. Outra relação, também observada, foi a de quanto "mais saudável” o grupo (de G1 para G3), maior a diversidade dos desejos representados pelo item "outros".

A categoria das Proibições foi muito pouco frequente entre os respondentes nessa fábula da notícia. As proibições foram manifestas mais pelas crianças de G3, vinculando-se à "Escola" (com 35\%), diminuindo sua frequência em G2 e em G1. Assim, quanto menor os indicadores de problemas de saúde mental (de G1 para G3), mais as crianças puderam manifestar proibições em suas respostas, vinculadas "a escola e interações sociais".

A categoria avaliativa referente às Informaçõesfoi também marcada por baixo índice de respostas. Quando presente, essa categoria vinculou-se a "fatos sobre a vida cotidiana", com frequência crescente de G1 para G3. Nesta categoria avaliativa, assim como na anterior, quanto menor os indicadores de problemas de saúde mental, mais as crianças puderam manifestar-se, apresentando informações "ligadas à vida cotidiana".

A única diferença estatisticamente significativa entre os grupos, diante dessa fábula, foi identificada na categoria das "Fantasias". Ficou bem claro o predomínio da "impotência" em G1, que cai em frequência em G2 e em G3, elevando-se a ocorrência 
da "onipotência". Assim, G1 sinalizou insegurança em seus recursos internos, enquanto G2 e G3 caminharam no sentido da superestimação da capacidade de solução do conflito estimulado pela fábula. Nesta categoria avaliativa notou-se que quanto menor os indicadores de problemas de saúde mental (de G1 para G3), menor a incidência das fantasias de "impotência" e maior a presença de fantasias de "onipotência", caracterizando padrão de respostas específico entre os grupos de crianças avaliadas.

Quanto ao Estado Emocional notou-se predomínio da "alegria" entre os grupos. Observou-se que, quanto menor os indicadores de problemas de saúde mental (de G1 para G3), maior a presença da "ansiedade" e menor a expressão da "tristeza".

Houve predomínio das defesas "com base na repressão" nos três grupos, sinalizando o predomínio da capacidade de contenção e uso de mecanismos adaptativos diante dessa fábula da notícia para o conjunto das crianças. Esse dado pode ser considerado sugestivo de adequado potencial para solucionar a proposta temática em foco nesse momento do Teste das Fábulas.

Em seguimento ao processo analítico específico da produção infantil nesse método projetivo, tem-se o foco agora na última fábula, conhecida como Fábula do Sonho Mau. Os resultados obtidos frente a Fábula 10 estão sistematizados na Tabela 13. 
94 | R e s u 1 t a d o s

Tabela 13 -Resultados (em frequência simples e porcentagem) e comparação estatística das categorias avaliativas da Fábula 10 (Fábula do Sonho Mau) em função dos grupos e na amostra total ( $n=60)$.

\begin{tabular}{|c|c|c|c|c|c|c|c|c|c|c|c|c|}
\hline \multirow{2}{*}{\multicolumn{2}{|c|}{$\begin{array}{c}\text { GRUPO } \\
\text { VARIÁVEL da Fábula }\end{array}$}} & \multicolumn{2}{|c|}{ Grupo 1} & \multicolumn{2}{|c|}{ Grupo 2} & \multicolumn{2}{|c|}{ Grupo 3} & \multicolumn{2}{|c|}{ TOTAL } & \multirow[b]{2}{*}{$\chi^{2}$} & \multirow[b]{2}{*}{$p$} & \multirow[b]{2}{*}{$V$ de Cramer* } \\
\hline & & $f$ & $\%$ & $f$ & $\%$ & $f$ & $\%$ & $f$ & $\%$ & & & \\
\hline \multirow{5}{*}{ Perseveração } & Não se aplica & 13 & 65,0 & 11 & 55,0 & 9 & 45,0 & 33 & 55,0 & & & \\
\hline & Fábula 4 & 1 & 5,0 & 1 & 5,0 & 3 & 15,0 & 5 & 8,3 & & & \\
\hline & Fábula 5 & 6 & 30,0 & 4 & 20,0 & 4 & 20,0 & 14 & 23,3 & & & \\
\hline & Outras (F1,F2,F3,F8,F9) & - & - & 4 & 20,0 & 4 & 20,0 & 8 & 13,3 & & & \\
\hline & Subtotal & 20 & 100,0 & 20 & 100,0 & 20 & 100,0 & 60 & 100,0 & 6,584 & 0,361 & 0,234 \\
\hline \multirow{6}{*}{$\begin{array}{l}\text { Novos } \\
\text { conteúdos }\end{array}$} & Sem resposta & 7 & 40,0 & 3 & 15,0 & - & - & 10 & 16,7 & & & \\
\hline & Animais & 1 & 5,0 & 3 & 15,0 & 2 & 10,0 & 6 & 10,0 & & & \\
\hline & $\begin{array}{l}\text { Bruxas / entidades } \\
\text { fantásticas }\end{array}$ & 1 & 5,0 & 1 & 5,0 & 5 & 25,0 & 7 & 11,7 & & & \\
\hline & Fatos aterrorizantes & 8 & 40,0 & 11 & 55,0 & 10 & 50,0 & 29 & 48,3 & & & \\
\hline & Outros & 3 & 10,0 & 2 & 10,0 & 3 & 15,0 & 8 & 13,3 & & & \\
\hline & Subtotal & 20 & 100,0 & 20 & 100,0 & 20 & 100,0 & 60 & 100,0 & 13,367 & 0,100 & 0,334 \\
\hline \multirow{4}{*}{ Fantasias } & Agressão & 12 & 54,5 & 17 & 64,3 & 12 & 54,2 & 41 & 68,3 & & & \\
\hline & Onipotência & - & - & - & - & 4 & 25,0 & 4 & 6,7 & & & \\
\hline & Impotência & 8 & 45,5 & 3 & 25,0 & 4 & 20,8 & 15 & 25,0 & & & \\
\hline & Subtotal & 20 & 100,0 & 20 & 100,0 & 20 & 100,0 & 60 & 100,0 & 12,963 & 0,044 & $0,329 *$ \\
\hline \multirow{4}{*}{$\begin{array}{c}\text { Estado } \\
\text { Emocional }\end{array}$} & Ansiedade & 15 & 75,0 & 13 & 65,0 & 17 & 85,0 & 45 & 75,0 & & & \\
\hline & Tristeza & 4 & 20,0 & 6 & 30,0 & 2 & 10,0 & 12 & 25,0 & & & \\
\hline & Alegria & 1 & 5,0 & 1 & 5,0 & 1 & 5,0 & 3 & 5,0 & & & \\
\hline & Subtotal & 20 & 100,0 & 20 & 100,0 & 20 & 100,0 & 60 & 100,0 & 0,936 & 0,919 & 0,088 \\
\hline \multirow{3}{*}{ Defesas } & Com base na negação & 8 & 45,0 & 6 & 30,0 & 3 & 15,0 & 17 & 28,3 & & & \\
\hline & Com base na repressão & 12 & 55,0 & 14 & 70,0 & 17 & 85,0 & 43 & 71,7 & & & \\
\hline & Subtotal & 20 & 100,0 & 20 & 100,0 & 20 & 100,0 & 60 & 100,0 & 2,174 & 0,337 & 0,190 \\
\hline
\end{tabular}

$* \mathrm{~V}$ de Cramer $\leq 0,05$ 
Uma vez mais os grupos apresentaram apenas uma diferença estatisticamente significativa entre as cinco categorias de análise dessa fábula. A exploração descritiva dos achados, entretanto, acrescenta informações relevantes para a compreensão da psicodinâmica das crianças avaliadas.

Apesar da reduzida incidência da categoria Perseveração na produção infantil, quando presente, apareceu de modo mais frequente diante da Fábula 5, com maior incidência em G1, sugerindo que as crianças desse grupo pode estar mais angustiadas frente às questões ligadas ao medo e à persecutoriedade propostas na fábula do medo. No entanto, há que se destacar que os grupos não apresentaram resultados estatisticamente diferentes no tocante a essa categoria avaliativa de sua produção.

No que se refere a Novos conteúdos, mais uma vez, as crianças de G1 mostraram reduzida manifestação de novos conteúdos em sua produção, sugerindo inibição produtiva, já presente em outras fábulas. Por outro lado, a expressão de novos conteúdos ficou bem marcada entre as crianças de G2 e de G3, provavelmente marcando sua maior espontaneidade de manifestações pessoais diante do tema proposto. Cabe destacar, no entanto, que os conteúdos apresentados como novos pelas crianças associaram-se majoritariamente a "acontecimentos aterrorizantes", além da presença de "bruxas e entidades fantásticas", evidências que deverão ser consideradas nos processos interpretativos da produção infantil diante dessa fábula.

Quanto à Fantasia, houve diferenças estatisticamente significativas (com efeito também relevante e significativo) no perfil de respostas entre os grupos. É possível observar o predomínio da "Agressão", sinalizando fantasia condizente com a possibilidade catártica da fábula. Nesta categoria avaliativa notou-se que quanto menor os indicadores de problemas de saúde mental (de G1 para G3), menor a frequência da fantasia de "impotência" nas crianças, elevando-se a fantasia de "onipotência".

$\mathrm{Na}$ categoria avaliativa do Estado emocional, o item predominante em todos os grupos foi a "ansiedade". Tratou-se de reação afetiva quase unânime entre as crianças avaliadas, frente à proposta dessa fábula do Sonho Mau.

Por fim, no que se refere às Defesas, houve predomínio das defesas adaptativas (“com base na repressão"). No entanto, notou-se decréscimo no uso de defesas "com base na negação" da realidade nas crianças com menor número de indicadores de problemas de saúde mental (de G1 para G3), com maior incidência desse tipo de defesas no grupo em tratamento psiquiátrico $(\mathrm{G} 1)$. 
Em síntese, pode-se notar que no conjunto da produção infantil diante do Teste das Fábulas, os três grupos aqui compostos apresentaram diferenças estatisticamente significativas em oito das 50 categorias avaliativas utilizadas no sistema revisto de Nunes e Cunha (1993). Elas ocorreram em seis das 10 fábulas existentes no instrumento, privilegiando conteúdos avaliativos referentes à ação, ao desfecho, às fantasias e às defesas utilizadas pelas crianças para responder às demandas propostas. A fábulas 4 (Fábula do Enterro), 5 (Fábula do Medo), 7 (Fábula do Objeto Fabricado) e 8 (Fábula do Passeio) não apresentaram indicadores de diferenças estatisticamente significativas entre os grupos de crianças presentemente avaliadas, podendo ser consideradas como estímulos aos quais a maioria das crianças (independentemente de sua condição psicológica) conseguem enfrentar. No entanto, há que se comentar que as crianças de G1 apresentaram, em termos gerais, sinais de inibição geral em suas produções. Os comentários relativos à análise qualitativa diante das fábulas também acrescentaram informações bastante relevantes para se compreender a psicodinâmica infantil, a partir dos estímulos propostos pelo Teste das Fábulas. Dessa forma, foi possível reunir e apresentar evidências empíricas de especificidades de reação das crianças diante das dez fábulas, atestando indicadores de validade para esse método projetivo a partir da contraposição de grupos com diferentes condições de saúde mental.

Ainda no sentido de explorar características da produção infantil diante do conjunto das dez fábulas, testou-se a hipótese de possível efeito do sexo e da idade sobre os resultados. Para tanto, os participantes (independentemente de seu grupo de origem) foram subdivididos em subgrupos quanto ao sexo (numa primeira análise) e em dois grupos etários: decinco a oito anos de idade $(\mathrm{n}=22)$ versus de nove a doze anos de idade ( $\mathrm{n}=38)$, numa segunda análise. As comparações estatísticas foram realizadas para todas as categorias avaliativas do Teste das Fábulas, conforme sistema revisto de Cunha e Nunes (1993), chegando-se a inexistência de diferenças estatisticamente significativas em função do sexo e da faixa etária das crianças avaliadas. Desse modo torna-se possível afirmar que essas variáveis demográficas não pareceram interferir, de modo estatisticamente significativo, na distribuição dos resultados. Essa análise complementar oferece, portanto, sustentação técnica adicional para que a interpretação dos dados das dez fábulas seja realmente associada aos indicadores de saúde mental, condição básica de delineamento dos grupos de crianças presentemente estudados. 


\subsection{Relativos a evidências de validade e de precisão do Teste das Fábulas}

Além da análise sistemática da produção infantil no conjunto das dez fábulas, a partir do sistema avaliativo de Cunha e Nunes (1993), aqui revisto, a presente pesquisa procurou chegar a uma classificação de cada protocolo em duas categorias: Clínico e Não clínico. Cabe esclarecer que essa classificação não se constitui como procedimento técnico padronizado pelo manual do Teste das Fábulas, porém foi aqui realizada por cada avaliador (de forma independente e às cegas, visto que receberam os casos sem identificação de sua origem), para se testar a precisão do sistema avaliativo utilizado.

No tocante à exploração das propriedades psicométricas do Teste das Fábulas, no que se refere à concordância entre avaliadores independentes na classificação das produções de G1, G2 e de G3, enquanto casos clínicos e não clínicos, os atuais achados mostram que houve grande concordância. Em apenas oito dos casos $(13,3 \%)$ do total da amostra $(n=60)$ houve discordância entre a avaliação dos dois examinadores externos de cada protocolo, sendo realizada nova avaliação por um terceiro juiz experiente para balizar a classificação final dos protocolos entre clínicos e não clínicos. Esses dados apontam concordância entre avaliadores independentes de 86,7\%, sugerindo adequado índice de precisão no Teste das Fábulas.

Para além da concordância entre examinadores em valores em porcentagem, calculou-se o índice Kappa para os resultados obtidos nesse processo classificatório dasproduções diante do Teste das Fábulas como casos clínicos ou não clínicos. Obtevese, dessa forma, o índice Kappa igual a 0,698 ( $p \leq 0,001)$. Fonseca, Silva e Silva (2007) afirmam que, "para o coeficiente Kappa, valores maiores que 0,75 representam nível excelente de concordância, valores abaixo de 0,40 representam baixa concordância e os situados entre 0,40 e 0,75 representam concordância mediana" (p. 50). Encontrou-se, portanto, mediano (tendendo a excelente) índice de concordância entre os juízes independentes na avaliação do conjunto da produção no Teste das Fábulas. Esses achados reiteram adequados indicadores técnicos de precisão para esse método projetivo de avaliação psicológica.

Ainda com objetivo de explorar a própria consistência dos achados com o Teste das Fábulas das crianças presentemente avaliadas, procurou-se contrapor sua classificação diagnóstica (caso clínico ou não clínico, a partir dos avaliadores 
$98 \mid R$ e s u lt a d o s

independentes) com aquela obtida a partir do instrumento SDQ. Esse procedimento foi realizado para os casos de G2 e de G3, visto que os casos psiquiátricos de $\mathrm{G} 1$ (n=20) já haviam passado por amplo e completo processo psicodiagnóstico, com objetivos clínicos.

Vale ressaltar que essa classificação dos casos em clínicos e não clínicos foi realizada de modo a examinar a sensibilidade diagnóstica do Teste das Fábulas. Esse procedimento não interferiu ou alterou a classificação inicial realizada por meio do SDQ para compor os grupos amostrais escolares e discriminar se comporiam G2 ou G3, conforme descrito no método. Os resultados derivados dessa análise encontram-se na Tabela 14.

Tabela 14-Resultados da classificação diagnóstica de juízes independentes e às cegas em relação à produção das crianças de $G 2$ e $G 3(n=40)$ no Teste das Fábulas comparativamente ao resultado no SDQ.

\begin{tabular}{ccccc}
\hline \multicolumn{1}{c}{ Instrumento } & $\begin{array}{c}\text { Teste das } \\
\text { Fábulas }\end{array}$ & SDQ & \multicolumn{2}{c}{$\begin{array}{c}\text { Concordância entre } \\
\text { instrumentos }\end{array}$} \\
$\begin{array}{c}\text { Classificação } \\
\text { diagnóstica }\end{array}$ & & & Acordo & Desacordo \\
\hline \multicolumn{1}{c}{ Caso Clínico } & $24(60 \%)$ & $20(50 \%)$ & $28(70 \%)$ & $12(30 \%)$ \\
Caso Não Clínico & $16(40 \%)$ & $20(50 \%)$ & & \\
\hline
\end{tabular}

No que se refere à classificação em categoria Clínica e Não Clínica, tomando como base o funcionamento psíquico e a qualidade das defesas utilizadas no Teste das Fábulas para os Grupos G2 e G3, os protocolos foram consistentes com a classificação obtida pelo SDQ em 28 ou 70\% dos casos. Apenas em 12 casos (ou 30\% dessa amostra de escolares) houve discordância entre a classificação do SDQ e a do Teste das Fábulas. Dos 12 casos de discordância entre a classificação dos instrumentos, em oito protocolos o SDQ não apontava dificuldades na criança e, pela análise do Teste das Fábulas, chegou-se à hipótese de caso clínico. Em outros quatro casos, o desacordo foi na direção contrária, ou seja, o SDQ apontava a criança como caso clínico e, pelo Teste das Fábulas, considerou-se o caso como não clínico. Desse modo, pode-se apontar que houve um acréscimo de casos na classificação "clínico", segundo o Teste das Fábulas.

Nesses casos onde houve discordância entre classificação a partir do Teste das Fábulas e do SDQ, foi necessário examinar com mais detalhe possíveis elementos de 
suas produções nos diferentes instrumentos.Entre esses dissidentes (12 casos), quatro casos (ou 33,3\%) tinham sido classificados pelo SDQ como clínico e, por meio do Teste das Fábulas, foi possível identificar seus recursos e reclassificá-los como não clínicos. Em contrapartida, oito casos (ou 66,6\%) foram classificados como não clínicos e, no Teste das Fábulas, foi possível identificar questões clínicas cujo SDQ não pôde identificar, sendo reclassificados como clínicos.

A comparação da classificação clínica e não clínica entre os dois instrumentos obteve Kappa de 0,40 $(p=0,01)$. Desta forma, segundo Fonseca, Silva e Silva (2007)pode-se considerar que o valor de Kappa aqui encontradorepresenta nível médio de concordância entre a classificação clínica e não clínica obtida por meio do SDQ (instrumento rastreador de problemas de saúde mental) e o Teste das Fábulas (instrumento projetivo e que acessa o funcionamento da dinâmica interna do sujeito). Esse resultado aponta para adequada sensibilidade clínica e diagnóstica desse método projetivo de avaliação psicológica, fortalecendo seus achados.

Além disso, as evidências empíricas colecionadas a partir do contraponto dos achados de SDQ e Teste das Fábulas sugerem, para além de diferenças claras entre os respondentes (SDQ traz o relato dos pais, enquanto as Fábulas foram produzidas pelas crianças) e os métodos avaliativos em si, indicadores da sensibilidade do Teste das Fábulas para avaliar limites e recursos da criança, a partir de uma perspectiva qualitativa. A grande consistência entre os achados advindos do SDQ e do Teste das Fábulas revela a efetividade das informações obtidas por meio desse método projetivo de avaliação psicológica, evidenciando seus bons indicadores de validade.

\subsection{Relativos ao SDQ na amostra de escolares}

Conforme informado nos procedimentos, no presente trabalho o conjunto total de crianças da escola colaboradora do estudo foi avaliado pelo SDQ, todas devidamente autorizadas por seus pais/responsáveis. Desse modo, tem-se, como dado adicional aos objetivos originais do estudo, a descrição dos achados do SDQ nesse grupo de crianças escolares $(n=170)$, o que se passa a apresentar como resultado complementar. Esses resultados estão sistematizados na Tabela 15. 
$100 \mid$ Re sult a d os

Tabela 15 -Distribuição dos escolares avaliados (n=170) em função da classificação no $S D Q$ e do sexo.

\begin{tabular}{|c|c|c|c|c|c|c|c|c|c|}
\hline \multirow{2}{*}{\multicolumn{2}{|c|}{$\begin{array}{l}\text { Classificação Diagnóstica } \\
\text { Característica do Estudante }\end{array}$}} & \multicolumn{2}{|c|}{ Clínico } & \multicolumn{2}{|c|}{ Não Clínico } & \multicolumn{2}{|c|}{ Limítrofe } & \multicolumn{2}{|c|}{ TOTAL } \\
\hline & & $f$ & $\%$ & $f$ & $\%$ & $f$ & $\%$ & $f$ & $\%$ \\
\hline \multirow{3}{*}{$\begin{array}{c}\text { Sexo } \\
\text { Masculino }\end{array}$} & Voluntário* & 28 & 40,0 & 29 & 33,7 & 6 & 42,8 & 57 & 33,5 \\
\hline & Participante ${ }^{* *}$ & 11 & 15,7 & 10 & 11,6 & - & - & 21 & 12,4 \\
\hline & Subtotal & 39 & 55,7 & 39 & 45,3 & 6 & 42,8 & 84 & 49,4 \\
\hline Sexo & Voluntário* & 22 & 31,4 & 37 & 43,0 & 8 & 57,2 & 67 & 39,4 \\
\hline \multirow[t]{2}{*}{ Feminino } & Participante** & 9 & 12,9 & 10 & 11,6 & - & - & 19 & 11,2 \\
\hline & Subtotal & 31 & 44,3 & 47 & 54,6 & 8 & 57,2 & 86 & 50,6 \\
\hline \multicolumn{2}{|c|}{ TOTAL } & 70 & 100,0 & 86 & 100,0 & 14 & 100,0 & 170 & 100,0 \\
\hline
\end{tabular}

* Voluntário: estudante colaborador, porém não incluído na amostra final.

** Participante: estudante colaborador, incluído na amostra final (em G2 ou G3).

Pode-se observar que houve, no total de 170 voluntários, 70 casos $(41,2 \%)$ classificados como clínicos por meio do SDQ, sendo 55,7\% do sexo masculino e 44,3\% do sexo feminino. O número de participantes efetivos da pesquisa entre os classificados como clínicos pelo SDQ corresponde a 11 meninos e nove meninas, os quais compõem $\mathrm{G} 2(\mathrm{n}=20)$.

Quanto aos voluntários com resultado no SDQ compatível com classificação não clínica, houve um total de 86 estudantes (50,6\%), distribuídos em 45,3\% do sexo masculino e 54,6\% do sexo feminino. Desse total foram selecionados 10 meninos e 10 meninas para comporem o grupo não clínico $(\mathrm{G} 3, \mathrm{n}=20)$ do presente estudo. Quanto aos limítrofes, a incidência foi de 14 voluntários $(8,2 \%$ do total de avaliados), dos quais $42,8 \%$ do sexo masculino e $57,2 \%$ do sexo feminino.

Embora não fosse um dos objetivos do presente trabalho esse rastreamento de saúde mental, a partir da aplicação do SDQ em escolares, constitui informação relevante, derivada do próprio trabalho. Sua inclusão poderá oferecer elementos 
Resultados | 101

complementares para análise e discussão dos achados específicos da pesquisa, conforme inicialmente delineado. 


\section{DISCUSSÃO}

O objetivo central do presente estudo foi examinar indicadores empíricos de validade e precisão do Teste das Fábulas, instrumento projetivo de avaliação do funcionamento psicodinâmico afetivo e de aspectos referentes à personalidade, muito importante por sua vasta utilização em diversas áreas da Psicologia.

O estudo trabalhou com a hipótese de que o Teste das Fábulas apresentaria adequados indicadores de validade de critério, contrastando a produção de crianças escolares de seis a 12 anos, subdivididas em três grupos: a) crianças com diagnóstico e tratamento para problemas de saúde mental (G1), b) crianças com indicadores sugestivos de problemas de saúde mental (G2) e c) crianças sem indicadores de problemas de saúde metal (G3). Desse modo, desejava-se examinar as possibilidades desse método projetivo captar diferenças no padrão de respostas dos três grupos de escolares, identificando-se possíveis variáveis do Teste das Fábulas sinalizadoras de indicadores de problemas de saúde mental em crianças na faixa etária avaliada.

Cabe inicialmente destacar os rigorosos cuidados metodológicos na composição dos grupos e na condução do estudo. Buscou-se compor a amostra de modo a ficar igualmente subdividida em função do sexo (masculino e feminino), idade (seis a 12 anos) e série escolar (primeira a quinta série do ensino fundamental). O grupo G1 foi composto por crianças que receberam diagnóstico e tratamento por problemas de Saúde Mental em hospital terciário, tendo realizado avaliação psicodiagnóstica, que incluiu, entre outros instrumentos, o Teste das Fábulas. Por sua vez, G2 foi composto por crianças que obtiverem pontuação classificada como "clínica" na escala total de sintomas do Questionário de Capacidades e Dificuldades (SDQ), sugerindo indicadores de prejuízo funcional a partir da percepção de seus pais ou responsáveis. Por fim, G3 englobou crianças que obtiverem pontuação classificada como "não clínica" na escala total de sintomas do Questionário de Capacidades e Dificuldades (SDQ), sugerindo indicadores de desenvolvimento típico para sua idade e contexto sociocultural, também segundo percepção de seus pais ou responsáveis. Os voluntários foram individualmente avaliados, com adequadas condições técnicas, seguindo-se procedimentos padronizados nos respectivos instrumentos de avaliação psicológica utilizados, oferecendo condições similares para a produção de cada criança. Esses cuidados metodológicos mostraram-se 
relevantes para o bom andamento do estudo e de suas etapas analíticas, favorecendo o alcance de seus objetivos iniciais.

Esperava-se, também, examinar indicadores de precisão do Teste das Fábulas, a partir da classificação independente de avaliadores. Foi possível implementar essa análise, bem como dos indicadores relativos à validade desse método projetivo de avaliação psicológica.

O sistema de classificação da produção infantil no Teste das Fábulas proposto por Cunha e Nunes (1993) foi revisto e reorganizado no presente trabalho. Esse foi um resultado originalmente não previsto, porém permitiu o alcance de uma proposta avaliativa que se mostrou operacional, didática e com bons indicadores de precisão entre avaliações independentes.

O conjunto dos dados presentemente obtidos mostrou-se capaz de identificar e discriminar o perfil de respostas entre os três grupos, reafirmando atualizadas evidências empíricas de validade do Teste das Fábulas. Foi possível identificar diferenças estatisticamente significativas no perfil de respostas entre G1, G2 e G3 em parte das categorias avaliativas utilizadas e na maioria das fábulas, comprovando a sensibilidade do teste no que se refere ao funcionamento psicodinâmico infantil, bem como sua possibilidade diagnóstica. Pode-se notar, de modo geral, quanto maior a presença de indicadores de problemas de saúde mental nas crianças, a produção no Teste das Fábulas ficou permeada por sinais de inibição produtiva, de dificuldades no contato a realidade, bem como por expressão reduzida de recursos psíquicos e adaptativos.

Levando em consideração o conjunto da produção da amostra total de crianças no Teste das Fábulas, independentemente de seu grupo de origem, verificou-se ausência de diferenças estatisticamente significativas na produção infantil em função do sexo e da faixa etária. Esse achado é discordante com os dados de Peixotto (1956), ao pesquisar escolares de oito a 14 anos de idade. Segundo esse pesquisador, haveria efeito da idade sobre o padrão de produção ao Teste das Fábulas, pois as respostas das crianças mais novas seriam mais fidedignas do que as das crianças mais velhas, supondo efeito da maturidade do respondente sobre os resultados. No entanto, há que lembrar que, no estudo de Peixotto (1956), as crianças mais novas tiveram administração coletiva do Teste das Fábulas, enquanto as crianças mais velhas receberam aplicação individual. Além disso, há grande distância temporal entre os dados do referido trabalho e os atuais, o que limita a possibilidade de sua análise comparativa. 
Pode-se observar, a partir dos estudos de aplicabilidade do Teste das Fábulas na literatura científica (apontados na introdução desse trabalho), o destaque dado às evidências relativas à capacidade do instrumento identificar conflitos situacionais. Podem ser citados como exemplos desse tipo de achados: a) Lopes (2008) ao discorrer sobre o impacto da chegada do segundo filho no funcionamento psíquico do primogênito; b) Serafini (2004) ao estudar o funcionamento psicodinâmico de crianças institucionalizadas; c) Tardivo (2005) ao aplicar o Teste das Fábulas de Düss em crianças vítimas de violência doméstica e/ou sexual; d) Anton e Piccini (2011) ao mostrar efeitos da doença crônica e do transplante hepático no desenvolvimento infantil, entre outras investigações. Em cada um destes estudos os autores relataram bons indicadores técnicos do Teste das Fábulas no sentido de representarem as situações clínicas vivenciadas por seus sujeitos, denotando a sensibilidade do teste não somente a questões do funcionamento da personalidade, mas também identificando aspectos particulares dos conflitos situacionais vivenciados pelas crianças avaliadas.

No presente estudo também foi possível contrapor dados da história clínica de crianças do G1 com a produção no Teste das Fábulas, confirmando a sensibilidade desse instrumento de avaliação psicológica. Nesse momento toma-se, como um dos exemplos ilustrativos da possibilidade do Teste das Fábulas identificar questões situacionais vivenciadas, a produção de uma criança integrante do G1, de nove anos de idade, do sexo feminino, da quinta série do ensino fundamental, com quadro de transtorno alimentar, sendo um de seus sintomas a dificuldade na ingestão de alimentos sólidos. Em sua produção no Teste das Fábulas sinalizou recursos cognitivos, com sinais de defesas de somatização, hipocondria e verbalizações diretas sobre questões orais, envolvendo a alimentação e a fantasia de comida envenenada, bem como de conteúdos de morte. Facilmente consegue-se associar, do ponto de vista clínico, o significado de sua produção no Teste das Fábulas aos sintomas presentes em sua história clinica de Transtorno Alimentar, mostrando o alcance das informações obtidas pelo referido método projetivo de avaliação psicológica.

Ao estudar adolescentes com o Teste das Fábulas, Cunha, Argimon, Santos e Escobar (1996) examinaram o efeito da aplicação coletiva do instrumento, confirmando suas possibilidades técnicas para identificar conflitos como: impotência versus onipotência, imaturidade versus maturidade, dependência versus independência. Embora a faixa etária do presente estudo (seis a 12 anos) seja distinta do referido trabalho, estes citados conflitos também foram identificados na produção infantil aqui 
avaliada, confirmando achados da literatura da área. Outro dado referido pelos autores como característico da produção de adolescentes com vivências depressivas diante do Teste das Fábulas refere-se a maior presença de sinais de heróis torturados, perseguidos ou mortos. No presente trabalho foi possível identificar, na produção de crianças com sintomas depressivos (principalmente as pertencentes ao G1), conteúdos ligados à morte do herói.

No estudo realizado por Prieto, Avanci e Loureiro (1998) com crianças portadoras de problemas de aprendizagem, houve destaque especial para a produção infantil diante das fábulas 1, 3, 7 e 9 do Teste das Fábulas. Seus resultados apontaram que essas crianças sinalizaram resoluções dos conflitos propostos pelas fábulas de forma realista e adaptada à realidade, porém com baixa tolerância a frustração e a experiências emocionais predominantemente negativas, vivenciando insatisfação nas relações interpessoais. Foram também identificados sinais de dificuldade dessas crianças em lidar com perdas inerentes ao próprio desenvolvimento, caracterizando imaturidade afetiva. Embora as crianças presentemente avaliadas tenham características clínicas diferentes daquelas citadas no referido estudo, notou-se produção com marcas de superficial adaptação aos estímulos naquelas com indicadores de problemas de saúde mental (G1 e G2), porém acompanhadas por sinais de dificuldades afetivas, desestabilizando suas verbalizações perante as fábulas propostas.

No estudo de caso desenvolvido por Prieto e Loureiro (1998) com uma criança de oito anos e diagnóstico clínico psiquiátrico de Transtorno de Personalidade Borderline, o Teste de Fábulas e o Método de Rorschach foram utilizados como recursos avaliativos. Os dados observados no Teste das Fábulas permitiram identificar: traços de imaturidade; tendências regressivas; fantasias de rejeição, impotência e agressão; vivência psíquica de abandono; sentimentos de ódio contra a figura materna; tendência autodestrutiva; indicadores de ansiedade persecutória. Estes aspectos do funcionamento psíquico condizentes a quadros clínicos como os de transtorno de personalidade também puderam ser identificados em respostas de crianças de G1, fortalecendo os alcances informativos do Teste das Fábulas.

A comparação entre a classificação diagnóstica (casos clínicos e não clínicos) nos grupos G2 e G3 por meio do SDQ e do Teste das Fábulas permitiu identificar que grande consistência entre a conclusão chegada pelo SDQ e pelo Teste das Fábulas. Esseresultado evidenciou o valor clínico discriminativo do Teste das Fábulas, na 
medida em que o SDQ tem sido usado como padrão-ouro enquanto instrumento rastreador clínico psiquiátrico (Saur\& Loureiro, 2012).

Há que se comentar ainda sobre a dificuldade de comparação dos atuais achados com a literatura científica da área, sobretudo pelo reduzido número de estudos voltados ao exame de características psicométricas do Teste das Fábulas. Como se pode apreciar na revisão da literatura presentemente realizada, os trabalhos com esse método projetivo de avaliação psicológica configuraram-se, em sua maioria, em estudos de aplicabilidade do Teste das Fábulas. Ainda nesse sentido, a maioria dos estudos posteriores à publicação do manual do Teste das Fábulas (Cunha \& Nunes, 1993), apresenta número amostral inferior ao apresentado no atual estudo, reforçando suas possibilidades informativas.

Diante do exposto, pode-se afirmar que o presente trabalho alcançou seus objetivos, possibilitando demonstrar empiricamente evidências de validade e de precisão do Teste das Fábulas. Possibilitou o atendimento às diretrizes do Conselho Federal de Psicologia (CFP, 2010 e 2011) no que se refere à constante investigação de evidências psicométricas nacionais sobre os testes psicológicos e, principalmente, no que se refere ao método projetivo de avaliação psicológica focalizado nesse trabalho.

Evidentemente, deve-se manter o contínuo aprimoramento dessa linha de pesquisa com amostras numericamente mais robustas e representativas, incluindo também amostras clínicas diversificadas e estudos de caráter qualitativo. Dever-se-ia investigar ainda padrões de produção infantil diante do Teste das Fábulas, coletados em extensos grupos de crianças com desenvolvimento típico, de modo a subsidiar referenciais normativos atualizados para esse método projetivo, de preferência incluindo diferentes regiões representativas da diversidade populacional do Brasil. Esses aspectos constituem limites inerentes ao presente trabalho e que poderão ser superados em novas investigações científicas, estimuladas a partir dos atuais achados. 
D i s c u s s ão | 107 


\section{CONSIDERACÕES FINAIS}

Os resultados encontrados do Teste das Fábulas demonstraram que um estudo que pudesse evidenciar empiricamente aspectos de validade e de revisão do sistema avaliativo fazia-se necessário. Isso permitiu aprimorar a proposta de uso do teste, contribuindo com a produção de conhecimento relativo a testes e a processos de avaliação psicológica no Brasil, tentando garantir qualidade e segurança na interpretação de dados, conforme diretrizes determinadas pelo CFP $(2003,2011)$.

Ao se realizar análises estatísticas comparativas do perfil de respostas entre os três grupos pesquisados, pode-se examinar, com clareza, que algumas categorias foram capazes de discriminar seus resultados. Assim, foi possível identificar alguns itens avaliativos do Teste das Fábulas que podem estar associados a indicadores de Saúde Mental (como a presença de fantasias de reparação) e outros associados a indicadores de problemas de Saúde Mental (como sinais de impotência, ações passivas e defesas com base na negação da realidade). Além disso, a adequada precisão do Teste das Fábulas também pôde ser verificada empiricamente por meio da boa consistência na avaliação realizada por avaliadores independentes (psicólogos com experiência em avaliação psicológica e treinados no sistema avaliativo).

As variáveis sociodemográficas sexo e idade, por sua vez, não pareceram exercer associação estatisticamente significativa nos indicadores técnicos do Teste das Fábulas nos diferentes grupos avaliados. Nota-se, diante do exposto, que o presente estudo apresentou evidências empíricas claras de validade e precisão do Teste das Fábulas, que reafirmam os resultados descritos na literatura cientifica sobre o tema, principalmente no que se refere à capacidade clínica e diagnóstica do teste.

Depreende-se que este trabalho conseguiu atingir seus objetivos, sistematizando informações relevantes sobre a sensibilidade e a capacidade diagnóstica do Teste das Fábulas, focalizando informações referentes às vivências de conflito psíquico presentes no desenvolvimento infantil. Esses dados, associados a indicadores de rastreamento de sinais e sintomas de problemas de saúde mental, podem ser úteis e no que se refere ao diagnóstico clínico psiquiátrico, sugerindo campo de aplicação para esse método projetivo de avaliação psicológica, entre outras possibilidades. 
Apesar da riqueza dos atuais resultados, fica também clara a necessidade de novas investigações científicas com o Teste das Fábulas, a partir de outros delineamentos metodológicos. Destaca-se aqui que o estudo em questão, apesar de realizado no interior de São Paulo, teve amostra quantitativamente suficiente para seus objetivos, com a participação de 60 voluntários. Entretanto, o tamanho da amostra e a faixa etária (somente escolares de seis a 12 anos) constituíram-se como limites do estudo.

Nesse sentido, faz-se necessário, novos estudos com outras amostras e de maior amplitude, a fim de melhor abranger a diversidade de características dos indivíduos. Seria também interessante realizar estudos normativos e de validade do Teste das Fábulas em âmbito nacional, envolvendo diferentes regiões do Brasil, com sua diversidade de realidades, diante do caráter continental de nosso país. Também seriam ricos os estudos produzidos com outras faixas etárias para compreensão de suas características de funcionamento em termos afetivos.

Outro aspecto importante a considerar no presente estudo é que a revisão do sistema avaliativo carece de relativização na comparação de resultados com outros trabalhos, que pode constituir um dos limites deste estudo. No entanto, ainda assim fazse relevante refletir sobre as análises comparativas dos achados, sobretudo do ponto de vista psicodinâmico, ampliando o campo de conhecimento sobre o instrumento.

Nos estudos realizados com o Teste das Fábulas, pesquisadores e profissionais de Psicologia tem retratado a facilidade de utilização e a boa aceitação da proposta em diferentes grupos de indivíduos, destacando a riqueza clínica de suas informações, de natureza psicodinâmica. Apesar destas qualidades, ainda são poucas as investigações científicas desenvolvidas na atualidade com esse método projetivo no Brasil, limitando sua aplicação na prática profissional, visto seu parecer desfavorável junto ao SATEPSI (CFP, 2011). Torna-se ainda necessário atualizar os referenciais normativos do Teste das Fábulas para o Brasil, o que não foi concretizado na presente pesquisa.

Depreende-se, então, que o presente estudo conseguiu atingir com plenitude seus objetivos iniciais. No entanto, há que se procurar estimular, nesse momento, novas possibilidades de investigação com o Teste das Fábulas, a fim de garantir seu contínuo aprimoramento técnico-científico, bem como dos processos de avaliação psicológica desenvolvidos na realidade nacional. 
$110 \mid$ Re f e rências

\section{REFERÊNCIAS}

(de acordo com APA - American PsychologicalAssociation).

Achenbach T. M. (2001). Manual for the ChildBehavior Checklist/6-18 and 2001 profile.Burlington: University of Vermont.

Alves, I. (2004) Técnicas projetivas: questões atuais na psicologia. In: Vaz, C.E. \&Graef, R.L. (Org.) Técnicas Projetivas - Produtividade em Pesquisa. Porto Alegre: Casa do Psicólogo.

Anastasi, A. \& Urbina, S. (2000).Testagem psicológica. Porto Alegre: Artes. Médicas.

Angelini, A.L., Alves, I.C.B.; Custódio, E.M.; Duarte, W.F. \& Duarte, J.L.M. (1999). Matrizes Progressivas Coloridas de Raven: Escala Especial. Manual. São Paulo: CETEPP.

Anton, M. C. \& Piccinini, C. A. (2011) O desenvolvimento emocional de crianças submetidas a transplante hepático. Estudos de Psicologia: Natal, 16 (1): 39-47, janabr.

Anzieu, D. (1986). Os métodos projetivos. (M. L. E. Silva, trad.). (5a ed.). Rio de Janeiro: Campus.

Bandeira, D.; Alves, I.; Giacomel, A. \&Lorenzatto, L.(2004). Matrizes progressivas coloridas de Raven - escala especial: normas para Porto Alegre, Psicologia em Estudo, 9 (3), p.479-486 .

Bee, Helen. (2003) A Criança em desenvolvimento. 9a ed. Porto Alegre: Artmed, 2003.

Berrios, G. (2008). Classificações em psiquiatria: uma história conceitual. Revista de Psiquiatria Clínica,35 (3), 113-127.

Bettelheim, B. (2002). A psicanálise dos contos de fadas. (Tradução A. Caetano) Rio de Janeiro: Paz e Terra, $16^{\text {a }}$. edição.

Borges, V. (2011). Teste dos Contos de Fadas: estudos de evidências de validade. Tese de Doutorado, Faculdade de Psicologia da Pontifícia Universidade Católica do Rio Grande do Sul, Porto Alegre (RS). 
Borsa, J \& Nunes, M. L. (2008) Concordância parental para crianças com problemas de comportamento através do CBCL. Ribeirão Preto: Paidéia, 18(40), 317-330. http://www.scielo.br/pdf/paideia/v18n40/09.pdf

Bowlby, John. Cuidados maternos e saúde mental. SP, Martins Fontes, 2006

Conselho Federal de Psicologia (2003). Resolução CFP $n^{\circ}$ 002/2003, de 24 de Março de 2003. Define e regulamenta o uso, a elaboração e a comercialização de testes psicológicos e revoga a Resolução CFP $n^{\circ}$ 025/2001. Jornal do Conselho Federal de Psicologia. Brasília,18 (75).

Conselho Federal de Psicologia (2011). SATEPSI. Recuperado em: 31/05/2011 de: http://www2.pol.org.br/satepsi/sistema/paginas/lista_desfavoraveis.cfm

Conti, F. D \& Souza, A. S. L. (2010) O momento de brincar no ato de contar histórias: uma modalidade diagnóstica.Psicologia: Ciência e Profissão, Brasília, v. 30, n. 1, mar. Recuperado em 14/ 04/ 2011 de: http://pepsic.bvsalud.org/scielo.php?script=sci_arttext\&pid=S14149893201000010 $\underline{0008 \& \operatorname{lng}=\mathrm{pt} \& \mathrm{nrm}=\mathrm{iso}}$

Couto, M. C. V; Duarte, C. S \& Delgado, P. G. G. (2008) A saúde mental infantil na Saúde Pública brasileira: situação atual e desafios. Revista. Brasileira. Psiquiatria: São Paulo, v. 30, n. 4, Dec. Recuperado em 05/01/13 de: http://dx.doi.org/10.1590/S1516-44462008000400015.

Cunha, J.; Oliveira, M.; \&Heineck, C. (1989 a). Teste das Fábulas: forma verbal e pictórica. Porto Alegre: IV Encontro sobre Testes Psicológicos.

Cunha, J.; Werlang, B.; Oliveira, M.; Nunes, M.; Heineck, C \& Silveira, H. (1989b). Respostas populares ao Teste das Fábulas. Porto Alegre, Psico, 19 (2), 28-42.

Cunha, J.; Oliveira, M.; Werlang, B.; Nunes, M.; Porto Alegre, A.; Heineck, C\& Silveira, H. (1989c). Modelo das Fábulas - uma versão pictórica. Buenos Aires: XXII Congresso Interamericano de Psicologia; Psic, 1 (1), 51-59.

Cunha, J. \& Nunes, M. (1993). Teste das Fábulas: forma verbal e pictórica. São Paulo: Centro Editor de Testes e Pesquisas em Psicologia.

Cunha, J., Argimon, I., Santos, M., \& Escobar, T. (1996). Considerações sobre os resultados da administração coletiva do Teste das Fábulas em adolescentes (pp. 
$112 \mid$ Re f e rências

45-50). In Anais, 2. Encontro da ASBRo, 1996, Ribeirão Preto, SP. Ribeirão Preto, SP: Sociedade Brasileira de Rorschach e Outras Técnicas Projetivas.

Cunha, J. (2000) Psicodiagnóstico - V. (5 ed.) Porto Alegre: Artes Médicas.

Duss, L. (1940). La méthode des fables en psychanalyse. Archives de Psychologie, 28, 1-51. recuperado em 31/05/11 de:http://psycnet.apa.org/?\&fa=main.doiLanding\&uid=1941-01715-001

Hutz, C. S. (org..) (2009). Avanços e polêmicas em avaliação psicológica. São Paulo: Casa do Psicólogo, p. 157, 318.

Feijó, M. (1997) Medos em pré-escolares em situação pré-cirurgica. Aletheia (5), 18-28, jan-julho.

Fensterseifer, L.\& Werlang, B. (2008). Apontamentos sobre o status científico das técnicas projetivas. In: Villemor-Amaral, A. \& Werlang, B. (Eds.). Atualizações em métodos projetivos para avaliação psicológica. (pp. 15-33) São Paulo: Casa do Psicólogo.

Fleitlich, B., Cortazar, P. G. \& Goodman, R. (2000). Questionário de Capacidades e Dificuldades (SDQ). Revista Infanto (de Neuropsiquiatria da Infância e da Adolescência), 8, 44-50.

Fonseca, R.; Silva, P. \& Silva, R. (2007). Acordo inter-juízes: O caso do coeficiente kappa. Instituto Superior de Psicologia Aplicada, Portugal. Laboratório de Psicologia, 5(1): 81-90.

Goodman, R. (1997). The Strengths and Difficulties Questionnaire: a research note. Journal of Child Psychology and Psychiatry, 38 (5), 581-586.

Koppitz, E. M. (1976). El debrejo de la figurahumana in los niños: evoluciónpsicológica. (M. J. Garcia e M. R. Braile, Trad.). 4 ${ }^{\mathrm{TM}}$ ed. Buenos Aires, Argentina: Editorial Guadalupe.

Lima, L. F \& Ribeiro, R. K. S. M. (2012). O Teste das Fábulas em crianças vítimas de violência doméstica. In Anais da $42^{a}$ Reunião Anual da Sociedade Brasileira de Psicologia e VIII Congresso Iberoamericano de Psicologia: São Paulo. (CD ROM) 
Loureiro, S. A validade e o enfoque clínico- a avaliação psicodiagnóstica em um serviço de psiquiatria. In: VAZ, C.E., GRAEFF, R.L. (org.) Técnicas Projetivas Produtividade em Pesquisa. Porto Alegre: Casa do Psicólogo, 2004.

Loosli, L \& Loureiro, S. (2012) Técnicas Projetivas e Avaliação Psicológica de Crianças Atendidas no Contexto Clínico Psiquiátrico. In: Anais do VI Congresso da Associação Brasileira de Rorschach e Métodos Projetivos, p.102-103.

Loureiro, S. (2004). A validade e o enfoque clínico- a avaliação psicodiagnóstica em um serviço de psiquiatria. In: Vaz, C.E., Graeff, R.L. (org.) Técnicas Projetivas Produtividade em Pesquisa. (pp. 431-433) Porto Alegre: Casa do Psicólogo.

Luque, D. (1998). Fábulas de L. Düss. Unestudio de psicología educativa. Psicología Educativa, 4 (1), 63-79.

Marôco, J. (2007). Análise Estatística - Com Utilização do SPSS. $3^{a}$ ed. Lisboa: Edições Sílabo, Lda.

Nunes, M., Cunha, J., \& Oliveira, M. (1990). O valor clínico do escore de concordância social no Teste das Fábulas. Psico, 20(2), 77-84.

Nunes, C. H. S. S. \&Primi, R. (2010). Aspectos técnicos e conceituais da ficha de avaliação dos testes psicológicos. In: Conselho Federal de Psicologia (Org.) Avaliação Psicológica: diretrizes na regulamentação da profissão (pp. 101-128). Brasília: CFP.

Oliveira, D. S. \& Lopes, R. C. S. (2008). Mãe quero ficar contigo...: comportamentos de dependência do primogênito no contexto da gestação de um irmão. Psicologia: Reflexão e Crítica, 21 (2), 212-220.

Prieto, D., Avanci, S., \& Loureiro, S. (1998). Fábulas de Düss e o nível de maturidade afetiva: Avaliação de crianças com dificuldades escolares (pp. 154-157). In Anais, 3. Encontro da ASBRo, 1998, Ribeirão Preto, SP. Ribeirão Preto, SP: Sociedade Brasileira de Rorschach e Outras Técnicas Projetivas.

Prieto, D., \& Loureiro, S. (1998). Estudo de caso. Características borderlines na infância, manifestações através do Rorschach e das Fábulas de Düss (pp. 150153). In Anais, 3. Encontro da SBRo, 1998, Ribeirão Preto, SP. Ribeirão Preto, SP: Sociedade Brasileira de Rorschach e Outras Técnicas Projetivas. 
$114 \mid$ Re f e rências

Peixotto, H. (1956) Reliability of the Despert fables, a story completion test for children. Journal of Clinical Psychology, 12, 75-78.

Peixotto, H. (1957) Popular responses for the Despert fables. Journal of Clinical Psychology, 13, 73-79.

Peixotto, H. E. (1960). Use of Despert fables with disturbed children. Journal of Clinical Psychology, 16, 173-179.

Primi, R., Muniz, M. \&Nunes. C. H. S. S. (2009). Definições contemporâneas de validade de testes psicológicos. In: C. S. Hutz (Org.). Avanços e polêmicas em avaliação psicológica (pp. 243-265). São Paulo: Casa do Psicólogo.

Ramires, V. R. R. \& Godinho, L. R. (2011). Psicoterapia baseada na mentalização de crianças que sofreram maus-tratos. Psicol.estud:Maringá, v. 16, n. 1, Mar. Recuperado em 31/12/12 de: http://www.scielo.br/scielo.php?script=sci_arttext\&pid=S141373722011000100008 \&lng=en\&nrm=iso

Ramires, V. R. R. \& Damiani, F. M (2012). O Teste das Fábulas na avaliação do funcionamento de crianças envolvidas no fenômeno da alienação parental. In Anais da $42^{a}$ Reunião Anual da Sociedade Brasileira de Psicologia e VIII Congresso Iberoamericano de Psicologia: São Paulo. (CD ROM)

Raven, J. C., Raven, J., \& Court, J. H. (1987). Matrizes Progressivas Coloridas. Série A, Ab, B. Escala especial. Padronização brasileira: Angelini, A. L., Alves, I. C. B., Custódio, E. M., \& Duarte, W. F. (1999) São Paulo: Casa do Psicólogo.

Ribeiro, P. R. M. (2006) História da saúde mental infantil: a criança brasileira da Colônia à República Velha. Psicol. estud., Maringá, v. 11, n. 1, Apr. Recuperado em 05/01/13 de: http://dx.doi.org/10.1590/S1413-73722006000100004.

Rodrigues,C. \& Loureiro, S. (2012) Indicadores de Saúde Mental Infantil de Acordo com o relato dos pais e das crianças. In Anais da $42^{a}$ Reunião Anual da Sociedade Brasileira de Psicologia e VIII Congresso Iberoamericano de Psicologia: São Paulo. (CD ROM)

Santos, A. S. P. (2011). Avaliação de fidedignidade entre os juízes para os temas do CAT-A. Tese de Mestrado, Faculdade de Psicologia da Pontifícia Universidade Católica do Rio Grande do Sul, Porto Alegre. 
Santos, J \& Damiani, P. (2004) Respuestas características em eltest de las fábulas de Duss y su poder para discriminar entre niñoscon y sin problemas emocionales. Psic; 5(1):22-33.

Santos, E. O. L., \& Silvares, E. F. M. (2006). Crianças enuréticas e crianças encaminhadas para clínicas-escola: Um estudo comparativo da percepção de seus pais, Psicologia: Reflexão e Crítica, 19,277-282.

Saur, A.; Correia, S.; Pasian, S. \& Loureiro, S.(2009) Questionário de Capacidades e Dificuldades (SQD): revisão de estudos de validade e fidedignidade. In: IV Congresso Brasileiro de Avaliação Psicológica; XIV Conferência Internacional de Avaliação Psicológica; V Congresso Brasileiro de Rorschach e métodos projetivos, Campinas. Avaliação psicológica: formação, atuação e interface, 1. (pp. 463).

Saur, Adriana Martins \& Loureiro, Sonia Regina. (2012) Qualidades psicométricas do Questionário de Capacidades e Dificuldades (SDQ): revisão da literatura. Estudos de Psicologia (PUCCAMP. Impresso), v. 29, p. 619-629.

Serafini, A. (2004). Teste das Fábulas: um estudo com crianças abrigadas. Tese de Mestrado, Faculdade de Psicologia da Pontifícia Universidade Católica do Rio Grande do Sul, Porto Alegre.

Tardivo, L. (1992). Teste de Apercepção Infantil com figuras de animais (CAT-A) e Teste das Fábulas de Düss: estudos normativos e aplicações no contexto das técnicas projetivas. Tese de Doutorado, Curso de Pós-Graduação em Psicologia Clínica, Universidade de São Paulo. São Paulo, SP.

Tardivo, L. (1998). O Teste de Apercepção Temática e o Teste das Fábulas de Düss: Aplicações no campo das técnicas projetivas. São Paulo: Vetor.

Tardivo, L. (2005). Avaliação psicológica de crianças vítimas de violência por meio do Teste das Fábulas de Duss. Psic; 6(1):59-66.

Tavares, M. Validação dos métodos projetivos: Propósitos e contextos.(2012) In: Anais do VI Congresso da Associação Brasileira de Rorschach e Métodos Projetivos,p.64.

Urbina, S. (2007). Fundamentos da Testagem Psicológica. Porto Alegre: Artmed. 
$116 \mid$ Re f e rênci as

Villemor- Amaral, Anna Elisa.(2012) As Teorias Psicológicas e a Validação dos Instrumentos de Avaliação. In: Anais do VI Congresso da Associação Brasileira de Rorschach e Métodos Projetivos,64-65.

Vostanis, P. (2006). Strenghts and Difficulties Questionnaire: research and clinical aplications. CurrentOpinionPsychiatric, 19 (4), 367-372.

Werlang, B., Villemor-Amaral, A. \& Nascimento, R. (2010). Avaliação psicológica, testes e possibilidades de uso. In: Conselho Federal de Psicologia/CFP (Org.) Avaliação Psicológica: diretrizes na regulamentação da profissão. (pp. 87-99) Brasília: CFP. 
Referências | 117 
118 Anexos e Apêndices

\section{ANEXOS E APÊNDICES}

ANEXO 1 - Aprovação do projeto pelo Comitê de Ética em Pesquisa com Seres Humanos da FFCLRP/USP.

\section{Universidade de São Paulo \\ Faculdade de Filosofia, Ciências e Letras de Ribeirão Preto}

"Campus" de Ribeirão Preto.

Of.CEtP/FFCLRP-USP/125/-jsI

Ribeirão Preto, 27 de setembro de 2011

Prezado Pesquisador,

Comunicamos a V. Sa. que o trabalho intitulado "EVIDÊNCIAS DE VALIDADE DO TESTE DAS FÁBULAS EM ESCOLARES" foi analisado pelo Comitê de Ética em Pesquisa da FFCLRP-USP, em sua $100^{\text {a }}$ Reunião, realizada em 22.09.11, e enquadrado na categoria: APROVADO, de acordo com o Processo CEP-FFCLRP $n^{\circ}$ 598/2011 - 2011.1.2198.59.5.

Atenciosamente,

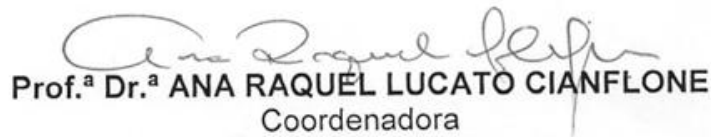

À Senhora

Marcelle Louise Coelho de Freitas

Mestranda do Programa de Pós-Graduação em Psicologia da FFCLRP - USP

Com cópia para a orientadora:

Prof. ${ }^{\text {a Dr. }}{ }^{\text {a Sonia Regina Pasian }}$

Docente do Departamento de Psicologia da FFCLRP - USP

CEP - Comité de Ética em Pesquisa da FFCLRP

Fone: (16) 3602-4681

Fax: (16) 3633-2660 (direto) ou 3633-5015

Avenida Bandeirantes, 3900 - bloco 1 - 14040-901 - Ribeirâo Preto - SP - Brasil

Homepage: http://www.ffclrp.usp.br - e-mail: coetp@ffclrp.usp.br 
ANEXO 2 - Autorização da Profa. Dra. Sonia Regina Loureiro para uso do Banco de Dados do Serviço de Psicodiagnóstico do Hospital das Clínicas da FMRP-USP

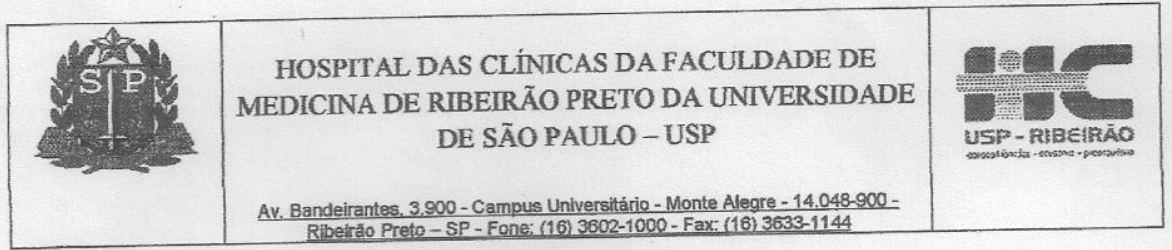

\section{Declaração de Intencão de Colaboração}

Declaro para os devidos fins a intenção de colaboração com o projeto de pesquisa "Evidências de validade do Teste das Fábulas em escolares" por meio da disponibilização do acervo dos protocolos oriundos de avaliação psicodiagnóstica de usuários do Serviço de Psiquiatria Infantil do Hospital das Clínicas da Faculdade de Medicina de Ribeirão Preto - USP, de modo a compor parte do banco de dados do referido projeto de pesquisa em Psicologia, a ser desenvolvido pela candidata a Pós Graduação Marcelle de Freitas, psicóloga e ex- aprimoranda do Serviço, sob a e orientação da Prof $f^{a}$. Dr ${ }^{2}$.Sônia Regina Pasian, docente da Faculdade de Filosofia, Ciências e Letras de Ribeirão Preto.

$$
\text { Ribeirão Preto, 2e de maio de } 2011 .
$$

Ahboureino

Profa. Dra. Sốnia Regina Loureiro

Coordenadora do Programa de Aprimoramento

Profissional - Psicologia em Saúde Mental do Hospital das Clínicas da Faculdade de Medicina de Ribeirão Preto - USP. 


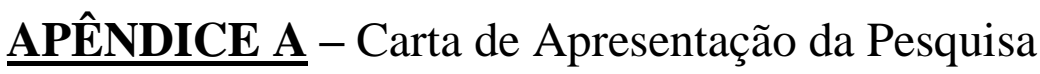

\author{
TSP \\ Universidade de São Paulo \\ Faculdade de Filosofia, Ciência e Letras de Ribeirão Preto \\ Departamento de Psicologia \\ Centro de Pesquisas em Psicodiagnóstico (CPP)
}

\section{CARTA DE APRESENTAÇ̃̃O}

Estamos desenvolvendo uma pesquisa em Ribeirão Preto (SP) com objetivo de conhecer características de personalidade de estudantes de seis a doze anos, por meio de um processo de avaliação psicológica. Este trabalho será desenvolvido sob responsabilidade da psicóloga Marcelle Louise Coelho de Freitas, aluna de Mestrado em Psicologia na Faculdade de Filosofia, Ciências e Letras de Ribeirão Preto (FFCLRP) da Universidade de São Paulo (USP), e da Profa. Dra. Sonia Regina Pasian, professora do Departamento de Psicologia desta mesma faculdade.

Essa pesquisa estudará cerca de 60 crianças de escolas públicas desta cidade. Esta escola foi identificada como uma possível participante e, sendo assim, gostaríamos de contar com sua colaboração, autorizando nossa inserção no estabelecimento educacional sob sua responsabilidade.

Nossa atuação na escola dar-se-á da seguinte forma: a pesquisadora visitará as salas dos alunos na escola, explicará o projeto em linhas gerais e fornecerá, para cada aluno, o Termo de Consentimento Livre e Esclarecido e um Questionário sobre capacidades e dificuldades da criança, que contém algumas questões sobre o desenvolvimento do estudante. Esses documentos deverão ser entregues aos pais ou responsáveis dos possíveis participantes e, posteriormente, devolvidos à pesquisadora.

Em seguida, a pesquisadora agendará, sob anuência da coordenação da escola, um horário em que o estudante possa se ausentar de suas aulas para participar da avaliação psicológica. Nesse contato, que durará cerca de uma hora, a pesquisadora explicará a pesquisa novamente ao participante e aplicará uma prova de raciocínio e uma atividade de elaboração de histórias, com objetivo de avaliação de características de personalidade, não apresentando riscos ou prejuízos significativos ao participante. Todas as informações são confidenciais e somente serão utilizadas para investigação científica, sem nenhuma identificação das pessoas que as forneceram.

A cooperação de seu estabelecimento será muito valiosa e imprescindível para que os objetivos desse estudo sejam alcançados. Este trabalho será uma contribuição voluntária e nenhum participante receberá pagamento por colaborar nesta pesquisa.

Colaborar com essa pesquisa representa contribuir para um melhor conhecimento das condições psicológicas dos estudantes dessa região e isso poderá auxiliar em planejamentos de eventuais serviços de Saúde Mental.

Desde já, agradecemos a atenção dispensada.

Atenciosamente,

\section{MARCELLE LOUISE COELHO DE FREITAS PROFA. DRA. SONIA REGINA}

\section{PASIAN}

\author{
Departamento de Psicologia - FFCLRP - USP \\ Av. Bandeirantes, 3900 - Monte Alegre \\ Fone: (16) 3602-3785 \\ Fax: (16) 3602-4835 \\ E-mail: srpasian@ffclrp.usp.br
}




\title{
$\underline{\text { APÊNDICE B }-T e r m o ~ d e ~ C o n s e n t i m e n t o ~ L i v r e ~ E s c l a r e c i d o ~}$
}

\author{
एك \\ Universidade de São Paulo \\ Faculdade de Filosofia, Ciência e Letras de Ribeirão Preto \\ Departamento de Psicologia \\ Centro de Pesquisas em Psicodiagnóstico (CPP)
}

\section{TERMO DE CONSENTIMENTO LIVRE E ESCLARECIDO}

Estamos desenvolvendo uma pesquisa em Ribeirão Preto (SP) que pretende conhecer características do desenvolvimento emocional de estudantes de seis a doze anos idade. Este trabalho será desenvolvido sob responsabilidade da psicóloga Marcelle Louise Coelho de Freitas, aluna de Mestrado em Psicologia da Faculdade de Filosofia, Ciências e Letras de Ribeirão Preto (FFCLRP) da Universidade de São Paulo (USP) e da Profa. Dra. Sonia Regina Pasian, professora do Departamento de Psicologia desta mesma Faculdade.

Essa pesquisa estudará cerca de 60 estudantes de escolas públicas de Ribeirão Preto e ou região. Esta escola em que seu (sua) filho(a) estuda irá colaborar conosco nesta pesquisa. Desta forma, gostaríamos de contar com sua colaboração, autorizando a participação dele(a) na mesma. Cada estudante selecionado passará por uma breve avaliação psicológica, sendo que este processo implica em que o participante responda uma prova de raciocínio e uma atividade de elaboração de histórias, não apresentando riscos ou prejuízos para ele. Aos pais será solicitado que preencham um questionário sobre capacidades e dificuldades de seu (sua) filho (a), caso autorizem sua participação nesta pesquisa.

Todas as informações desta pesquisa são confidenciais e somente serão utilizadas para investigação científica, sem nenhuma identificação das pessoas que as forneceram. A sua cooperação e a de seu (sua) filho (a) será muito valiosa e necessária para tornar possível esta pesquisa. Não será oferecido aos participantes desta pesquisa nenhum pagamento por sua colaboração neste trabalho. Colaborar com essa pesquisa poderá ajudar a conhecer as características afetivas dos estudantes de Ribeirão Preto e isso poderá auxiliar em planejamentos futuros para serviços de Psicologia nesta região.

Desde já, agradecemos sua colaboração e estaremos disponíveis para outras informações, caso necessário.

Atenciosamente,

Marcelle Louise Coelho de Freitas (CRP: 06/86029)
Profa. Dra. Sonia Regina Pasian

(CRP: 06/24018-0)

declaro que estou de acordo com a participação de meu (minha) filho (a)

voluntário no projeto de pesquisa "TESTE DAS FABULAS: UM ESTUDO DE EVIDÊNCIA DE VALIDADE.", sob responsabilidade da psicóloga Marcelle Louise Coelho de Freitas e da Profa. Dra. Sonia Regina Pasian, assim como estou ciente de que os registros relativos a esse trabalho serão utilizados como material de trabalho científico e poderão ser divulgados em congressos e publicados em revistas ou livros especializados, resguardando-se o devido sigilo quanto à nossa identificação.

Ribeirão Preto, de de 20 
APÊNDICE C-Tabelas descritivas dos resultados no Teste das Fábulas a partir do sistema de classificação original (Cunha \& Nunes, 1993), seguidos pela descrição dos itens que foram agrupados na presente revisão das categorias e itens avaliativos.

\section{FÁBULA 1}

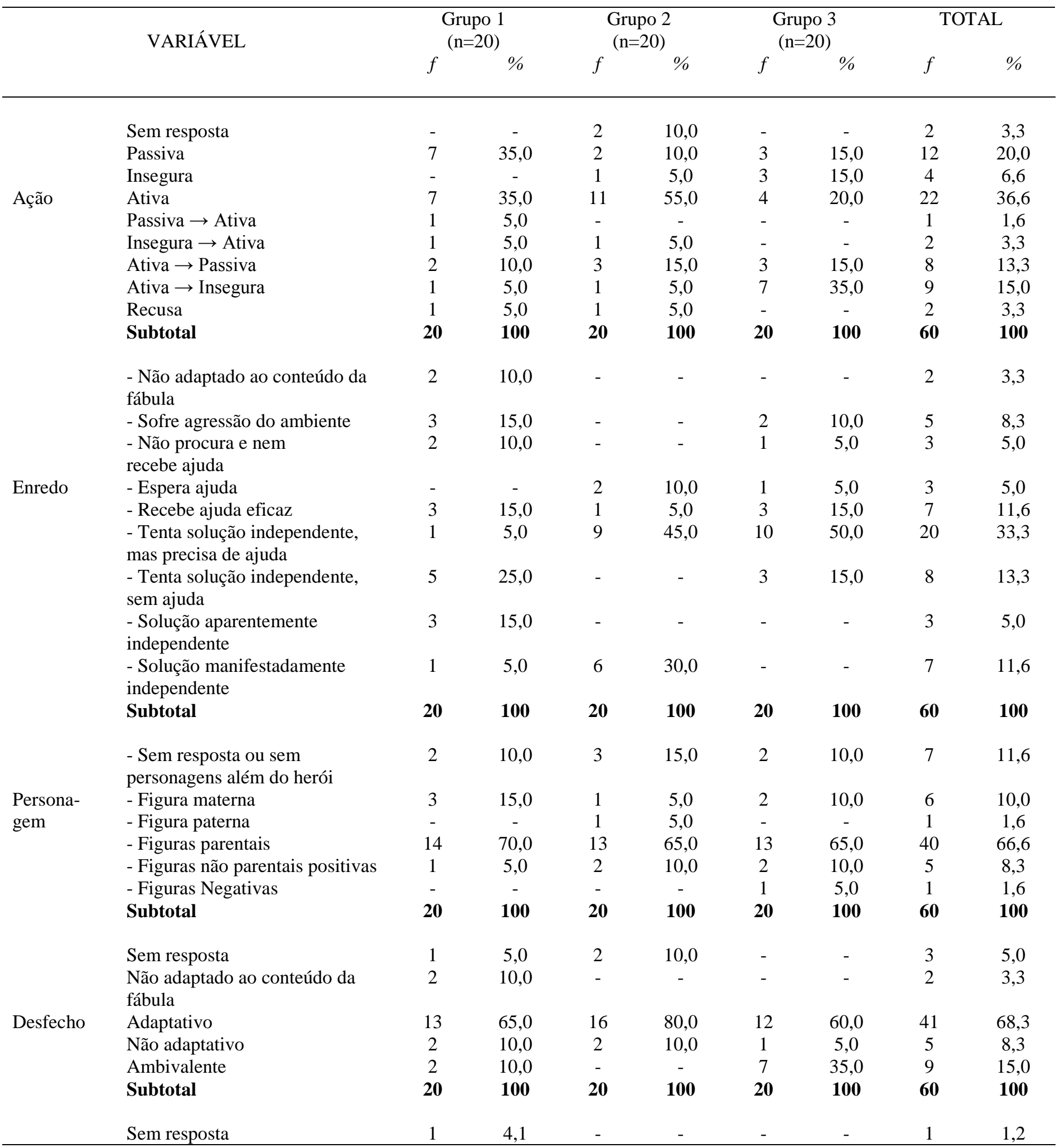




\begin{tabular}{|c|c|c|c|c|c|c|c|c|c|}
\hline & Abandono & 6 & 25,0 & 9 & 31,0 & 5 & 18,5 & 20 & 25,0 \\
\hline & Rejeição & 1 & 4,1 & 3 & 10,3 & 1 & 3,7 & 5 & 6,2 \\
\hline & $\begin{array}{l}\text { Agressão deslocada } \\
\text { para ambiente }\end{array}$ & 4 & 16,6 & 3 & 10,3 & 2 & 7,4 & 9 & 11,2 \\
\hline & Autoagressão & 1 & 4,1 & - & - & 2 & 7,4 & 3 & 3,7 \\
\hline & Volta ao útero & 1 & 4,1 & - & - & - & - & 1 & 1,2 \\
\hline \multirow[t]{15}{*}{ Fantasias } & Onipotência & 6 & 25,0 & 7 & 24,1 & 5 & 18,5 & 18 & 22,5 \\
\hline & Edípica & - & - & - & - & 1 & 3,7 & 1 & 1,2 \\
\hline & Reparação & - & - & 3 & 10,3 & 5 & 18,5 & 8 & 10,0 \\
\hline & Narcisista & - & - & 1 & 3,4 & - & - & 1 & 1,2 \\
\hline & Ganho Secundário & - & - & 1 & 3,4 & - & - & 1 & 1,2 \\
\hline & Impotência & 2 & 8,3 & 1 & 3,4 & 5 & 18,5 & 8 & 10,0 \\
\hline & Aniquilamento* & - & 0 & 1 & 3,4 & 1 & 3,7 & 2 & 2,5 \\
\hline & Perda (separação)* & 2 & 8,3 & - & - & - & - & 2 & 2,5 \\
\hline & Subtotal & 24 & 100 & 29 & 100 & 27 & 100 & 80 & 100 \\
\hline & Tristeza & 9 & 36,0 & 8 & 28,5 & 4 & 15,3 & 21 & 26,5 \\
\hline & Medo & 6 & 24,0 & - & - & 2 & 7,6 & 8 & 10,1 \\
\hline & Ansiedade & - & - & 1 & 3,5 & - & - & 1 & 1,2 \\
\hline & Onipotência & 3 & 12,0 & 4 & 14,2 & 5 & 19,2 & 12 & 15,1 \\
\hline & Alegria & 3 & 12,0 & 8 & 28,5 & 3 & 11,5 & 14 & 17,7 \\
\hline & Pesar & - & - & - & - & 4 & 15,3 & 4 & 5,0 \\
\hline Estado & Impotência & 1 & 4,0 & 2 & 7,1 & 3 & 11,5 & 6 & 7,5 \\
\hline \multirow[t]{13}{*}{ Emocional } & Ambivalência & - & - & 1 & 3,5 & 2 & 7,6 & 3 & 3,7 \\
\hline & Vulnerabilidade* & 1 & 4,0 & - & - & - & - & 1 & 1,2 \\
\hline & Gratidão* & - & - & - & - & 1 & 3,8 & 1 & 1,2 \\
\hline & Alívio* & - & - & - & - & 1 & 3,8 & 1 & 1,2 \\
\hline & Amparo* & - & - & 1 & 3,5 & - & - & 1 & 1,2 \\
\hline & Solidão* & 2 & 8,0 & 3 & 10,7 & 1 & 3,8 & 6 & 7,5 \\
\hline & Subtotal & 25 & 100 & 28 & 100 & 26 & 100 & 79 & 100 \\
\hline & Sem resposta & 2 & 6,8 & - & - & - & - & 2 & 2,4 \\
\hline & Projeção & 1 & 3,4 & 1 & 4,3 & 4 & 13,3 & 6 & 7,3 \\
\hline & Negação & 7 & 24,1 & 1 & 4,3 & 7 & 23,3 & 15 & 18,2 \\
\hline & Distorção & 2 & 6,8 & 1 & 4,3 & - & - & 3 & 3,6 \\
\hline & Bloqueio & - & - & 1 & 4,3 & - & - & 1 & 1,2 \\
\hline & Introjeção & - & - & - & - & 2 & 6,6 & 2 & 2,4 \\
\hline \multirow[t]{10}{*}{ Defesas } & Regressão & 3 & 10,3 & 2 & 8,6 & 2 & 6,6 & 7 & 8,5 \\
\hline & Somatização & 1 & 3,4 & - & - & 1 & 3,3 & 2 & 2,4 \\
\hline & Deslocamento & 1 & 3,4 & 1 & 4,3 & - & - & 2 & 2,4 \\
\hline & Racionalização & 4 & 13,7 & - & - & 3 & 10,0 & 7 & 8,5 \\
\hline & Formação Reativa & - & - & 1 & 4,3 & 2 & 6,6 & 3 & 3,6 \\
\hline & Repressão & 6 & 20,6 & 13 & 56,5 & 9 & 30,0 & 28 & 34,1 \\
\hline & Idealização* & - & - & 2 & 8,6 & - & - & 2 & 2,4 \\
\hline & Dissociação* & 1 & 3,4 & - & - & - & - & 1 & 1,2 \\
\hline & Concretude* & 1 & 3,4 & - & - & - & - & 1 & 1,2 \\
\hline & Subtotal & 29 & 100 & 23 & 100 & 30 & 100 & 82 & 100 \\
\hline
\end{tabular}

*Categoria avaliativa incluída por sugestão dos avaliadores dos casos.

Na categoria Ação junção dos itens:

- Sem Resposta + Recusa = RECUSA

- Passiva + Ativa-Passiva = PASSIVA

- Insegura + Ativa-Insegura = INSEGURA

- Ativa + Passiva-Ativa + Insegura-Ativa= ATIVA 
124|Anexos e Apêndices

Na categoria Enredo junção dos itens:

- Sofre agressão do ambiente + Recusa + Não adaptado ao conteúdo da fábula = NÃO ADAPTADO AO CONTEÚDO.

- Não procura nem recebe ajuda + Espera ajuda + Recebe ajuda eficaz = BUSCA AJUDA (Dependência)

- Tenta solução independente, mas precisa de ajuda + Solução Manifestadamente independente $=$ BUSCA AUTONOMIA (Independência)

Na categoria Personagens junção dos itens:

- Sem resposta + Sem personagens além do herói = HERÓI.

- Figura Paterna + Figura Materna = FIGURAS PARENTAIS.

- Figuras Negativas + Figuras não parentais positivas = FIGURAS NÃO PARENTAIS.

Na categoria Desfecho junção dos itens:

- Sem Resposta + Não adaptativo + Não adaptado ao conteúdo da fábula = NÃO ADAPTADO.

- Alteração do nome do item Adaptativo = ADAPTADO, de modo a padronizar em todas as fábulas em que há a categoria Desfecho.

Na categoria Fantasias junção dos itens:

- Volta ao útero + Edípica + Ganho Secundário + Narcisista + Onipotência (por proximidade de conteúdo) $=$ ONIPOTÊNCIA .

- $\quad$ Sem resposta + Rejeição+ Perda+ Abandono + Impotência = IMPOTÊNCIA.

- Agressão deslocada para o ambiente + Autoagressão + Aniquilamento = AGRESSÃO.

Na categoria Estado Emocional junção dos itens:

- Vulnerabilidade + solidão + impotência + pesar + tristeza = TRISTEZA

- Medo + Ambivalência + Ansiedade = ANSIEDADE

- Gratidão + Alívio + Amparo + Onipotência + Alegria = ALEGRIA

Na categoria Defesas junção dos itens:

- Sem resposta + Projeção + Negação + Distorção + Dissociação = COM BASE na NEGAÇÃO.

- Bloqueio + Introjeção + Regressão + Somatização + Deslocamento + Racionalização + Formação Reativa + Repressão + Idealização e Concretude = COM BASE na REPRESSÃO. 
FÁBULA 2

\begin{tabular}{|c|c|c|c|c|c|c|c|c|c|}
\hline & \multirow[t]{2}{*}{ VARIÁVEL } & \multicolumn{2}{|c|}{$\begin{array}{c}\text { Grupo 1 } \\
(\mathrm{n}=20)\end{array}$} & \multicolumn{2}{|c|}{$\begin{array}{c}\text { Grupo } 2 \\
(\mathrm{n}=20)\end{array}$} & \multicolumn{2}{|c|}{$\begin{array}{c}\text { Grupo } 3 \\
(\mathrm{n}=20)\end{array}$} & \multicolumn{2}{|c|}{ TOTAL } \\
\hline & & $f$ & $\%$ & $f$ & $\%$ & $f$ & $\%$ & $f$ & $\%$ \\
\hline \multirow{8}{*}{ Ação } & Sem resposta & 2 & 10,0 & 6 & 30,0 & 2 & 10,0 & 10 & 16,6 \\
\hline & $\begin{array}{l}\text { Não adaptada ao } \\
\text { conteúdo da fábula }\end{array}$ & 1 & 5,0 & - & - & - & - & 1 & 1,6 \\
\hline & Passiva & 11 & 55,0 & 7 & 35,0 & 11 & 55,0 & 29 & 48,3 \\
\hline & Ativa & 6 & 30,0 & 5 & 25,0 & 7 & 35,0 & 18 & 30,0 \\
\hline & Projetada & - & - & 2 & 10,0 & - & - & 2 & 3,3 \\
\hline & Subtotal & 20 & 100 & 20 & 100 & 20 & 100 & 60 & 100 \\
\hline & - Sem resposta & 2 & 10,0 & - & - & - & - & 2 & 3,3 \\
\hline & $\begin{array}{l}\text { - Não adaptado ao } \\
\text { conteúdo da fábula }\end{array}$ & 2 & 10,0 & 1 & 5,0 & 4 & 20,0 & 7 & 11,6 \\
\hline \multirow[t]{12}{*}{ Motivo } & $\begin{array}{l}\text { - Sugestivo de } \\
\text { conflito edípico }\end{array}$ & 3 & 15,0 & 4 & 20,0 & 7 & 35,0 & 14 & 23,3 \\
\hline & $\begin{array}{l}\text { - Associado a } \\
\text { conflito edípico }\end{array}$ & 3 & 15,0 & 1 & 5,0 & - & - & 4 & 6,6 \\
\hline & -Associado à rejeição & 6 & 30,0 & 9 & 45,0 & 8 & 40,0 & 23 & 38,3 \\
\hline & $\begin{array}{l}\text { - Deslocado para } \\
\text { temas orais }\end{array}$ & 3 & 15,0 & - & - & - & - & 3 & 5 \\
\hline & - Outro & 1 & 5,0 & 5 & 25,0 & 1 & 5,0 & 7 & 11,6 \\
\hline & Subtotal & 20 & 100 & 20 & 100 & 20 & 100 & 60 & 100 \\
\hline & Sem resposta & 4 & 15,3 & 1 & 3,5 & - & - & 5 & 6,0 \\
\hline & Abandono & 4 & 15,3 & 6 & 21,4 & 3 & 10,3 & 13 & 15,6 \\
\hline & Rejeição & 8 & 30,7 & 10 & 35,7 & 7 & 24,1 & 25 & 30,1 \\
\hline & $\begin{array}{l}\text { Agressão deslocada } \\
\text { para ambiente }\end{array}$ & 1 & 3,8 & - & - & - & - & 1 & 1,2 \\
\hline & Onipotência & 3 & 11,5 & 2 & 7,1 & 2 & 6,8 & 7 & 8,4 \\
\hline & Edípica & 4 & 15,3 & 4 & 14,2 & 6 & 20,6 & 14 & 16,8 \\
\hline \multirow[t]{15}{*}{ Fantasia } & Reparação & 2 & 7,6 & - & - & 3 & 10,3 & 5 & 6,0 \\
\hline & Narcisista & - & - & - & - & 2 & 6,8 & 2 & 2,4 \\
\hline & Ganho secundário & - & - & 2 & 7,1 & - & - & 2 & 2,4 \\
\hline & Impotência & - & - & 1 & 3,5 & 4 & 13,7 & 5 & 6,0 \\
\hline & Castigo & - & - & 1 & 3,5 & - & - & 1 & 1,2 \\
\hline & Hipocondria* & - & - & - & - & 1 & 3,4 & 1 & 1,2 \\
\hline & Inadequação* & - & - & - & - & 1 & 3,4 & 1 & 1,2 \\
\hline & Persecutória* & - & - & 1 & 3,5 & - & - & 1 & 1,2 \\
\hline & Subtotal & 26 & 100 & 28 & 100 & 29 & 100 & 83 & 100 \\
\hline & Sem resposta & 1 & 3,2 & 1 & 3,3 & - & - & 2 & 2,2 \\
\hline & Tristeza & 10 & 32,2 & 3 & 10,0 & 12 & 44,4 & 25 & 28,4 \\
\hline & Medo & - & - & 1 & 3,3 & - & - & 1 & 1,1 \\
\hline & Raiva & 1 & 3,2 & - & - & - & - & 1 & 1,1 \\
\hline & Ansiedade & - & - & 1 & 3,3 & - & - & 1 & 1,1 \\
\hline & Onipotência & 1 & 3,2 & 1 & 3,3 & 4 & 14,8 & 6 & 6,8 \\
\hline Estado & Ciúme & 4 & 12,9 & 1 & 3,3 & 1 & 3,7 & 6 & 6,8 \\
\hline \multirow[t]{9}{*}{ Emocional } & Culpa & 1 & 3,2 & 2 & 6,6 & 1 & 3,7 & 4 & 4,5 \\
\hline & Impertinência & - & - & - & - & 1 & 3,7 & 1 & 1,1 \\
\hline & Alegria & 6 & 19,3 & 8 & 26,6 & 2 & 7,4 & 16 & 18,1 \\
\hline & Pesar & - & - & 2 & 6,6 & - & - & 2 & 2,2 \\
\hline & Impotência & - & - & 3 & 10,0 & 1 & 3,7 & 4 & 4,5 \\
\hline & Ambivalência & - & - & 2 & 6,6 & 2 & 7,4 & 4 & 4,5 \\
\hline & Inveja & 1 & 3,2 & - & - & - & - & 1 & 1,1 \\
\hline & Cansado* & 1 & 3,2 & - & - & - & - & 1 & 1,1 \\
\hline & Chateado* & 1 & 3,2 & - & - & 1 & 3,7 & 2 & 2,2 \\
\hline
\end{tabular}


126|Anexos e Apêndices

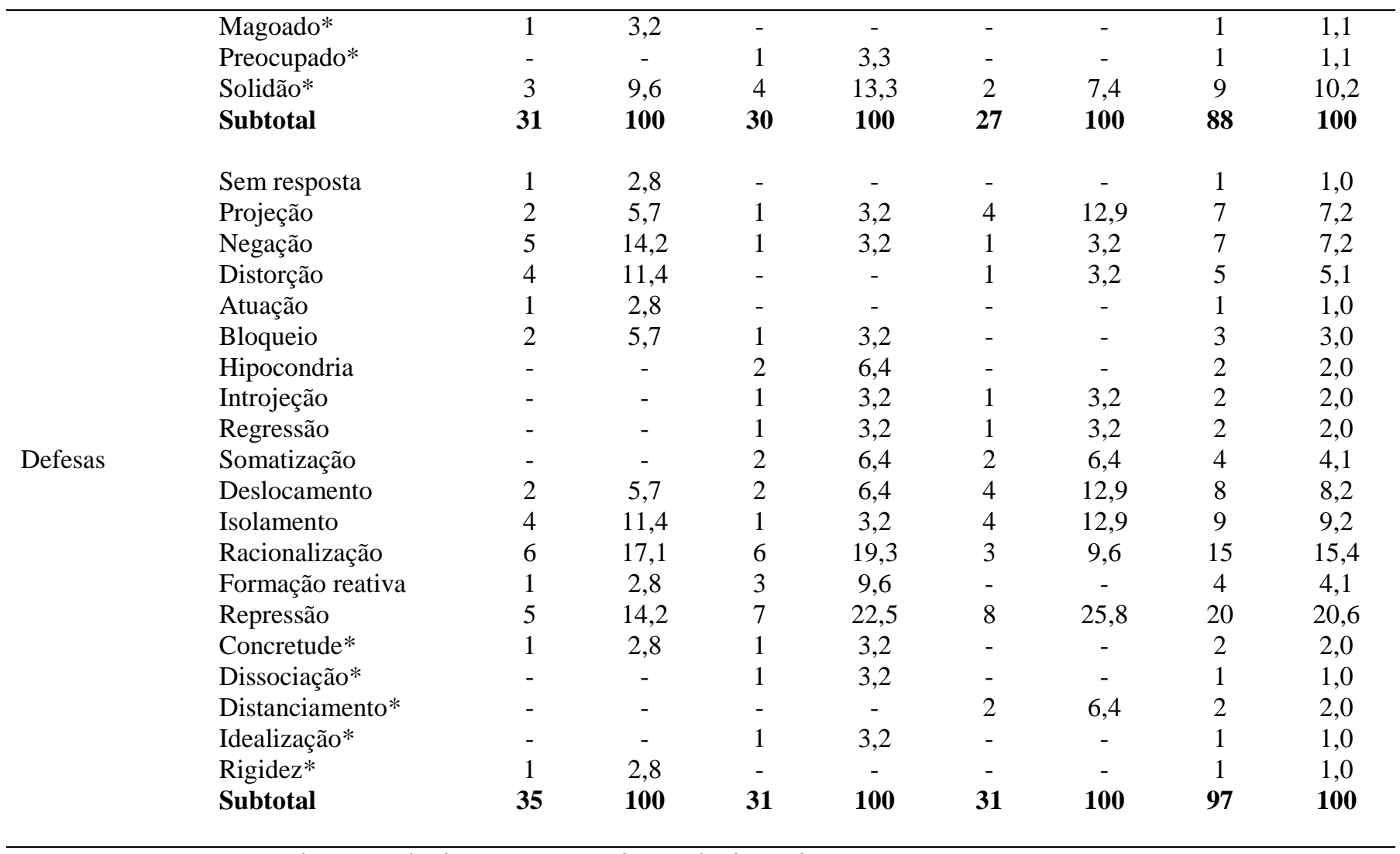

*Categoria avaliativa incluída por sugestão dos avaliadores dos casos.

Na categoria Ação junção dos itens:

- Sem resposta + Não adaptada ao conteúdo da fábula + Recusa $=$ NÃO ADAPTADA.

- Projetada + Passiva $=$ PASSIVA.

Na categoria Motivo junção dos itens:

- Sem resposta + Não adaptado ao conteúdo da fábula = NÃO ADAPTADO.

- Sugestivo de conflito edípico + Associado a conflito edípico = CONFLITO EDÍPICO.

- Associado à rejeição + Deslocado para temas orais + Outro = OUTROS TEMAS (não trata do conflito edípico, mas se relaciona com esta fábula).

Na categoria Fantasia junção dos itens:

- Sem resposta + Abandono + Rejeição + Hipocondria + Inadequação + Impotência = IMPOTÊNCIA.

- Castigo + Persecutória + Agressão = AGRESSÃO.

- Edípica + Narcisista + Ganho Secundário + Onipotência = ONIPOTÊNCIA.

Na categoria Estado Emocional junção dos itens:

- Sem Resposta + Impertinência + Pesar + Cansado + Chateado + Magoado Impotência + Tristeza $=$ TRISTEZA. 
- Medo + Ambivalência + Preocupado + Ansiedade = ANSIEDADE.

- $\quad$ Ciúme + Inveja + Raiva = RAIVA.

- Onipotência + Alegria = ALEGRIA.

Na categoria Defesas junção dos itens:

- Sem resposta + projeção + negação + distorção + atuação + dissociação = COM BASE na NEGAÇÃO.

- Bloqueio + Hipocondria + Introjeção + Regressão + Somatização + Deslocamento + Isolamento + Racionalização + Formação Reativa + Repressão + Concretude + Distanciamento + Idealização + Rigidez $=$ COM BASE na REPRESSÃO. 
128|Anexos e Apêndices

FÁBULA 3

\begin{tabular}{|c|c|c|c|c|c|c|c|c|c|}
\hline & \multirow[t]{2}{*}{ VARIÁVEL } & \multicolumn{2}{|c|}{$\begin{array}{c}\text { Grupo } 1 \\
(n=20)\end{array}$} & \multicolumn{2}{|c|}{$\begin{array}{c}\text { Grupo } 2 \\
(n=20)\end{array}$} & \multicolumn{2}{|c|}{$\begin{array}{c}\text { Grupo } 3 \\
(n=20)\end{array}$} & \multicolumn{2}{|c|}{ TOTAL } \\
\hline & & $f$ & $\%$ & $f$ & $\%$ & $f$ & $\%$ & $f$ & $\%$ \\
\hline \multirow{9}{*}{ Ação } & - Sem resposta & - & - & 1 & 5,0 & - & - & 1 & 1,6 \\
\hline & $\begin{array}{l}\text { - Não adaptada ao } \\
\text { conteúdo da fábula }\end{array}$ & 1 & 5,0 & - & - & 1 & 5,0 & 2 & 3,3 \\
\hline & - Passiva & 1 & 5,0 & - & - & 1 & 5,0 & 2 & 3,3 \\
\hline & - Ativa e adaptada & 6 & 30,0 & 10 & 50,0 & 5 & 25,0 & 21 & 35,0 \\
\hline & $\begin{array}{l}\text { - Ativa, mas não } \\
\text { adaptada }\end{array}$ & 5 & 25,0 & 2 & 10,0 & 5 & 25,0 & 12 & 20,0 \\
\hline & $\begin{array}{l}\text { - Com resistência } \\
\text { ativa }\end{array}$ & 4 & 20,0 & 2 & 10,0 & 2 & 10,0 & 8 & 13,3 \\
\hline & $\begin{array}{l}\text { - Com resistência } \\
\text { passiva }\end{array}$ & - & - & - & - & 1 & 5,0 & 1 & 1,6 \\
\hline & - Ambivalente & 3 & 15,0 & 5 & 25,0 & 5 & 25,0 & 13 & 21,6 \\
\hline & Subtotal & 20 & 100 & 20 & 100 & 20 & 100 & 60 & 100 \\
\hline \multirow{5}{*}{ Desfecho } & $\begin{array}{l}\text { - Não adaptado ao } \\
\text { conteúdo da fábula }\end{array}$ & 4 & 20,0 & 4 & 20,0 & 1 & 5,0 & 9 & 15,0 \\
\hline & - Adaptativo & 5 & 25,0 & 6 & 30,0 & 5 & 25,0 & 16 & 26,6 \\
\hline & - Não adaptativo & 6 & 30,0 & 6 & 30,0 & 6 & 30,0 & 18 & 30,0 \\
\hline & - Ambivalente & 5 & 25,0 & 4 & 20,0 & 8 & 40,0 & 17 & 28,3 \\
\hline & Subtotal & 20 & 100 & 20 & 100 & 20 & 100 & 60 & 100 \\
\hline \multirow{18}{*}{ Fantasias } & Sem resposta & 3 & 11,1 & 1 & 3,3 & - & - & 4 & 4,5 \\
\hline & Abandono & 3 & 11,1 & 2 & 6,6 & 5 & 16,6 & 10 & 11,4 \\
\hline & Rejeição & 5 & 18,5 & 3 & 10,0 & 6 & 20,0 & 14 & 16,0 \\
\hline & $\begin{array}{l}\text { Agressão deslocada } \\
\text { para ambiente }\end{array}$ & 2 & 7,4 & 1 & 3,3 & - & - & 3 & 3,4 \\
\hline & Autoagressão & 1 & 3,7 & - & - & 1 & 3,3 & 2 & 2,2 \\
\hline & Heteroagressão ativa & 1 & 3,7 & 3 & 10,0 & - & - & 4 & 4,5 \\
\hline & $\begin{array}{l}\text { Heteroagressão } \\
\text { passiva }\end{array}$ & - & - & 1 & 3,3 & - & - & 1 & 1,1 \\
\hline & Onipotência & 8 & 29,6 & 10 & 33,3 & 6 & 20,0 & 24 & 27,5 \\
\hline & Edípica & - & - & - & - & 2 & 6,6 & 2 & 2,2 \\
\hline & Privação & 3 & 11,1 & 5 & 16,6 & 6 & 20,0 & 14 & 16,0 \\
\hline & Reparação & - & - & - & - & 2 & 6,6 & 2 & 2,2 \\
\hline & Ganho secundário & 1 & 3,7 & 3 & 10,0 & - & - & 4 & 4,5 \\
\hline & Impotência & - & - & - & - & 2 & 6,6 & 2 & 2,2 \\
\hline & Amparo* & - & - & 1 & 3,3 & - & - & 1 & 1,1 \\
\hline & Subtotal & 27 & 100 & 30 & 100 & 30 & 100 & 87 & 100 \\
\hline & Sem resposta & 3 & 9,6 & 1 & 3,7 & - & - & 4 & 4,9 \\
\hline & Tristeza & 6 & 19,3 & 8 & 29,6 & 7 & 30,4 & 21 & 25,9 \\
\hline & Medo & - & - & - & - & 1 & 4,3 & 1 & 1,2 \\
\hline \multirow{12}{*}{$\begin{array}{l}\text { Estado } \\
\text { Emocional }\end{array}$} & Raiva & 2 & 6,7 & 1 & 3,7 & 1 & 4,3 & 4 & 4,9 \\
\hline & Ansiedade & - & - & 1 & 3,7 & 2 & 8,6 & 3 & 3,7 \\
\hline & Onipotência & 2 & 6,7 & 4 & 14,8 & 4 & 17,3 & 10 & 12,3 \\
\hline & Ciúme & 6 & 19,3 & - & - & 2 & 8,6 & 8 & 9,8 \\
\hline & Rebeldia & 1 & 3,2 & - & - & - & - & 1 & 1,2 \\
\hline & Culpa & - & - & 1 & 3,7 & - & - & 1 & 1,2 \\
\hline & Alegria & 6 & 19,3 & 4 & 14,8 & 2 & 8,6 & 12 & 14,8 \\
\hline & Pesar & - & - & 1 & 3,7 & 1 & 4,3 & 2 & 2,4 \\
\hline & Impotência & - & - & - & - & 1 & 4,3 & 1 & 1,2 \\
\hline & Ambivalência & - & - & 2 & 7,4 & 2 & 8,6 & 4 & 4,9 \\
\hline & Voracidade & 1 & 3,2 & 2 & 7,4 & - & - & 3 & 3,7 \\
\hline & Inveja & 1 & 3,2 & - & - & - & - & 1 & 1,2 \\
\hline
\end{tabular}




\begin{tabular}{|c|c|c|c|c|c|c|c|c|c|}
\hline & Amparado* & - & - & 1 & 3,7 & - & - & 1 & 1,2 \\
\hline & Angústia* & 1 & 3,2 & - & - & - & - & 1 & 1,2 \\
\hline & Com fome* & 2 & 6,7 & - & - & - & - & 2 & 2,4 \\
\hline & Solidão* & - & - & 1 & 3,7 & - & - & 1 & 1,2 \\
\hline & Subtotal & 31 & 100 & 27 & 100 & 23 & 100 & 81 & 100 \\
\hline & Sem resposta & 1 & 3,0 & - & - & - & - & 1 & 1,0 \\
\hline & Projeção & 2 & 6,0 & 1 & 3,3 & 6 & 16,2 & 9 & 9,0 \\
\hline & Negação & 8 & 24,2 & 9 & 30,0 & 11 & 29,7 & 28 & 28,0 \\
\hline & Distorção & 4 & 12,1 & 1 & 3,3 & 1 & 2,7 & 6 & 6,0 \\
\hline & Atuação & 2 & 6,0 & 2 & 6,6 & 1 & 2,7 & 5 & 5,0 \\
\hline & Introjeção & - & - & - & - & 2 & 5,4 & 2 & 2,0 \\
\hline & $\begin{array}{l}\text { Comportamento } \\
\text { passivo-agressivo }\end{array}$ & 1 & 3,0 & - & - & - & - & 1 & 1,0 \\
\hline & Regressão & 1 & 3,0 & 3 & 10,0 & 3 & 8,1 & 7 & 7,0 \\
\hline Defesas & Somatização & 1 & 3,0 & 1 & 3,3 & 1 & 2,7 & 3 & 3,0 \\
\hline & Deslocamento & 2 & 6,0 & 2 & 6,6 & 3 & 8,1 & 7 & 7,0 \\
\hline & Isolamento & 1 & 3,0 & 2 & 6,6 & 2 & 5,4 & 5 & 5,0 \\
\hline & Racionalização & 1 & 3,0 & 3 & 10,0 & - & - & 4 & 4,0 \\
\hline & Formação reativa & 5 & 15,1 & 1 & 3,3 & 4 & 10,8 & 10 & 10,0 \\
\hline & Repressão & 3 & 9,0 & 3 & 10,0 & 1 & 2,7 & 7 & 7,0 \\
\hline & Concretude* & 1 & 3,0 & 1 & 3,3 & - & - & 2 & 2,0 \\
\hline & Confabulação* & - & - & - & - & 1 & 2,7 & 1 & 1,0 \\
\hline & Idealização* & - & - & 1 & 3,3 & - & - & 1 & 1,0 \\
\hline & Sublimação* & - & - & - & - & 1 & 2,7 & 1 & 1,0 \\
\hline & Subtotal & 33 & 100 & 30 & 100 & 37 & 100 & 100 & 100 \\
\hline
\end{tabular}

*Categoria avaliativa incluída por sugestão dos avaliadores dos casos.

Na categoria $\underline{\text { Ação, }}$ junção dos itens:

- Sem resposta + Não adaptado ao conteúdo da fábula + Recusa + Passiva $=$ NÃO ADAPTADA.

- Ativa e Adaptada = ADAPTADA.

- Ativa, mas não adaptada + Ambivalente = AMBIVALENTE.

- Com resistência ativa + Com resistência passiva = RESISTENTE

Na categoria Desfecho, junção dos itens:

- Não adaptado ao conteúdo da fábula + Não adaptativo = NÃO ADAPTADO.

Na categoria Fantasia junção dos itens:

- Sem resposta + Abandono + Rejeição + Privação + Impotência = IMPOTÊNCIA.

- Agressão deslocada para o ambiente + Autoagressão + Heteroagressão ativa + Heteroagressão passiva $=$ AGRESSÃO.

- Ganho secundário + Edípica + Onipotência = ONIPOTÊNCIA.

- Amparo + Reparação = REPARAÇÃO.

Na categoria Estado Emocional, junção dos itens:

- Sem resposta + Pesar + Impotência + Solidão + Tristeza = TRISTEZA.

- Medo + Culpa + Ambivalência + Angústia + Com fome + Ansiedade = ANSIEDADE. 
130|Anexos e Apêndices

- Rebeldia + Inveja + Ciúme + Raiva = RAIVA.

- Voracidade + Onipotência + Amparado + Alegria = ALEGRIA

Na categoria Defesas, junção dos itens:

- Sem resposta + Projeção + Negação + Distorção + Atuação + Comportamento passivo-agressivo + Confabulação = COM BASE na NEGAÇÃO.

- Introjeção + Regressão + Somatização + Deslocamento + Isolamento + Racionalização + Formação Reativa + Repressão + Concretude + Idealização e Sublimação = COM BASE na REPRESSÃO. 
FÁBULA 4

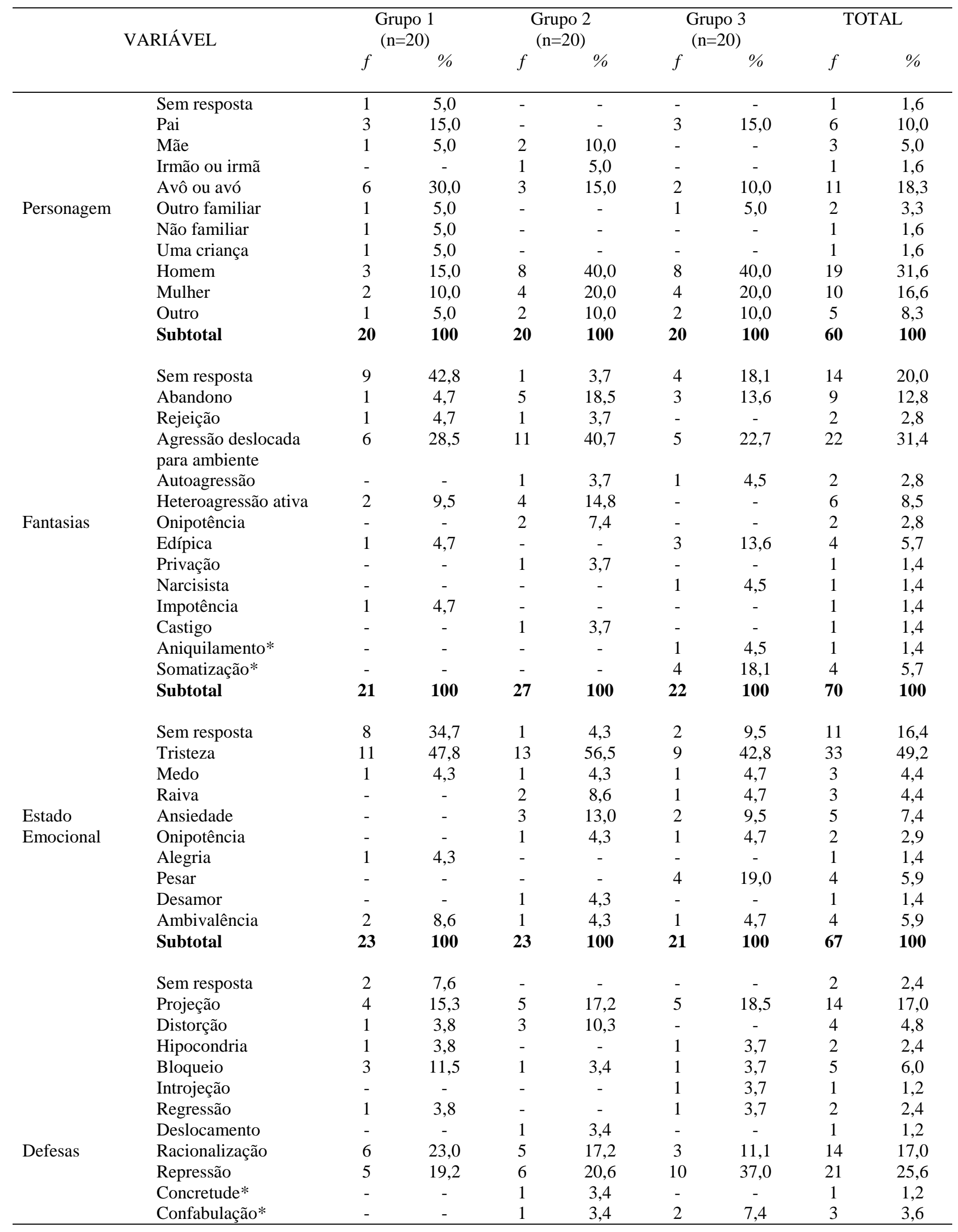


132 Anexos e Apêndices

$\begin{array}{lcccccccc}\text { Distanciamento* } & 1 & 3,8 & 4 & 13,7 & 2 & 7,4 & 7 & 8,5 \\ \text { Idealização* } & - & - & 1 & 3,4 & - & - & 1 & 1,2 \\ \text { Maníaca* } & 1 & 3,8 & - & - & - & - & 1 & 1,2 \\ \text { Restrição* } & 1 & 3,8 & - & - & - & - & 1 & 1,2 \\ \text { Sublimação* } & - & - & - & - & 1 & 3,7 & 1 & 1,2 \\ \text { Perseveração* } & - & - & 1 & 3,4 & - & - & 1 & 1,2 \\ \text { Subtotal } & \mathbf{2 6} & \mathbf{1 0 0} & \mathbf{2 9} & \mathbf{1 0 0} & \mathbf{2 7} & \mathbf{1 0 0} & \mathbf{8 2} & \mathbf{1 0 0}\end{array}$

*Categoria avaliativa incluída por sugestão dos avaliadores dos casos.

Na categoria Personagem, junção dos itens:

- Irmão ou Irmã + Uma criança = CRIANÇA / IRMÃ(O).

- $\quad$ Homem + Pai $=$ HOMEM/PAI.

- $\quad$ Mulher + Mãe = MULHER/MÃE

- Sem resposta + Outro familiar + Não familiar + Outro = OUTROS

Na categoria Fantasia, junção dos itens:

- Agressão deslocada para o ambiente + Autoagressão + Heteroagressão ativa + Castigo + Aniquilamento $=$ AGRESSÃO.

- Edípica + Narcisista + Onipotência = ONIPOTÊNCIA.

- Sem Resposta + Abandono + Rejeição + Privação + Somatização + Impotência $=$ IMPOTÊNCIA.

Na categoria Estado Emocional, junção dos itens:

- Sem resposta + Pesar + Tristeza $=$ TRISTEZA

- Medo + Ambivalência + Ansiedade = ANSIEDADE

- Desamor + Raiva = RAIVA.

- Alegria + Onipotência = ALEGRIA.

Na categoria Defesas, junção dos itens:

- Sem resposta + Projeção + Distorção + Confabulação + Maníaca + Perseveração = COM BASE na NEGAÇÃO.

- Hipocondria + Bloqueio + Introjeção + Regressão + Deslocamento + Racionalização + Repressão + Concretude + Distanciamento + Idealização + Restrição + Sublimação = COM BASE na REPRESSÃO. 
FÁBULA 5

\begin{tabular}{|c|c|c|c|c|c|c|c|c|c|}
\hline & \multirow[t]{2}{*}{ VARIÁVEL } & \multicolumn{2}{|c|}{$\begin{array}{c}\text { Grupo } 1 \\
(\mathrm{n}=20)\end{array}$} & \multicolumn{2}{|c|}{$\begin{array}{c}\text { Grupo 2 } \\
(\mathrm{n}=20)\end{array}$} & \multicolumn{2}{|c|}{$\begin{array}{c}\text { Grupo } 3 \\
(\mathrm{n}=20)\end{array}$} & \multicolumn{2}{|c|}{ TOTAL } \\
\hline & & $f$ & $\%$ & $f$ & $\%$ & $f$ & $\%$ & $f$ & $\%$ \\
\hline \multirow{8}{*}{ Objeto } & - Sem resposta & 1 & 5,0 & - & - & 1 & 5,0 & 2 & 3,3 \\
\hline & $\begin{array}{l}\text { - De bicho, } \\
\text { especificado ou não }\end{array}$ & 2 & 10,0 & 8 & 40,0 & 2 & 10,0 & 12 & 20,0 \\
\hline & $\begin{array}{l}\text { - Animal (feroz ou } \\
\text { nocivo) }\end{array}$ & - & - & 2 & 10,0 & 2 & 10,0 & 4 & 6,6 \\
\hline & $\begin{array}{l}\text { - Ladrão, assassino e } \\
\text { similares }\end{array}$ & 1 & 5,0 & 1 & 5,0 & 1 & 5,0 & 3 & 5,0 \\
\hline & - Personagens de ficção & 9 & 45,0 & 4 & 20,0 & 6 & 30,0 & 19 & 31,6 \\
\hline & - Escuro ou solidão & 6 & 30,0 & 3 & 15,0 & 6 & 30,0 & 15 & 25,0 \\
\hline & - Outro & 1 & 5,0 & 2 & 10,0 & 2 & 10,0 & 5 & 8,3 \\
\hline & Subtotal & 20 & 100 & 20 & 100 & 20 & 100 & 60 & 100 \\
\hline \multirow{18}{*}{ Fantasias } & Sem resposta & 3 & 13,0 & 1 & 3,8 & 1 & 3,7 & 5 & 7,1 \\
\hline & Abandono & 2 & 8,3 & 2 & 7,6 & 3 & 11,1 & 7 & 10,0 \\
\hline & Rejeição & 1 & 4,1 & - & - & - & - & 1 & 1,2 \\
\hline & $\begin{array}{l}\text { Agressão deslocada para } \\
\text { ambiente }\end{array}$ & 11 & 47,8 & 11 & 42,3 & 14 & 51,8 & 36 & 46,7 \\
\hline & Autoagressão & - & - & - & - & 1 & 3,7 & 1 & 1,2 \\
\hline & Heteroagressão ativa & 1 & 4,1 & - & - & 1 & 3,7 & 2 & 2,5 \\
\hline & Onipotência & - & - & 3 & 11,5 & 2 & 7,4 & 5 & 7,1 \\
\hline & Edípica & 1 & 4,1 & 2 & 7,6 & 1 & 3,7 & 4 & 5,7 \\
\hline & Ganho secundário & - & - & 1 & 3,8 & - & - & 1 & 1,2 \\
\hline & Impotência & 1 & 4,1 & 3 & 11,5 & 1 & 3,7 & 5 & 7,1 \\
\hline & Castigo & - & - & 1 & 3,8 & - & - & 1 & 1,2 \\
\hline & Aniquilamento* & 2 & 8,3 & - & - & 1 & 3,7 & 3 & 4,2 \\
\hline & Desamor* & - & - & - & - & 1 & 3,7 & 1 & 1,2 \\
\hline & Desamparo* & - & - & 1 & 3,8 & - & - & 1 & 1,2 \\
\hline & Orais* & 1 & 4,1 & - & - & - & - & 1 & 1,2 \\
\hline & Persecutória* & - & - & 1 & 3,8 & 1 & 3,7 & 2 & 2,5 \\
\hline & Vulnerabilidade* & 1 & 4,1 & - & - & - & - & 1 & 1,2 \\
\hline & Subtotal & 24 & 100 & 26 & 100 & 27 & 100 & 77 & 100 \\
\hline \multirow{17}{*}{ Defesas } & Projeção & 7 & 20,0 & 7 & 24,1 & 9 & 34,6 & 23 & 25,6 \\
\hline & Negação & 1 & 2,8 & 3 & 10,3 & - & - & 4 & 4,4 \\
\hline & Distorção & - & - & 2 & 6,8 & - & - & 2 & 2,2 \\
\hline & Atuação & 1 & 2,8 & - & - & 1 & 3,8 & 2 & 2,2 \\
\hline & Bloqueio & - & - & - & - & 1 & 3,8 & 1 & 1,1 \\
\hline & Introjeção & 1 & 2,8 & 1 & 3,4 & - & - & 2 & 2,2 \\
\hline & Somatização & 1 & 2,8 & - & - & - & - & 1 & 1,1 \\
\hline & Deslocamento & 2 & 5,7 & 1 & 3,4 & - & - & 3 & 3,3 \\
\hline & Racionalização & 11 & 31,4 & 8 & 27,5 & 8 & 30,7 & 27 & 30,0 \\
\hline & Repressão & 6 & 17,1 & 6 & 10,3 & 5 & 19,2 & 17 & 18,9 \\
\hline & Anulação* & 1 & 2,8 & - & - & - & - & 1 & 1,1 \\
\hline & Concretude* & 2 & 5,7 & - & - & - & - & 2 & 2,2 \\
\hline & Confabulação* & - & - & 1 & 3,4 & 1 & 3,8 & 2 & 2,2 \\
\hline & Distanciamento* & - & - & - & - & 1 & 3,8 & 1 & 1,1 \\
\hline & Idealização* & 1 & 2,8 & - & - & - & - & 1 & 1,1 \\
\hline & $\begin{array}{l}\text { Perseveração de } \\
\text { conteúdo* }\end{array}$ & 1 & 2,8 & - & - & - & - & 1 & 1,1 \\
\hline & Subtotal & 35 & 100 & 29 & 100 & 26 & 100 & 90 & 100 \\
\hline
\end{tabular}

\footnotetext{
*Categoria avaliativa incluída por sugestão dos avaliadores dos casos.
} 
134 Anexos e Apêndices

Na categoria Objeto, junção dos itens:

- De bicho especificado ou não + Animal (feroz ou nocivo) =ANIMAL / BICHO.

- Sem resposta + Ladrão + Assassino e similares + Outro = OUTROS.

Na categoria Fantasias, junção dos itens:

- Sem resposta + Abandono + Rejeição + Desamparo + Vulnerabilidade + Impotência $=$ IMPOTÊNCIA.

- Agressão deslocada para o ambiente + Autoagressão + Heteroagressão ativa + Castigo + Aniquilamento + Desamor + Persecutória $=$ AGRESSÃO.

- Ganho secundário + Orais + Edípica + Onipotência = ONIPOTÊNCIA.

Na categoria Defesas, junção dos itens:

- Sem resposta + Projeção + Distorção + Confabulação + Maníaca + Perseveração = COM BASE na NEGAÇÃO.

- Hipocondria + Bloqueio + Introjeção + Regressão + Deslocamento + Racionalização + Repressão + Concretude + Distanciamento + Idealização + Restrição + Sublimação = COM BASE na REPRESSÃO. 


\section{FÁBULA 6}

\begin{tabular}{|c|c|c|c|c|c|c|c|c|c|}
\hline & \multirow[t]{2}{*}{ VARIÁVEL } & \multicolumn{2}{|c|}{$\begin{array}{c}\text { Grupo } 1 \\
(n=20)\end{array}$} & \multicolumn{2}{|c|}{$\begin{array}{l}\text { Grupo } 2 \\
(\mathrm{n}=20)\end{array}$} & \multicolumn{2}{|c|}{$\begin{array}{c}\text { Grupo } 3 \\
(n=20)\end{array}$} & \multicolumn{2}{|c|}{ TOTAL } \\
\hline & & $f$ & $\%$ & $f$ & $\%$ & $f$ & $\%$ & $f$ & $\%$ \\
\hline \multirow{7}{*}{$\begin{array}{l}\text { Natureza } \\
\text { da Mudança }\end{array}$} & $\begin{array}{l}\text { Não adaptada ao } \\
\text { conteúdo da fábula }\end{array}$ & 3 & 15,0 & - & - & - & - & 3 & 5,0 \\
\hline & Por acidente & - & - & 3 & 15,0 & 1 & 5,0 & 4 & 6,6 \\
\hline & Mutilação & 2 & 10,0 & 4 & 20,0 & 4 & 20,0 & 10 & 16,6 \\
\hline & Transformação Física & 1 & 5,0 & 2 & 10,0 & 3 & 15,0 & 6 & 10,0 \\
\hline & $\begin{array}{l}\text { Transformação } \\
\text { Psicológica }\end{array}$ & 5 & 25,0 & 5 & 25,0 & 2 & 10,0 & 12 & 20,0 \\
\hline & Substituição & 3 & 15,0 & 1 & 5,0 & 2 & 10,0 & 6 & 10,0 \\
\hline & $\begin{array}{l}\text { Modificação na } \\
\text { aparência }\end{array}$ & 3 & 15,0 & 4 & 20,0 & 6 & 30,0 & 13 & 21,6 \\
\hline \multirow{13}{*}{$\begin{array}{l}\text { Identificação } \\
\text { da Mudança }\end{array}$} & Outra & 3 & 15,0 & 1 & 5,0 & 2 & 10,0 & 6 & 10,0 \\
\hline & Subtotal & 20 & 100 & 20 & 100 & 20 & 100 & 60 & 100 \\
\hline & Sem resposta & 3 & 15,0 & 2 & 10,0 & 4 & 20,0 & 9 & 15,0 \\
\hline & $\begin{array}{l}\text { Não adaptada ao } \\
\text { conteúdo da fábula }\end{array}$ & - & - & - & - & 1 & 5,0 & 1 & 1,6 \\
\hline & Tamanho pequeno & 1 & 5,0 & 1 & 5,0 & 1 & 5,0 & 3 & 5,0 \\
\hline & Tamanho grande & 1 & 5,0 & 2 & 10,0 & 1 & 5,0 & 4 & 6,6 \\
\hline & Sujeira & 1 & 5,0 & 1 & 5,0 & 2 & 10,0 & 4 & 6,6 \\
\hline & Velhice & - & - & 1 & 5,0 & 1 & 5,0 & 2 & 3,3 \\
\hline & Brabeza & - & - & - & - & 1 & 5,0 & 1 & 1,6 \\
\hline & Cor & 2 & 10,0 & 5 & 25,0 & 4 & 20,0 & 11 & 18,3 \\
\hline & Identidade & 1 & 5,0 & - & - & 2 & 10,0 & 3 & 5,0 \\
\hline & Outra & 11 & 55,0 & 8 & 40,0 & 3 & 15,0 & 22 & 36,6 \\
\hline & Subtotal & 20 & 100 & 20 & 100 & 20 & 100 & 60 & 100 \\
\hline \multirow{5}{*}{$\begin{array}{l}\text { Local da } \\
\text { Mudança }\end{array}$} & Sem resposta & 6 & 30,0 & - & - & - & - & - & 10,0 \\
\hline & Tromba & - & - & 1 & 5,0 & 3 & 15,0 & 4 & 6,6 \\
\hline & Elefante & 14 & 70,0 & 18 & 90,0 & 17 & 85,0 & 49 & 81,6 \\
\hline & $\begin{array}{l}\text { Objeto do ambiente ou } \\
\text { ambiente em geral }\end{array}$ & - & - & 1 & 5,0 & - & - & 1 & 1,6 \\
\hline & Subtotal & 20 & 100 & 20 & 100 & 20 & 100 & 60 & 100 \\
\hline \multirow{21}{*}{ Fantasias } & Sem resposta & 4 & 16,7 & 1 & 3,7 & - & - & 5 & 6,8 \\
\hline & Abandono & 3 & 12,5 & 3 & 11,1 & 2 & 8,7 & 8 & 10,8 \\
\hline & Rejeição & 3 & 12,5 & 3 & 11,1 & 1 & 4,3 & 7 & 9,5 \\
\hline & $\begin{array}{l}\text { Agressão deslocada } \\
\text { para ambiente }\end{array}$ & 4 & 16,7 & 3 & 11,1 & 2 & 8,7 & 9 & 12,2 \\
\hline & Heteroagressão passiva & - & - & 1 & 3,7 & - & - & 1 & 1,4 \\
\hline & Autoagressão & - & - & 1 & 3,7 & 1 & 4,3 & 2 & 2,7 \\
\hline & Onipotência & 3 & 12,5 & 4 & 14,8 & 1 & 4,3 & 8 & 10,8 \\
\hline & Privação & 2 & 8,3 & - & - & - & - & 2 & 2,7 \\
\hline & Reparação & 1 & 4,2 & 3 & 11,1 & 5 & 21,7 & 9 & 12,2 \\
\hline & Narcisista & - & - & - & - & 2 & 8,7 & 2 & 2,7 \\
\hline & Ganho secundário & - & - & 2 & 7,4 & - & - & 2 & 2,7 \\
\hline & Castração & 1 & 4,2 & 5 & 18,5 & 3 & 13,0 & 9 & 12,2 \\
\hline & Impotência & - & - & - & - & 3 & 13,0 & 3 & 4,1 \\
\hline & Castigo & - & - & 1 & 3,7 & - & - & 1 & 1,4 \\
\hline & Aniquilamento* & - & - & - & - & 1 & 4,3 & 1 & 1,4 \\
\hline & Fragmentação* & 1 & 4,2 & - & - & - & - & 1 & 1,4 \\
\hline & Negligência* & 1 & 4,2 & - & - & - & - & 1 & 1,4 \\
\hline & Rivalidade Fraterna* & - & - & - & - & 1 & 4,3 & 1 & 1,4 \\
\hline & Roubo* & 1 & 4,2 & - & - & - & - & 1 & 1,4 \\
\hline & Voracidade* & - & - & - & - & 1 & 4,3 & 1 & 1,4 \\
\hline & Subtotal & 24 & 100 & 27 & 100 & 23 & 100 & 74 & 100 \\
\hline
\end{tabular}




\begin{tabular}{|c|c|c|c|c|c|c|c|c|c|}
\hline & Sem resposta & 1 & 3,7 & 2 & 6,7 & - & - & 3 & 3,5 \\
\hline & Tristeza & 7 & 25,9 & 9 & 30,0 & 8 & 28,6 & 24 & 28,2 \\
\hline & Medo & 2 & 7,4 & - & - & 1 & 3,6 & 3 & 3,5 \\
\hline & Raiva & 2 & 7,4 & - & - & 1 & 3,6 & 3 & 3,5 \\
\hline & Ansiedade & 3 & 11,1 & - & - & 1 & 3,6 & 4 & 4,7 \\
\hline & Onipotência & 2 & 7,4 & 4 & 13,3 & 5 & 17,9 & 11 & 12,9 \\
\hline & Ciúme & 1 & 3,7 & - & - & - & - & 1 & 1,2 \\
\hline Estado & Vergonha & - & - & - & - & 1 & 3,6 & 1 & 1,2 \\
\hline \multirow[t]{19}{*}{ Emocional } & Culpa & - & - & 1 & 3,3 & 2 & 7,1 & 3 & 3,5 \\
\hline & Impertinência & - & - & - & - & 1 & 3,6 & 1 & 1,2 \\
\hline & Alegria & 6 & 22,2 & 7 & 23,3 & 3 & 10,7 & 16 & 18,8 \\
\hline & Pesar & - & - & 2 & 6,7 & 4 & 14,3 & 6 & 7,1 \\
\hline & Impotência & - & - & 1 & 3,3 & - & - & 1 & 1,2 \\
\hline & Desamor & - & - & 1 & 3,3 & 1 & 3,6 & 2 & 2,4 \\
\hline & Ambivalência & - & - & 2 & 6,7 & - & - & 2 & 2,4 \\
\hline & Carência* & 1 & 3,7 & - & - & - & - & 1 & 1,2 \\
\hline & Confusão* & 1 & 3,7 & - & - & - & - & 1 & 1,2 \\
\hline & Com fome* & 1 & 3,7 & - & - & - & - & 1 & 1,2 \\
\hline & Solidão* & - & - & 1 & 3,3 & - & - & 1 & 1,2 \\
\hline & Subtotal & 27 & 100 & 30 & 100 & 28 & 100 & 85 & 100 \\
\hline & Sem resposta & 1 & 3,2 & - & - & - & - & 1 & 1,2 \\
\hline & Projeção & 3 & 9,7 & 4 & 15,4 & 4 & 14,8 & 11 & 13,1 \\
\hline & Negação & 4 & 12,9 & 2 & 7,7 & 3 & 11,1 & 9 & 10,7 \\
\hline & Distorção & 3 & 9,7 & 2 & 7,7 & - & - & 5 & 6,0 \\
\hline & Atuação & - & - & - & - & 1 & 3,7 & 1 & 1,2 \\
\hline & Bloqueio & 1 & 3,2 & - & - & - & - & 1 & 1,2 \\
\hline & Hipocondria & 2 & 6,5 & - & - & 2 & 7,4 & 4 & 4,8 \\
\hline \multirow[t]{14}{*}{ Defesas } & Introjeção & - & - & 1 & 3,8 & 2 & 7,4 & 3 & 3,6 \\
\hline & $\begin{array}{l}\text { Comportamento } \\
\text { passivo-agressivo }\end{array}$ & - & - & 1 & 3,8 & - & - & 1 & 1,2 \\
\hline & Somatização & 4 & 12,9 & - & 0,0 & 3 & 11,1 & 7 & 8,3 \\
\hline & Deslocamento & - & - & 4 & 15,4 & 3 & 11,1 & 7 & 8,3 \\
\hline & Isolamento & 1 & 3,2 & - & - & - & - & 1 & 1,2 \\
\hline & Racionalização & 5 & 16,1 & 4 & 15,4 & 2 & 7,4 & 11 & 13,1 \\
\hline & Formação reativa & 1 & 3,2 & - & - & - & - & 1 & 1,2 \\
\hline & Repressão & 3 & 9,7 & 5 & 19,2 & 4 & 14,8 & 12 & 14,3 \\
\hline & Confabulação* & - & - & 1 & 3,8 & 1 & 3,7 & 2 & 2,4 \\
\hline & Dissociação* & 1 & 3,2 & - & 0,0 & 1 & 3,7 & 2 & 2,4 \\
\hline & Distanciamento* & 1 & 3,2 & 1 & 3,8 & 1 & 3,7 & 3 & 3,6 \\
\hline & Idealização* & - & - & 1 & 3,8 & - & - & 1 & 1,2 \\
\hline & Rigidez* & 1 & 3,2 & - & - & - & - & 1 & 1,2 \\
\hline & Subtotal & 31 & 100 & 26 & 100 & 27 & 100 & 84 & 100 \\
\hline
\end{tabular}

*Categoria avaliativa incluída por sugestão dos avaliadores dos casos.

Na categoria Natureza da mudança, junção dos itens:

- Por Acidente + Por Mutilação = POR ACIDENTE / MUTILAÇÃO.

- Modificação na aparência + Transformação Física = TRANSFORMAÇÃO FÍSICA.

- Não adaptada ao conteúdo da fábula + Outra = OUTRA.

Na categoria Identificação da Mudança, junção dos itens:

- Sujeira + Cor $=$ SUJEIRA $/$ COR . 
- $\quad$ Tamanho Pequeno + Tamanho Grande = TAMANHO.

- Velhice, Identidade e Brabeza = IDENTIDADE.

- Sem resposta + Não adaptada ao conteúdo + Outra = OUTRAS.

Na categoria Local da mudança, junção dos itens:

- Sem resposta + Objeto do ambiente + Ambiente em geral $=$ FORA DO ELEFANTE.

Na categoria Fantasias, junção dos itens:

- Sem resposta + Abandono + Rejeição + Privação + Castração + Negligência + Impotência = IMPOTÊNCIA.

- Agressão deslocada para o ambiente + Heteroagressão passiva + Autoagressão + Castigo + Aniquilamento + Fragmentação + Roubo = AGRESSÃO.

- Narcisista + Ganho Secundário + Rivalidade Fraterna + Voracidade + Onipotência $=$ ONIPOTÊNCIA.

Na categoria Estado emocional, junção dos itens:

- Sem resposta + Impertinência + Vergonha + Pesar + Impotência + Carência + Solidão + Com fome + Tristeza $=$ TRISTEZA.

- Medo + Culpa + Ambivalência + Confusão + Ansiedade $=$ ANSIEDADE .

- Desamor + Ciúme + Raiva = RAIVA.

- Alegria + Onipotência = ALEGRIA.

Na categoria Defesas, junção dos itens:

- Sem resposta + Projeção + Negação + Distorção + Atuação + Comportamento passivo-agressivo + Confabulação + Dissociação = COM BASE na NEGAÇÃO.

- Bloqueio + Hipocondria + Introjeção + Somatização + Deslocamento + Isolamento + Racionalização + Formação reativa + Repressão + Distanciamento + Idealização + Rigidez = COM BASE na REPRESSÃO. 
138|Anexos e Apêndices

FÁBULA 7

\begin{tabular}{|c|c|c|c|c|c|c|c|c|c|}
\hline & \multirow[t]{2}{*}{ VARIÁVEL } & \multicolumn{2}{|c|}{$\begin{array}{c}\text { Grupo } 1 \\
(\mathrm{n}=20)\end{array}$} & \multicolumn{2}{|c|}{$\begin{array}{c}\text { Grupo } 2 \\
(\mathrm{n}=20)\end{array}$} & \multicolumn{2}{|c|}{$\begin{array}{c}\text { Grupo } 3 \\
(\mathrm{n}=20)\end{array}$} & \multicolumn{2}{|c|}{ TOTAL } \\
\hline & & $f$ & $\%$ & $f$ & $\%$ & $f$ & $\%$ & $f$ & $\%$ \\
\hline & $\begin{array}{l}\text { - Não adaptada ao } \\
\text { conteúdo da fábula }\end{array}$ & 2 & 10,0 & - & - & - & - & 2 & 3,3 \\
\hline & $\begin{array}{l}\text { - Insegura, bloqueada ou } \\
\text { ambivalente }\end{array}$ & 4 & 20,0 & 9 & 45,0 & 2 & 10,0 & 15 & 25,0 \\
\hline \multirow[t]{12}{*}{ Ação } & - Ativa e adaptada & 5 & 25,0 & 5 & 25,0 & 9 & 45,0 & 19 & 31,6 \\
\hline & - Ativa mas deslocada & 6 & 30,0 & 2 & 10,0 & 4 & 20,0 & 12 & 20,0 \\
\hline & - Ação com resistência ativa & 1 & 5,0 & 4 & 20,0 & 5 & 25,0 & 10 & 16,6 \\
\hline & - Ação com resistência passiva & 2 & 10 & - & - & - & - & 2 & 3,3 \\
\hline & Subtotal & 20 & 100 & 20 & 100 & 20 & 100 & 60 & 100 \\
\hline & Sem resposta & 8 & 33,3 & 3 & 10,3 & 2 & 8,0 & 13 & 16,7 \\
\hline & Abandono & 1 & 4,2 & - & - & - & - & 1 & 1,3 \\
\hline & $\begin{array}{l}\text { Agressão deslocada para } \\
\text { ambiente }\end{array}$ & - & - & 1 & 3,4 & - & - & 1 & 1,3 \\
\hline & Heteroagressão passiva & 1 & 4,2 & 1 & 3,4 & - & - & 2 & 2,6 \\
\hline & Onipotência & 6 & 25,0 & 6 & 20,7 & 9 & 36,0 & 21 & 26,9 \\
\hline & Edípica & - & - & - & - & 1 & 4,0 & 1 & 1,3 \\
\hline & Privação & - & - & 2 & 6,9 & - & - & 2 & 2,6 \\
\hline \multirow[t]{14}{*}{ Fantasias } & Reparação & - & - & - & - & 2 & 8,0 & 2 & 2,6 \\
\hline & Narcisista & 3 & 12,5 & 8 & 27,6 & 5 & 20,0 & 16 & 20,5 \\
\hline & Ganho secundário & 4 & 16,7 & 3 & 10,3 & 4 & 16,0 & 11 & 14,1 \\
\hline & Impotência & - & - & 3 & 10,3 & - & - & 3 & 3,8 \\
\hline & Castigo & - & - & 1 & 3,4 & 1 & 4,0 & 2 & 2,6 \\
\hline & Culpa & - & - & - & - & 1 & 4,0 & 1 & 1,3 \\
\hline & Gratidão & 1 & 4,2 & - & - & - & - & 1 & 1,3 \\
\hline & Roubo & - & - & 1 & 3,4 & - & - & 1 & 1,3 \\
\hline & Subtotal & 24 & 100 & 29 & 100 & 25 & 100 & 78 & 100 \\
\hline & Sem resposta & 2 & 7,7 & - & - & - & - & 2 & 2,6 \\
\hline & Tristeza & 4 & 15,4 & 4 & 15,4 & 4 & 16,7 & 12 & 15,8 \\
\hline & Raiva & - & - & - & - & 1 & 4,2 & 1 & 1,3 \\
\hline & Ansiedade & 1 & 3,8 & - & - & 1 & 4,2 & 2 & 2,6 \\
\hline & Onipotência & 2 & 7,7 & 6 & 23,1 & 10 & 41,7 & 18 & 23,7 \\
\hline Estado & Culpa & 1 & 3,8 & - & - & 1 & 4,2 & 2 & 2,6 \\
\hline \multirow[t]{15}{*}{ Emocional } & Alegria & 8 & 30,8 & 8 & 30,8 & 3 & 12,5 & 19 & 25,0 \\
\hline & Pesar & - & - & 3 & 11,5 & 1 & 4,2 & 4 & 5,3 \\
\hline & Ambivalência & 7 & 26,9 & 4 & 15,4 & 2 & 8,3 & 13 & 17,1 \\
\hline & Dor & 1 & 3,8 & - & - & - & - & 1 & 1,3 \\
\hline & Gratidão & - & - & - & - & 1 & 4,2 & 1 & 1,3 \\
\hline & Saudade & - & - & 1 & 3,8 & - & - & 1 & 1,3 \\
\hline & Subtotal & 26 & 100 & 26 & 100 & 24 & 100 & 76 & 100 \\
\hline & Projeção & - & - & 1 & 3,1 & 4 & 12,9 & 5 & 5,3 \\
\hline & Negação & 5 & 16,1 & 3 & 9,4 & 11 & 35,5 & 19 & 20,2 \\
\hline & Distorção & 3 & 9,7 & 2 & 6,3 & - & - & 5 & 5,3 \\
\hline & Atuação & - & - & 1 & 3,1 & 1 & 3,2 & 2 & 2,1 \\
\hline & Bloqueio & 1 & 3,2 & - & - & - & - & 1 & 1,1 \\
\hline & Introjeção & - & - & - & - & 1 & 3,2 & 1 & 1,1 \\
\hline & Somatização & 1 & 3,2 & - & - & - & - & 1 & 1,1 \\
\hline & Deslocamento & - & - & 4 & 12,5 & 2 & 6,5 & 6 & 6,4 \\
\hline \multirow[t]{4}{*}{ Defesas } & Racionalização & 8 & 25,8 & 5 & 15,6 & 1 & 3,2 & 14 & 14,9 \\
\hline & Formação reativa & 5 & 16,1 & 9 & 28,1 & 2 & 6,5 & 16 & 17,0 \\
\hline & Repressão & 6 & 19,4 & 3 & 9,4 & 8 & 25,8 & 17 & 18,1 \\
\hline & Confabulação* & - & - & 1 & 3,1 & - & - & 1 & 1,1 \\
\hline
\end{tabular}




\begin{tabular}{llccccccc}
\hline Idealização* & 1 & 3,2 & 2 & 6,3 & - & - & 3 & 3,2 \\
Dissociação* $^{\text {Sedução* }}$ & - & - & 1 & 3,1 & - & - & 1,1 \\
Sublimação* & 1 & 3,2 & - & - & - & - & 1 \\
Subtotal & - & - & - & - & 1 & 3,2 & 1 & 1,1 \\
& $\mathbf{3 1}$ & $\mathbf{1 0 0}$ & $\mathbf{3 2}$ & $\mathbf{1 0 0}$ & $\mathbf{3 1}$ & $\mathbf{1 0 0}$ & $\mathbf{9 4}$ & $\mathbf{1 0 0}$ \\
\hline
\end{tabular}

*Categoria avaliativa incluída por sugestão dos avaliadores dos casos.

Na categoria Ação, junção dos itens:

- Não adaptado ao conteúdo da fábula + Ativa, mas deslocada + Insegura + Bloqueada ou Ambivalente $=$ AMBIVALENTE.

- Com resistência ativa + Com resistência passiva $=$ RESISTENTE.

Na categoria Fantasias, junção dos itens:

- Sem resposta + Abandono + Privação + Culpa + Impotência = IMPOTÊNCIA

- Agressão deslocada para o ambiente + Heteroagressão passiva + Castigo = AGRESSÃO.

- Edípica + Narcisista + Ganho Secundário + Roubo + Onipotência = ONIPOTÊNCIA.

- Gratidão = REPARAÇÃO.

Na categoria Estado Emocional, junção dos itens:

- Sem resposta + Pesar + Dor + Saudade + Tristeza + Raiva $=$ TRISTEZA

- Culpa + Ambivalência + Ansiedade = ANSIEDADE.

- Onipotência + Gratidão + Alegria = ALEGRIA

Na categoria Defesas, junção dos itens:

- Projeção + Negação + Distorção + Atuação + Confabulação + Dissociação + Sedução = COM BASE na NEGAÇÃO.

- Bloqueio + Introjeção + Somatização + Deslocamento + Racionalização + Formação reativa + Repressão + Idealização + Sublimação = COM BASE na REPRESSÃO. 
140|Anexos e Apêndices

FÁBULA 8

\begin{tabular}{|c|c|c|c|c|c|c|c|c|c|}
\hline & \multirow[t]{2}{*}{ VARIÁVEL } & \multicolumn{2}{|c|}{$\begin{array}{c}\text { Grupo } 1 \\
(\mathrm{n}=20)\end{array}$} & \multicolumn{2}{|c|}{$\begin{array}{c}\text { Grupo } 2 \\
(n=20)\end{array}$} & \multicolumn{2}{|c|}{$\begin{array}{c}\text { Grupo } 3 \\
(n=20)\end{array}$} & \multicolumn{2}{|c|}{ TOTAL } \\
\hline & & $f$ & $\%$ & $f$ & $\%$ & $f$ & $\%$ & $f$ & $\%$ \\
\hline \multirow{7}{*}{ Motivo } & - Sem resposta & 2 & 10,0 & - & - & - & - & 2 & 3,3 \\
\hline & $\begin{array}{l}\text { - Não adaptado ao } \\
\text { conteúdo da fábula }\end{array}$ & 4 & 20,0 & 3 & 15,0 & 3 & 15,0 & 10 & 16,6 \\
\hline & $\begin{array}{l}\text { - Sugestivo de } \\
\text { conflito edípico }\end{array}$ & 8 & 40,0 & 4 & 20,0 & 8 & 40,0 & 20 & 33,3 \\
\hline & $\begin{array}{l}\text { - Associado a } \\
\text { conflito edípico }\end{array}$ & - & - & 1 & 5,0 & 1 & 5,0 & 2 & 3,3 \\
\hline & $\begin{array}{l}\text { - Associado a omissão } \\
\text { de deveres }\end{array}$ & 4 & 20,0 & 12 & 60,0 & 7 & 35,0 & 23 & 38,3 \\
\hline & - Outro & 2 & 10,0 & - & - & 1 & 5,0 & 3 & 5,0 \\
\hline & Subtotal & 20 & 100 & 20 & 100 & 20 & 100 & 60 & 100 \\
\hline \multirow{12}{*}{ Fantasias } & Sem resposta & 3 & 11,1 & - & - & 1 & 4,3 & 4 & 5,1 \\
\hline & Abandono & 1 & 3,7 & 2 & 7,1 & - & - & 3 & 3,8 \\
\hline & Rejeição & - & - & - & - & 1 & 4,3 & 1 & 1,3 \\
\hline & $\begin{array}{l}\text { Agressão deslocada } \\
\text { para ambiente }\end{array}$ & 2 & 7,4 & 2 & 7,1 & 3 & 13,0 & 7 & 9,0 \\
\hline & Heteroagressão ativa & 1 & 3,7 & - & - & - & - & 1 & 1,3 \\
\hline & $\begin{array}{l}\text { Heteroagressão } \\
\text { passiva }\end{array}$ & - & - & 1 & 3,6 & - & - & 1 & 1,3 \\
\hline & Onipotência & 1 & 3,7 & 1 & 3,6 & 1 & 4,3 & 3 & 3,8 \\
\hline & Edípica & 6 & 22,2 & 7 & 25,0 & 9 & 39,1 & 22 & 28,2 \\
\hline & Reparação & 4 & 14,8 & 2 & 7,1 & 2 & 8,7 & 8 & 10,3 \\
\hline & Ganho secundário & - & - & 2 & 7,1 & - & - & 2 & 2,6 \\
\hline & Castração & - & - & 1 & 3,6 & - & - & 1 & 1,3 \\
\hline & Impotência & - & - & 2 & 7,1 & 2 & 8,7 & 4 & 5,1 \\
\hline \multirow{21}{*}{$\begin{array}{l}\text { Estado } \\
\text { Emocional }\end{array}$} & Castigo & 8 & 29,6 & 4 & 14,3 & 3 & 13,0 & 15 & 19,2 \\
\hline & Impertinência & - & - & - & - & 1 & 4,3 & 1 & 1,3 \\
\hline & Perda & 1 & 3,7 & - & - & - & - & 1 & 1,3 \\
\hline & Culpa & - & - & 2 & 7,1 & - & - & 2 & 2,6 \\
\hline & Separação & - & - & 2 & 7,1 & - & - & 2 & 2,6 \\
\hline & Subtotal & 27 & 100 & 28 & 100 & 23 & 100 & 78 & 100 \\
\hline & Sem resposta & 2 & 8,0 & 2 & 8,3 & - & - & 4 & 5,2 \\
\hline & Tristeza & 5 & 20,0 & 6 & 25,0 & 4 & 14,3 & 15 & 19,5 \\
\hline & Medo & 4 & 16,0 & 1 & 4,2 & - & - & 5 & 6,5 \\
\hline & Raiva & 1 & 4,0 & - & - & 2 & 7,1 & 3 & 3,9 \\
\hline & Ansiedade & - & - & - & - & 1 & 3,6 & 1 & 1,3 \\
\hline & Onipotência & - & - & 1 & 4,2 & 3 & 10,7 & 4 & 5,2 \\
\hline & Ciúme & - & - & 1 & 4,2 & 2 & 7,1 & 3 & 3,9 \\
\hline & Vergonha & 2 & 8,0 & - & - & - & - & 2 & 2,6 \\
\hline & Culpa & 4 & 16,0 & 5 & 20,8 & 15 & 53,6 & 24 & 31,2 \\
\hline & Alegria & 5 & 20,0 & 3 & 12,5 & - & - & 8 & 10,4 \\
\hline & Pesar & 1 & 4,0 & 1 & 4,2 & - & - & 2 & 2,6 \\
\hline & Impotência & 1 & 4,0 & 1 & 4,2 & - & - & 2 & 2,6 \\
\hline & Ambivalência & - & - & 2 & 8,3 & 1 & 3,6 & 3 & 3,9 \\
\hline & Confusão* & - & - & 1 & 4,2 & 0 & 0,0 & 1 & 1,3 \\
\hline & Subtotal & 25 & 100 & 24 & 100 & 28 & 100 & 77 & 100 \\
\hline \multirow{5}{*}{ Defesas } & Sem resposta & 2 & 6,7 & - & - & - & - & 2 & 2,0 \\
\hline & Projeção & - & - & 4 & 11,8 & 7 & 18,9 & 11 & 10,9 \\
\hline & Negação & 3 & 10,0 & 0 & 0,0 & 5 & 13,5 & 8 & 7,9 \\
\hline & Distorção & 3 & 10,0 & 3 & 8,8 & 1 & 2,7 & 7 & 6,9 \\
\hline & Bloqueio & - & - & 1 & 2,9 & 1 & 2,7 & 2 & 2,0 \\
\hline
\end{tabular}




\begin{tabular}{|c|c|c|c|c|c|c|c|c|c|}
\hline & Introjeção & - & - & - & - & 3 & 8,1 & 3 & 3,0 \\
\hline & $\begin{array}{l}\text { Comportamento } \\
\text { passivo-agressivo }\end{array}$ & 1 & 3,3 & - & - & - & - & 1 & 1,0 \\
\hline & Deslocamento & 5 & 16,7 & 5 & 14,7 & 4 & 10,8 & 14 & 13,9 \\
\hline & Isolamento & - & - & 1 & 2,9 & - & - & 1 & 1,0 \\
\hline \multirow[t]{9}{*}{ Defesas } & Somatização & - & - & 1 & 2,9 & - & - & 1 & 1,0 \\
\hline & Racionalização & 11 & 36,7 & 7 & 20,6 & 5 & 13,5 & 23 & 22,8 \\
\hline & Formação reativa & - & - & - & - & 1 & 2,7 & 1 & 1,0 \\
\hline & Repressão & 5 & 16,7 & 9 & 26,5 & 8 & 21,6 & 22 & 21,8 \\
\hline & Confabulação* & - & - & - & - & 1 & 2,7 & 1 & 1,0 \\
\hline & Equação Simbólica* & - & - & - & - & 1 & 2,7 & 1 & 1,0 \\
\hline & Idealização* & - & - & 2 & 5,9 & - & - & 2 & 2,0 \\
\hline & Sedução* & - & - & 1 & 2,9 & - & - & 1 & 1,0 \\
\hline & Subtotal & 30 & 100 & 34 & 100 & 37 & 100 & 101 & 100 \\
\hline
\end{tabular}

*Categoria avaliativa incluída por sugestão dos avaliadores dos casos.

Na categoria Motivo, junção dos itens:

- Sem resposta + Não adaptado ao conteúdo da fábula + Outros = OUTROS.

- Sugestivo conflito edípico + Associado a conflito edípico $=$ CONFLITO EDÍPICO.

Na categoria Fantasias, junção dos itens:

- Sem resposta + Abandono + Rejeição + Castração + Impertinência + Perda + Separação + Impotência = IMPOTÊNCIA.

- Agressão deslocada para o ambiente + Heteroagressão ativa + Heteroagressão passiva + Castigo + Culpa + Ansiedade $=$ AGRESSÃO.

- Edípica + Ganho Secundário + Onipotência = ONIPOTÊNCIA.

Na categoria Estado Emocional, junção dos itens:

- Sem resposta + Pesar + Impotência + Tristeza $=$ TRISTEZA

- Medo + Culpa + Ambivalência + Confusão + Ansiedade = ANSIEDADE.

- $\quad$ Ciúme + Vergonha + Raiva = RAIVA

- Onipotência + Alegria = ALEGRIA.

Na categoria Defesas, junção dos itens:

- Sem resposta + Projeção + Negação + Distorção + Comportamento passivoagressivo + Confabulação + Equação simbólica + Sedução = COM BASE na NEGAÇÃO.

- Bloqueio + Introjeção + Deslocamento + Isolamento + Somatização + Racionalização + Formação reativa + Repressão + Idealização = COM BASE na REPRESSÃO. 
142|Anexos e Apêndices

FÁBULA 9

\begin{tabular}{|c|c|c|c|c|c|c|c|c|c|}
\hline & \multirow[t]{2}{*}{ VARIÁVEL } & \multicolumn{2}{|c|}{$\begin{array}{c}\text { Grupo } 1 \\
(\mathrm{n}=20)\end{array}$} & \multicolumn{2}{|c|}{$\begin{array}{c}\text { Grupo } 2 \\
(\mathrm{n}=20)\end{array}$} & \multicolumn{2}{|c|}{$\begin{array}{c}\text { Grupo } 3 \\
(n=20)\end{array}$} & \multicolumn{2}{|c|}{ TOTAL } \\
\hline & & $f$ & $\%$ & $f$ & $\%$ & $f$ & $\%$ & $f$ & $\%$ \\
\hline \multirow[t]{5}{*}{ Medos } & Sem resposta & 16 & 80,0 & 17 & 85,0 & 14 & 70,0 & 47 & 78,4 \\
\hline & Outro & 4 & 20,0 & 3 & 15,0 & 6 & 30,0 & 13 & 21,6 \\
\hline & Subtotal & 20 & 100 & 20 & 100 & 20 & 100 & 60 & 100 \\
\hline & - Sem resposta & 11 & 55,0 & 7 & 35,0 & 6 & 30,0 & 24 & 40,0 \\
\hline & $\begin{array}{l}\text { - Relacionados com } \\
\text { presentes ou lazer }\end{array}$ & 7 & 35,0 & 10 & 50,0 & 9 & 45,0 & 26 & 43,3 \\
\hline \multirow[t]{7}{*}{ Desejos } & $\begin{array}{l}\text { - Relacionados com } \\
\text { satisfação oral }\end{array}$ & 1 & 5,0 & 1 & 5,0 & - & - & 2 & 3,3 \\
\hline & $\begin{array}{l}\text { - Relacionados com } \\
\text { melhoria de vida }\end{array}$ & - & - & 1 & 5,0 & - & - & 1 & 1,6 \\
\hline & $\begin{array}{l}\text { - Relacionados com } \\
\text { êxito pessoal }\end{array}$ & - & - & 1 & 5,0 & 1 & 5,0 & 2 & 3,3 \\
\hline & $\begin{array}{l}\text { - Relacionados com as } \\
\text { relações familiares }\end{array}$ & 1 & 5 & - & - & 4 & 20,0 & 5 & 8,3 \\
\hline & Subtotal & 20 & 100 & 20 & 100 & 20 & 100 & 60 & 100 \\
\hline & - Sem resposta & 16 & 80,0 & 15 & 75,0 & 13 & 65,0 & 44 & 73,4 \\
\hline & $\begin{array}{l}\text { - Relacionadas } \\
\text { com escola }\end{array}$ & 2 & 10,0 & 3 & 15,0 & 6 & 30,0 & 11 & 18,3 \\
\hline \multirow[t]{4}{*}{ Proibições } & $\begin{array}{l}\text { - Relacionadas com } \\
\text { interações sociais }\end{array}$ & 2 & 10,0 & 1 & 5,0 & - & - & 3 & 5,0 \\
\hline & - Outra & - & - & 1 & 5,0 & 1 & 5,0 & 2 & 3,3 \\
\hline & Subtotal & 20 & 100 & 20 & 100 & 20 & 100 & 60 & 100 \\
\hline & - Sem resposta & 16 & 80,0 & 12 & 60,0 & 9 & 45,0 & 37 & 61,7 \\
\hline \multirow[t]{9}{*}{ Informações } & $\begin{array}{l}\text { - Sobre fatos da } \\
\text { vida cotidiana }\end{array}$ & 4 & 20,0 & 8 & 40,0 & 11 & 55,0 & 23 & 38,3 \\
\hline & Subtotal & 20 & 100 & 20 & 100 & 20 & 100 & 60 & 100 \\
\hline & Sem resposta & 8 & 33,3 & 4 & 14,8 & 2 & 7,7 & 14 & 18,2 \\
\hline & Abandono & 2 & 8,3 & 3 & 11,1 & - & - & 5 & 6,5 \\
\hline & Rejeição & 1 & 4,2 & 2 & 7,4 & - & - & 3 & 3,9 \\
\hline & $\begin{array}{l}\text { Agressão deslocada } \\
\text { para ambiente }\end{array}$ & 2 & 8,3 & 1 & 3,7 & 1 & 3,8 & 4 & 5,2 \\
\hline & Autoagressão & - & - & - & - & 1 & 3,8 & 1 & 1,3 \\
\hline & Heteroagressão passiva & 1 & 4,2 & - & - & 1 & 3,8 & 2 & 2,6 \\
\hline & Onipotência & 3 & 12,5 & 2 & 7,4 & 1 & 3,8 & 6 & 7,8 \\
\hline \multirow[t]{12}{*}{ Fantasias } & Edípica & - & - & 4 & 14,8 & 3 & 11,5 & 7 & 9,1 \\
\hline & Privação & - & - & - & - & 1 & 3,8 & 1 & 1,3 \\
\hline & Reparação & - & - & - & - & 1 & 3,8 & 1 & 1,3 \\
\hline & Narcisista & 1 & 4,2 & 4 & 14,8 & 9 & 34,6 & 14 & 18,2 \\
\hline & Ganho secundário & 1 & 4,2 & 5 & 18,5 & 1 & 3,8 & 7 & 9,1 \\
\hline & Impotência & 1 & 4,2 & - & - & - & - & 1 & 1,3 \\
\hline & Castigo & 2 & 8,3 & 2 & 7,4 & 3 & 11,5 & 7 & 9,1 \\
\hline & Amparo* & 1 & 4,2 & - & - & - & - & 1 & 1,3 \\
\hline & Controle* & - & - & - & - & 1 & 3,8 & 1 & 1,3 \\
\hline & Persecutoriedade* & 1 & 4,2 & - & - & - & - & 1 & 1,3 \\
\hline & Superegóica* & - & - & - & - & 1 & 3,8 & 1 & 1,3 \\
\hline & Subtotal & 24 & 100 & 27 & 100 & 26 & 100 & 77 & 100 \\
\hline
\end{tabular}




\begin{tabular}{|c|c|c|c|c|c|c|c|c|c|}
\hline & Sem resposta & 3 & 12.5 & 2 & 9,1 & 2 & 8.7 & 7 & 10,1 \\
\hline & Tristeza & 5 & 20,8 & 2 & 9,1 & 1 & 4,3 & 8 & 11,6 \\
\hline & Medo & 2 & 8,3 & - & - & - & - & 2 & 2,9 \\
\hline & Raiva & - & - & - & - & 1 & 4,3 & 1 & 1,4 \\
\hline & Ansiedade & - & - & 2 & 9,1 & 1 & 4,3 & 3 & 4,3 \\
\hline & Onipotência & - & - & 1 & 4,5 & - & - & 1 & 1,4 \\
\hline Estado & Culpa & - & - & 2 & 9,1 & 4 & 17,4 & 6 & 8,7 \\
\hline \multirow[t]{14}{*}{ Emocional } & Alegria & 12 & 50,0 & 11 & 50,0 & 9 & 39,1 & 32 & 46,4 \\
\hline & Impotência & - & - & - & - & 1 & 4,3 & 1 & 1,4 \\
\hline & Ambivalência & 1 & 4,2 & 1 & 4,5 & 2 & 8,7 & 4 & 5,8 \\
\hline & Voracidade & - & - & - & - & 1 & 4,3 & 1 & 1,4 \\
\hline & Gratidão* & - & - & - & - & 1 & 4,3 & 1 & 1,4 \\
\hline & Angústia* & 1 & 4,2 & - & - & - & - & 1 & 1,4 \\
\hline & Surpreso* & - & - & 1 & 4,5 & - & - & 1 & 1,4 \\
\hline & Subtotal & 24 & 100 & 22 & 100 & 23 & 100 & 69 & 100 \\
\hline & Sem resposta & 3 & 12,5 & - & - & - & - & 3 & 4,1 \\
\hline & Projeção & 2 & 8,3 & 1 & 3,8 & 4 & 16,7 & 7 & 9,5 \\
\hline & Negação & 2 & 8,3 & 1 & 3,8 & 2 & 8,3 & 5 & 6,8 \\
\hline & Distorção & 1 & 4,2 & 3 & 11,5 & 2 & 8,3 & 6 & 8,1 \\
\hline & Bloqueio & 1 & 4,2 & - & - & 1 & 4,2 & 2 & 2,7 \\
\hline & Introjeção & - & - & - & - & 2 & 8,3 & 2 & 2,7 \\
\hline \multirow[t]{11}{*}{ Defesas } & Regressão & - & - & 1 & 3,8 & - & - & 1 & 1,4 \\
\hline & Somatização & - & - & - & - & 1 & 4,2 & 1 & 1,4 \\
\hline & Deslocamento & - & - & 2 & 7,7 & - & - & 2 & 2,7 \\
\hline & Isolamento & - & - & 1 & 3,8 & - & - & 1 & 1,4 \\
\hline & Racionalização & 7 & 29,2 & 4 & 15,4 & 2 & 8,3 & 13 & 17,6 \\
\hline & Formação Reativa & 1 & 4,2 & - & - & - & - & 1 & 1,4 \\
\hline & Repressão & 5 & 20,8 & 9 & 34,6 & 9 & 37,5 & 23 & 31,1 \\
\hline & Distanciamento & 1 & 4,2 & - & - & - & - & 1 & 1,4 \\
\hline & Idealização & 1 & 4,2 & 3 & 11,5 & - & - & 4 & 5,4 \\
\hline & Sublimação & - & - & 1 & 3,8 & 1 & 4,2 & 2 & 2,7 \\
\hline & Subtotal & 24 & 100 & 26 & 100 & 24 & 100 & 74 & 100 \\
\hline
\end{tabular}

*Categoria avaliativa incluída por sugestão dos avaliadores dos casos.

Na categoria Medo, mudança dos nomes dos itens:

- Sem resposta $=$ AUSENTE

- Outro = PRESENTE

Na categoria Desejos, junção dos itens:

- Relacionados com satisfação Oral + Com melhoria de vida + Com êxito pessoal + Com relações familiares $=$ OUTROS.

- Relacionados com presentes ou lazer $=$ GANHAR PRESENTE OU LAZER

Na categoria Proibições, junção dos itens:

- Relacionados com escola + Relacionados com Interações Sociais + Outro = ESCOLA E INTERAÇÕES SOCIAIS.

Na categoria Informações:

- Outros + Fatos da vida cotidiana = VIDA COTIDIANA. 
144 Anexos e Apêndices

Na categoria Fantasias, junção dos itens:

- Sem resposta + Abandono + Rejeição + Privação + Impotência = IMPOTÊNCIA.

- Agressão deslocada para o ambiente + Autoagressão + Heteroagressão passiva + Castigo + Persecutoriedade + Superegóica $=$ AGRESSÃO.

- Edípica + Narcisista + Ganho secundário + Controle + Onipotência $=$ ONIPOTÊNCIA.

Na categoria Estado Emocional, junção dos itens:

- Sem Resposta + Medo + Impotência + Tristeza = TRISTEZA

- Raiva + Voracidade + Onipotência = RAIVA.

- Culpa + Ambivalência + Angústia + Ansiedade = ANSIEDADE.

- Gratidão + Surpreso + Alegria = ALEGRIA

Na categoria Defesas, junção dos itens:

- Sem resposta + Projeção + Negação + Distorção = COM BASE na NEGAÇÃO.

- Bloqueio + Introjeção + Regressão + Somatização + Deslocamento + Isolamento + Racionalização + Formação reativa + Repressão + Distancimento + Idealização + Sublimação = COM BASE na REPRESSÃO. 
FÁBULA 10

\begin{tabular}{|c|c|c|c|c|c|c|c|c|c|}
\hline & \multirow[t]{2}{*}{ VARIÁVEL } & \multicolumn{2}{|c|}{$\begin{array}{c}\text { Grupo } 1 \\
(n=20)\end{array}$} & \multicolumn{2}{|c|}{$\begin{array}{c}\text { Grupo } 2 \\
(n=20)\end{array}$} & \multicolumn{2}{|c|}{$\begin{array}{c}\text { Grupo } 3 \\
(n=20)\end{array}$} & \multicolumn{2}{|c|}{ TOTAL } \\
\hline & & $f$ & $\%$ & $f$ & $\%$ & $f$ & $\%$ & $f$ & $\%$ \\
\hline \multirow{8}{*}{ Perseveração } & O item não se aplica & 13 & 65,0 & 11 & 55,0 & 9 & 45,0 & 33 & 55,0 \\
\hline & $\mathrm{F} 1$ & - & - & 1 & 5,0 & - & - & 1 & 1,6 \\
\hline & $\mathrm{F} 2$ & - & - & 2 & 10,0 & 1 & 5,0 & 3 & 5,0 \\
\hline & F3 & - & - & 1 & 5,0 & - & - & 1 & 1,6 \\
\hline & $\mathrm{F} 4$ & 1 & 5,0 & 1 & 5,0 & 3 & 15,0 & 5 & 8,3 \\
\hline & F5 & 6 & 30,0 & 4 & 20,0 & 4 & 20,0 & 14 & 23,3 \\
\hline & F8 & - & - & - & - & 2 & 10,0 & 2 & 3,3 \\
\hline & F9 & - & - & - & - & 1 & 5,0 & 1 & 1,6 \\
\hline \multirow{10}{*}{$\begin{array}{l}\text { Novos } \\
\text { conteúdos }\end{array}$} & Subtotal & 20 & 100 & 20 & 100 & 20 & 100 & 60 & 100 \\
\hline & - Sem resposta & 8 & 40,0 & 3 & 15,0 & - & - & 11 & 18,3 \\
\hline & - Animais reais ou não & 1 & 5,0 & 3 & 15,0 & 2 & 10,0 & 6 & 10,0 \\
\hline & $\begin{array}{l}\text { - Bruxas ou outras } \\
\text { entidades fantásticas }\end{array}$ & 1 & 5,0 & 1 & 5,0 & 5 & 25,0 & 7 & 11,6 \\
\hline & $\begin{array}{l}\text { - Ambientes fantásticos } \\
\text { ou sobrenaturais }\end{array}$ & - & - & 1 & 5,0 & - & - & 1 & 1,6 \\
\hline & $\begin{array}{l}\text { - Pessoas reais } \\
\text { ameaçadoras }\end{array}$ & 1 & 5,0 & - & - & 2 & 10,0 & 3 & 5,0 \\
\hline & $\begin{array}{l}\text { - Acontecimentos } \\
\text { aterrorizantes }\end{array}$ & 6 & 30,0 & 7 & 35,0 & 7 & 35,0 & 20 & 33,3 \\
\hline & $\begin{array}{l}\text { - Combinação das } \\
\text { alternativas anteriores }\end{array}$ & 2 & 10,0 & 4 & 20,0 & 3 & 15,0 & 9 & 15,0 \\
\hline & $\begin{array}{l}\text { - Não característicos de } \\
\text { pesadelos }\end{array}$ & 1 & 5,0 & 1 & 5,0 & 1 & 5,0 & 3 & 5,0 \\
\hline & Subtotal & 20 & 100 & 20 & 100 & 20 & 100 & 60 & 100 \\
\hline \multirow{15}{*}{ Fantasias } & Sem resposta & 5 & 22,7 & 1 & 3,6 & - & - & 6 & 8,1 \\
\hline & Abandono & 3 & 13,6 & 5 & 17,9 & 2 & 8,3 & 10 & 13,5 \\
\hline & $\begin{array}{l}\text { Agressão deslocada } \\
\text { para ambiente }\end{array}$ & 10 & 45,5 & 17 & 60,7 & 11 & 45,8 & 38 & 51,4 \\
\hline & Heteroagressão ativa & - & - & 1 & 3,6 & 1 & 4,2 & 2 & 2,7 \\
\hline & Onipotência & - & - & 1 & 3,6 & 1 & 4,2 & 2 & 2,7 \\
\hline & Edípica & - & - & 1 & 3,6 & 3 & 12,5 & 4 & 5,4 \\
\hline & Privação & - & - & 1 & 3,6 & - & - & 1 & 1,4 \\
\hline & Reparação & - & - & 1 & 3,6 & - & - & 1 & 1,4 \\
\hline & Narcisista & - & - & - & - & 1 & 4,2 & 1 & 1,4 \\
\hline & Impotência & - & - & - & - & 1 & 4,2 & 1 & 1,4 \\
\hline & Aniquilamento* & 2 & 9,1 & - & - & 1 & 4,2 & 3 & 4,1 \\
\hline & Hipocondria* & - & - & - & - & 1 & 4,2 & 1 & 1,4 \\
\hline & Perda* & 1 & 4,5 & - & - & 2 & 8,3 & 3 & 4,1 \\
\hline & Solidão* & 1 & 4,5 & - & - & - & - & 1 & 1,4 \\
\hline & Subtotal & 22 & 100 & 28 & 100 & 24 & 100 & 74 & 100 \\
\hline \multirow{11}{*}{$\begin{array}{l}\text { Estado } \\
\text { Emocional }\end{array}$} & Sem resposta & 3 & 10,7 & 3 & 10,7 & - & - & 6 & 7,7 \\
\hline & Tristeza & 2 & 7,1 & 5 & 17,9 & - & - & 7 & 9,0 \\
\hline & Medo & 13 & 46,4 & 11 & 39,3 & 13 & 59,1 & 37 & 47,4 \\
\hline & Raiva & - & - & 1 & 3,6 & - & - & 1 & 1,3 \\
\hline & Ansiedade & 3 & 10,7 & 3 & 10,7 & - & - & 6 & 7,7 \\
\hline & Onipotência & - & - & - & - & 1 & 4,5 & 1 & 1,3 \\
\hline & Culpa & - & - & - & - & 2 & 9,1 & 2 & 2,6 \\
\hline & Alegria & 5 & 17,9 & 3 & 10,7 & 1 & 4,5 & 9 & 11,5 \\
\hline & Ambivalência & - & - & - & - & 1 & 4,5 & 1 & 1,3 \\
\hline & Alívio* & - & - & 1 & 3,6 & 1 & 4,5 & 2 & 2,6 \\
\hline & Angústia* & 1 & 3,6 & - & - & 2 & 9,1 & 3 & 3,8 \\
\hline
\end{tabular}


146|Anexos e Apêndices

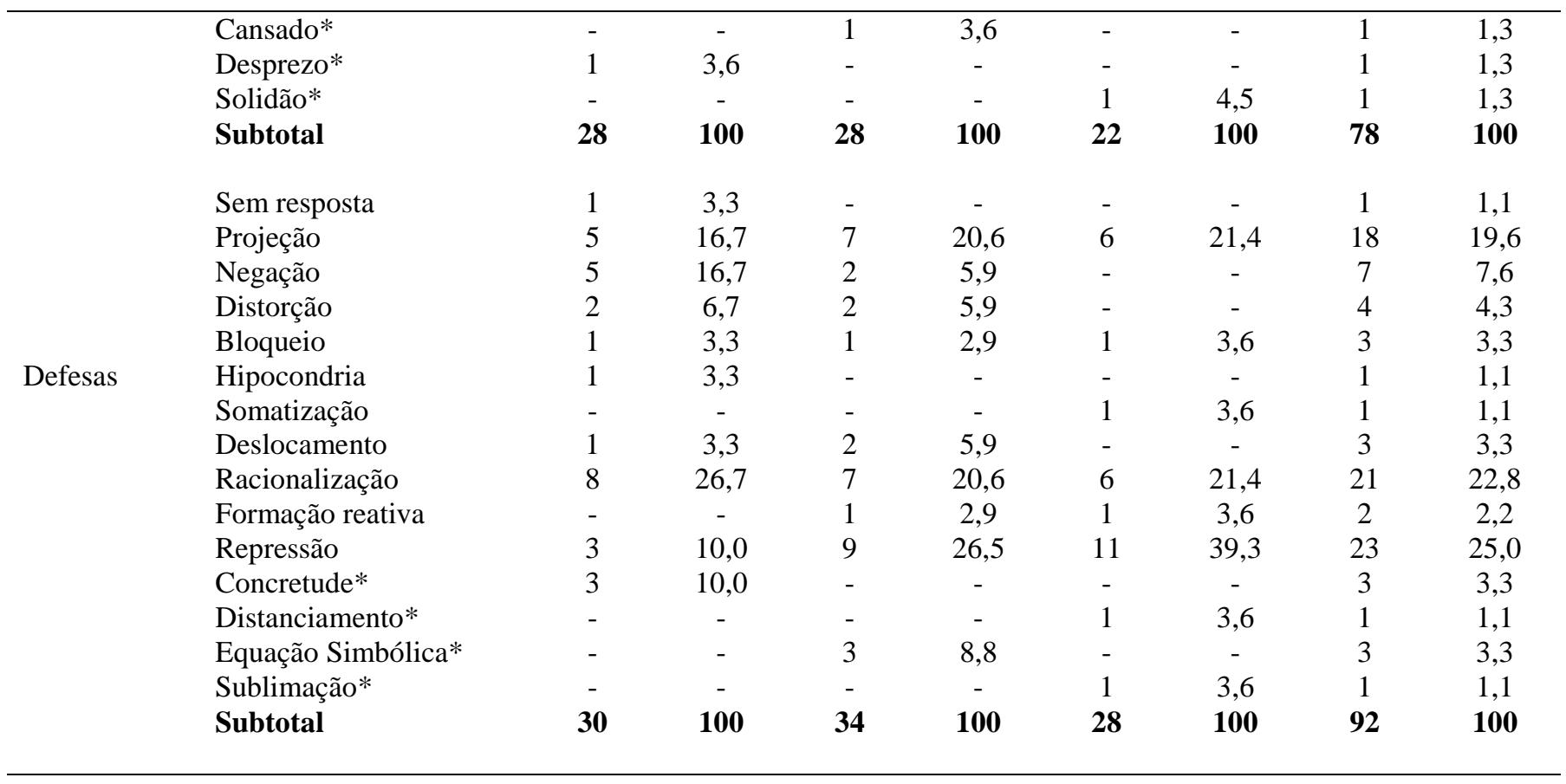

Na categoria Perseveração, junção dos itens:

- $\mathrm{F} 1+\mathrm{F} 2+\mathrm{F} 3+\mathrm{F} 8+\mathrm{F} 9=$ OUTRAS FÁBULAS.

Na categoria Novos Conteúdos, junção dos itens:

- Animais reais ou não = ANIMAIS

- Combinação das alternativas anteriores + Acontecimentos aterrorizantes = FATOS ATERRORIZANTES.

- Ambientes Fantásticos ou sobrenaturais + Pessoas reais ameaçadoras + Não característicos de pesadelos $=$ OUTROS

Na categoria Fantasias, junção dos itens:

- Sem resposta + Abandono + Privação + Perda + Solidão + Impotência $=$ IMPOTÊNCIA.

- Agressão deslocada para o ambiente + Heteroagressão ativa + Aniquilamento = AGRESSÃO.

- $\quad$ Edípica + Narcisista + Hipocondria + Onipotência = ONIPOTÊNCIA.

Na categoria Estado Emocional, junção dos itens:

- Sem resposta + Solidão + Tristeza + Raiva + Desprezo $=$ TRISTEZA

- Medo + Culpa + Ambivalência + Angústia + Cansado + Ansiedade = ANSIEDADE.

- Alívio + Onipotência +Alegria = ALEGRIA.

Na categoria Defesas, junção dos itens:

- Sem resposta + Projeção + Negação + Distorção + Equação Simbólica = COM BASE na NEGAÇÃO. 
- Hipocondria + Somatização + Deslocamento + Racionalização + Formação Reativa + Repressão + Concretude + Distanciamento + Sublimação $=$ COM BASE na REPRESSÃO. 
148 Anexos e Apêndices

APÊEDICE D -Tabelas descritivas dos resultados em termos de frequência e porcentagem no Teste das Fábulas com sistema de classificação revisto.

Tabela 1 -Distribuição (em frequência simples e porcentagem) das categorias avaliativas da Fábula 1 (Fábula do Passarinho) em função dos grupos e na amostra total $(n=60)$.

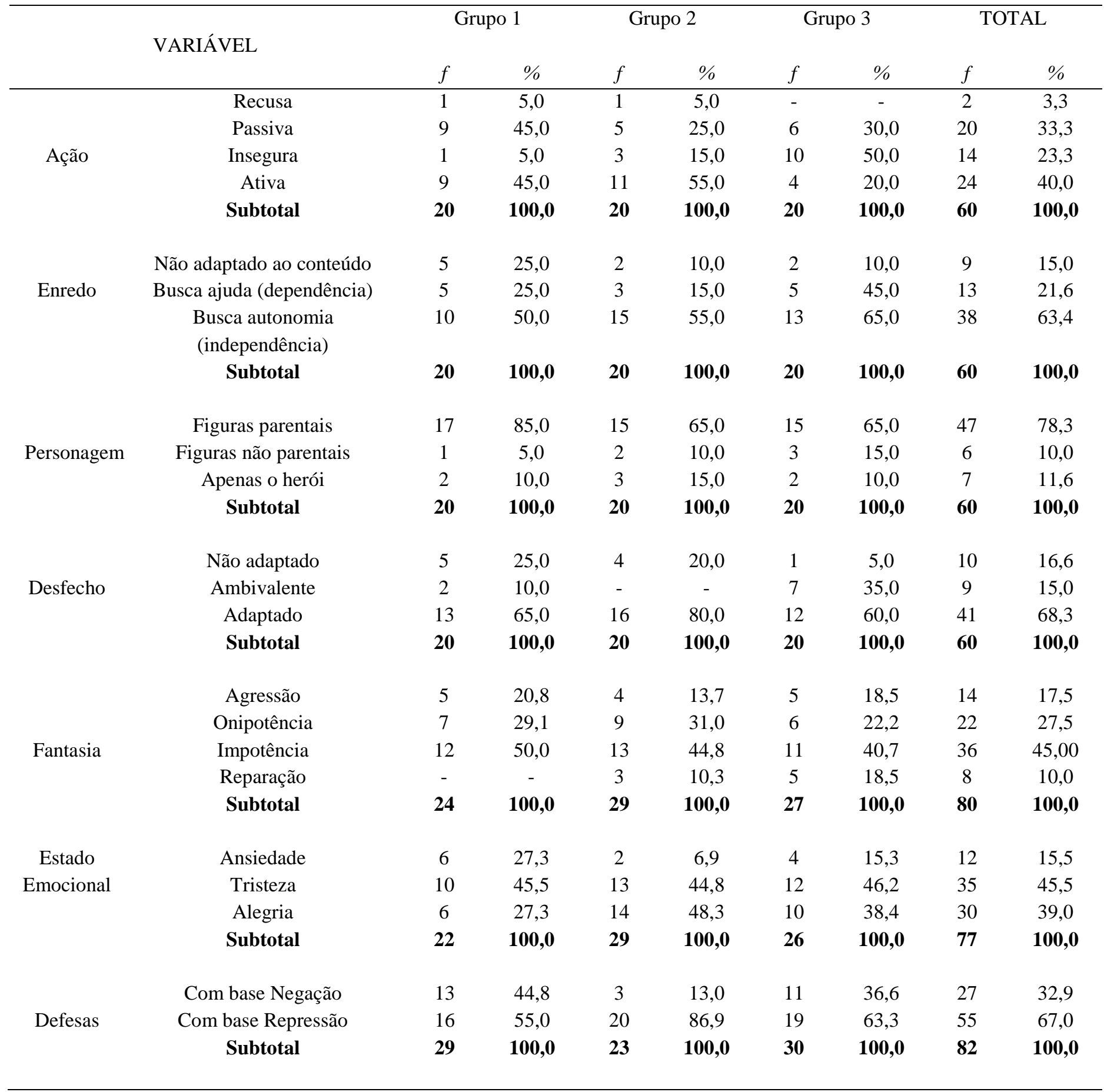


Tabela 2 -Distribuição (em frequência simples e porcentagem) das categorias avaliativas da Fábula 2 (Fábula do Casamento) em função dos grupos e na amostra total $(n=60)$.

\begin{tabular}{|c|c|c|c|c|c|c|c|c|c|}
\hline & \multirow{2}{*}{ VARIÁVEL } & \multicolumn{2}{|c|}{ Grupo 1} & \multicolumn{2}{|c|}{ Grupo 2} & \multicolumn{2}{|c|}{ Grupo 3} & \multicolumn{2}{|c|}{ TOTAL } \\
\hline & & $f$ & $\%$ & $f$ & $\%$ & $f$ & $\%$ & $f$ & $\%$ \\
\hline \multirow{4}{*}{ Ação } & Não adaptada & 3 & 15,0 & 6 & 30,0 & 2 & 10,0 & 11 & 18,3 \\
\hline & Passiva & 11 & 55,0 & 9 & 45,0 & 11 & 55,0 & 31 & 51,6 \\
\hline & Ativa & 6 & 30,0 & 5 & 25,0 & 7 & 35,0 & 18 & 30,0 \\
\hline & Subtotal & 20 & 100,0 & 20 & 100,0 & 20 & 100,0 & 60 & 100,0 \\
\hline \multirow{4}{*}{ Motivo } & Não adaptado & 4 & 20,0 & 1 & 5,0 & 4 & 20,0 & 9 & 15,0 \\
\hline & Conflito edípico & 6 & 30,0 & 5 & 25,0 & 7 & 35,0 & 18 & 30,0 \\
\hline & Outros temas & 10 & 50,0 & 14 & 70,0 & 9 & 45,0 & 33 & 55,0 \\
\hline & Subtotal & 20 & 100,0 & 20 & 100,0 & 20 & 100,0 & 60 & 100,0 \\
\hline \multirow{5}{*}{ Fantasia } & Agressão & 1 & 3,8 & 2 & 7,1 & - & - & 3 & 3,6 \\
\hline & Onipotência & 7 & 26,9 & 8 & 28,5 & 10 & 34,4 & 25 & 30,1 \\
\hline & Impotência & 16 & 61,5 & 18 & 64,2 & 16 & 55,1 & 50 & 60,2 \\
\hline & Reparação & 2 & 7,6 & - & - & 3 & 10,3 & 5 & 6,0 \\
\hline & Subtotal & 26 & 100,0 & 28 & 100,0 & 29 & 100,0 & 83 & 100,0 \\
\hline \multirow{5}{*}{$\begin{array}{c}\text { Estado } \\
\text { Emocional }\end{array}$} & Raiva & 6 & 19,3 & 1 & 3,3 & 1 & 3,7 & 8 & 9,1 \\
\hline & Ansiedade & 1 & 3,2 & 7 & 23,3 & 3 & 11,1 & 11 & 12,5 \\
\hline & Tristeza & 17 & 54,8 & 13 & 43,3 & 17 & 63,0 & 47 & 53,4 \\
\hline & Alegria & 7 & 22,5 & 9 & 30,0 & 6 & 22,2 & 22 & 25,0 \\
\hline & Subtotal & 31 & 100,0 & 30 & 100,0 & 27 & 100,0 & 88 & 100,0 \\
\hline \multirow{3}{*}{ Defesas } & Com base negação & 14 & 38,9 & 5 & 15,2 & 6 & 19,3 & 25 & 25,0 \\
\hline & Com base repressão & 22 & 61,1 & 28 & 84,8 & 25 & 80,6 & 75 & 75,0 \\
\hline & Subtotal & 36 & 100,0 & 33 & 100,0 & 31 & 100,0 & 100 & 100,0 \\
\hline
\end{tabular}


150|Anexos e Apêndices

$\underline{\text { Tabela } 3}$-Distribuição (em frequência simples e porcentagem) das categorias avaliativas da Fábula 3 (Fábula do Cordeirinho) em função dos grupos e na amostra total $(n=60)$.

\begin{tabular}{|c|c|c|c|c|c|c|c|c|c|}
\hline & \multirow{2}{*}{ VARIÁVEL } & \multicolumn{2}{|c|}{ Grupo 1} & \multicolumn{2}{|c|}{ Grupo 2} & \multicolumn{2}{|c|}{ Grupo 3} & \multicolumn{2}{|c|}{ TOTAL } \\
\hline & & $f$ & $\%$ & $f$ & $\%$ & $f$ & $\%$ & $f$ & $\%$ \\
\hline \multirow{5}{*}{ Ação } & Não adaptada & 2 & 10,0 & 1 & 5,0 & 2 & 10,0 & 5 & 8,4 \\
\hline & Resistente & 4 & 20,0 & 2 & 10,0 & 3 & 15,0 & 9 & 15,0 \\
\hline & Ambivalente & 8 & 40,0 & 7 & 35,0 & 10 & 50,0 & 25 & 41,6 \\
\hline & Adaptada & 6 & 30,0 & 10 & 50,0 & 5 & 25,0 & 21 & 35,0 \\
\hline & Subtotal & 20 & 100,0 & 20 & 100,0 & 20 & 100,0 & 60 & 100,0 \\
\hline \multirow{5}{*}{ Desfecho } & Não adaptado & 10 & 50,0 & 10 & 50,0 & 7 & 35,0 & 27 & 45,0 \\
\hline & Ambivalente & 5 & 25,0 & 4 & 20,0 & 8 & 40,0 & 17 & 28,3 \\
\hline & Adaptado & 5 & 25,0 & 6 & 30,0 & 5 & 25,0 & 16 & 26,6 \\
\hline & Subtotal & 20 & 100,0 & 20 & 100,0 & 20 & 100,0 & 60 & 100,0 \\
\hline & Agressão & 4 & 14,8 & 5 & 16,7 & 1 & 3,2 & 10 & 11,4 \\
\hline \multirow{4}{*}{ Fantasias } & Onipotência & 9 & 33,3 & 13 & 43,3 & 9 & 29,0 & 31 & 35,2 \\
\hline & Impotência & 14 & 51,9 & 11 & 36,7 & 19 & 61,3 & 44 & 50,0 \\
\hline & Reparação & - & - & 1 & 3,3 & 2 & 6,5 & 3 & 3,4 \\
\hline & Subtotal & 27 & 100,0 & 30 & 100,0 & 31 & 100,0 & 88 & 100,0 \\
\hline \multirow{5}{*}{$\begin{array}{c}\text { Estado } \\
\text { Emocional }\end{array}$} & Raiva & 4 & 13,0 & 1 & 3,7 & 3 & 13,0 & 8 & 9,9 \\
\hline & Ansiedade & 9 & 29,0 & 4 & 14,8 & 5 & 21,7 & 18 & 22,2 \\
\hline & Tristeza & 9 & 29,0 & 11 & 40,7 & 9 & 39,1 & 29 & 35,8 \\
\hline & Alegria & 9 & 29,0 & 11 & 40,7 & 6 & 26,1 & 26 & 32,1 \\
\hline & Subtotal & 31 & 100,0 & 27 & 100,0 & 23 & 100,0 & 81 & 100,0 \\
\hline \multirow{3}{*}{ Defesas } & Com base negação & 18 & 54,5 & 13 & 44,8 & 20 & 54,1 & 51 & 51,5 \\
\hline & Com base repressão & 15 & 45,5 & 16 & 55,2 & 17 & 45,9 & 48 & 48,5 \\
\hline & Subtotal & 33 & 100,0 & 29 & 100,0 & 37 & 100,0 & 99 & 100,0 \\
\hline
\end{tabular}


Tabela 4 -Distribuição (em frequência simples e porcentagem) das categorias avaliativas da Fábula 4 (Fábula do Enterro) em função dos grupos e na amostra total $(n=60)$.

\begin{tabular}{|c|c|c|c|c|c|c|c|c|c|}
\hline \multicolumn{2}{|r|}{ VARIÁVEL } & \multicolumn{2}{|c|}{ Grupo 1} & \multicolumn{2}{|c|}{ Grupo 2} & \multicolumn{2}{|c|}{ Grupo 3} & \multicolumn{2}{|c|}{ TOTAL } \\
\hline & & $f$ & $\%$ & $f$ & $\%$ & $f$ & $\%$ & $f$ & $\%$ \\
\hline \multirow{6}{*}{ Personagem } & Criança / Irmã(o) & 1 & 5,0 & 1 & 5,0 & - & - & 2 & 3,3 \\
\hline & Homem/Pai & 6 & 30,0 & 8 & 40,0 & 11 & 55,0 & 25 & 41,7 \\
\hline & Mulher/Mãe & 3 & 15,0 & 6 & 30,0 & 4 & 20,0 & 13 & 21,7 \\
\hline & Avô ou avó & 6 & 30,0 & 3 & 15,0 & 2 & 10,0 & 11 & 18,3 \\
\hline & Outros & 4 & 20,0 & 2 & 10,0 & 3 & 15,0 & 9 & 15,0 \\
\hline & Subtotal & 20 & 100,0 & 20 & 100,0 & 20 & 100,0 & 60 & 100,0 \\
\hline \multirow{4}{*}{ Fantasias } & Agressão & 8 & 38,1 & 17 & 63,0 & 7 & 31,8 & 32 & 45,7 \\
\hline & Onipotência & 1 & 4,8 & 2 & 7,4 & 4 & 18,2 & 7 & 10,0 \\
\hline & Impotência & 12 & 57,1 & 8 & 29,6 & 11 & 50,0 & 31 & 44,3 \\
\hline & Subtotal & 21 & 100,0 & 27 & 100,0 & 22 & 100,0 & 70 & 100,0 \\
\hline \multirow{5}{*}{$\begin{array}{c}\text { Estado } \\
\text { Emocional }\end{array}$} & Raiva & - & - & 3 & 13,0 & 1 & 4,8 & 4 & 6,0 \\
\hline & Ansiedade & 3 & 13,1 & 5 & 21,7 & 4 & 19,0 & 12 & 17,9 \\
\hline & Tristeza & 19 & 82,6 & 14 & 60,9 & 15 & 71,4 & 48 & 71,6 \\
\hline & Alegria & 1 & 4,3 & 1 & 4,3 & 1 & 4,8 & 3 & 4,5 \\
\hline & Subtotal & 23 & 100,0 & 23 & 100,0 & 21 & 100,0 & 67 & 100,0 \\
\hline \multirow{3}{*}{ Defesas } & Com base na negação & 8 & 30,8 & 10 & 34,5 & 7 & 25,9 & 25 & 30,5 \\
\hline & Com base na repressão & 18 & 69,2 & 19 & 65,5 & 20 & 74,1 & 57 & 69,5 \\
\hline & Subtotal & 26 & 100,0 & 29 & 100,0 & 27 & 100,0 & 82 & 100,0 \\
\hline
\end{tabular}


152|Anexos e Apêndices

Tabela 5 -Distribuição (em frequência simples e porcentagem) das categorias avaliativas da Fábula 5 (Fábula do Medo) em função dos grupos e na amostra total $(n=60)$.

\begin{tabular}{|c|c|c|c|c|c|c|c|c|c|}
\hline & \multirow{2}{*}{ VARIÁVEL } & \multicolumn{2}{|c|}{ Grupo 1} & \multicolumn{2}{|c|}{ Grupo 2} & \multicolumn{2}{|c|}{ Grupo 3} & \multicolumn{2}{|c|}{ TOTAL } \\
\hline & & $f$ & $\%$ & $f$ & $\%$ & $f$ & $\%$ & $f$ & $\%$ \\
\hline \multirow{5}{*}{ Objeto } & Animal / Bicho & 2 & 10,0 & 10 & 50,0 & 4 & 20,0 & 16 & 26,7 \\
\hline & Personagens de ficção & 9 & 45,0 & 4 & 20,0 & 6 & 30,0 & 19 & 31,7 \\
\hline & Escuro ou solidão & 6 & 30,0 & 3 & 15,0 & 6 & 30,0 & 15 & 25,0 \\
\hline & Outros & 3 & 15,0 & 3 & 15,0 & 4 & 20,0 & 10 & 16,7 \\
\hline & Subtotal & 20 & 100,0 & 20 & 100,0 & 20 & 100,0 & 60 & 100,0 \\
\hline \multirow{4}{*}{ Fantasias } & Agressão & 14 & 58,3 & 13 & 50,0 & 19 & 70,4 & 46 & 59,7 \\
\hline & Onipotência & 1 & 4,2 & 4 & 15,4 & 3 & 11,1 & 8 & 10,4 \\
\hline & Impotência & 9 & 37,5 & 9 & 34,6 & 5 & 18,5 & 23 & 29,9 \\
\hline & Subtotal & 24 & 100,0 & 26 & 100,0 & 27 & 100,0 & 77 & 100,0 \\
\hline \multirow{3}{*}{ Defesas } & Com base na Negação & 12 & 34,3 & 13 & 44,8 & 11 & 44,0 & 36 & 40,4 \\
\hline & Com base na Repressão & 23 & 65,7 & 16 & 55,2 & 14 & 56,0 & 53 & 59,6 \\
\hline & Subtotal & 35 & 100,0 & 29 & 100,0 & 25 & 100,0 & 89 & 100,0 \\
\hline
\end{tabular}


Tabela 6 -Distribuição (em frequência simples e porcentagem) das categorias avaliativas da Fábula 6 (Fábula do Elefante) em função dos grupos e na amostra total $(n=60)$.

\begin{tabular}{|c|c|c|c|c|c|c|c|c|c|}
\hline & & & 001 & & & & & & \\
\hline & & $f$ & $\%$ & $f$ & $\%$ & $f$ & $\%$ & $f$ & $\%$ \\
\hline & Por acidente / Mutilação & 2 & 10,0 & 7 & 35,0 & 5 & 25,0 & 14 & 23,3 \\
\hline & Transformação Física & 4 & 20,0 & 6 & 30,0 & 9 & 45,0 & 19 & 31,7 \\
\hline Natureza & Transformação Psicológica & 5 & 25,0 & 5 & 25,0 & 2 & 10,0 & 12 & 20,0 \\
\hline da Mudança & Substituição & 3 & 15,0 & 1 & 5,0 & 2 & 10,0 & 6 & 10,0 \\
\hline & Outra & 6 & 30,0 & 1 & 5,0 & 2 & 10,0 & 9 & 15,0 \\
\hline & Subtotal & 20 & 100,0 & 20 & 100,0 & 20 & 100,0 & 60 & 100,0 \\
\hline & Sujeira / cor & 3 & 15,0 & 5 & 25,0 & 6 & 30,0 & 14 & 23,3 \\
\hline Identificação & Tamanho & 2 & 10,0 & 3 & 15,0 & 2 & 10,0 & 7 & 11,7 \\
\hline da Mudança & Identidade & 1 & 5,0 & 1 & 5,0 & 4 & 20,0 & 6 & 10,0 \\
\hline & Outras & 14 & 70,0 & 11 & 55,0 & 8 & 40,0 & 33 & 55,0 \\
\hline & Subtotal & 20 & 100,0 & 20 & 100,0 & 20 & 100,0 & 60 & 100,0 \\
\hline & Tromba & - & - & 2 & 10,0 & 3 & 15,0 & 5 & 8,3 \\
\hline Local da & Elefante & 14 & 70,0 & 17 & 85,0 & 17 & 85,0 & 48 & 80,0 \\
\hline Mudança & Fora do elefante & 6 & 30,0 & 1 & 5,0 & - & . & 7 & 11,7 \\
\hline & Subtotal & 20 & 100,0 & 20 & 100,0 & 20 & 100,0 & 60 & 100,0 \\
\hline & Agressão & 6 & 25,0 & 6 & 22,2 & 4 & 17,4 & 16 & 21,6 \\
\hline & Onipotência & 3 & 12,5 & 6 & 22,2 & 5 & 21,7 & 14 & 18,9 \\
\hline Fantasias & Impotência & 14 & 58,3 & 12 & 44,4 & 9 & 39,1 & 35 & 47,3 \\
\hline & Reparação & 1 & 4,2 & 3 & 11,1 & 5 & 21,7 & 9 & 12,2 \\
\hline & Subtotal & 24 & 100,0 & 27 & 100,0 & 23 & 100,0 & 74 & 100,0 \\
\hline & Raiva & 2 & 7,4 & 1 & 3,3 & 2 & 7,1 & 5 & 5,9 \\
\hline Estado & Ansiedade & 6 & 22,2 & 3 & 10,0 & 4 & 14,3 & 13 & 15,3 \\
\hline Emocional & Tristeza & 10 & 37,1 & 15 & 50,0 & 14 & 50,0 & 39 & 45,9 \\
\hline & Alegria & 9 & 33,3 & 11 & 36,7 & 8 & 28,6 & 28 & 32,9 \\
\hline & Subtotal & 27 & 100,0 & 30 & 100,0 & 28 & 100,0 & 85 & 100,0 \\
\hline & Com base na negação & 12 & 38,7 & 10 & 38,5 & 10 & 37,0 & 32 & 38,1 \\
\hline Defesas & Com base na repressão & 19 & 61,3 & 16 & 61,5 & 17 & 63,0 & 52 & 61,9 \\
\hline & Subtotal & 31 & 100,0 & 26 & 100,0 & 27 & 100,0 & 84 & 100,0 \\
\hline
\end{tabular}


154|Anexos e Apêndices

Tabela 7 -Distribuição (em frequência simples e porcentagem) das categorias avaliativas da Fábula 7 (Fábula do Objeto fabricado) em função dos grupos e na amostra total $(n=60)$.

\begin{tabular}{|c|c|c|c|c|c|c|c|c|c|}
\hline & \multirow{2}{*}{ VARIÁVEL } & \multicolumn{2}{|c|}{ Grupo 1} & \multicolumn{2}{|c|}{ Grupo 2} & \multicolumn{2}{|c|}{ Grupo 3} & \multicolumn{2}{|c|}{ TOTAL } \\
\hline & & $f$ & $\%$ & $f$ & $\%$ & $f$ & $\%$ & $f$ & $\%$ \\
\hline \multirow{4}{*}{ Ação } & Resistente & 3 & 15,0 & 4 & 20,0 & 5 & 25,0 & 12 & 20,0 \\
\hline & Ambivalente & 12 & 60,0 & 11 & 55,0 & 6 & 30,0 & 29 & 48,3 \\
\hline & Ativa e adaptada & 5 & 25,0 & 5 & 25,0 & 9 & 45,0 & 19 & 31,7 \\
\hline & Subtotal & 20 & 100 & 20 & 100 & 20 & 100 & 60 & 100 \\
\hline \multirow{5}{*}{ Fantasias } & Onipotência & 13 & 54,2 & 18 & 62,1 & 19 & 76,0 & 50 & 64,1 \\
\hline & Agressão & 1 & 4,2 & 3 & 10,3 & 1 & 4,0 & 5 & 6,4 \\
\hline & Impotência & 9 & 37,5 & 8 & 27,6 & 3 & 12,0 & 20 & 25,6 \\
\hline & Reparação & 1 & 4,2 & - & - & 2 & 8,0 & 3 & 3,8 \\
\hline & Subtotal & 24 & 100 & 29 & 100 & 25 & 100 & 78 & 100 \\
\hline \multirow{4}{*}{$\begin{array}{c}\text { Estado } \\
\text { Emocional }\end{array}$} & Ansiedade & 9 & 34,6 & 4 & 15,4 & 4 & 16,7 & 17 & 22,4 \\
\hline & Tristeza & 7 & 26,9 & 8 & 30,8 & 6 & 25,0 & 21 & 27,6 \\
\hline & Alegria & 10 & 38,5 & 14 & 53,8 & 14 & 58,3 & 38 & 50,0 \\
\hline & Subtotal & 26 & 100 & 26 & 100 & 24 & 100 & 76 & 100 \\
\hline \multirow{3}{*}{ Defesas } & Com base na negação & 9 & 29,0 & 9 & 28,1 & 15 & 48,4 & 33 & 35,1 \\
\hline & Com base na repressão & 22 & 71,0 & 23 & 71,9 & 16 & 51,6 & 61 & 64,9 \\
\hline & Subtotal & 31 & 100 & 32 & 100 & 31 & 100 & 94 & 100 \\
\hline
\end{tabular}


Anexos e Apêndices|155

Tabela 8 -Distribuição (em frequência simples e porcentagem) das categorias avaliativas da Fábula 8 (Fábula do Passeio) em função dos grupos e na amostra total $(\boldsymbol{n}=60)$.

\begin{tabular}{|c|c|c|c|c|c|c|c|c|c|}
\hline \multicolumn{2}{|c|}{ VARIÁVEL } & \multicolumn{2}{|c|}{ Grupo 1} & \multicolumn{2}{|c|}{ Grupo 2} & \multicolumn{2}{|c|}{ Grupo 3} & \multicolumn{2}{|c|}{ TOTAL } \\
\hline & & $f$ & $\%$ & $f$ & $\%$ & $f$ & $\%$ & $f$ & $\%$ \\
\hline \multirow{4}{*}{ Motivo } & Conflito edípico & 8 & 40,0 & 5 & 25,0 & 9 & 45,0 & 22 & 36,7 \\
\hline & Omissão de deveres & 4 & 20,0 & 12 & 60,0 & 7 & 35,0 & 23 & 38,3 \\
\hline & Outros & 8 & 40,0 & 3 & 15,0 & 4 & 20,0 & 15 & 25,0 \\
\hline & Subtotal & 20 & 100,0 & 20 & 100,0 & 20 & 100,0 & 60 & 100,0 \\
\hline \multirow{5}{*}{ Fantasias } & Agressão & 11 & 40,7 & 9 & 32,1 & 5 & 21,7 & 25 & 32,1 \\
\hline & Onipotência & 7 & 25,9 & 10 & 35,7 & 11 & 47,8 & 28 & 35,9 \\
\hline & Impotência & 5 & 18,5 & 7 & 25,0 & 3 & 13,0 & 15 & 19,2 \\
\hline & Reparação & 4 & 14,8 & 2 & 7,1 & 4 & 17,4 & 10 & 12,8 \\
\hline & Subtotal & 27 & 100,0 & 28 & 100,0 & 23 & 100,0 & 78 & 100,0 \\
\hline \multirow{5}{*}{$\begin{array}{c}\text { Estado } \\
\text { Emocional }\end{array}$} & Raiva & 3 & 12,0 & 1 & 4,2 & 4 & 14,3 & 8 & 10,4 \\
\hline & Ansiedade & 8 & 32,0 & 9 & 37,5 & 17 & 60,7 & 34 & 44,2 \\
\hline & Tristeza & 9 & 36,0 & 10 & 41,7 & 4 & 14,3 & 23 & 29,9 \\
\hline & Alegria & 5 & 20,0 & 4 & 16,6 & 3 & 10,7 & 12 & 15,5 \\
\hline & Subtotal & 25 & 100,0 & 24 & 100,0 & 28 & 100,0 & 77 & 100,0 \\
\hline \multirow{3}{*}{ Defesas } & Com base na negação & 9 & 30,0 & 8 & 23,5 & 15 & 40,5 & 32 & 31,7 \\
\hline & Com base na repressão & 21 & 70,0 & 26 & 76,5 & 22 & 59,5 & 69 & 68,3 \\
\hline & Subtotal & 30 & 100,0 & 34 & 100,0 & 37 & 100,0 & 101 & 100,0 \\
\hline
\end{tabular}


156|Anexos e Apêndices

Tabela 9 -Distribuição (em frequência simples e porcentagem) das categorias avaliativas da Fábula 9 (Fábula da Notícia) em função dos grupos e na amostra total $(n=60)$.

\begin{tabular}{|c|c|c|c|c|c|c|c|c|c|}
\hline \multirow{3}{*}{ 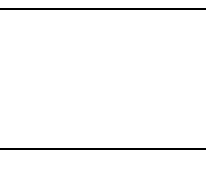 } & \multirow{2}{*}{ VARIÁVEL } & \multicolumn{2}{|c|}{ Grupo 1} & \multicolumn{2}{|c|}{ Grupo 2} & \multicolumn{2}{|c|}{ Grupo 3} & \multicolumn{2}{|c|}{ TOTAL } \\
\hline & & $f$ & $\%$ & $F$ & $\%$ & $f$ & $\%$ & $f$ & $\%$ \\
\hline & Ausente & 16 & 80,0 & 17 & 85,0 & 14 & 70,0 & 47 & 78,4 \\
\hline \multirow[t]{2}{*}{ Medo } & Presente & 4 & 20,0 & 3 & 15,0 & 6 & 30,0 & 13 & 21,6 \\
\hline & Subtotal & 20 & 100,0 & 20 & 100,0 & 20 & 100,0 & 60 & 100,0 \\
\hline \multirow{4}{*}{ Desejos } & Sem resposta & 11 & 55,0 & 7 & 35,0 & 6 & 30,0 & 24 & 40,0 \\
\hline & Ganhar presente ou lazer & 7 & 35,0 & 10 & 50,0 & 9 & 45,0 & 26 & 43,3 \\
\hline & Outros & 2 & 10,0 & 3 & 15,0 & 5 & 25,0 & 10 & 16,7 \\
\hline & Subtotal & 20 & 100,0 & 20 & 100,0 & 20 & 100,0 & 60 & 100,0 \\
\hline \multirow{3}{*}{ Proibições } & Sem resposta & 16 & 80,0 & 15 & 75,0 & 13 & 65,0 & 44 & 73,3 \\
\hline & Escola e interações sociais & 4 & 20,0 & 5 & 25,0 & 7 & 35,0 & 16 & 26,7 \\
\hline & Subtotal & 20 & 100,0 & 20 & 100,0 & 20 & 100,0 & 60 & 100,0 \\
\hline \multirow{3}{*}{ Informações } & Sem resposta & 16 & 80,0 & 12 & 60,0 & 9 & 45,0 & 37 & 61,7 \\
\hline & Vida cotidiana & 4 & 20,0 & 8 & 40,0 & 11 & 55,0 & 23 & 38,3 \\
\hline & Subtotal & 20 & 100,0 & 20 & 100,0 & 20 & 100,0 & 60 & 100,0 \\
\hline \multirow{5}{*}{ Fantasias } & Agressão & 6 & 25,0 & 3 & 11,1 & 7 & 26,9 & 16 & 21,1 \\
\hline & Onipotência & 5 & 20,8 & 15 & 55,6 & 15 & 57,7 & 35 & 46,1 \\
\hline & Impotência & 12 & 50,0 & 9 & 33,3 & 3 & 11,5 & 24 & 31,6 \\
\hline & Reparação & - & - & - & - & 1 & 3,8 & 1 & 1,3 \\
\hline & Subtotal & 23 & 100,0 & 27 & 100,0 & 26 & 100,0 & 76 & 100,0 \\
\hline \multirow{5}{*}{$\begin{array}{c}\text { Estado } \\
\text { Emocional }\end{array}$} & Raiva & - & - & 1 & 4,5 & 2 & 8,7 & 3 & 4,3 \\
\hline & Ansiedade & 4 & 16,7 & 5 & 22,7 & 7 & 30,4 & 16 & 23,2 \\
\hline & Tristeza & 8 & 33,3 & 4 & 18,2 & 4 & 17,4 & 16 & 23,2 \\
\hline & Alegria & 12 & 50,0 & 12 & 54,5 & 10 & 43,5 & 34 & 49,3 \\
\hline & Subtotal & 24 & 100,0 & 22 & 100,0 & 23 & 100,0 & 69 & 100,0 \\
\hline \multirow{3}{*}{ Defesas } & Com base negação & 8 & 33,3 & 5 & 19,2 & 8 & 33,3 & 21 & 28,4 \\
\hline & Com base repressão & 16 & 66,7 & 21 & 80,8 & 16 & 66,7 & 53 & 71,6 \\
\hline & Subtotal & 24 & 100,0 & 26 & 100,0 & 24 & 100,0 & 74 & 100,0 \\
\hline
\end{tabular}


Tabela 10 -Distribuição (em frequência simples e porcentagem) das categorias avaliativas da Fábula 10 (Fábula do Sonho mau) em função dos grupos e na amostra total $(n=60)$.

\begin{tabular}{|c|c|c|c|c|c|c|c|c|c|}
\hline & & & 01 & & & & & & \\
\hline & & $f$ & $\%$ & $F$ & $\%$ & $f$ & $\%$ & $f$ & $\%$ \\
\hline & Não se aplica & 13 & 65,0 & 11 & 55,0 & 9 & 45,0 & 33 & 55,0 \\
\hline Perseveração & Fábula 4 & 1 & 5,0 & 1 & 5,0 & 3 & 15,0 & 5 & 8,3 \\
\hline & Fábula 5 & 6 & 30,0 & 4 & 20,0 & 4 & 20,0 & 14 & 23,3 \\
\hline & Outras (F1,F2,F3,F8,F9) & - & - & 4 & 20,0 & 4 & 20,0 & 8 & 13,3 \\
\hline & Subtotal & 20 & 100,0 & 20 & 100,0 & 20 & 100,0 & 60 & 100,0 \\
\hline & Sem resposta & 7 & 40,0 & 3 & 15,0 & - & - & 10 & 16,7 \\
\hline & Animais & 1 & 5,0 & 3 & 15,0 & 2 & 10,0 & 6 & 10,0 \\
\hline $\begin{array}{l}\text { Novos } \\
\text { conteúdos }\end{array}$ & $\begin{array}{l}\text { Bruxas / entidades } \\
\text { fantásticas }\end{array}$ & 1 & 5,0 & 1 & 5,0 & 5 & 25,0 & 7 & 11,7 \\
\hline & Fatos aterrorizantes & 8 & 40,0 & 11 & 55,0 & 10 & 50,0 & 29 & 48,3 \\
\hline & Outros & 3 & 10,0 & 2 & 10,0 & 3 & 15,0 & 8 & 13,3 \\
\hline & Subtotal & 20 & 100,0 & 20 & 100,0 & 20 & 100,0 & 60 & 100,0 \\
\hline & Agressão & 12 & 54,5 & 18 & 64,3 & 13 & 54,2 & 43 & 58,1 \\
\hline & Onipotência & - & - & 2 & 7,1 & 6 & 25,0 & 8 & 10,8 \\
\hline Fantasias & Impotência & 10 & 45,5 & 7 & 25,0 & 5 & 20,8 & 22 & 29,7 \\
\hline & Reparação & - & - & 1 & 3,6 & - & - & 1 & 1,4 \\
\hline & Subtotal & 22 & 100,0 & 28 & 100,0 & 24 & 100,0 & 74 & 100,0 \\
\hline Estado & Ansiedade & 17 & 60,7 & 15 & 53,6 & 17 & 77,3 & 49 & 62,8 \\
\hline Emocional & Tristeza & 6 & 21,4 & 9 & 32,1 & 2 & 9,1 & 17 & 21,8 \\
\hline & Alegria & 5 & 17,9 & 4 & 14,3 & 3 & 13,6 & 12 & 15,4 \\
\hline & Subtotal & 28 & 100,0 & 28 & 100,0 & 22 & 100,0 & 78 & 100,0 \\
\hline & Com base na negação & 13 & 44,8 & 13 & 39,4 & 6 & 21,4 & 32 & 35,6 \\
\hline Defesas & Com base na repressão & 16 & 55,2 & 20 & 60,6 & 22 & 78,6 & 58 & 64,4 \\
\hline & Subtotal & 29 & 100,0 & 33 & 100,0 & 28 & 100,0 & 90 & 100,0 \\
\hline
\end{tabular}

